


\section{UNMASKING CIRCULATING TUMOR CELLS}

Joost Franciscus Swennenhuis

University of Twente

December 2016 
Samenstelling promotiecommissie:

Prof.dr.ir. J.W.M. Hilgenkamp Universiteit Twente (voorzitter/secretaris)

Prof. dr. L.W.M.M. Terstappen Universiteit Twente (promotor)

Prof. dr. P.C.J.J. Passier Universiteit Twente

Dr. J. Prakash Universiteit Twente

Prof. dr. J.A. Schalken Radboud Universiteit Nijmegen

Prof. dr. J.S. de Bono Institute of Cancer Research, Verenigd Koninkrijk.

Prof. dr. N.H. Stoecklein Heinrich-Heine-Universität Düsseldorf, Duitsland

This work has been financially supported by CTCTrap FP7 health.2012.1.2-1 \#305341

Copyright (C) by J.F.Swennenhuis, Eefde, The Netherlands

All rights reserved. No part of this book may be reproduced or transmitted, in any form or by any means, electronically or mechanically, including photocopying, microfilming and recording or by any information storage or retrieval system, without prior written permission of the author.

ISBN 978-90-365-4268-5

DOI $\quad 10.3990 / 1.9789036542685$ 


\title{
UNMASKING CIRCULATING TUMOR CELLS
}

\author{
PROEFSCHRIFT
}

ter verkrijging van

de graad van doctor aan de Universiteit Twente,

op gezag van de rector magnificus,

prof. dr. H.Brinksma,

volgens besluit van het College voor Promoties

in het openbaar te verdedigen

op vrijdag 13 januari 2017 om 14:45 uur

door

Joost Franciscus Swennenhuis

Geboren op 23 juli 1973

te Apeldoorn 
This dissertation has been approved by:

Prof. dr. L.W.M.M. Terstappen

Cover:

Designed and created by Sebastiaan Franciscus Swennenhuis 


\section{Table of Contents}

UNMASKING CIRCULATING TUMOR CELLS …....................................................................... 1

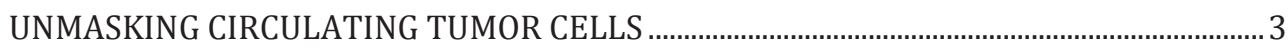

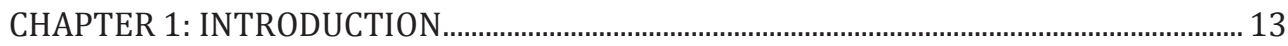

CHAPTER 2: IMPROVING THE CELLSEARCH SYSTEM ..................................................... 17

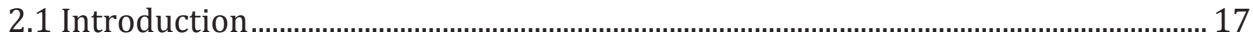

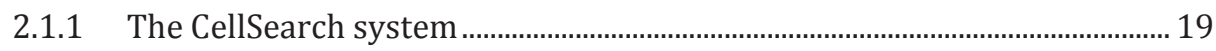

2.1.2 Commercially available CellSearch kits ............................................................ 20

2.2 Applications beyond the standard CellSearch assays ......................................... 24

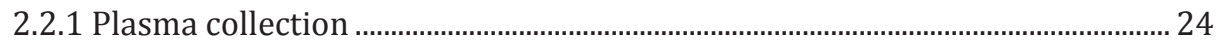

2.2.2 Changing the antibodies on the ferrofluids and/or CellSearch assay

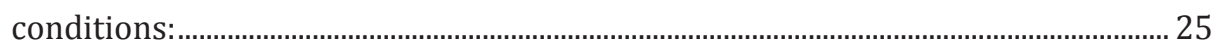

2.2.3 Collection of the immunomagnetically depleted blood ...................................... 28

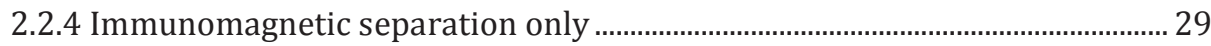

2.2.5 Additional reagents for cell labeling …............................................................. 30

2.2.6 Collection of the Immunomagnetically enriched and fluorescently labeled

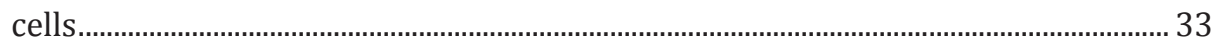

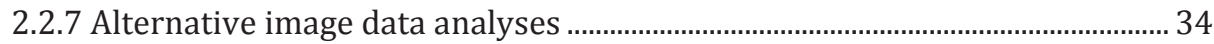

2.2.8 FISH on CTC in CellSearch cartridges ..................................................................... 35

2.2.9 Use of CellSearch for other body fluids ............................................................ 37

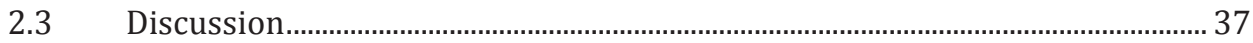

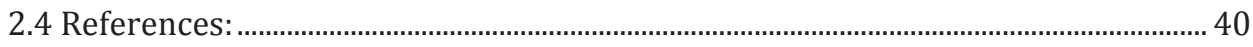

CHAPTER 3: SAMPLE PREPARATION METHODS FOR UPSTREAM SINGLE CELL

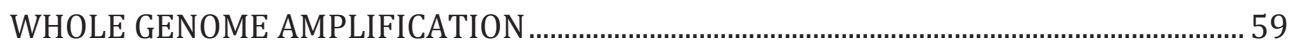

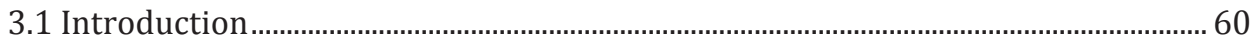

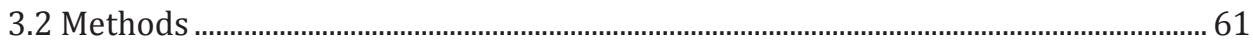

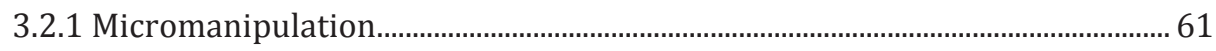

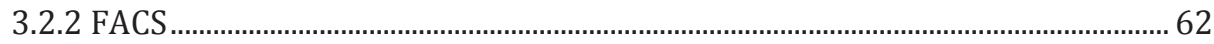

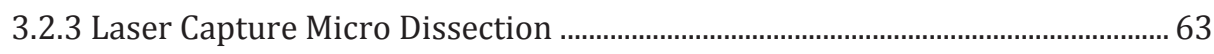




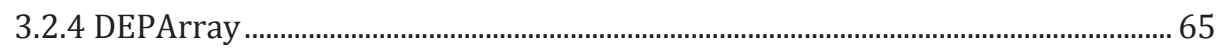

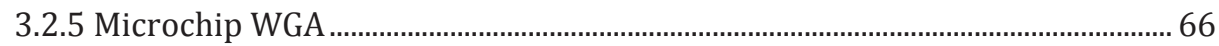

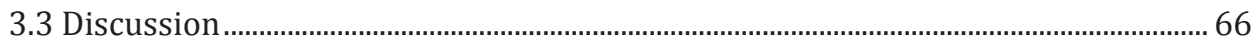

3.4 References ............................................................................................................... 68

CHAPTER 4: TECHNICAL OVERVIEW OF SINGLE CELL WHOLE GENOME AMPLIFICATION METHODS.................................................................................................... 73

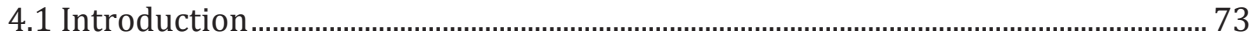

Whole Genome Amplification general categories. ……………………………………... 73

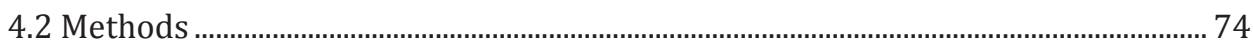

4.2.1 GenomePlex kit (Sigma)............................................................................................ 74

4.2.2 Ampli-1 Kit (Silicon Biosystems) ......................................................................... 75

4.2.3 Multiple Displacement Amplification (MDA) kits .............................................. 76

4.2.4 Combinations of MDA and PCR................................................................................ 78

4.3 Downstream analysis ...................................................................................................... 80

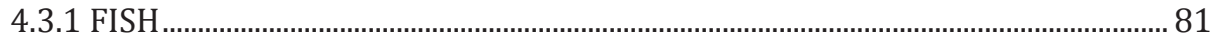

4.3.2 RNA Microarray ........................................................................................................ 82

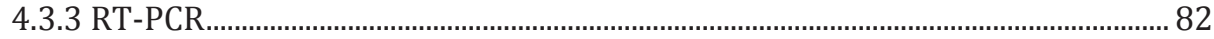

4.3.4 Single cell RTqPCR ................................................................................................ 84

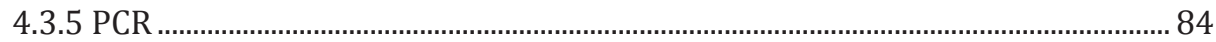

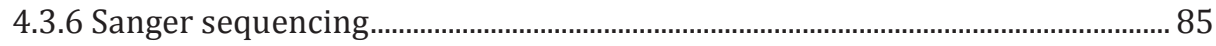

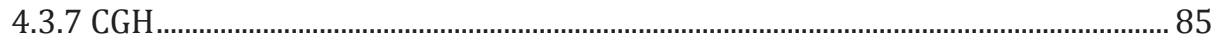

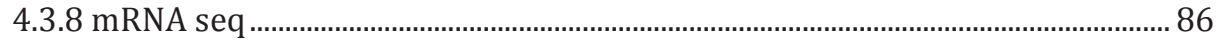

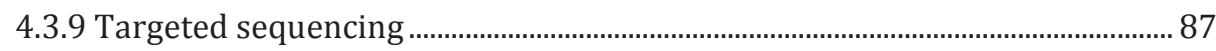

4.3.10 Exome sequencing ...................................................................................................... 87

4.4 WGA methods developed at MCBP.................................................................................. 88

4.4.1 Sigma GenomePlex on AmpliGrid slides................................................................ 89

4.4.2 GE GenomiPhi WGA on slide................................................................................... 89

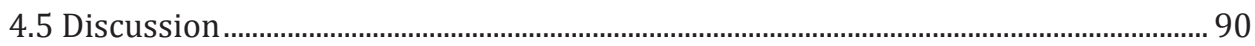

4.5.1 When to use what: Upstream WGA......................................................................... 90 
4.5.2 When to use what: Downstream WGA.

4.6 References

CHAPTER 5: QUALITY CONTROL ON SINGLE CELL WHOLE GENOME AMPLIFICATION PRODUCTS

5.1 Introduction: .95

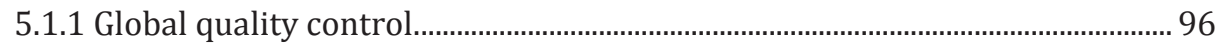

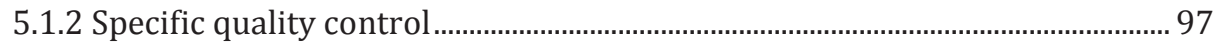

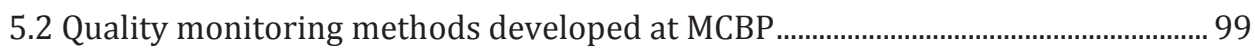

5.2.1 Real time monitoring of WGA reactions ............................................................... 99

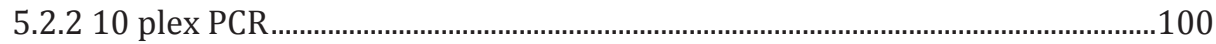

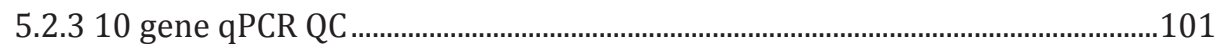

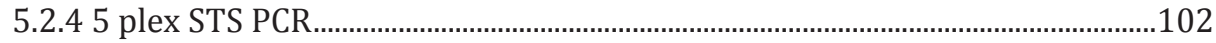

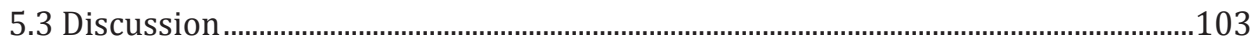

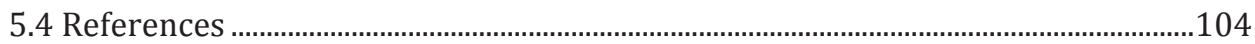

CHAPTER 6: EFFICIENCY OF WHOLE GENOME AMPLIFICATION OF SINGLE CIRCULATING TUMOR CELLS ENRICHED BY CELLSEARCH AND SORTED BY FACS..105

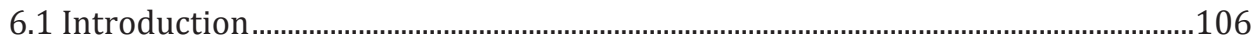

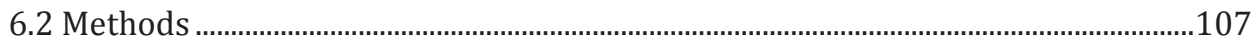

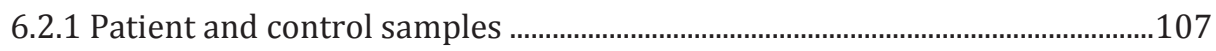

6.2.2 CTC identification and preparation for cell sorting ..........................................107

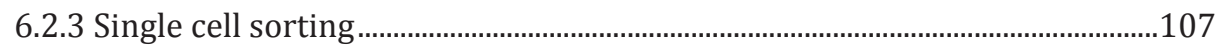

6.2.4 Efficiency of DNA amplification......................................................................................109

6.2.5 Sample quality analysis of fixed cells, unfixed cells and isolated DNA by

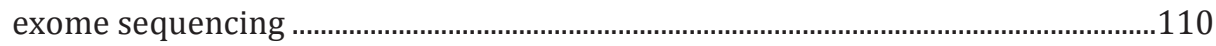

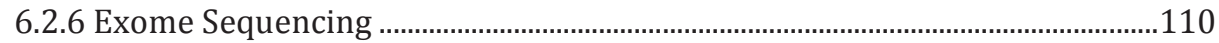

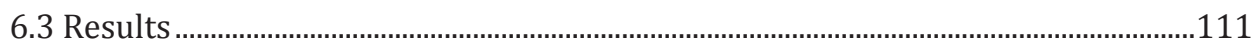

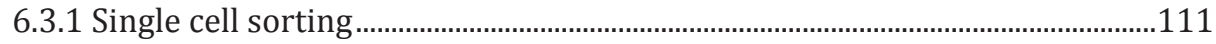

6.3.2 Efficiency of DNA amplification....................................................................... 111

6.3.3 Yield and reproducibility of CTC isolation and WGA amplification of spiked samples. 
6.3.4 Efficiency of CTC isolation and WGA amplification in non small cell lung cancer patients . .113

6.3.5 Quality of the WGA amplified DNA by exome sequencing . .114

6.4 Discussion .116

6.5 References. 119

6.6 Supplementary data 122

CHAPTER 7: CHARACTERIZATION OF CIRCULATING TUMOR CELLS BY FLUORESCENCE IN-SITU HYBRIDIZATION 125

7.1 Introduction. .126

7.2 Methods 127

7.2.1 Patient samples. 127

7.2.2 Enumeration of circulating tumor cells 127

7.2.3 Preservation of CTC for FISH analysis 128

7.2.4 Hybridization of CTC 128

7.2.5 Fluorescent Microscope for CTC FISH analysis 129

7.3 Results 129

7.3.1 Preservation of CTC for FISH analysis 129

7.3.2 FISH analysis of CTC and leukocytes 130

7.3.3 Apoptosis of CTC and FISH analysis . .132

7.3.4 Aneuploidy of CTC in hormone refractory prostate cancer. 133

7.4 Discussion 134

7.5 References 137

CHAPTER 8: CONSTRUCTION OF REPEAT FREE FLUORESCENCE IN-SITU HYBRIDIZATION (FISH) PROBES

8.1 Introduction 144

8.2 Methods . 144

8.2.1 BAC clones 144

8.2.2 Repeat free procedure 144

8.2.3 qPCR . .145 


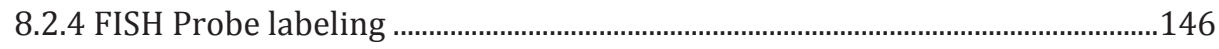

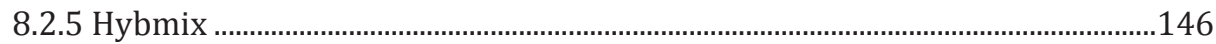

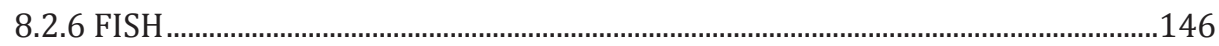

8.2.6 Signal and background measurements ...............................................................147

8.3 Results ........................................................................................................................147

8.3.1 Repeat removal process.............................................................................................147

8.3.2 Measurement of repetitive sequence removal ...................................................147

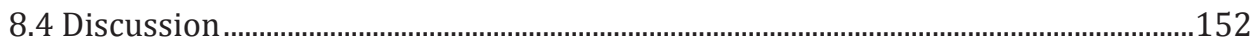

8.5 References .......................................................................................................................153

CHAPTER 9: SELF-SEEDING MICROWELL CHIP FOR THE ISOLATION AND CHARACTERIZATION OF SINGLE CELLS..............................................................................155

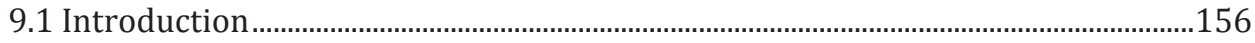

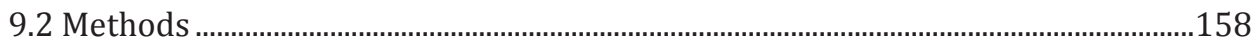

9.2.1 Microwell chip fabrication ......................................................................................158

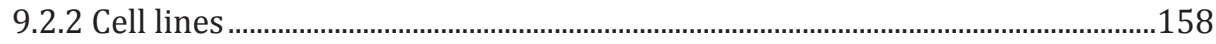

9.2.3 Single cell isolation of viable cells ........................................................................158

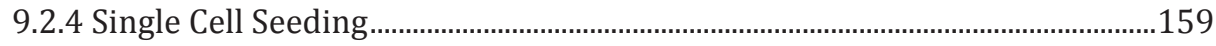

9.2.5 DNA WGA …………………………………………………………………………....159

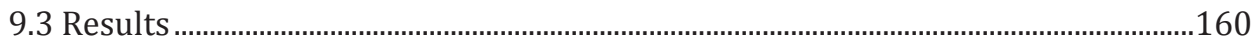

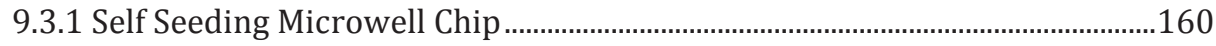

9.3.2 Single cell seeding efficiency ...................................................................................161

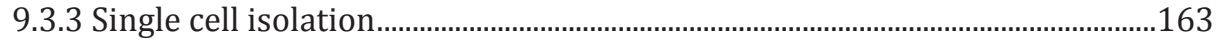

9.3.4 Single cell isolation for DNA analysis....................................................................166

9.3.5 Single cell isolation of viable cells. .........................................................................168

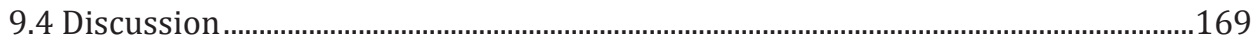

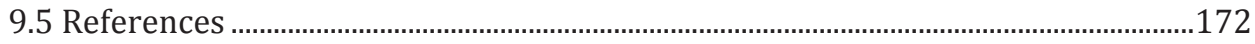

CHAPTER 10: OUTLOOK..........................................................................................................175

10.1 CTC enumeration ..........................................................................................................

10.2 CTC from larger blood volumes ....................................................................................175 
10.3 Single cell isolation progress ................................................................................... 175

10.4 Whole genome amplification..................................................................................176

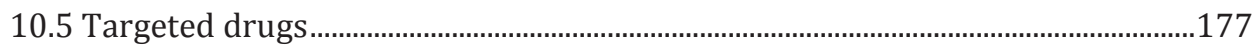

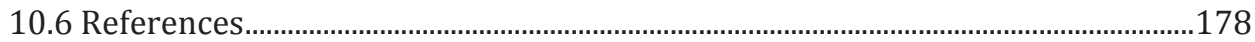

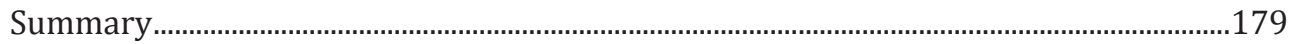

Summary in Dutch / Samenvatting...................................................................................180

Eenvoudige weergave van dit proefschrift ............................................................................183

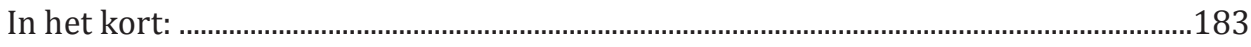

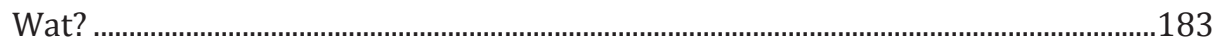

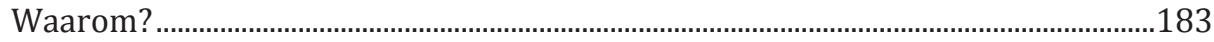

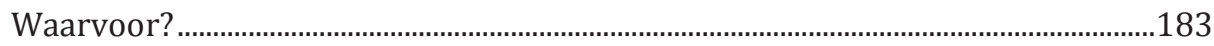

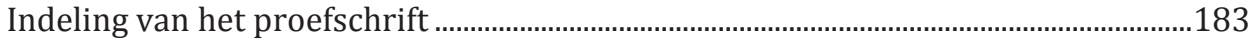

Stap 1: Bloedafname ………………………………………………………………………...184

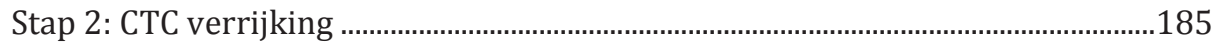

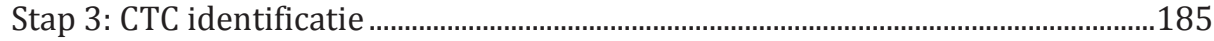

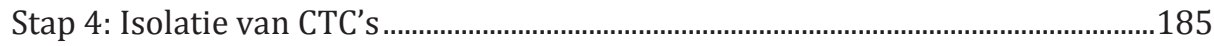

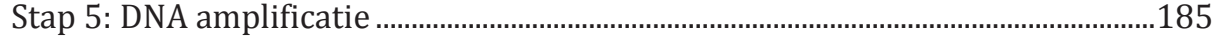

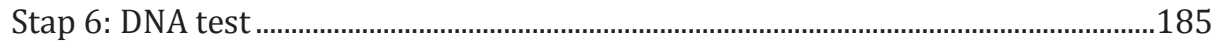

Stap 7: De analyse ………………………………………………………………………….....185

Hoofdstuk 2: Het CellSearch systeem ...............................................................................186

Het Cellsearch systeem...................................................................................................186

De methode..............................................................................................................................186

Gebruik van het CellSearch systeem ...........................................................................186

Hoofdstuk 3: Beschrijving van methodes om een enkele cel te kunnen isoleren ....187

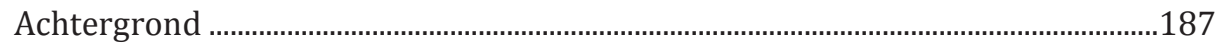

Hoofdstuk 4 en 5: Methodes voor DNA amplificatie van een enkele cel ......................187

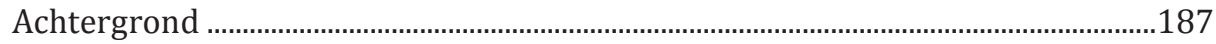

WGA (Whole Genome Amplification) ...........................................................................187

Inhoud van hoofdstuk 4 en 5 ........................................................................................188 
Hoofdstuk 6: Een methode om DNA te pakken te krijgen van enkele tumorcellen uit bloed .188

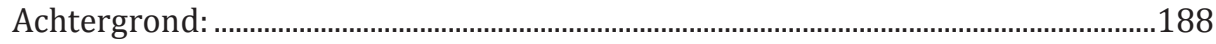

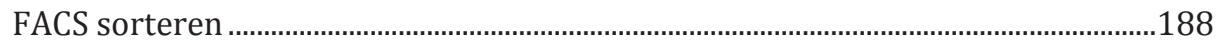

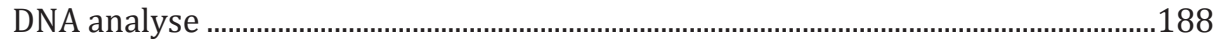

Efficiëntie van de hele procedure ...................................................................................189

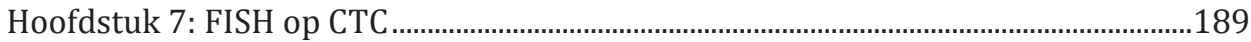

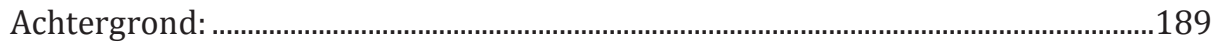

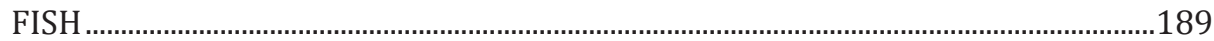

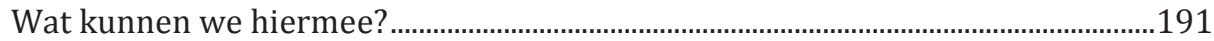

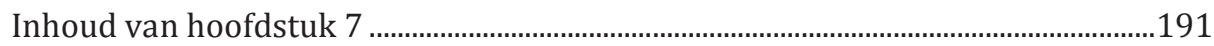

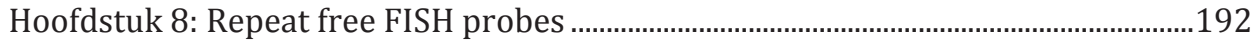

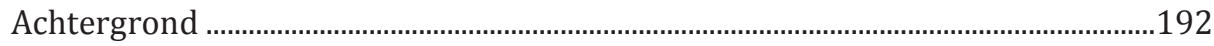

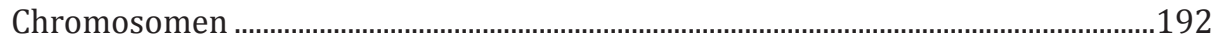

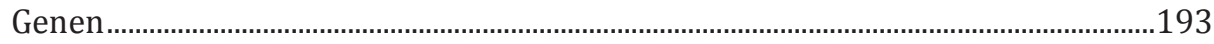

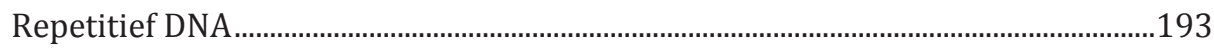

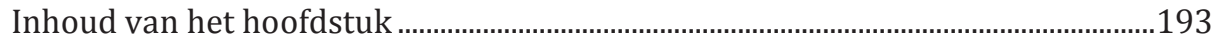

Hoofdstuk 9: Het opvangen en scheiden van CTC's met een microchip ......................193

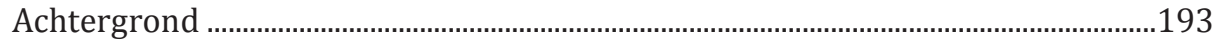

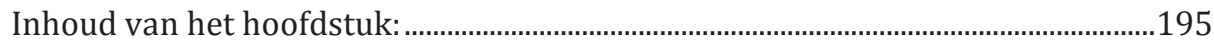

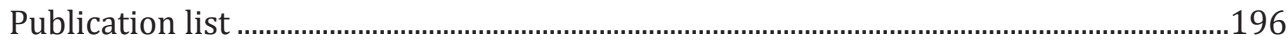

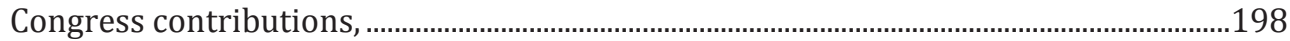

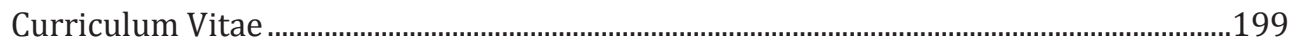

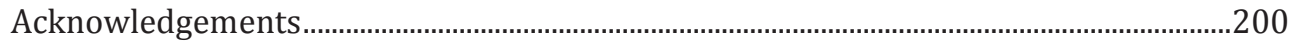

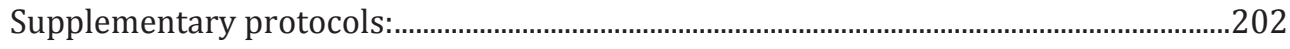

Protocol: Sigma GenomePlex on Ampligrid slide ............................................................202

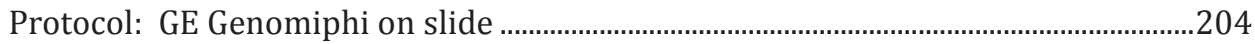

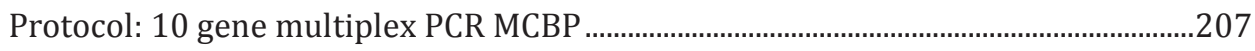

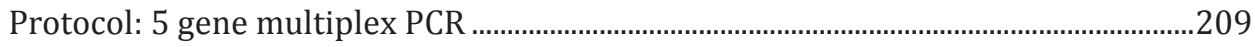


Protocol: 10 gene qPCR MCBP

Protocol: Six gene mpPCR.

. .212

Protocol: Evagreen monitoring of RubiconNGS, Genomeplex, NEB, Qiagen, GE and Ampli-1.

. .214 


\section{CHAPTER 1: INTRODUCTION}

In this thesis the isolation of Circulating Tumor Cells (CTC) and analysis of the genetic composition is explored to ultimately enable to choose the treatment most likely to be effective in the individual cancer patient. Several techniques for isolation, processing and genetic testing of CTC are investigated and the most promising developed such that they can be used in the diagnostic clinical setting.

Under the supervision of Leon Terstappen the CellSearch test was developed to detect and enumerate a clinically relevant group of circulating tumor cells in the blood of cancer patients. In this thesis CTC's isolated with this method were used. In Chapter 1 the developments of the various CellSearch tests are reviewed. Proteomic and genetic tests have been developed to detect tumor specific aberrations in situ, in the CellSearch cartridge or in vitro.

It is about 10 years ago that the first Next gen DNA sequencers became available for researchers. Due to this technology in depth analysis of the genomes of cancer cells from different sources and time points has become possible. It appears that in most cases some common mutations can be found, but within the tumor, in metastasis or disseminated cells a variation of driver mutations can exist. Due to this it has become clear that the old model, which described a linear progression of tumor cells cannot hold up. The previous model described a sequential accumulation of mutations in cancer related genes ending up in clonal expansion of the cells. It has become clear that most cancer types follow a branched evolution where random mutations in various driver genes are selected for growth or survival characteristics. This insight makes it immediately useful to follow the progress of the disease in time. Traditionally, only the primary tumor and possible local metastasis at the time of primary resection are analyzed for their genetic and proteomic makeup to determine the treatment plan. Awareness that this is not sufficient is increasing and the need for "real time" testing is growing.

Parallel to this progress a large number of targeted drugs have come to the market. The first Trastuzimab (Herceptin) and Imatinib (Gleevec) were approved by the FDA in 1998 and 2001 respectively. Now already over 70 different FDA approved therapeutic targeted drugs in the form of monoclonal antibodies or small molecules are available. These drugs can block specific protein interactions, receptor activations or enzyme activities, which stimulate the progression of the tumor cells. 
During the last 7 to eight years the single cell genome analysis has made big steps forward. Before 2009 there were only a few groups capable of repetitively and reliably amplifying the DNA of single cells. At this time many different kits have come to the market with a few completely different approaches. Most kits have been investigated and used. Some are not used anymore because of inconsistent results, but for most applications the kit that is used depends on the downstream analysis that is intended. Chapter 4 describes the WGA kits in detail and discusses the usability of each kit or approach. The choice of Quality control done on the amplification products again depends on both upstream WGA method as on downstream application. The sometimes large number of samples or the extreme expensive downstream sequencing experiments require a different quality control assay. All known and used WGA quality control methods are discussed in Chapter 5.

The FISH test was the first test that was developed to analyze genomic information of CellSearch CTC's. In first instance to confirm that the detected cells were cancerous by detecting aneuploidy, which is described in chapter 7. In this chapter the work is done with centromeric, repetitive probes. For detection of unique sequences, higher concentrations of probe are needed and together with the larger volume of a CellSearch cartridge hybridization, this was becoming an expensive endeavor. The repeat free technology described in chapter 8 was invented and developed and came forward from the need to reduce cost, save time on the hybridization process and circumvent the existing FISH patent estate. Using these probes immediately a large study was done to investigate a rearrangement of the TMPRSS/ERG gene together with a deletion of the PTEN gene and an amplification of the AR gene[1].

A lot of effort has gone into the isolation of single cells. Chapter 3 gives an overview and a review of the available techniques. The ALS Cellselector [2] is not described in chapter 3 , this as it was written before its release. In the meantime there has also been progress at Silicon Biosystems and the latest releases from machine describes a procedure that has 30.000 slots and allows for isolation of 30 cells in 90 minutes.

First attempts to isolate single cells were done using a micromanipulator. After some practice and proper installation of the equipment, picking up cultured cells was doable and placing them to a desired place also, though both not $100 \%$. When there are enough cells a cell can be chosen which has no surrounding cells and has good morphology. Efficiency went down when moving to lower cell numbers or patient material. Due to cell loss during sample handling some more cells are lost. Then, during micromanipulation time is limited due to evaporation. When handling, the cells are sometimes touched and smeared to the surface. This gets worse when cells are 
processed through the AutoPrep system where cell permeabilization reagents are used. On top of this all, patient derived samples will show even more variations in cell quality, rigidity and strength. Also variation in samples will cause a large variation in the number of co-isolated white blood cells from $\sim 1000$ to up to, or more than 200.000. This will become worse in multi-center studies as samples will vary age and variation in shipment conditions. Although it has not been tested, also a large difference in cell quality is expected between cancer types. This large sum of complications made it unattractive to continue with this approach and explore other techniques.

In Chapter 6 FACS sorting of CellSearch CTC's is introduced. Since the tests with cultured cells showed promising results a small cohort of patient samples has been sorted and quantified together with the analysis of amplified DNA material from FACS sorted single cells. We showed that we were capable of producing amplified material from about $30 \%$ of the CTC's that were found in the cartridge from lung cancer patients. Also, sequencing results showed that the amplified material from the single cells was suitable for Whole Exome sequencing. Obvious downside is the big loss of CTC's, but also the fact that there is no visual confirmation possible, which is needed because the cells go into a costly process where the DNA is amplified and sequenced. Another negative side to this technique is that expensive equipment is needed which needs to be well maintained and operated by a skilled operator. Each sample or patient will be a little bit different and the gates will have to be adjusted. During the time needed for adjustments some of the cells will get lost.

To overcome most of the issues with micromanipulation and FACS we have come up with the Puncher. A chip with cups to sort individual cells and simply a needle to punch out the bottom of the cup with the cell. Advantages are that there is a visual confirmation, potentially little cell loss, good separation between cells and enough time to analyze the cells. Chapter 9 shows the potential of this technique by showing the sorting of three different blood spiked cell lines, isolated by CellSearch, quantification of the sorted cells in the cups and molecular identification of the cells by Whole Genome Amplified DNA of the individual cells.

Although this technique was promising we experienced some drawbacks. The first was patient sample material which contained only very few CTC's so patient samples for testing were scarce. Second was that the CellSearch cartridges started to contain many more WBC. In these full cartridges DNA of the cells started to merge and could not be separated from each other. Unclear is whether this is an effect of the patient samples, CellSave fixative, the CellSearch kit or of a combination of factors. This higher 
number of cells has two implications. The first is that the cells tend to stick to each other and will form a network. A stronger fixative will prevent this from happening. The second is that the few CTC can only be captured in many cups chips. One chip contains 6400 wells. If used correct no more than this number of cells can be added. The chip does have a small filtering capacity so it is possible to load up to 30.000 cells. The bigger CTC will then be captured and the smaller WBC will flow through. However there is a chance that the WBC will lyse and that the DNA sticks to the pore. When filtering $>30.000$ cells many WBC will pile up in pig clumps under the chip. Solution is simply to take only 6400 cells each time but then only a fraction of the CTC will be found.

These drawbacks account only for the exceptions. Most samples can be filtered and punched without a problem. Latest improvement is the possibility of the punching of wet cells, which reduces the number of breaks in the DNA and therefore will improve the quality of the WGA products. Current work focuses on capturing cells enriched with other techniques such as depletion of leukocytes with RosetteSep.

\section{References}

1. Attard G, Swennenhuis JF, Olmos D, Reid AHM, Vickers E, A'Hern R, Levink R, Coumans F, Moreira J, Riisnaes R, Oommen NB, Hawche G, Jameson C, Thompson EE, Sipkema R, Carden CP, Parker C, Dearnaley D, Kaye SB, Cooper CS, Molina A, Cox ME, Terstappen LWMM, de Bono JS: Characterization of ERG, AR and PTEN gene status in circulating tumor cells from patients with castration-resistant prostate cancer. Cancer Res 2009, 69:2912-8.

2. Neumann MHD, Schneck H, Decker Y, Schömer S, Franken A, Endris V, Pfarr N, Weichert W, Niederacher D, Fehm T, Neubauer H: Isolation and characterization of circulating tumor cells using a novel workflow combining the CellSearch® system and the CellCelectorTM. Biotechnol Prog 2016. 


\section{CHAPTER 2: IMPROVING THE CELLSEARCH SYSTEM}

Authors: J.F. Swennenhuis, G. van Dalum, L.L. Zeune, L.W.M.M.Terstappen

Published in: Expert review of Molecular Diagnostics DOI: 10.1080/14737159. 2016.1255144

Running title: Improving the CellSearch System

\section{Abstract}

The CellSearch ${ }^{\circledR}$ test for the isolation of circulating Tumor Cells (CTC's) from peripheral blood is on the market for 12 years. The kit has been cleared by the American Food and Drug Administration for clinical use in metastatic prostate, breast and colon cancer patients and also showed clinical relevance in many other types of cancer. With the growing need of biomarkers for cancer, the CTC's isolated by the CellSearch system have been extensively explored. Immunoassays, single cell isolation, arrayCGH, next gen sequencing, qPCR and FISH have been developed on these cells. The CellSearch system has also been used for the isolation of other cell types and subgroups. This review will describe the CellSearch test and will discuss all improvements, extensions and modifications that were developed using the CellSearch equipment or reagents.

\subsection{Introduction}

The CellSearch test (Janssen Diagnostics, LLC, Raritan, NJ, United States) for the isolation of circulating tumor cells (CTCs) from peripheral blood is on the market for 
12 years. The kit has been cleared by the US FDA for clinical use in metastatic prostate, breast and colon cancer patients and also showed clinical relevance in many other types of cancer. Due to the emergence of personalized medicine in cancer treatment, the need for biomarkers giving accurate and actual insight in the state of the disease is rising quickly [1]. In recent years, many new targeted drugs have come to the market for treating cancer patients, and a lot more are expected in the upcoming years $[2,3]$. Circulating biomarkers such as CTCs, circulating proteins, and nucleic acids are expected to contain the biomarkers needed to select a suitable therapy. Sampling is minimally invasive, and can easily be done on a frequent basis for close monitoring. The survival of CTCs in blood is hypothesized to be short, resulting in real-time information of the state of the disease [4-6]. Because the cells can be individually captured and analyzed, heterogeneity can be determined as well as the combinations of aberrations present in each cell. Also when therapy resistance occurs and a change in therapy is needed, the CTCs will most probably reflect the resistant population of cells. An obvious disadvantage of these cells is the low number. Only in advanced patients, a tube of blood contains CTCs in single or in some cases double digits. The CTCs isolated by the CellSearch system have been extensively explored. Immunoassays, single-cell isolation, array-comparative genome hybridization (CGH), next-generation sequencing, quantitative polymerase chain reaction (qPCR), and fluorescence in situ hybridization (FISH) have been developed on these cells. The CellSearch system has also been used for the isolation of other cell types and subgroups. This review will describe the CellSearch test and will discuss all improvements, extensions, and modifications that were developed using the CellSearch equipment or reagents.

A wide variety of isolation and detection methods have been developed to enrich and enumerate CTCs. Most of these methods end with an enriched CTC population, which is subsequently analyzed and enumerated. The enrichment techniques can be separated in two major categories: Enrichment based on affinity, using selective antibodies, and enrichment based on biophysical properties, for example, size, density, deformability, or dielectric properties. An extensive overview of these methods is published by Esmaeilsabzali et al. [7], and a number of these methods have been commercialized. Only one of these commercialized tests has been cleared by the FDA for in vitro diagnostic (IVD) use: the CellSearch test. Even though many studies show that more populations of tumor cells, or tumor-like cells, exist in the bloodstream of cancer patients, only the population of CTCs isolated with the CellSearch test has been proven to be clinically relevant in a variety of different cancer types [8-12]. 
The CellSearch test has been developed for enumeration of CTCs of epithelial origin. This test is cleared by the FDA for monitoring patients with metastatic breast, prostate, and colorectal cancer. Next to the FDA-cleared CellSearch test, a number of extended, related, and accompanying tests have been developed which will be described in this review. Important to note is that these extended tests are not in any case cleared for clinical prognostic, diagnostic, or predictive use. These tests are either detecting different cell types or cancer types or allowing a further analysis on the isolated fraction of cells or on the contents of these cells. Future analysis of CTCs will probably account for genomic, transcriptomic, epigenetic, and proteomic aberrations to obtain complete insight in the disease at each specific moment during the course of the disease.

\subsubsection{The CellSearch system}

The CellSearch test starts with a blood draw of the patient in a CellSave tube. About 8$10 \mathrm{ml}$ of blood is collected in a CellSave tube, which contains a slow fixing preservative. Leukocytes and CTCs are stabilized and the sample can be processed up to $96 \mathrm{~h}$ after blood draw. The standard CellSearch procedure is illustrated in Figure 2.1 using the numbers 1 through 9 in the black circles. The green squares A to I show the alternative and extended tests that are discussed in this review. Step 1: $7.5 \mathrm{ml}$ of the fixed blood is pipetted into a specific CellSearch conical tube and $5.5 \mathrm{ml}$ of CellSearch dilution buffer is added to the blood after which it is centrifuged at $800 \times \mathrm{g}$ for $10 \mathrm{~min}$ without brake. Step 2: The tube is carefully loaded into the AutoPrep system. Step 3: The diluted plasma will be removed until $1 \mathrm{~cm}$ above the red blood cell layer. Step 4: Anti-epithelial cell adhesion molecule (EpCAM) ferrofluid and dilution buffer are added to the tubes and mixed by pipetting. In addition, magnets are moved back and forward towards the tube to enhance the collisions between cells and ferrofluids. Step 5: After an incubation period, the magnets remain against the tube, anti-EpCAMferrofluids, and the cells that have bound ferrofluid will be pulled to the magnets, and the rest of the cells are removed in a single pipetting step. Step 6: The cells are permeabilized and stained. Step 7: Cells are washed with the use of magnetic stations to retain the cells. Step 8: The cells are resuspended in a small volume. Step 9: In this last step, the cells are transferred to a cartridge, which is placed in a magnetic field to pull the cells in one focal plane against a glass surface. This cartridge is scanned on a dedicated fluorescent microscope scanner (CellTracks Analyzer II) (Janssen Diagnostics, LLC, Raritan, NJ, United States) for each individual fluorochrome. The software selects and presents all events that contain phycoerythrin (PE) and 4',6diamidino-2-phenylindole, dihydrochloride (DAPI) close together, and a trained operator will select the events according to the CellSearch CTC definition. This definition is described in detail by Coumans and Terstappen [13]. 


\subsubsection{Commercially available CellSearch kits}

The commercially available CellSearch kits are listed in table 2.1. The CellSearch CTC kit identifies a clinically relevant population of CTCs. The clearance of this test by the FDA as an IVD test implies that the whole procedure, from reagent production and instrument maintenance to operator training, is carefully described and secured. Therefore, any change to the system, reagents, or analysis would risk a chance of

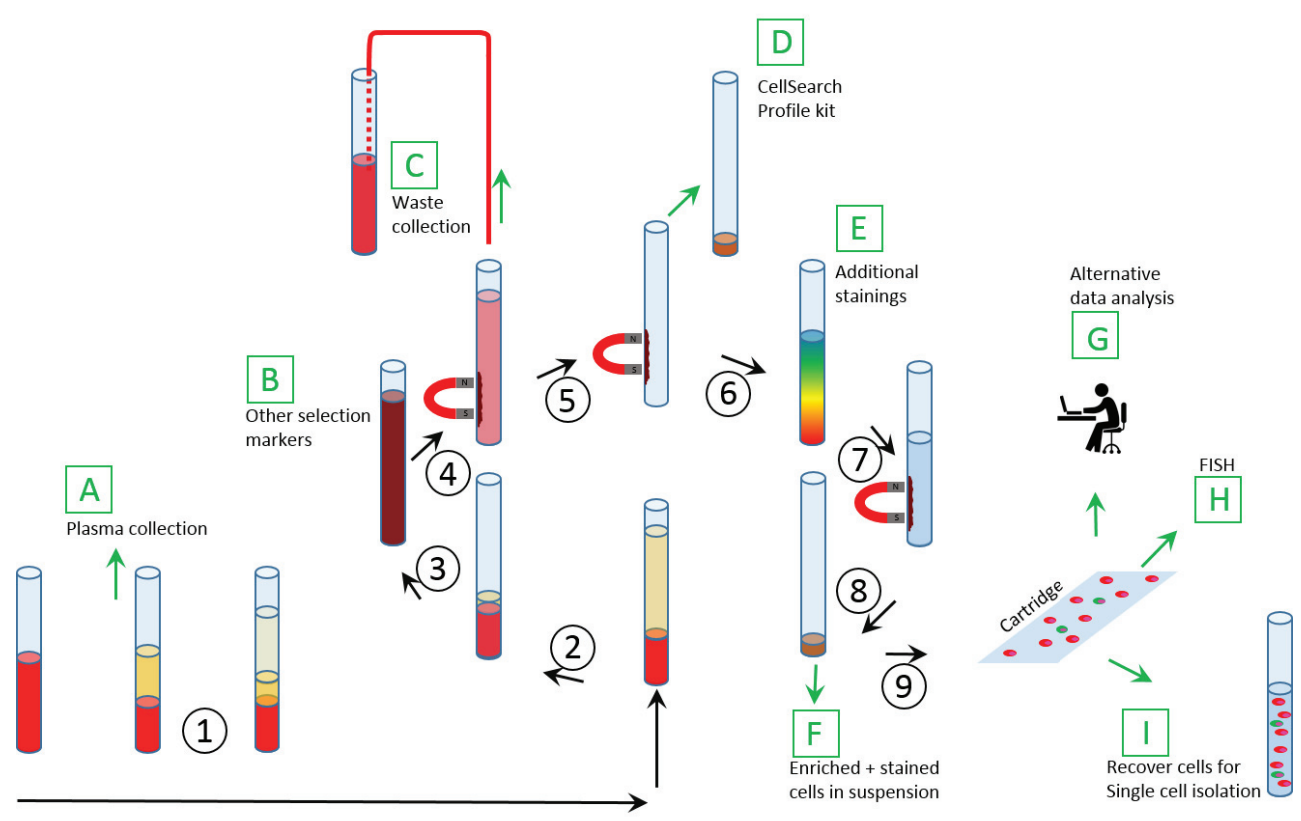

Figure 2.1: Schematic presentation of the CellSearch procedure. Numbers 1 to 9 in the black circles describe the basic CellSearch procedure. Green squares A to I indicate alternative CellSearch methods, additions to the test and extra analysis of the isolated CTCs discussed in this review. CellSearch processing procedure: 1: Preparation of 7,5 $\mathrm{ml}$ of blood by the addition of CellSearch dilution buffer and centrifugation. 2: Removal of the excess of diluted plasma by the CellTracks AutoPrep. 3: Addition of anti-EpCAM-ferrofluid. 4: Magnetic incubation and removal of the unlabeled cells. 5: Washing of the cells. 6: Addition and incubation with staining reagents. 7: Magnetic incubation and washing of the cells. 8: Resuspension of the cells in a small volume. 9: Loading of the cell suspension into a cartridge for scanning.

detecting a population of cells that has a different relevance. The Circulating Epithelial Cell kit is the research-use-only (RUO) version of the IVD kit. Both kits isolate CTCs 
based on their EpCAM expression, stain the DNA of the cells with DAPI, epithelial cells with PE labeled antibodies recognizing cytokeratins identified by the clone C11 and A.53B/A2, and leukocytes with APC-labeled antibodies recognizing CD45. The procedure is described in more detail elsewhere [14]. The intended use of the FDAcleared CellSearch test is: "The presence of CTC in the peripheral blood, as detected by the CELLSEARCH Circulating Tumor Cell Kit, is associated with decreased progression-free survival and decreased overall survival in patients treated for metastatic breast, colorectal, or prostate cancer. The test is to be used as an aid in the monitoring of patients with metastatic breast, colorectal, or prostate cancer. Serial testing for CTC should be used in conjunction with other clinical methods for monitoring metastatic breast, colorectal and prostate cancer. Evaluation of CTC at any time during the course of disease allows assessment of patient prognosis and is predictive of progression-free survival and overall survival'. Twelve years after the FDA clearance the CellSearch test is however not commonly used in routine clinical practice as its best use and benefits are not sufficiently clear. At present 868 clinical trials are registered (www.clinicaltrials.gov) in which a role for CTC in routine clinical practice, a surrogate for survival in clinical trials or a guide for therapy is being explored. The outcome of these studies hopefully will provide clarity of the best use of CTC in clinical practice.

The CellSearch test used for the FDA clearance has also been tested in many other cancers [15] and the presence of CTC is also associated with poor clinical outcome in gastric cancer [16,17], small-cell lung cancer [18-20], melanoma [21,22], endometrial cancer [23], esophageal squamous-cell carcinoma [24,25], cholangiocarcinoma [26], colon cancer-liver metastasis [27], hepatocellular carcinoma [28], pancreatic cancer [29], rectal cancer [30], bladder cancer [31], head and neck cancer [32], and ovarian cancer [33]. Publications referred to above are just examples. In most cases, CellSearch has been used in multiple studies. The CellSearch system has also been used in patients with no known metastasis, and the presence of CTC in these setting also predicted an increased chance of relapse [34,35].

In the CXC kit, the antibodies recognizing cytokeratins are conjugated to FITC instead of PE. This is done to detect antigens on CTC expressed at a low antigen density, which is enabled by the high quantum yield of the PE dye as in comparison to FITC. The first example for the need of the higher sensitivity was the detection of the insulin-like growth factor receptor-1 on CTC [36], and many have followed since. An overview of tumor marker identification using the CellSearch kit is given in table 2.2. 


\begin{tabular}{|c|c|c|c|c|c|}
\hline $\begin{array}{l}\text { Test name } \\
\text { CellSearch } ®\end{array}$ & $\begin{array}{l}\text { Capture } \\
\text { Antigen }\end{array}$ & $\begin{array}{l}\text { Positive } \\
\text { staining } \\
\text { antigen }\end{array}$ & Dye & $\begin{array}{l}\text { Negative } \\
\text { staining } \\
\text { antigen }\end{array}$ & Dye \\
\hline Circulating & EpCAM & CK (clone C11 & $\mathrm{PE}$ & CD45 & APC \\
\hline Circulating & EpCAM & CK (clone C11 & PE & CD45 & APC \\
\hline CXC Kit & EpCAM & CK (clone C11 & FITC & CD45 & APC \\
\hline Circulating & EpCAM & None & - & None & - \\
\hline Qualified marker & & Her2 & FITC & - & - \\
\hline & & EGFR & FITC & & \\
\hline & & IGF-1R & PE & & \\
\hline Circulating & CD146 & RAB38/NY- & PE & CD45 \& CD34 & APC \\
\hline Circulating & CD146 & CD105 & $\mathrm{PE}$ & CD45 & APC \\
\hline Circulating & CD146 & None & & None & \\
\hline Circulating & \multicolumn{5}{|c|}{ Fixed SKBR-3 cells at low and high concentration } \\
\hline Epithelial Cell & \multicolumn{5}{|c|}{ Fixed SKBR-3 cells at low and high concentration } \\
\hline CXC Cell Control kit & \multicolumn{5}{|c|}{ Fixed SKBR-3 cells at low and high concentration } \\
\hline CEC/CMC Control & \multicolumn{5}{|c|}{ Fixed SK-MEL-28 cells at low and high concentration } \\
\hline
\end{tabular}

Table 2.1: commercially available CellSearch kits. IVD: in vitro diagnostic; CEC: circulating endothelial cell; CMC: circulating melanoma cell; PE: phycoerythrin; APC: allophycocyanin; EpCAM: epithelial cell adhesion molecule; CK: cytokeratin; EGFR: Epidermal growth factor receptor; IGF-1R: Insulin like growth factor 1 receptor; FITC: Fluorescein isothiocyanate.

In the circulating epithelial cell profile kit, the protocol is the same up to step 5 (see figure 2.1) after which the immunomagnetically enriched cells are resuspended in a tube for further alternative analysis. This kit was originally developed to maintain the viability of the cells and enable the analysis of the ribonucleic acid (RNA) content of the cells [37]. To maintain viability, the blood has to be drawn in Ethylenediaminetetraacetic acid (EDTA) collection tubes rather than CellSave blood collection tubes. Since the introduction of the Profile kit, a variety of alternative technologies have been introduced that use EpCAM expressing cells from blood. A more detailed description of the applications for which the profile-enriched cells are used is given in section 2.4 .

Assessment of the presence or absence of targets for therapy is one of the important applications of CTC. The first demonstration of this potential was done by showing the expression of Her2 on CTC in breast cancer patients [38]. The antibodies recognizing Her2-FITC, EGFR-FITC, MUC-FITC (withdrawn from the market) and IGF-1r have been 
made available. Assays for other treatment targets such as the androgen receptor, estrogen receptor, bcl-2, and vascular endothelial growth factor receptor (VEGFR) have been developed but are not commercially available. A summary of markers assessed on CTC using the CellSearch system and the expansion of the number of markers that can be assessed simultaneously is described in section 2.5.

In the CellSearch system the antibodies on the ferrofluids determine the class of cells that will be enriched. For the enrichment of non-hematopoietic cells it is of utmost importance that the antibody does not recognize hematopoietic cells specifically or nonspecifically [39,40]. A variety of antibody ferrofluids have been used on the CellSearch system and those that are not commercially available are described in section 2.2.

In the Melanoma Cell kit ferrofluids conjugated to CD146 are used. The antigen recognized by CD146 is also known as the melanoma cell adhesion molecule (MCAM) and cell surface glycoprotein MUC18. CD146 is expressed on melanoma cells, endothelial cells, smooth muscle cells, and a subset of activated T-lymphocytes. The melanoma cells are identified as nucleated cells that express the high-molecularweight melanoma-associated antigen (HMW-MAA) and lack CD45 and CD34 [22]. Circulating melanoma cells identified in this manner also associate with poor clinical outcome [21,22,41-43].

The circulating endothelial cell kit also uses CD146 ferrofluids but uses a different staining cocktail, resulting in nucleated endothelial cells defined as CD146+, CD105+, and CD45- [44]. Increased levels of circulating endothelial cells have been observed in patients with cancer and cardiovascular disease [45-48].

Similar to the epithelial cell profile kit, the endothelial/melanoma cell profile kit is available. Only the CD146-enriched fraction is provided that can be used to characterize the enriched cells by other means such as RNA profiling [49].

To ensure that the CellSearch system is performing, control kits are provided that contain a low number $(\sim 50)$ and high number $(\sim 1000)$ fluorescently labeled and preserved cells derived from either the breast cancer cell line SKBR-3 or the melanoma cell line SK-MEL-28. The cells at the low and high number are labeled with different fluorescent membrane dyes. After processing on the CellSearch AutoPrep they are analyzed on the CellTracks Analyzer II. The high number of cells is automatically counted, and the cells with the low number have to be manually identified. 


\subsection{Applications beyond the standard CellSearch assays}

\subsubsection{Plasma collection}

Circulating biomarkers such as proteins, DNA or microparticles can also be of great value for monitoring cancer patients. The use of proteins such as carcinoma antigen125 (CA-125), carcinoembryonic antigen (CEA), mucin-1 (MUC1) and prostatespecific antigen (PSA) is already common in clinical practice. Circulating DNA can be used for the detection of tumor-specific single-base substitutions, insertions, deletions, and translocations. The use of ctDNA as a cancer biomarker has already been shown in a number of larger studies [50-52]. Tumor microparticles (TMPs), tumor-derived exosomes, or tumor-derived extracellular microvesicles (tEVs) are vesicular structures derived from tumor cells. tEVs can be derived from the plasma membrane by apoptosis or cell death or can be actively produced by endosomal pathways. Most of the larger vesicles have high densities and will end up in the cell fraction of centrifuged blood and not in the plasma. For isolation of the small sized tEVs from plasma several methods are available, which are done mainly by size exclusion chromatography or ultracentrifugation [53]. The potential of tEVs as cancer biomarkers is currently being investigated $[54,55]$.

In the standard CellSearch assay, the plasma is discarded. It is, however, straightforward to aspirate and collect the plasma before placing the tubes on the CellTracks AutoPrep. To do this, $7.5 \mathrm{ml}$ blood is centrifuged inside a CellSearch conical tube for $10 \mathrm{~min}$ at $800 \times \mathrm{g}$. Plasma can be taken up to $1 \mathrm{~cm}$ above the red blood cell layer. After this the tube can be filled with the CellSearch dilution buffer. Blood draws for CellSearch enrichment of the CTCs using a CellSave blood collection tube are particularly suitable for the collection of a plasma sample to isolate ctDNA. The cellstabilizing fixative in the tubes will prevent normal genomic DNA to be released in the plasma by cell lysis or apoptosis of leukocytes. The high variation in background DNA is one of the main difficulties in the development of tests identifying tumor-derived plasma DNA. Although the number of patients is still limited, Kang et al. showed that the plasma samples from CellSave tubes contain detectable concentrations of cancerspecific mutations using digital droplet PCR for up to $48 \mathrm{~h}$ after blood draw and perform equal or better compared to the Streck cell-free DNA tubes and better than EDTA tubes [56]. Biomarkers assessed in plasma and CTC may provide complementary information, and when it can be obtained from the same blood drawtube, it provides clear advantages. 
2.2.2 Changing the antibodies on the ferrofluids and/or CellSearch assay conditions:

The choice of EpCAM as the target for enrichment in the CellSearch CTC kit was based on preliminary work that was performed in which flowcytometry was used as the platform to analyze immunomagnetically enriched cells [57-59]. In these studies EpCAM antibodies derived from the GA73.3 clone were used that were later replaced by antibodies derived from the VU1D9 clone, recognizing the same EpCAM epitope. Whether or not a higher recovery of CTC can be obtained when using antibodies with a higher affinity and/or a combination of antibodies recognizing different epitopes has never been thoroughly investigated [60]. The use of controlled aggregation of EpCAM ferrofluids in the CellSearch kits has, however, already made quite an improvement in the recovery of CTC with relatively low EpCAM antigen density [61]. An alternative is the use of antibodies recognizing different antigens expressed on cells of epithelial origin. Jo Hilgers also known as the great "MUCinier" believed that antibodies against Muc-1 were needed to efficiently capture CTC as they would otherwise be stuck in the Muc. Comparisons of the CTC capture efficiency of ferrofluids labeled with EpCAM or EPCAM \& Muc-1 in patients with metastatic breast cancer however showed no improvement in CTC capture (Figure 2.2 Panel A) and was associated with an increase in white blood cell carry over (Figure 2.2 Panel B). The study was stopped after 11 patients were included as the larger number of white blood cells decreased the specificity of the test, and many more patients would need to be analyzed to determine whether any patients expressed Muc-1, but not EpCAM.

In studies by Mostert et al. and Onstenk et al., the addition of CD146 (MCAM) to EpCAM ferrofluid as a selection marker for CTCs in breast cancer patients was tested $[62,63]$. The rationale was that breast cancer cell lines with epithelial to mesenchymal transition (EMT) characteristics might express CD146. In the assay, CD34 is used to exclude circulating endothelial cells, which are co-isolated using CD146. Although the number of patients is low, the number of patients positive for CTC increased from $\sim 16 \%$ to $\sim 30 \%$ when combining the results for EpCAM (ferrofluid)+ CK+/CD45/DAPI+ and CD146 (ferrofluid)+ CK+/CD34-/CD45-/DAPI+. Both CTC types, however, did not correlate with clinical parameters in this study, and further investigation is needed to determine the clinical relevance of these cells. 

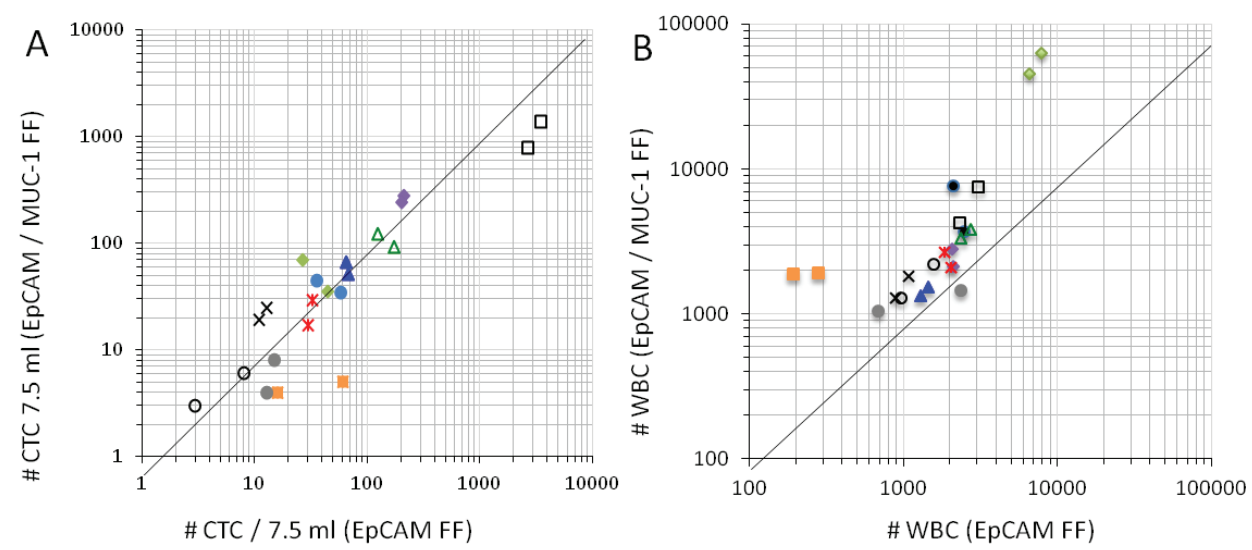

Figure 2.2. Thirty $\mathrm{ml}$ of blood from 11 metastatic breast cancer patients were immunomagnetically enriched. Two $7.5 \mathrm{ml}$ aliquots using EpCAM ferrofluids and two with a combo of EpCAM \& Muc-1 ferrofluids. Enriched samples were stained with a nucleic acid dye, antibodies directed against Cytokeratin and CD45. CTC and white blood cells (WBC) were enumerated by flowcytometry. Each symbol represents a patient and duplicates are represented with the same symbol in both panels.

To identify disseminated tumor cells (DTCs) in bone marrow the CellSearch CTC kit was adapted. Assay optimization was performed using bone marrow aspirates from normal donors. The optimal volume of bone marrow aspirates to process on a CellTracks AutoPrep was found to be $3 \mathrm{ml}$ (CellSave added as anticoagulant and preservative) the EpCAM ferrofluid concentration was reduced by $40 \%$, and the antibody recognizing cytokeratin 19 was removed as it was found to be expressed on megakaryocytes as confirmed by expression of CD61 (Figure 2.3). The staining reagents used in the final assay were cytokeratins antibody C11 FITC and CD45-APC. The larger leukocyte concentration resulted in a two- to threefold higher leukocyte carry-over when compared with the CellSearch whole blood assay, but recovery, accuracy, and linearity of spiked cell lines were similar. 


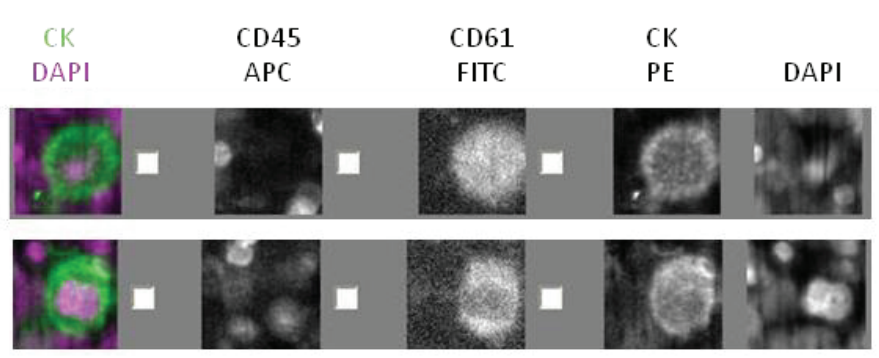

Figure 2.3. Megakaryocytes in bone marrow enriched by EpCAM ferrofluid and staining with Cytokeratin 19 and CD61 and lacking CD45.

A study was conducted to compare the assay with the assay used in the Pantel laboratories (University Medical Centre Hamburg-Eppendorf, Hamburg, Germany) on bone marrow samples from 54 healthy donors and 93 patients with primary breast or prostate cancer. Bone marrow aliquots were split into two, one for the CellSearch Marrow assay and one for staining and analysis in the Pantel laboratories. Results are illustrated in Figure 2.4 and show little concordance, which would imply that a large study would need to be performed to demonstrate a relation with an increased risk for recurrence as was already demonstrated for the slide-based CTC assay $[64,65]$. At present, DTCs are not used in clinical practice, and besides the availability of a validated assay, studies will be needed to determine the potential benefits above gene signatures obtained from the primary tumor that recently have been introduced to identify patients that will or will not benefit from adjuvant therapy $[66,67]$.

CellSearch was also tested, optimized, and confirmed to work on small-volume mouse (xenograft) samples $[68,69]$. Puncture methods were investigated to identify the best way to be able to repeatedly sample the mice. Lateral tail vein, retro-orbital venous plexus, jugular vein, and the left ventricle of the heart were compared. In retro-orbital and jugular puncture samples, epithelial cells were found in the negative control mice. Tail vein samples were too small and therefore obtained no CTC in the positive controls, but the cardiac puncture was found to contain no cells in the negative controls and epithelial cells in the positive controls. Tests on patient-derived xenograft models showed that in a number of patients CTCs can be found in the blood of the mice and that the mice could be monitored in time using cardiac punctures. The CellSearch test adapted for mouse samples was commercially available as mouse/rat cell capture kit but has been discontinued. Lowes et al. have described the use of the CellSearch reagents for a manual isolation based on this kit [70]. 
To identify circulating multiple myeloma cells (CMMCs), a CellSearch test was developed in which antibodies recognizing CD138 were conjugated to ferrofluids and used to enrich for plasma cells. These cells will be isolated from peripheral blood using CD38 and/or CD138 as was presented at the American association for cancer research (AACR) annual meeting 2016 [71]. These cells are found in elevated levels in the peripheral blood of patients with plasma cell disorders. FISH and transcriptional profiling of these cells show aberrations consistent with those found in the tumors. Multiple myeloma patient groups at risk can be separated using the CellSearch CMMC enumeration data.
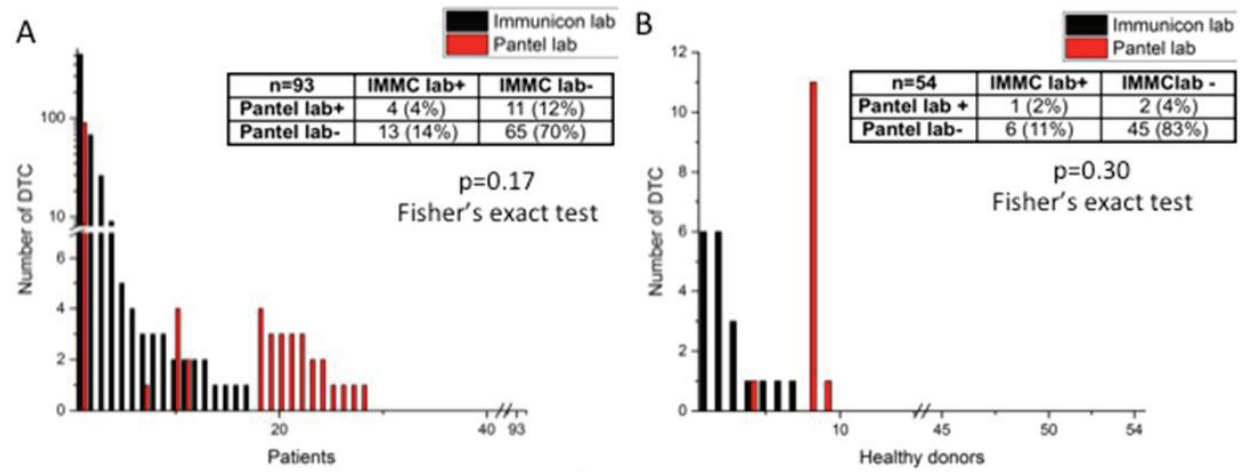

Figure 2.4. Comparison of the number of DTC detected with CellSearch Marrow assay and the standard DTC assay used in the Pantel laboratories in 93 patients with primary breast and prostate cancer (Panel A) and 54 bone marrow aspirated of healthy donors (Panel B). Although a Fisher's exact test showed no significant difference between both DTC assays, the concordance was low which can be expected with the low numbers of DTC detected [72]. The background of DTC detected in bone marrow of healthy donors is higher as compared with the CTC in $7.5 \mathrm{ml}$ of blood of healthy donors [73].

\subsubsection{Collection of the immunomagnetically depleted blood}

CellSearch captures a clinically relevant group of CTCs based on EpCAM expression. Several studies indicate that there are tumor cells expressing lower EpCAM that are missed by CellSearch [73,74]. To investigate if these cells can indeed be found in the depleted fraction of blood, de Wit et al. introduced a device that collects the blood from the CellTracks AutoPrep after immunomagnetic cell capture [75]. In this study, the standard CellSearch assay was performed; the EpCAM-depleted blood was collected and subsequently passed through a filter with $5 \mu \mathrm{m}$ pores. The cells collected 
on the filter were stained for cytokeratins and leukocyte markers and counted. On the filters, about the same number of CTCs could be found as with CellSearch. However, other than the CellSearch cells alone, the cells on the filter or the sum of CTCs did not correlate with clinical outcome. Studies are ongoing to reveal the differences in the EpCAM+ and EpCAM- tumor cells as well as studies in other cancers. A protocol to manually collect the discarded blood is available on the medical cell biophysics (MCBP) website (https://www.utwente.nl/tnw/mcbp/ protocolsandtools/).

\subsubsection{Immunomagnetic separation only}

The first step in the CellSearch AutoPrep system is the enrichment of the CTCs. After this isolation the system will perform permeabilization, staining, and washing steps. The CellSearch profile kit will only do the enrichment step and present the enriched cell suspension in the same conical tube. This procedure is comparable to Illumina's MagSweeper system. A user can now do a manual staining procedure or proceed immediately to a lysis step for total RNA analysis. Samples isolated with the regular CTC kit are permeabilized for optimal cytokeratin and nuclear staining and are therefore not expected to retain the mRNAs. Important for RNA work is that the cells are not fixed. Blood draw should therefore not be done in CellSave tubes but in EDTA, acid citrate dextrose (ACD), or heparin tubes. Doing a total RNA analysis using the profile kit has the advantage that the procedure is fast and standardized. Disadvantage is that the number of background cells is unknown. An estimation of the CTC number could be made by also performing a standard CellSearch CTC test. The first demonstration of the feasibility of this approach was reported by Smirnov et al. [37]. Onstenk et al. recently showed the detection of the splice variant of AR (AR V7), which is associated with resistance to abiraterone and enzalutamide, by using reverse transcriptase (RT)-qPCR after mRNA isolation of the profile kit products [76]. The same procedure was also used by others $[37,49,77,78]$. Cho et al. are using a linear T7 preamplification step for the RNA to compare the profile kit CTC mRNA to mRNA from microdissected single bone lesions [79]. They found a high concordance between presence and absence of detectable gene expression in both fractions.

Next to mRNA analysis the CellSearch profile kit has also been used for the isolation of viable CTC to attempt expansion of the tumor cells. An example is a study by Rossi et al. who used the CTC for xenografts [80]. Blood drawn in EDTA tubes was enriched using the CellSearch profile kit and was injected subcutaneously into nonobese diabetic/severe combined immunodeficient (NOD/SCID) mice. Cells were found back 
in the peripheral blood, bone marrow, and spleen, which indicates the migratory capabilities of this EpCAM-positive cell fraction.

\subsubsection{Additional reagents for cell labeling}

Additional markers can be added to the CellSearch test staining mix. To do this, a fluorescent-labeled antibody can be added to the system in a separate vial. For the normal CTC kit, this antibody needs to be labeled with a dye that fits into the free FITC channel. Janssen has three commercially available CellSearch tumor phenotyping reagents: Her-2/neu, IGF-1R and EGFR. Protocols for AR, ER, Ki-67 and VEGFR-2 are also available. If a target with low expression is investigated, it is possible to use the CXC kit. This kit uses, as described above, the FITC channel for the cytokeratin detection leaving the stronger PE dye free to use for the extra marker. Many studies have been done looking at the Her-2 expression on CTCs using CellSearch [38,81-89]. Most of these studies show that a number of patients develop Her-2-positive CTCs, while the primary tumor was negative indicating a new possible treatment target for this group of patients. A recent article from Paoletti et al. shows the use of the CXC kit for studying the development of resistance of breast cancer patients to the estrogen receptor down regulating drug Fulvestrant [90,91]. This small study suggests a heterogeneous cause of resistance based on the expression of estrogen receptor (ER) and B-cell lymphoma-2 (BCL-2) on CTCs. Table 2.2 gives a complete overview of the studies, research, and development work done on extra target analysis of CellSearch CTCs. 
CHAPTER 2: IMPROVING THE CELLSEARCH SYSTEM

\begin{tabular}{|c|c|c|c|c|}
\hline PMID & Year & Target & Cancer & Author \\
\hline 17079488 & 2006 & UPAR Her2* & Breast Cancer & Meng [84] \\
\hline 17906897 & 2007 & Her2 & Breast Cancer & Stojadinovic [38] \\
\hline 17575225 & 2007 & IGF1R & Prostate Cancer & De Bono [36] \\
\hline 19102715 & 2009 & EGFR & Breast Cancer & Payne [92] \\
\hline 20838621 & 2010 & EGFR plus FISH and qPCR & General & Punnoose [93] \\
\hline 20859679 & 2010 & Her2 & Breast Cancer & Fehm [85] \\
\hline 20406831 & 2010 & Her2 & Breast Cancer & Riethdorf [82] \\
\hline 20978147 & 2010 & M30 & General & Rossi [94] \\
\hline 21264346 & 2011 & Her2 & Breast Cancer & Ignatiadis [81] \\
\hline 22899576 & 2012 & CD44 M30 & assay development & Lowes [95] \\
\hline 22476856 & 2012 & Her2 & Breast Cancer & Pestrin [86] \\
\hline 22277196 & 2012 & Her2 & Breast Cancer & Rink [87] \\
\hline 23275633 & 2013 & Her2 & Breast Cancer & Ligthart [96] \\
\hline 23538216 & 2013 & M30 BCL2 & Breast Cancer & Smerage [11] \\
\hline 24023327 & 2013 & EGFR & Colorectal cancer & Kuboki [97] \\
\hline 24201755 & 2013 & Her2 & Gastriointestinal Cancer & Iwatsuki [98] \\
\hline 24637923 & 2014 & optimization & General & Lowes [70] \\
\hline 25528628 & 2015 & CK20 & Colorectal cancer & Welinder [99] \\
\hline 25719830 & 2015 & $\mathrm{AR}$ & Prostate Cancer & Crespo, M [100] \\
\hline 25972110 & 2015 & Her2 & Breast Cancer & Wallwiener [83] \\
\hline 25957999 & 2015 & MCT1 MCT4 & General & Kershaw [101] \\
\hline 26093818 & 2015 & PDL1 & Breast Cancer & Mazel [102] \\
\hline 25896421 & 2015 & Post CellSearch ER, Her2 & Breast Cancer & Frithiof [89] \\
\hline 25381338 & 2015 & ER BCL2 Her2 KI67 & Breast Cancer & Paoletti [91] \\
\hline 25450039 & 2015 & Ecadherin CD133 & Prostate Cancer & Pal [73] \\
\hline 26923772 & 2016 & Vimentin Ki67 & Prostate Cancer & Lindsay [103] \\
\hline 26695546 & 2016 & Post CellSearch CK7/20, TTF-1, ER, PSA & Cancer of unknown origin & Matthew [104] \\
\hline 27145459 & 2016 & PSA & Prostate Cancer & Gorges [105] \\
\hline 26967453 & 2016 & MUC-1 & Pancreatic Cancer & Dotan [106] \\
\hline 27178224 & 2016 & ER BCL 2Her2 KI67 & Breast Cancer & Paoletti [90] \\
\hline
\end{tabular}

Table 2.2. Publications on extra stainings using the CellSearch system. *Immunicon anti-EpCAM ferrofluids were used for manual CTC enrichment and staining.

In principle, any fluorescently labeled antibody can be added to the CellSearch test. The choice of the fluorochrome depends on the fluorescent microscope used to analyze the CellTracks cartridges. The CellTracks Analyzer III that is not commercially available is, for example, equipped with a 10X objective (NA 0.45) and a 40X objective 
(NA 0.6) and has place for eight fluorescent cubes. The filters in these cubes need to match the fluorochromes used with as little spectral overlap as possible. Interpretation of the images can be quite different between operators, and guidelines have been introduced to define what is and what is not considered a CTC in the CellSearch system [15]. This definition has shown to be quite robust in several ring studies that have been conducted $[107,108]$. A variety of new technologies have been introduced after the introduction of CellSearch, and most compare the results obtained with those from CellSearch [109-111]. A difficulty here is that the definitions used to define a CTC are not the same, thus comparing apples with oranges. To overcome the image analysis component of this problem, an open source image analysis program baptized automated CTC classification enumeration and phenotyping tool (ACCEPT), is being developed as part of the European union (EU)funded programs CTCTrap (https://www.utwente.nl/tnw/ctctrap/) and CANCER-ID (http://www.cancer-id.eu/) and will be available at the MCBP and CANCER-ID websites. ACCEPT uses a novel approach to identify objects in the stored images [112], and a variety of features can be extracted from the identified objects. An example of the use of ACCEPT is illustrated in Figure 2.5. A CellSearch CXC test is done on a healthy donor blood sample spiked with $\sim 200$ SKBR3 cells and 200 MCF7 cells (SKBR3: High Cytokeratin, moderate EpCAM, and high Her2/neu) (MCF7: high cytokeratin, high EpCAM, and negative Her2/neu). The extra marker possibility was used to add three markers: polyclonal anti-EpCAM-PE (Sigma cat SAB4700425), antiHer2/neu-DEAC (Antibody clone Her81 conjugated with DEAC-NHS (Sigma cat. 36801) and antiCD16-PERCP (BioLegend cat.302030) as an extra negative marker. Figure 2.5 shows three scatter plots of the objects identified in the cartridge. Only the mean intensity is shown in this figure, but other features such as area, roundness, and overlap with other channels are also measured and can be used to create more complex gates or definitions. In panel a, a gate is set on Cytokeratin FITC+ and DAPI+ objects to select possible CTC candidates; the position of these objects can be observed as orange dots in the scatter plots. In Panel b several of the orange cells express CD45 and CD16 or only CD16 and are excluded as CTC. Panel c shows the Her2/neu DEAC and EpCAM PE expression of the Cytokeratin FITC+, DAPI+, CD16PerCP-, and CD45- CTC. Two distinct populations of CTC can be observed based on Her2/neu expression (Her2/neu positive and Her2/neu negative). A large variation in EpCAM expression can be observed with a relatively higher EpCAM expression of the Her2-negative CTC compared to the Her2-positive CTC. Note that in a portion of CTC, no EpCAM was detected using the polyclonal EpCAM antibody, suggesting a greater sensitivity of the EpCAM ferrofluid to extract CTC with low EpCAM expression compared to the fluorescent detection of EpCAM. 

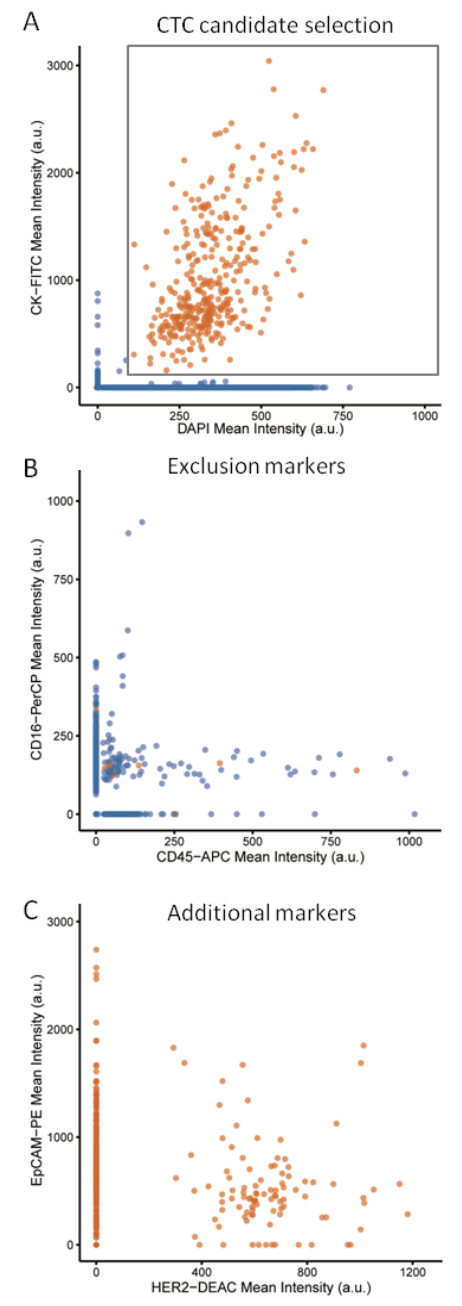

Figure 2.5: Three scatter plots of objects found in a sample by the ACCEPT algorithm. In panel A, a gate is set around the Cytokeratin FITC and DAPI positive events to identify CTC candidates depicted in orange (all other events are shown in blue). Panel B shows the mean intensity of the exclusion markers CD16-PerCP and CD45-APC, the majority of orange events are present at the origin. Panel $\mathrm{C}$ shows the mean intensity of EpCAM-PE and HER2-DEAC of Cytokeratin FITC+, DAPI+, CD16-PerCP-, CD45- CTC.

2.2.6 Collection of the Immunomagnetically enriched and fluorescently labeled cells

The operation of the CellTracks AutoPrep is controlled through a set of commands that can be altered to perform certain tasks. With these so called 'TDefs', the AutoPrep can, for example, be set such that the stained and enriched CTCs are deposited in a 
conical cell isolation tube instead of in the CellTracks cartridge and Magnest. The sample can then be analyzed and sorted using for example fluorescence-assisted cell sorting (FACS) or a DEPArray. Advantage of this approach is that the potential loss of cells by retrieval from the CellTracks cartridge can be avoided. Drawback of this approach is that one cannot get the standard CellSearch read out. The CellTracks cartridge and Magnest are designed to immediately magnetically pull and distribute the magnetically labeled cells and free ferrofluid to the surface for analysis on the CellTracks Analyzer and is not designed for the retrieval of cells.

The few CTCs isolated with the CellSearch system could contain valuable information on drug sensitivity or resistance. A variable number of leukocytes will remain in the CTC fraction and will be transferred to the cartridge. The number of these leukocytes can vary from 500 to even around $2 \times 105$. Tumor cell DNA will be lost in this background. An inevitable step therefore is to pick and isolate the single CTCs in individual tubes or as a pure CTC fraction for genomic analysis. Methods used to isolate single cells for individual analysis in combination with CellSearch-enriched CTCs: Micromanipulation [113], ALS Cellselector [114], the Silicon Biosystems DEPArray [115-118], FACS [28,119,120], and the Punch system using self-seeding Microwell Chips [121]. This step seems a minor intermediate part of the whole workflow but is crucial for the end result. If the step needs to be integrated in the standard laboratory workflow, it will take either very well-trained operators for FACS or micromanipulation or special equipment has to be installed such as the ALS Cellselector, the DEPArray, or the Punch system.

\subsubsection{Alternative image data analyses}

The CellSearch software only selects those events out of the scanned cartridge that are both cytokeratin (PE) and DAPI positive, and only those events will be shown for CTC identification and enumeration to the user. The pictures of events that are presented have digitally optimized color brightness for optimal CTC identification, but this makes it difficult to subtract any quantitative information. Other cytokeratin positive events can also be found in these cartridges. Coumans et al. manually reanalyzed CellSearch data of 179 patients with metastatic carcinoma's [122]. Here, all cytokeratin-positive particles are counted and sorted into seven classes from large and intact cells to smaller particles with DAPI and smaller and larger particles without DAPI. From this study it has become clear that all cytokeratin positive particles are predictive for survival but that the CTC have the lowest background. Ligthart et al. have extracted more morphological features of CTC from the CellSearch images and 
have identified a clinically relevant definition by combining a number of features which can be extracted from the data by an automated algorithm $[88,123]$. One of the features was the label intensity data from the cells in the CellSearch cartridge, which can now be used for analysis. Crespo et al. used this type of analysis to quantify staining of the Androgen receptor in prostate cancer CTCs [100]. Currently, ACCEPT, a new open source, platform-independent, automatic CTC identification and scoring software is being developed. This software should help users of different CTC platforms to come to a more unified CTC definition. An example is illustrated in Figure 2.5 .

\subsubsection{FISH on CTC in CellSearch cartridges}

FISH has first been developed on CellSearch cartridges to confirm that the epithelial cells found by CellSearch indeed were tumor cells. To do this, a five-color test for the detection of DAPI and the centromeres of chromosome 1, 7, 8, and 17 was developed together with a protocol to fix and hybridize the cells at the position where they were found inside the cartridge [124]. The cells lose the fluorescence after fixation, but the CellTracks Analyzer software has stored the position of the cells and specific FISH software is able to relocate these cells after fixation and hybridization. Using the CellTracks Analyzer III the original position is observed with a 40x objective using filter cubes that allow visualization of DAPI, Dy415 (chromosome 17), Dy550 (Chromosome 7), Dy495 (Chromosome 8) and Dy647 (Chromosome 1), all CTCs can be individually and automatically scanned. Together this enables a five-color FISH on each of the identified CTCs. This study showed a high degree of aneuploidy of the CTCs and also heterogeneity between CTCs from individual patients. A small cohort of the patients used for this study was also stained with M30, an antibody detecting caspasecleaved cytokeratin 18 which is a marker for apoptosis. Evaluable FISH signals were obtained for $567 / 590$ (96\%) of the M30-negative CTC, but only 101/175 (58\%) of the M30-positive CTC, which indicates that due to apoptosis a part of the CTCs cannot be used for DNA analysis (figure 2.6). 
A
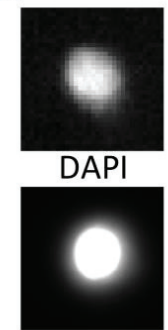

DAPI

B
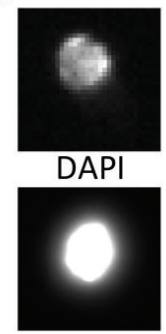

DAPI
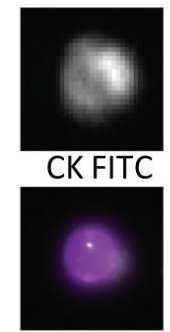

Ch17 Dy415
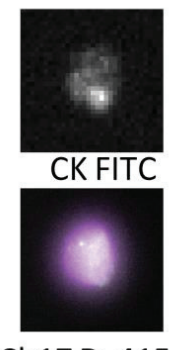

Ch17 Dy415
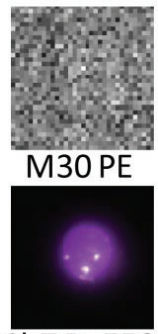

Ch7 Dy550
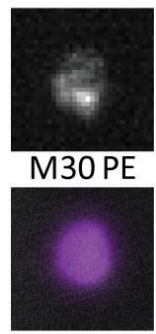

Ch7 Dy550
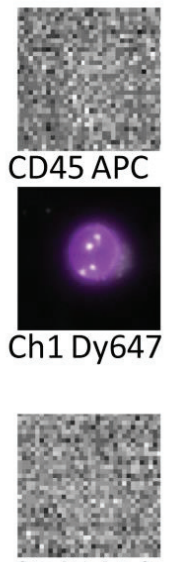

CD45 APC

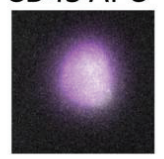

Ch1 Dy647

Figure 2.6. FISH on M30+ and M30- 765 CTCs from 24 prostate cancer patients. Evaluable FISH signals were obtained for 567/590 (96\%) of the M30 negative CTC but only 101/175 (58\%) of the M30 positive CTC.

Attard et al. used the FISH method to detect a combination of phosphatase and tensin homolog (PTEN) deletion, transmembrane protease, serine 2/ erythroblast transformation-specific (ETS)-related gene (TMPRSS/ERG) translocation and AR amplification in each CTC of castration-resistant prostate cancer patients. Homogeneity in ERG rearrangement, significant heterogeneity of AR copy number, and PTEN loss was found within the CTCs of the patients identifying early and late events in the course of the disease [125].

Recently, Gasch et al. also showed a detection technique of microRNA using locked nucleic acid (LNA) probes against mir10b on CTCs fixed in the CellSearch cartridge [126]. To relocate the CTCs, Gasch uses the CellSearch staining reagents again on the fixed and hybridized samples after which the cells are manually examined for FISH signal. They show the ability to relocate and recognize the CTCs after hybridization and re-staining and show heterogeneity of Mir10b expression in breast, prostate and colon cancer CTCs. So far, all work on RNA in CellSearch has been done on the bulk of cells in the cartridge using the profile kit because of the hypothesis that permeabilized cells would not contain RNA any more. This profile kit uses no staining and most 
important no cell permeabilization reagent. The presence of RNA in the stained and permeabilized CellSearch CTCs shows a possibility for in-situ detection of more RNAs in single cells.

\subsubsection{Use of CellSearch for other body fluids}

Besides in blood, tumor cells can also be found in other fluids using the CellSearch system. A normal CellSearch assay depends on the separation line between the erythrocytes and the plasma. This line is automatically detected, and the plasma is removed until $1 \mathrm{~cm}$ above this line. In most other fluids, there are not enough erythrocytes to make a clear layer. A solution to this problem is to run the samples as a control by using $4.5 \mathrm{ml}$ in total or to dilute the sample to this volume. The control cell test skips the layer detection and initial plasma removal step. Patel et al., Tu et al., and Lee et al. show the detection of epithelial cells in cerebrospinal fluid and the possibility of monitoring leptomeningeal metastasis [127-129]. The same method is used to find tumor cells in the fluid of the drain used by a head and neck cancer dissection [130]. Also for leukapheresis samples, which are concentrated mononuclear cells from blood, the same method is used. For these samples, a maximum of $2 \times 108$ cells is used which is about five times as many as in $7.5 \mathrm{ml}$ of blood [131]. In this study, diagnostic leukapheresis (DLA) was performed preoperatively for 23 patients. Detection rates were $28 \%$ for the peripheral blood and $72 \%$ for the DLA products and even $90 \%$ in the breast cancer patients. This shows great promise for the use of CTCs as a liquid biopsy. Other studies have been done where intraoperative blood samples were taken such as portal venous blood or liver venous blood. These samples can be run as normal CellSearch CTC samples $[132,133]$.

\subsection{Discussion}

The CellSearch test is being marketed as an FDA-cleared test for the monitoring of metastatic breast, colorectal, and prostate cancer since 2004. The first 6 years after its introduction, studies were published where the test was mainly used in its basic configuration on different cancer types to enumerate CTCs. Figure 2.7 shows the basic CellSearch publications where the number of CTCs is used as a prognostic biomarker and/or a biomarker to predict the response to therapy after the first cycles of therapy. In the original studies a CTC cutoff was used to discriminate between patients with a relatively good and bad prognosis. In reality, the peripheral blood tumor load is 
directly correlated with the clinical outcome. Also survival is reduced by 6.6 months for each 10 -fold CellSearch-defined CTC increase [72,96,122,134].

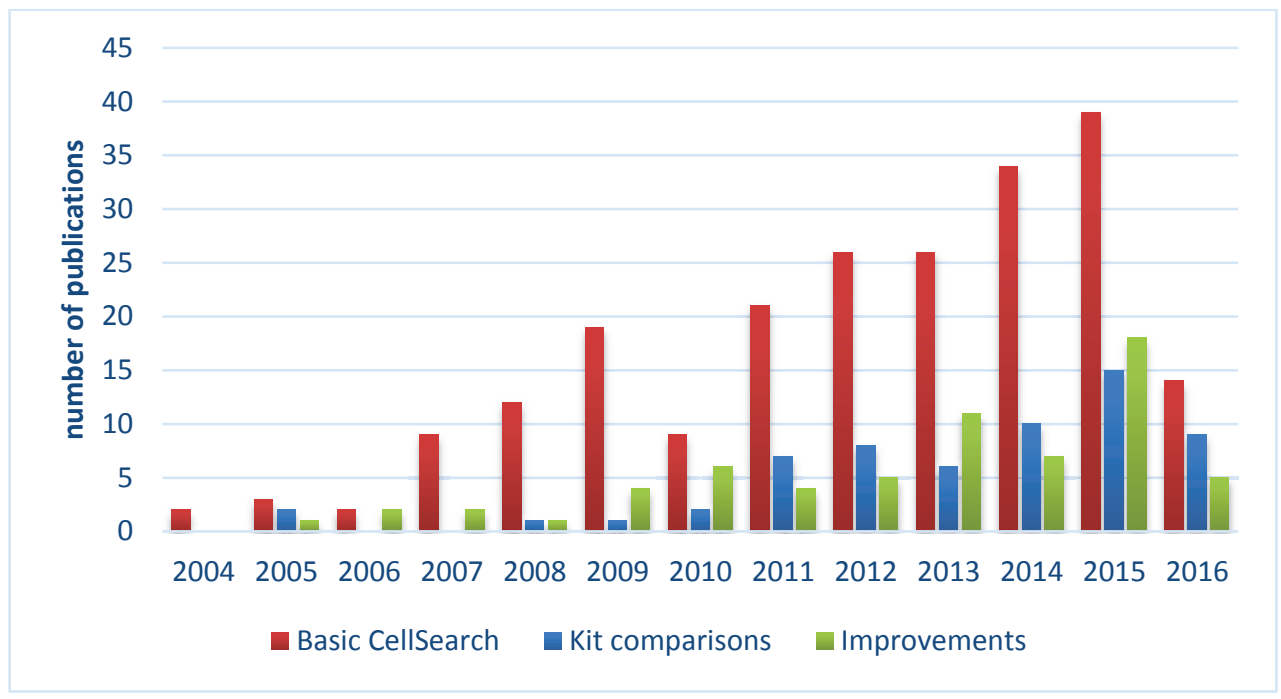

Figure 2.7. Overview of the number of publications using CellSearch. Basic CellSearch are the papers where CellSearch has been used for a clinical study with enumerating the CTCs without extra staining or analysis. Kit comparisons are the number of publications that were done to compare CellSearch to other CTC isolation methods. Improvements are the CellSearch publications discussed in this review where extra staining or analysis of the CTCs were done.

This article only discusses CellSearch tests and does not go into detail about other isolation techniques. Clearly there have been many different CTC isolation techniques introduced after the introduction of CellSearch, and many of these techniques compared the CTC numbers obtained to CellSearch, as can be seen in the blue bars of Figure 2.7. One of the most mentioned reasons for developing a different isolation method is that CellSearch is targeting only the EpCAM positive CTCs and not the CTCs, which have lost their EpCAM expression due to, for example, EMT. Another reason might be that some studies might not need the isolation precision of the fully automated AutoPrep system but allow a variation in quantification precision to gain time and lower the costs. In most cases a different fraction of cells is detected either by capturing or by detection, which includes possible false positives. It is important to keep in mind that different fractions of cells are enumerated due to different capturing or detection technologies. Finding more cells than CellSearch is often referred to as an improvement over CellSearch. In most cases there is only the enumeration 
comparison data with CellSearch, but no clinical data to demonstrate the significance of this subgroup of cells. It is however of high importance that all classes of CTCs will be studied so that more insight can be gained into the metastatic process and the value of these classes of cells as biomarkers for patient treatment.

Biomarkers are needed for the effective use of the growing number of available targeted drugs. The number of publications done on improvements in Figure 2.7 shows that the CellSearch system is also increasingly used to further analyze the cells captured by this system. Proteins are being analyzed in the form of immunofluorescence, DNA with array-CGH, qPCR, sequencing and FISH, RNA with arrays and qPCR, and microRNAs with ISH. It is shown that the CTCs can be taken out of the cartridge and that pure single cells can be accessed and that the crude CellSearch fractions can be analyzed for the expression of aberrant genes.

CellSearch is considered the golden standard for CTC enumeration, but also has a great potential for the use beyond standard CTC enumeration as is clear from the numerous assays that have been developed but not commercialized or have been introduced by users of the system. One of the large impediments for making use of the full capabilities of the CellSearch system of which some are described in this review is that many of its features are not made available to the users of the system or support has been withdrawn. A valid reason for this is that any change to the system can invalidate the FDA-cleared use of the system. Future will tell whether a solution for this obstacle will be found.

At present several clinical studies are ongoing to provide solid evidence for the use of CTC defined by CellSearch as a surrogate for survival in studies probing new therapies. It is expected that within 5 years, the FDA will accept CellSearch-defined CTC as a surrogate for survival, which will accelerate the development of more effective therapies as well as the use of CTC in the management of cancer patients. The first study conducted to switch to therapy based on perseverance of CTC after the first cycle of therapy in metastatic breast cancer showed no benefit [135]. Although CTC predicted treatment failure, the switch to an alternative chemotherapy did not improve progression-free or overall survival. Lesson learned from this study is that an early switch to an alternative therapy should be guided by the characteristics of the tumor. At present studies are being designed and conducted in which a switch to a targeted therapy is prescribed. A positive outcome of such studies will boost the CTC field. At present, a large number of clinical studies are ongoing in which CTC are incorporated (https://clinicaltrials.gov), and we can expect reports of the results from these studies in years to come. 
The extraction of information relevant for therapy from the CTC likely will lead to the development of companion diagnostics. In the next 5 years, it is expected that more clinical studies will be done using more protein markers and using DNA analysis techniques. Whole-genome amplification products will be made from single isolated CTCs, captured from the cartridge, from which multiple analysis can be done such as array-CGH, qPCR, and sequencing. There will be more attention to the development of single-cell techniques to analyze other regulation mechanisms such as DNA methylation and microRNAs. Because of its clinical usability, CellSearch will most probably play a leading role in this research. Next to this, there will be continuous research to investigate the clinical relevance of subgroups of CTC.

Acknowledgements

This work would not have been possible without the dedicated efforts of the employees of Immunicon Corporation that developed the CellSearch system.This work was supported in part by EU FP7 HEALTH.2012.1.2-1 [grand number 305341] (CTCTrap) and the Innovative Medicines Initiative Joint Undertaking [grand number 115749] (Cancer-ID).

\subsection{References:}

1. Dietel M, Jöhrens K, Laffert M V, Hummel M, Bläker H, Pfitzner BM, Lehmann A, Denkert C, Darb-Esfahani S, Lenze D, Heppner FL, Koch A, Sers C, Klauschen F, Anagnostopoulos I: A 2015 update on predictive molecular pathology and its role in targeted cancer therapy: a review focussing on clinical relevance. Cancer Gene Ther 2015, 22:417-30.

2. Graham DM, Coyle VM, Kennedy RD, Wilson RH: Molecular Subtypes and Personalized Therapy in Metastatic Colorectal Cancer. Curr Colorectal Cancer Rep 2016, 12:141-150.

3. Bailey AM, Mao Y, Zeng J, Holla V, Johnson A, Brusco L, Chen K, Mendelsohn J, Routbort MJ, Mills GB, Meric-Bernstam F: Implementation of Biomarker-Driven Cancer Therapy: Existing Tools and Remaining Gaps. Discov Med 2014, 17:101-114.

4. Stott SL, Lee RJ, Nagrath S, Yu M, Miyamoto DT, Ulkus L, Inserra EJ, Ulman M, Springer S, Nakamura Z, Moore AL, Tsukrov DI, Kempner ME, Dahl DM, Wu C-L, Iafrate AJ, Smith MR, Tompkins RG, Sequist L V, Toner M, Haber DA, Maheswaran S: Isolation 
and characterization of circulating tumor cells from patients with localized and metastatic prostate cancer. Sci Transl Med 2010, 2:25ra23.

5. Coumans FFA, Siesling S, Terstappen LWL, Minn A, Massagué J, Klein C, Pantel K, Brakenhoff R, Woodhouse E, Chuaqui R, Liotta L, Fidler I, Weiss L, Chambers A, Groom A, MacDonald I, Bono J de, Scher H, Montgomery R, Parker C, Miller M, Tissing H, Doyle G, Terstappen LWL, Pienta K, Raghavan D, Cohen S, Punt C, Iannotti N, Saidman B, et al.: Detection of cancer before distant metastasis. BMC Cancer 2013, 13:283.

6. Meng S, Tripathy D, Frenkel EP, Shete S, Naftalis EZ, Huth JF, Beitsch PD, Leitch M, Hoover S, Euhus D, Haley B, Morrison L, Fleming TP, Herlyn D, Terstappen LWMM, Fehm T, Tucker TF, Lane N, Wang J, Uhr JW: Circulating tumor cells in patients with breast cancer dormancy. Clin Cancer Res 2004, 10:8152-62.

7. Esmaeilsabzali H, Beischlag T V, Cox ME, Parameswaran AM, Park EJ: Detection and isolation of circulating tumor cells: Principles and methods. Biotechnol Adv 2013, 31:1063-1084.

8. Cohen SJ, Punt CJ a, Iannotti N, Saidman BH, Sabbath KD, Gabrail NY, Picus J, Morse M, Mitchell E, Miller MC, Doyle G V, Tissing H, Terstappen LWMM, Meropol NJ: Relationship of circulating tumor cells to tumor response, progression-free survival, and overall survival in patients with metastatic colorectal cancer. J Clin Oncol 2008, 26:3213-21.

9. de Bono JS, Parker C, Scher HI, Montgomery RB, Miller MC, Tissing H, Doyle G V., Terstappen LWWM, Pienta KJ, Raghavan D: Quantitative Analysis of Circulating Tumor Cells as a Survival Predictor in Metastatic Castration-Resistant Prostate Cancer: Missing Parts in a Superb Study. Clin Cancer Res 2009, 15:1504-1505.

10. de Bono JS, Scher HI, Montgomery RB, Parker C, Miller MC, Tissing H, Doyle G V, Terstappen LWWM, Pienta KJ, Raghavan D: Circulating tumor cells predict survival benefit from treatment in metastatic castration-resistant prostate cancer. Clin Cancer Res 2008, 14:6302-9.

11. Smerage JB, Budd GT, Doyle G V, Brown M, Paoletti C, Muniz M, Miller MC, Repollet MI, Chianese DA, Connelly MC, Terstappen LWWM, Hayes DF: Monitoring apoptosis and $\mathrm{Bcl}-2$ on circulating tumor cells in patients with metastatic breast cancer. Mol Oncol 2013, 7:680-92.

12. Cristofanilli M, Budd GT, Ellis MJ, Stopeck A, Matera J, Miller MC, Reuben JM, Doyle G V., Allard WJ, Terstappen LWMM, Hayes DF: Circulating Tumor Cells, Disease 
Progression, and Survival in Metastatic Breast Cancer. N Engl J Med 2004, 351:781791.

13. Coumans F, Terstappen L: Detection and Characterization of Circulating Tumor Cells by the CellSearch Approach. Methods Mol Biol 2015, 1347:263-78.

14. Kagan M, Howard D, Bendele T, Rao C, Terstappen L: Circulating tumor cells as cancer markers, a sample preparation and analysis system. Tumor markers Physiol Pathobiol Technol Clin Appl Washington, DC AACC Press 2002495-8 2002, 16:3-6.

15. Allard WJ, Matera J, Miller MC, Repollet M, Connelly MC, Rao C, Tibbe AGJ, Uhr JW, Terstappen LWMM: Tumor cells circulate in the peripheral blood of all major carcinomas but not in healthy subjects or patients with nonmalignant diseases. Clin Cancer Res 2004, 10:6897-904.

16. Li Y, Gong J, Zhang Q, Lu Z, Gao J, Li Y, Cao Y, Shen L: Dynamic monitoring of circulating tumour cells to evaluate therapeutic efficacy in advanced gastric cancer. $\mathrm{Br}$ J Cancer 2016, 114:138-45.

17. Okabe H, Tsunoda S, Hosogi H, Hisamori S, Tanaka E, Tanaka S, Sakai Y: Circulating Tumor Cells as an Independent Predictor of Survival in Advanced Gastric Cancer. Ann Surg Oncol 2015, 22:3954-61.

18. Belani CP, Dahlberg SE, Rudin CM, Fleisher M, Chen HX, Takebe N, Velasco MR, Tester WJ, Sturtz K, Hann CL, Shanks JC, Monga M, Ramalingam SS, Schiller JH: Vismodegib or cixutumumab in combination with standard chemotherapy for patients with extensive-stage small cell lung cancer: A trial of the ECOG-ACRIN Cancer Research Group (E1508). Cancer 2016, 122:2371-2378.

19. Hiltermann TJN, Pore MM, van den Berg A, Timens W, Boezen HM, Liesker JJW, Schouwink JH, Wijnands WJ a, Kerner GSM a, Kruyt F a E, Tissing H, Tibbe a GJ, Terstappen LWMM, Groen HJM: Circulating tumor cells in small-cell lung cancer: a predictive and prognostic factor. Ann Oncol 2012, 23:2937-42.

20. Naito T, Tanaka F, Ono A, Yoneda K, Takahashi T, Murakami H, Nakamura Y, Tsuya A, Kenmotsu H, Shukuya T, Kaira K, Koh Y, Endo M, Hasegawa S, Yamamoto N, Jackman D, Johnson B, Krug L, Kris M, Travis W, Allard W, Matera J, Miller M, al. et, Fetsch P, Cowan K, Weng D, al. et, Loberg R, Fridman Y, et al.: Prognostic Impact of Circulating Tumor Cells in Patients with Small Cell Lung Cancer. J Thorac Oncol 2012, 7:512-519. 
21. Hida T, Yoneta A, Wakamatsu K, Yanagisawa K, Ishii-Osai Y, Kan Y, Kato J, Yamashita T: Circulating melanoma cells as a potential biomarker to detect metastasis and evaluate prognosis. Australas J Dermatol 2016, 57:145-9.

22. Rao C, Bui T, Connelly M, Doyle G, Karydis I, Middleton MR, Clack G, Malone M, Coumans FAW, Terstappen LWMM: Circulating melanoma cells and survival in metastatic melanoma. Int J Oncol 2011, 38:755-60.

23. Lemech CR, Ensell L, Paterson JC, Eminowicz G, Lowe H, Arora R, Arkenau H-T, Widschwendter M, MacDonald N, Olaitan A, Mould T, Meyer T, Hartley J, Mitra A, Ledermann JA, McCormack M, Kristeleit RS: Enumeration and Molecular Characterisation of Circulating Tumour Cells in Endometrial Cancer. Oncology 2016, 91:48-54.

24. Matsushita D, Uenosono Y, Arigami T, Yanagita S, Nishizono Y, Hagihara T, Hirata M, Haraguchi N, Arima H, Kijima Y, Kurahara H, Maemura K, Okumura H, Ishigami S, Natsugoe S: Clinical Significance of Circulating Tumor Cells in Peripheral Blood of Patients with Esophageal Squamous Cell Carcinoma. Ann Surg Oncol 2015, 22:367480 .

25. Reeh M, Effenberger KE, Koenig AM, Riethdorf S, Eichstädt D, Vettorazzi E, Uzunoglu FG, Vashist YK, Izbicki JR, Pantel K, Bockhorn M: Circulating Tumor Cells as a Biomarker for Preoperative Prognostic Staging in Patients With Esophageal Cancer. Ann Surg 2015, 261:1124-30.

26. Yang JD, Campion MB, Liu MC, Chaiteerakij R, Giama NH, Ahmed Mohammed H, Zhang X, Hu C, Campion VL, Jen J, Venkatesh SK, Halling KC, Kipp BR, Roberts LR: Circulating tumor cells are associated with poor overall survival in patients with cholangiocarcinoma. Hepatology 2016, 63:148-58.

27. Connor AA, McNamara K, Al-Sukhni E, Diskin J, Chan D, Ash C, Lowes LE, Allan AL, Zogopoulos G, Moulton C-A, Gallinger S: Central, But Not Peripheral, Circulating Tumor Cells are Prognostic in Patients Undergoing Resection of Colorectal Cancer Liver Metastases. Ann Surg Oncol 2016, 23:2168-75.

28. Kelley RK, Magbanua MJM, Butler TM, Collisson EA, Hwang J, Sidiropoulos N, Evason K, McWhirter RM, Hameed B, Wayne EM, Yao FY, Venook AP, Park JW: Circulating tumor cells in hepatocellular carcinoma: a pilot study of detection, enumeration, and next-generation sequencing in cases and controls. BMC Cancer 2015, $15: 206$. 
29. Bissolati M, Sandri MT, Burtulo G, Zorzino L, Balzano G, Braga M: Portal veincirculating tumor cells predict liver metastases in patients with resectable pancreatic cancer. Tumour Biol 2015, 36:991-6.

30. Magni E, Botteri E, Ravenda PS, Cassatella MC, Bertani E, Chiappa A, Luca F, Zorzino L, Bianchi P Pietro, Adamoli L, Sandri MT, Zampino MG: Detection of circulating tumor cells in patients with locally advanced rectal cancer undergoing neoadjuvant therapy followed by curative surgery. Int J Colorectal Dis 2014, 29:10539.

31. Rink M, Chun FKH, Minner S, Friedrich M, Mauermann O, Heinzer H, Huland H, Fisch M, Pantel K, Riethdorf S: Detection of circulating tumour cells in peripheral blood of patients with advanced non-metastatic bladder cancer. BJU Int 2011, 107:1668-75.

32. Nichols AC, Lowes LE, Szeto CCT, Basmaji J, Dhaliwal S, Chapeskie C, Todorovic B, Read N, Venkatesan V, Hammond A, Palma DA, Winquist E, Ernst S, Fung K, Franklin JH, Yoo J, Koropatnick J, Mymryk JS, Barrett JW, Allan AL: Detection of circulating tumor cells in advanced head and neck cancer using the CellSearch system. Head Neck 2012, 34:1440-4.

33. Poveda A, Kaye SB, McCormack R, Wang S, Parekh T, Ricci D, Lebedinsky CA, Tercero JC, Zintl P, Monk BJ, Jemal A, Siegel R, Ward E, al. et, Armstrong DK, Bundy B, Wenzel L, al. et, Cannistra SA, Bois A du, Quinn M, Thigpen T, al. et, Tuxen MK, Soletormos G, Dombernowsky P, Tuxen MK, Soletormos G, Dombernowsky P, Allard WJ, et al.: Circulating tumor cells predict progression free survival and overall survival in patients with relapsed/recurrent advanced ovarian cancer. Gynecol Oncol 2011, 122:567-72.

34. Janni WJ, Rack B, Terstappen LWMM, Pierga J-Y, Taran F-A, Fehm T, Hall C, de Groot MR, Bidard F-C, Friedl TWP, Fasching PA, Brucker SY, Pantel K, Lucci A: Pooled Analysis of the Prognostic Relevance of Circulating Tumor Cells in Primary Breast Cancer. Clin Cancer Res 2016, 22:2583-93.

35. van Dalum G, Stam G-J, Scholten LFA, Mastboom WJB, Vermes I, Tibbe AGJ, De Groot MR, Terstappen LWMM: Importance of circulating tumor cells in newly diagnosed colorectal cancer. Int J Oncol 2015, 46:1361-8.

36. de Bono JS, Attard G, Adjei A, Pollak MN, Fong PC, Haluska P, Roberts L, Melvin C, Repollet M, Chianese D, Connely M, Terstappen LWMM, Gualberto A: Potential 
applications for circulating tumor cells expressing the insulin-like growth factor-I receptor. Clin Cancer Res 2007, 13:3611-6.

37. Smirnov DA, Zweitzig DR, Foulk BW, Miller MC, Doyle G V, Pienta KJ, Meropol NJ, Weiner LM, Cohen SJ, Moreno JG, Connelly MC, Terstappen LWMM, O'Hara SM: Global gene expression profiling of circulating tumor cells. Cancer Res 2005, 65:4993-7.

38. Stojadinovic A, Mittendorf EA, Holmes JP, Amin A, Hueman MT, Ponniah S, Peoples GE: Quantification and Phenotypic Characterization of Circulating Tumor Cells for Monitoring Response to a Preventive HER2/neu Vaccine-Based Immunotherapy for Breast Cancer: A Pilot Study. Ann Surg Oncol 2007, 14:3359-3368.

39. Terstappen LW. M. M.: Detection of infrequent cells in blood and bone marrow by flowcytometry. In Hematopoietic Stem Cell Transplantation. Edited by Anthony D . Ho RH and RE. C. CRC Press, Boca Raton, FL, USA.; 2000:137-152.

40. Rao CG, Chianese D, Doyle G V, Miller MC, Russell T, Sanders RA, Terstappen LWMM: Expression of epithelial cell adhesion molecule in carcinoma cells present in blood and primary and metastatic tumors. Int J Oncol 2005, 27:49-57.

41. Roland CL, Ross MI, Hall CS, Laubacher B, Upshaw J, Anderson AE, Lucci A: Detection of circulating melanoma cells in the blood of melanoma patients: a preliminary study. Melanoma Res 2015, 25:335-41.

42. Bidard F-C, Madic J, Mariani P, Piperno-Neumann S, Rampanou A, Servois V, Cassoux N, Desjardins L, Milder M, Vaucher I, Pierga J-Y, Lebofsky R, Stern M-H, Lantz 0 : Detection rate and prognostic value of circulating tumor cells and circulating tumor DNA in metastatic uveal melanoma. Int J cancer 2014, 134:1207-13.

43. Le Rhun E, Tu Q, De Carvalho Bittencourt M, Farre I, Mortier L, Cai H, Kohler C, Faure GC: Detection and quantification of CSF malignant cells by the CellSearch technology in patients with melanoma leptomeningeal metastasis. Med Oncol 2013, 30:538.

44. Rowand JL, Martin G, Doyle G V, Miller MC, Pierce MS, Connelly MC, Rao C, Terstappen LWMM: Endothelial cells in peripheral blood of healthy subjects and patients with metastatic carcinomas. Cytometry A 2007, 71:105-13.

45. Strijbos MH, Gratama JW, Schmitz PIM, Rao C, Onstenk W, Doyle G V, Miller MC, de Wit R, Terstappen LWMM, Sleijfer S: Circulating endothelial cells, circulating tumour 
cells, tissue factor, endothelin-1 and overall survival in prostate cancer patients treated with docetaxel. Eur J Cancer 2010, 46:2027-35.

46. Strijbos MH, Rao C, Schmitz PIM, Kraan J, Lamers CH, Sleijfer S, Terstappen LWMM, Gratama JW: Correlation between circulating endothelial cell counts and plasma thrombomodulin levels as markers for endothelial damage. Thromb Haemost 2008, 100:642-7.

47. Simkens LHJ, Tol J, Terstappen LWMM, Teerenstra S, Punt CJA, Nagtegaal ID: The predictive and prognostic value of circulating endothelial cells in advanced colorectal cancer patients receiving first-line chemotherapy and bevacizumab. Ann Oncol 2010, 21:2447-8.

48. Damani S, Bacconi A, Libiger O, Chourasia AH, Serry R, Gollapudi R, Goldberg R, Rapeport K, Haaser S, Topol S, Knowlton S, Bethel K, Kuhn P, Wood M, Carragher B, Schork NJ, Jiang J, Rao C, Connelly M, Fowler VM, Topol EJ: Characterization of circulating endothelial cells in acute myocardial infarction. Sci Transl Med 2012, $4: 126 r a 33$.

49. Smirnov DA, Foulk BW, Doyle G V, Connelly MC, Terstappen LWMM, O’Hara SM: Global gene expression profiling of circulating endothelial cells in patients with metastatic carcinomas. Cancer Res 2006, 66:2918-22.

50. Bettegowda C, Sausen M, Leary RJ, Kinde I, Wang Y, Agrawal N, Bartlett BR, Wang H, Luber B, Alani RM, Antonarakis ES, Azad NS, Bardelli A, Brem H, Cameron JL, Lee CC, Fecher LA, Gallia GL, Gibbs P, Le D, Giuntoli RL, Goggins M, Hogarty MD, Holdhoff M, Hong S-M, Jiao Y, Juhl HH, Kim JJ, Siravegna G, Laheru DA, et al:: Detection of circulating tumor DNA in early- and late-stage human malignancies. Sci Transl Med 2014, 6:224ra24.

51. De Mattos-Arruda L, Caldas C: Cell-free circulating tumour DNA as a liquid biopsy in breast cancer. Mol Oncol 2015, 10:464-474.

52. Mohan S, Heitzer E, Ulz P, Lafer I, Lax S, Auer M, Pichler M, Gerger A, Eisner F, Hoefler G, Bauernhofer T, Geigl JB, Speicher MR: Changes in colorectal carcinoma genomes under anti-EGFR therapy identified by whole-genome plasma DNA sequencing. PLoS Genet 2014, 10:e1004271.

53. Muller L, Hong C-S, Stolz DB, Watkins SC, Whiteside TL: Isolation of biologicallyactive exosomes from human plasma. J Immunol Methods 2014, 411:55-65. 
54. Vader P, Breakefield XO, Wood MJA: Extracellular vesicles: emerging targets for cancer therapy. Trends Mol Med 2014, 20:385-93.

55. Verma M, Lam TK, Hebert E, Divi RL, Beach A, Zhang H, Ratajczak M, Kakar S, Liang B, Peng P, Chen S, Li L, Zhang M, Cao D, Park J, Choi D, Choi D, Kim H, Kang J, Jung J, Vader P, Breakefield X, Wood M, Lee J, Park S, Jung B, Jeon Y, Lee Y, Kim M, Jorfi S, et al.: Extracellular vesicles: potential applications in cancer diagnosis, prognosis, and epidemiology. BMC Clin Pathol 2015, 15:6.

56. Kang Q, Henry NL, Paoletti C, Jiang H, Vats P, Chinnaiyan AM, Hayes DF, Merajver SD, Rae JM, Tewari M: Comparative analysis of circulating tumor DNA stability In K3EDTA, Streck, and CellSave blood collection tubes. Clin Biochem 2016, (in press).

57. Racila E, Euhus D, Weiss AJ, Rao C, McConnell J, Terstappen LW, Uhr JW: Detection and characterization of carcinoma cells in the blood. Proc Natl Acad Sci U S A 1998, 95:4589-94.

58. Terstappen LW, Rao C, Gross S, Weiss AJ: Peripheral blood tumor cell load reflects the clinical activity of the disease in patients with carcinoma of the breast. Int J Oncol 2000, 17:573-8.

59. Moreno JG, O’Hara SM, Gross S, Doyle G, Fritsche H, Gomella LG, Terstappen LW: Changes in circulating carcinoma cells in patients with metastatic prostate cancer correlate with disease status. Urology 2001, 58:386-92.

60. Andree KC, Barradas AMC, Nguyen AT, Mentink A, Stojanovic I, Baggerman J, van Dalum J, van Rijn CJM, Terstappen LWMM: Capture of Tumor Cells on Anti-EpCAMFunctionalized Poly(acrylic acid)-Coated Surfaces. ACS Appl Mater Interfaces 2016, 8:14349-56.

61. Liberti PA, Rao CG, Terstappen LWM.: Optimization of ferrofluids and protocols for the enrichment of breast tumor cells in blood. J Magn Magn Mater 2001, 225:301-307.

62. Onstenk W, Kraan J, Mostert B, Timmermans MM, Charehbili A, Smit VTHBM, Kroep JR, Nortier JWR, van de Ven S, Heijns JB, Kessels LW, van Laarhoven HWM, Bos MMEM, van de Velde CJH, Gratama JW, Sieuwerts AM, Martens JWM, Foekens JA, Sleijfer S: Improved Circulating Tumor Cell Detection by a Combined EpCAM and MCAM CellSearch Enrichment Approach in Patients with Breast Cancer Undergoing Neoadjuvant Chemotherapy. Mol Cancer Ther 2015, 14:821-827. 
63. Mostert B, Kraan J, Bolt-de Vries J, van der Spoel P, Sieuwerts AM, Schutte M, Timmermans AM, Foekens R, Martens JWM, Gratama J-W, Foekens JA, Sleijfer S: Detection of circulating tumor cells in breast cancer may improve through enrichment with anti-CD146. Breast Cancer Res Treat 2011, 127:33-41.

64. Naume B, Zhao X, Synnestvedt M, Borgen E, Russnes HG, Lingjærde OC, Strømberg M, Wiedswang G, Kvalheim G, Kåresen R, Nesland JM, Børresen-Dale A-L, Sørlie T: Presence of bone marrow micrometastasis is associated with different recurrence risk within molecular subtypes of breast cancer. Mol Oncol 2007, 1:160-171.

65. Braun S, Naume B: Circulating and Disseminated Tumor Cells. J Clin Oncol 2005, 23:1623-1626.

66. Cardoso F, van't Veer LJ, Bogaerts J, Slaets L, Viale G, Delaloge S, Pierga J-Y, Brain E, Causeret S, DeLorenzi M, Glas AM, Golfinopoulos V, Goulioti T, Knox S, Matos E, Meulemans B, Neijenhuis PA, Nitz U, Passalacqua R, Ravdin P, Rubio IT, Saghatchian M, Smilde TJ, Sotiriou C, Stork L, Straehle C, Thomas G, Thompson AM, van der Hoeven JM, Vuylsteke P, et al.: 70-Gene Signature as an Aid to Treatment Decisions in Early-Stage Breast Cancer. N Engl J Med 2016, 375:717-729.

67. Sparano JA, Gray RJ, Makower DF, Pritchard KI, Albain KS, Hayes DF, Geyer CE, Dees EC, Perez EA, Olson JA, Zujewski J, Lively T, Badve SS, Saphner TJ, Wagner LI, Whelan TJ, Ellis MJ, Paik S, Wood WC, Ravdin P, Keane MM, Gomez Moreno HL, Reddy PS, Goggins TF, Mayer IA, Brufsky AM, Toppmeyer DL, Kaklamani VG, Atkins JN, Berenberg JL, et al.: Prospective Validation of a 21-Gene Expression Assay in Breast Cancer. N Engl J Med 2015, 373:2005-2014.

68. Eliane J-P, Repollet M, Luker KE, Brown M, Rae JM, Dontu G, Schott AF, Wicha M, Doyle G V, Hayes DF, Luker GD: Monitoring serial changes in circulating human breast cancer cells in murine xenograft models. Cancer Res 2008, 68:5529-32.

69. Mordant P, Loriot Y, Lahon B, Castier Y, Lesèche G, Soria J-C, Vozenin M-C, Decraene C, Deutsch E: Bioluminescent orthotopic mouse models of human localized non-small cell lung cancer: feasibility and identification of circulating tumour cells. PLoS One 2011, 6:e26073.

70. Lowes LE, Hedley BD, Keeney M, Allan AL: Adaptation of semiautomated circulating tumor cell (CTC) assays for clinical and preclinical research applications. J Vis Exp 2014:e51248. 
71. Foulk B, Schaffer M, Gross S, Rao C, Smirnov D, Chaturvedi S, Reddy M, Repollet M, Rojas C, Auclair D, DeRome M, Weiss B, Sasser K: Peripheral blood CMMCs correlate with disease burden and can be used to characterize high-risk cytogenetics in newly diagnosed and smoldering myeloma. AACR Abstr 2016, 76:supplement.

72. Coumans FA, Ligthart ST, Terstappen LW: Interpretation of changes in circulating tumor cell counts. Transl Oncol 2012, 5:486-91.

73. Pal SK, He M, Wilson T, Liu X, Zhang K, Carmichael C, Torres A, Hernandez S, Lau C, Agarwal N, Kawachi M, Yen Y, Jones JO: Detection and phenotyping of circulating tumor cells in high-risk localized prostate cancer. Clin Genitourin Cancer 2015, 13:130-6.

74. Polioudaki H, Agelaki S, Chiotaki R, Politaki E, Mavroudis D, Matikas A, Georgoulias V, Theodoropoulos PA: Variable expression levels of keratin and vimentin reveal differential EMT status of circulating tumor cells and correlation with clinical characteristics and outcome of patients with metastatic breast cancer. BMC Cancer $2015,15: 399$.

75. de Wit S, van Dalum G, Lenferink ATM, Tibbe AGJ, Hiltermann TJN, Groen HJM, van

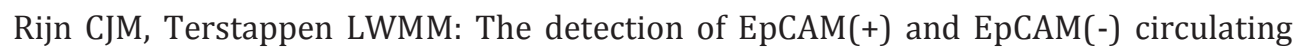
tumor cells. Sci Rep 2015, 5:12270.

76. Onstenk W, Sieuwerts AM, Kraan J, Van M, Nieuweboer AJM, Mathijssen RHJ, Hamberg P, Meulenbeld HJ, De Laere B, Dirix LY, van Soest RJ, Lolkema MP, Martens JWM, van Weerden WM, Jenster GW, Foekens JA, de Wit R, Sleijfer S: Efficacy of Cabazitaxel in Castration-resistant Prostate Cancer Is Independent of the Presence of AR-V7 in Circulating Tumor Cells. Eur Urol 2015, 68:939-45.

77. Mostert B, Sieuwerts AM, Bolt-de Vries J, Kraan J, Lalmahomed Z, van Galen A, van der Spoel P, de Weerd V, Ramírez-Moreno R, Smid M, Verhoef C, IJzermans JNM, Gratama JW, Sleijfer S, Foekens JA, Martens JWM: mRNA expression profiles in circulating tumor cells of metastatic colorectal cancer patients. Mol Oncol 2015, 9:920-32.

78. Jiang Y, Palma JF, Agus DB, Wang Y, Gross ME: Detection of androgen receptor mutations in circulating tumor cells in castration-resistant prostate cancer. Clin Chem 2010, 56:1492-5.

79. Cho WJW, Oliveira DSM, Najy AJ, Mainetti LE, Aoun HD, Cher MML, Heath E, Kim HRC, Bonfil RDR, Inoue T, Segawa T, Kamba T, Yoshimura K, Nakamura E, Nishiyama H, 
Berruti A, Tucci M, Mosca A, Tarabuzzi R, Gorzegno G, Terrone C, Dunn T, Fedor H, Marzo A, Luo J, Taylor B, Schultz N, Hieronymus H, Gopalan A, Xiao Y, et al.: Gene expression analysis of bone metastasis and circulating tumor cells from metastatic castrate-resistant prostate cancer patients. J Transl Med 2016, 14:72.

80. Rossi E, Rugge M, Facchinetti A, Pizzi M, Nardo G, Barbieri V, Manicone M, De Faveri S, Chiara Scaini M, Basso U, Amadori A, Zamarchi R: Retaining the long-survive capacity of Circulating Tumor Cells (CTCs) followed by xeno-transplantation: not only from metastatic cancer of the breast but also of prostate cancer patients. Oncoscience 2014, 1:49-56.

81. Ignatiadis M, Rothé F, Chaboteaux C, Durbecq V, Rouas G, Criscitiello C, Metallo J, Kheddoumi N, Singhal SK, Michiels S, Veys I, Rossari J, Larsimont D, Carly B, Pestrin M, Bessi S, Buxant F, Liebens F, Piccart M, Sotiriou C: HER2-positive circulating tumor cells in breast cancer. PLoS One 2011, 6:e15624.

82. Riethdorf S, Müller V, Zhang L, Rau T, Loibl S, Komor M, Roller M, Huober J, Fehm T, Schrader I, Hilfrich J, Holms F, Tesch H, Eidtmann H, Untch M, von Minckwitz G, Pantel $\mathrm{K}$ : Detection and HER2 expression of circulating tumor cells: prospective monitoring in breast cancer patients treated in the neoadjuvant GeparQuattro trial. Clin Cancer Res 2010, 16:2634-45.

83. Wallwiener M, Hartkopf AD, Riethdorf S, Nees J, Sprick MR, Schönfisch B, Taran FA, Heil J, Sohn C, Pantel K, Trumpp A, Schneeweiss A: The impact of HER2 phenotype of circulating tumor cells in metastatic breast cancer: a retrospective study in 107 patients. BMC Cancer 2015, 15:403.

84. Meng S, Tripathy D, Shete S, Ashfaq R, Saboorian H, Haley B, Frenkel E, Euhus D, Leitch M, Osborne C, Clifford E, Perkins S, Beitsch P, Khan A, Morrison L, Herlyn D, Terstappen LWMM, Lane N, Wang J, Uhr J: uPAR and HER-2 gene status in individual breast cancer cells from blood and tissues. Proc Natl Acad Sci U S A 2006, 103:173615.

85. Fehm T, Müller V, Aktas B, Janni W, Schneeweiss A, Stickeler E, Lattrich C, Löhberg CR, Solomayer E, Rack B, Riethdorf S, Klein C, Schindlbeck C, Brocker K, Kasimir-Bauer S, Wallwiener D, Pantel K: HER2 status of circulating tumor cells in patients with metastatic breast cancer: a prospective, multicenter trial. Breast Cancer Res Treat 2010, 124:403-12. 
86. Pestrin M, Bessi S, Puglisi F, Minisini AM, Masci G, Battelli N, Ravaioli A, Gianni L, Di Marsico R, Tondini C, Gori S, Coombes CR, Stebbing J, Biganzoli L, Buyse M, Di Leo A: Final results of a multicenter phase II clinical trial evaluating the activity of singleagent lapatinib in patients with HER2-negative metastatic breast cancer and HER2positive circulating tumor cells. A proof-of-concept study. Breast Cancer Res Treat 2012, 134:283-9.

87. Rink M, Chun FK, Dahlem R, Soave A, Minner S, Hansen J, Stoupiec M, Coith C, Kluth LA, Ahyai SA, Friedrich MG, Shariat SF, Fisch M, Pantel K, Riethdorf S: Prognostic role and HER2 expression of circulating tumor cells in peripheral blood of patients prior to radical cystectomy: a prospective study. Eur Urol 2012, 61:810-7.

88. Ligthart ST, Coumans FAW, Bidard F-C, Simkens LHJ, Punt CJA, de Groot MR, Attard G, de Bono JS, Pierga J-Y, Terstappen LWMM: Circulating Tumor Cells Count and Morphological Features in Breast, Colorectal and Prostate Cancer. PLoS One 2013, 8:e67148.

89. Frithiof H, Welinder C, Larsson A-M, Rydén L, Aaltonen K: A novel method for downstream characterization of breast cancer circulating tumor cells following CellSearch isolation. J Transl Med 2015, 13:126.

90. Paoletti C, Larios JM, Muñiz MC, Aung K, Cannell EM, Darga EP, Kidwell KM, Thomas DG, Tokudome N, Brown ME, Connelly MC, Chianese DA, Schott AF, Henry NL, Rae JM, Hayes DF: Heterogeneous estrogen receptor expression in circulating tumor cells suggests diverse mechanisms of fulvestrant resistance. Mol Oncol 2016, 10:1078-1085.

91. Paoletti C, Muñiz MC, Thomas DG, Griffith KA, Kidwell KM, Tokudome N, Brown ME, Aung K, Miller MC, Blossom DL, Schott AF, Henry NL, Rae JM, Connelly MC, Chianese DA, Hayes DF: Development of circulating tumor cell-endocrine therapy index in patients with hormone receptor-positive breast cancer. Clin Cancer Res 2015, 21:2487-98.

92. Payne RE, Yagüe E, Slade MJ, Apostolopoulos C, Jiao LR, Ward B, Coombes RC, Stebbing J: Measurements of EGFR expression on circulating tumor cells are reproducible over time in metastatic breast cancer patients. Pharmacogenomics 2009, 10:51-57. 
93. Punnoose EA, Atwal SK, Spoerke JM, Savage H, Pandita A, Yeh R-F, Pirzkall A, Fine BM, Amler LC, Chen DS, Lackner MR: Molecular Biomarker Analyses Using Circulating Tumor Cells. PLoS One 2010, 5:e12517.

94. Rossi E, Basso U, Celadin R, Zilio F, Pucciarelli S, Aieta M, Barile C, Sava T, Bonciarelli G, Tumolo S, Ghiotto C, Magro C, Jirillo A, Indraccolo S, Amadori A, Zamarchi R: M30 neoepitope expression in epithelial cancer: quantification of apoptosis in circulating tumor cells by CellSearch analysis. Clin Cancer Res 2010, 16:5233-43.

95. Lowes LE, Hedley BD, Keeney M, Allan AL: User-defined protein marker assay development for characterization of circulating tumor cells using the CellSearch $®$ system. Cytometry A 2012, 81:983-95.

96. Ligthart ST, Bidard F-C, Decraene C, Bachelot T, Delaloge S, Brain E, Campone M, Viens P, Pierga J-Y, Terstappen LWMM: Unbiased quantitative assessment of Her-2 expression of circulating tumor cells in patients with metastatic and non-metastatic breast cancer. Ann Oncol 2013, 24:1231-8.

97. Kuboki Y, Matsusaka S, Minowa S, Shibata H, Suenaga M, Shinozaki E, Mizunuma N, Ueno M, Yamaguchi T, Hatake K: Circulating tumor cell (CTC) count and epithelial growth factor receptor expression on CTCs as biomarkers for cetuximab efficacy in advanced colorectal cancer. Anticancer Res 2013, 33:3905-10.

98. Iwatsuki M, Toyoshima K, Watanabe M, Hayashi N, Ishimoto T, Eto K, Iwagami S, Baba Y, Yoshida N, Hayashi A, Ohta Y, Baba H: Frequency of HER2 expression of circulating tumour cells in patients with metastatic or recurrent gastrointestinal cancer. Br J Cancer 2013, 109:2829-32.

99. Welinder C, Jansson B, Lindell G, Wenner J: Cytokeratin 20 improves the detection of circulating tumor cells in patients with colorectal cancer. Cancer Lett 2015, 358:4346.

100. Crespo M, van Dalum G, Ferraldeschi R, Zafeiriou Z, Sideris S, Lorente D, Bianchini D, Rodrigues DN, Riisnaes R, Miranda S, Figueiredo I, Flohr P, Nowakowska K, de Bono JS, Terstappen LWMM, Attard G: Androgen receptor expression in circulating tumour cells from castration-resistant prostate cancer patients treated with novel endocrine agents. Br J Cancer 2015, 112:1166-74. 
101. Kershaw S, Cummings J, Morris K, Tugwood J, Dive C: Optimisation of immunofluorescence methods to determine MCT1 and MCT4 expression in circulating tumour cells. BMC Cancer 2015, 15:387.

102. Mazel M, Jacot W, Pantel K, Bartkowiak K, Topart D, Cayrefourcq L, Rossille D, Maudelonde T, Fest T, Alix-Panabières C: Frequent expression of PD-L1 on circulating breast cancer cells. Mol Oncol 2015, 9:1773-82.

103. Lindsay CR, Le Moulec S, Billiot F, Loriot Y, Ngo-Camus M, Vielh P, Fizazi K, Massard C, Farace F: Vimentin and Ki67 expression in circulating tumour cells derived from castrate-resistant prostate cancer. BMC Cancer 2016, 16:168.

104. Matthew EM, Zhou L, Yang Z, Dicker DT, Holder SL, Lim B, Harouaka R, Zheng S-Y, Drabick JJ, Lamparella NE, Truica CI, El-Deiry WS: A multiplexed marker-based algorithm for diagnosis of carcinoma of unknown primary using circulating tumor cells. Oncotarget 2016, 7:3662-76.

105. Gorges TM, Riethdorf S, von Ahsen O, Nastaly P, Roeck K, Boede M, Peine S, Kuske A, Schmid E, Kneip C, Koenig F, Rudolph M, Pantel K: Heterogeneous PSMA expression on circulating tumor cells - a potential basis for stratification and monitoring of PSMAdirected therapies in prostate cancer. Oncotarget 2016, 7:34930-34941.

106. Dotan E, Alpaugh RK, Ruth K, Benjamin P, Denlinger CS, Hall MJ, Astsaturov I, Mcaleer C, Halbherr T, Fittipaldi P, Thrash-bingham C, Meropol NJ, Cohen SJ: Prognostic Significance of MUC-1 in Circulating Tumor Cells in Patients With Metastatic Pancreatic Adenocarcinoma. Pancreas 2016, 0:1-5.

107. Riethdorf S, Fritsche H, Müller V, Mu«V, Rau T, Schindlbeck C, Rack B, Janni W, Coith C, Beck K, Ja« F, Jackson S, Gornet T, Cristofanilli M, Pantel K: Detection of Circulating Tumor Cells in Peripheral Blood of Patients with Metastatic Breast Cancer: A Validation Study of the CellSearch System. Clin Cancer Res 2007, 13:920-928.

108. Kraan J, Sleijfer S, Strijbos MH, Ignatiadis M, Peeters D, Pierga J-Y, Farace F, Riethdorf S, Fehm T, Zorzino L, Tibbe AGJ, Maestro M, Gisbert-Criado R, Denton G, de Bono JS, Dive C, Foekens JA, Gratama JW: External quality assurance of circulating tumor cell enumeration using the CellSearch(®) system: a feasibility study. Cytometry B Clin Cytom 2011, 80:112-8.

109. Che J, Yu V, Dhar M, Renier C, Matsumoto M, Heirich K, Garon EB, Goldman J, Rao J, Sledge GW, Pegram MD, Sheth S, Jeffrey SS, Kulkarni RP, Sollier E, Di Carlo D: 
Classification of large circulating tumor cells isolated with ultra-high throughput microfluidic Vortex technology. Oncotarget 2016, 7:12748-60.

110. Magbanua MJM, Pugia M, Lee JS, Jabon M, Wang V, Gubens M, Marfurt K, Pence J, Sidhu H, Uzgiris A, Rugo HS, Park JW: A Novel Strategy for Detection and Enumeration of Circulating Rare Cell Populations in Metastatic Cancer Patients Using Automated Microfluidic Filtration and Multiplex Immunoassay. PLoS One 2015, 10:e0141166.

111. Xu L, Mao X, Imrali A, Syed F, Mutsvangwa K, Berney D, Cathcart P, Hines J, Shamash J, Lu Y-J: Optimization and Evaluation of a Novel Size Based Circulating Tumor Cell Isolation System. PLoS One 2015, 10:e0138032.

112. Zeune L, van Dalum G, Terstappen LWMM, van Gils SA, Brune C: Multiscale Segmentation via Bregman Distances and Nonlinear Spectral Analysis. Submitt to SIAM J Imaging Sci 2016.

113. Gasch C, Bauernhofer T, Pichler M, Langer-Freitag S, Reeh M, Seifert AM, Mauermann O, Izbicki JR, Pantel K, Riethdorf S: Heterogeneity of Epidermal Growth Factor Receptor Status and Mutations of KRAS/PIK3CA in Circulating Tumor Cells of Patients with Colorectal Cancer. Clin Chem 2013, 59:252-260.

114. Neumann MHD, Schneck H, Decker Y, Schömer S, Franken A, Endris V, Pfarr N, Weichert W, Niederacher D, Fehm T, Neubauer H: Isolation and characterization of circulating tumor cells using a novel workflow combining the CellSearch® system and the CellCelectorTM. Biotechnol Prog 2016.

115. Salvianti F, Rotunno G, Galardi F, De Luca F, Pestrin M, Vannucchi AM, Di Leo A, Pazzagli M, Pinzani P: Feasibility of a workflow for the molecular characterization of single cells by next generation sequencing. Biomol Detect Quantif 2015, 5:23-29.

116. De Luca F, Rotunno G, Salvianti F, Galardi F, Pestrin M, Gabellini S, Simi L, Mancini I, Vannucchi AM, Pazzagli M, Leo A Di, Pinzani P: Mutational analysis of single circulating tumor cells by next generation sequencing in metastatic breast cancer. Oncotarget 2016, 7:26107-26119.

117. Pestrin M, Salvianti F, Galardi F, De Luca F, Turner N, Malorni L, Pazzagli M, Di Leo A, Pinzani P: Heterogeneity of PIK3CA mutational status at the single cell level in circulating tumor cells from metastatic breast cancer patients. Mol Oncol 2015, 9:74957. 
118. Fernandez S V, Bingham C, Fittipaldi P, Austin L, Palazzo J, Palmer G, Alpaugh K, Cristofanilli M: TP53 mutations detected in circulating tumor cells present in the blood of metastatic triple negative breast cancer patients. Breast Cancer Res 2014, $16: 445$.

119. Neves RPL, Raba K, Schmidt O, Honisch E, Meier-Stiegen F, Behrens B, Möhlendick B, Fehm T, Neubauer H, Klein CA, Polzer B, Sproll C, Fischer JC, Niederacher D, Stoecklein NH: Genomic high-resolution profiling of single CKpos/CD45neg flow-sorting purified circulating tumor cells from patients with metastatic breast cancer. Clin Chem 2014, 60:1290-7.

120. Swennenhuis JF, Reumers J, Thys K, Aerssens J, Terstappen LW: Efficiency of whole genome amplification of single circulating tumor cells enriched by CellSearch and sorted by FACS. Genome Med 2013, 5:106.

121. Swennenhuis JF, Tibbe AGJ, Stevens M, Katika MR, van Dalum J, Tong HD, van Rijn CJM, Terstappen LWMM: Self-seeding microwell chip for the isolation and characterization of single cells. Lab Chip 2015, 15:3039-46.

122. Coumans FAW, Doggen CJM, Attard G, de Bono JS, Terstappen LWMM: All circulating EpCAM+CK+CD45- objects predict overall survival in castration-resistant prostate cancer. Ann Oncol 2010, 21:1851-7.

123. Ligthart ST, Coumans FAW, Attard G, Cassidy AM, de Bono JS, Terstappen LWMM: Unbiased and automated identification of a circulating tumour cell definition that associates with overall survival. PLoS One 2011, 6:e27419.

124. Swennenhuis JF, Tibbe AGJ, Levink R, Sipkema RCJ, Terstappen LWMM: Characterization of circulating tumor cells by fluorescence in situ hybridization. Cytometry A 2009, 75:520-7.

125. Attard G, Swennenhuis JF, Olmos D, Reid AHM, Vickers E, A'Hern R, Levink R, Coumans F, Moreira J, Riisnaes R, Oommen NB, Hawche G, Jameson C, Thompson EE, Sipkema R, Carden CP, Parker C, Dearnaley D, Kaye SB, Cooper CS, Molina A, Cox ME, Terstappen LWMM, de Bono JS: Characterization of ERG, AR and PTEN gene status in circulating tumor cells from patients with castration-resistant prostate cancer. Cancer Res 2009, 69:2912-8.

126. Gasch C, Plummer PN, Jovanovic L, McInnes LM, Wescott D, Saunders CM, Schneeweiss A, Wallwiener M, Nelson C, Spring KJ, Riethdorf S, Thompson EW, Pantel 
K, Mellick AS: Heterogeneity of miR-10b expression in circulating tumor cells. Sci Rep 2015, 5:15980.

127. Tu Q, Wu X, Le Rhun E, Blonski M, Wittwer B, Taillandier L, De Carvalho Bittencourt M, Faure GC: CellSearch technology applied to the detection and quantification of tumor cells in CSF of patients with lung cancer leptomeningeal metastasis. Lung Cancer 2015, 90:352-7.

128. Lee JS, Melisko ME, Magbanua MJM, Kablanian AT, Scott JH, Rugo HS, Park JW: Detection of cerebrospinal fluid tumor cells and its clinical relevance in leptomeningeal metastasis of breast cancer. Breast Cancer Res Treat 2015, 154:33949.

129. Patel AS, Allen JE, Dicker DT, Peters KL, Sheehan JM, Glantz MJ, El-Deiry WS: Identification and enumeration of circulating tumor cells in the cerebrospinal fluid of breast cancer patients with central nervous system metastases. Oncotarget 2011, 2:752-60.

130. Mastronicola R, Berteau C, Tu Q, Cortese S, Guillet J, Phulpin B, Gangloff P, Bezdetnaya L, Merlin J-L, Faure G, Dolivet G: Detection of disseminated tumor cells in aspirative drains after neck dissection. Eur Arch Otorhinolaryngol 2016, 273:465-9.

131. Fischer JC, Niederacher D, Topp SA, Honisch E, Schumacher S, Schmitz N, Zacarias Föhrding L, Vay C, Hoffmann I, Kasprowicz NS, Hepp PG, Mohrmann S, Nitz U, Stresemann A, Krahn T, Henze T, Griebsch E, Raba K, Rox JM, Wenzel F, Sproll C, Janni W, Fehm T, Klein CA, Knoefel WT, Stoecklein NH: Diagnostic leukapheresis enables reliable detection of circulating tumor cells of nonmetastatic cancer patients. Proc Natl Acad Sci U S A 2013, 110:16580-5.

132. Rahbari NN, Bork U, Schölch S, Reissfelder C, Thorlund K, Betzler A, Kahlert C, Schneider M, Ulrich AB, Büchler MW, Weitz J, Koch M: Metastatic Spread Emerging From Liver Metastases of Colorectal Cancer: Does the Seed Leave the Soil Again? Ann Surg 2016, 263:345-52.

133. Wind J, Tuynman JB, Tibbe AGJ, Swennenhuis JF, Richel DJ, van Berge Henegouwen MI, Bemelman W a: Circulating tumour cells during laparoscopic and open surgery for primary colonic cancer in portal and peripheral blood. Eur J Surg Oncol 2009, 35:942-50.

134. Coumans FAW, Ligthart ST, Uhr JW, Terstappen LWMM: Challenges in the enumeration and phenotyping of CTC. Clin Cancer Res 2012, 18:5711-8. 
135. Smerage JB, Barlow WE, Hortobagyi GN, Winer EP, Leyland-Jones B, Srkalovic G, Tejwani S, Schott AF, O'Rourke MA, Lew DL, Doyle G V., Gralow JR, Livingston RB, Hayes DF: Circulating Tumor Cells and Response to Chemotherapy in Metastatic Breast Cancer: SWOG S0500. J Clin Oncol 2014, 32:3483-3489. 
CHAPTER 2: IMPROVING THE CELLSEARCH SYSTEM 


\title{
CHAPTER 3: SAMPLE PREPARATION METHODS FOR UPSTREAM SINGLE CELL WHOLE GENOME AMPLIFICATION
}

Authors: Joost F. Swennenhuis, Leon W.M.M. Terstappen

Published in: Whole Genome Amplification Methods and Protocols, editor Thomas Kroneis. Humana Press, USA ISBN 978-1-4939-2990-0, pp 57-67, 2015.

Running title: Sample prep methods.

\begin{abstract}
Single cells are increasingly used to determine the heterogeneity of therapy targets in the genome during the course of a disease. The first challenge using single cells is to isolate these cells from the surrounding cells, especially when the targeted cells are rare. A number of techniques have been developed for this goal, each having specific limitations and possibilities. In this chapter, five of these techniques are discussed in the light of the isolation of Circulating Tumor Cells (CTC) present at extremely low frequency in the blood of patients with metastatic cancer. The techniques described are micromanipulation, FACS, laser lapture microdissection, DEPArray and microfluidic solutions. All platforms are hampered with a low efficiency and differences in hands-on time and costs are the most important drivers for selection of the optimal platform.
\end{abstract}




\subsection{Introduction}

Whole Genome Amplification (WGA) is increasingly used for the amplification of DNA from small biological samples. In cell biology the main use of WGA is the amplification of the DNA from single or low numbers of cells. Individual cells are hard to isolate since the targeted cells are often in between an excess of other cells and are in general fragile and sticky. This chapter describes several methods to isolate cells from their surroundings. The fields where WGA is applied profit from the revolutionary power of the emerging field of Next-Gen DNA-sequencing. Complete genomes can now be sequenced and quantified within a reasonable amount of time and for continuously decreasing costs. Within cell biology WGA before genetic analysis is mainly used for preïmplantation genetic diagnostics and cancer research. For preïmplantation genetic diagnostics the sample material is always the embryo, in most cases a blastomere from the eight-cell stage, which is removed and isolated by micromanipulation. The use of WGA in cancer research is expanding. Traditionally, cancer is diagnosed and characterized on the resected primary tumor or surrounding lymph nodes. The resected tumor generally provides enough material to determine the immunologic and genetic makeup. In recent years, a new generation of targeted cancer treatments options have been added for cancer patients and this is likely to increase substantially in the years to come [1]. To be able to predict whether or not these treatments will be effective, the targets of these therapies will need to be present on the tumor cells. At the time therapy is needed, the tumor cells of patients with metastatic disease may no longer be sensitive to the intended therapy as tumor cells may have altered during time or have developed resistance to a therapy [2]. Since biopsies cannot be taken frequently, Circulating Tumor Cells (CTC) are being explored as a 'real time liquid biopsy' to assess the potential sensitivity of the tumor cells [3]. The main challenge is that most cancer patients, even in metastatic state, only have a few CTC in a tube of blood [4]. In a blood tube of $10 \mathrm{ml}$ approximately 4-11*107 cells are present that contain DNA in between around $5 * 1010$ red blood cells. This background is too large for any DNA analysis technique. Besides that, to be able to do a good DNA analysis of the cancer cell, there should be no background at all, which implies that the targeted cells should be isolated from the other cells. CTC enrichment techniques such as the CellSearch system from Veridex, as discussed in the previous chapter, are capable of enriching the CTC's to a few in a background of 500-10.000 leukocytes. The final isolation step still has to be done after this enrichment. Currently, techniques used to isolate single cells are micromanipulation, Laser Capture Microdissection (LCM), FACS, the DEPArray system from Silicon Microsystems and a recently released microchip based system from Fluidigm capable of capturing and downstream processing of 
single cells. In this chapter these methods will be described and evaluated for the use of CTC isolation prior to Whole Genome Amplification.

\subsection{Methods}

\subsubsection{Micromanipulation}

The most straightforward technique of just picking up a cell and placing it on the target site is the oldest and most known system for single cell isolation. A micromanipulation setup consists of an inverted microscope, a XYZ motorized needle holder and a liquid dispenser. The targeted cells can be picked up by moving the needle near the cell and slowly flow the cell into the needle. The cell then needs to be deposited on the target site such as a tube or microtiter plate. A downside of this technique is that the deposition of the cell has to be done outside the optical plane of the microscope making it impossible to monitor the deposition of the single cell. If single cells need to be picked, the cell density must be rather low to prevent unwanted cells to be picked together. CTC enriched with the CellSearch system are present in a volume of $330 \mu \mathrm{l}$ and after placing on a microscope slide, the area will become quite large and the localization of the cells can take quite a long time. Nonetheless if plenty of cells are accessible a skilled and experienced operator will be able to isolate up till about 60 cells per hour from a single sample. Heizer et al recently used micromanipulation and WGA for studying the genomes of single colorectal cancer cells [5]. The paper shows that mutations that were found in individual CTC could be found back in the primary tumor and metastases by deep sequencing. Although it shows the possibility of using these single CTC WGA products for diagnostic purposes, it was applied on only the $16 \%$ of the patients that had more than 10 CTC. Mathiesen et al also shows the use of micromanipulation to isolate CTC. [6] Here, a total of 32 cells were isolated from a set of 8 patients using this technique. Not clear from the literature is what the efficiency of micromanipulation is when used for isolating CTC's and whether or not CTC WGA product can be obtained by micromanipulation from patients with lower cell counts. To our knowledge, only a few large scale studies have been conducted on patient samples using micromanipulation as the main CTC isolation technique in Klein et al [7] 144 cells, in 71 patients, in Stoecklein et al [8] 60 cells in 35 patients and in Schmidt Kittler et al [9] 189 cells, in 83 patients. Robotics could be a good alternative for the manual picking of cells. A number of automated systems are under development or already available. To prevent co-isolation of unwanted cells a number of new systems use a separation of cells into microwells before automated micromanipulation. The physical separation of the cells provides 
the opportunity to scan the cells, analyze for tumor markers and revisit for automated picking of cells. Lohr et al [10] is using the CellSelector system (A.L.S., Jena, Germany) in combination with microwell separated cells. More comparable automated micromanipulation systems have been developed which could be used for the same purpose $[11,12]$.

\subsubsection{FACS}

Flowcytometry is mainly used for the differentiation and sorting of cells when large quantities of cells are available. Since CTC are present in very low numbers, direct detection by flowcytometry is hampered by the large excess of hematopoietic cells. [13] Pre enrichment steps are necessary to effectively separate the CTC from the blood cells. CTC enrichment by CellSearch from $7.5 \mathrm{ml}$ of blood from patients with metastatic disease usually results in a 330 $\mu \mathrm{l}$ sample with 500-10.000 white blood cells and 0-100 CTC. The main challenge with sorting individual CTC is the limited number of cells present in a small volume. In FACS, the sort precision or purity is always a trade off with sort efficiency. Since CTC are so rare, it is not acceptable to lose cells in favor of purity. Neither can it be that a CTC is unintentionally sorted together with another cell. This problem can be avoided by diluting the cell suspension and by lowering the flow speed which results in longer processing times. In our hands a dilution from the $300 \mu \mathrm{l}$ CellSearch sample to $700 \mu \mathrm{l}$ at a slow speed of $25 \mu \mathrm{l} / \mathrm{min}$ works well. The dilution is also required to reduce the portion of the sample that cannot be analyzed (dead volume at the start and at the end of the sort). The limited amount of sample also requires one to use pre-set sorting gates. Stability of the flowcytometer over time is therefore of utmost importance. The use of a blood sample from a healthy individual spiked with cells from a tumor cell line and processed with the CellSearch system can help to assure that the gate settings on the flowcytometer are correct. Figure 3.1 shows an example of flowcytometric analysis from a healthy donor (Panel A,B) and a patient with metastatic lung cancer (Panel C,D) after processing $7.5 \mathrm{ml}$ of blood with the CellSearch system. Gates in the scatter plot of DNA (DAPI) versus side scatter and CD45-APC versus Cytokeratin-PE are used to identify and sort CTC. Question always remains whether the events detected around the border of the gates are CTC or not. A solution to this problem would be the use of larger gates and the ability to retrospectively analyze which well contains which cell in the gate. This index-sorting feature on our FACS ARIA can however not (yet) be used for rare cell sorts because it only functions in the highest purity mode causing a high abort rate and therefore cell loss. Other flowcytometers such as the MoFlow system from Beckman Coulter are described to have this feature. In our hands, using 
the CellSearch system and a FACS ARIA around 20\% of the detected CTC's could be isolated and the genomes amplified. [14]
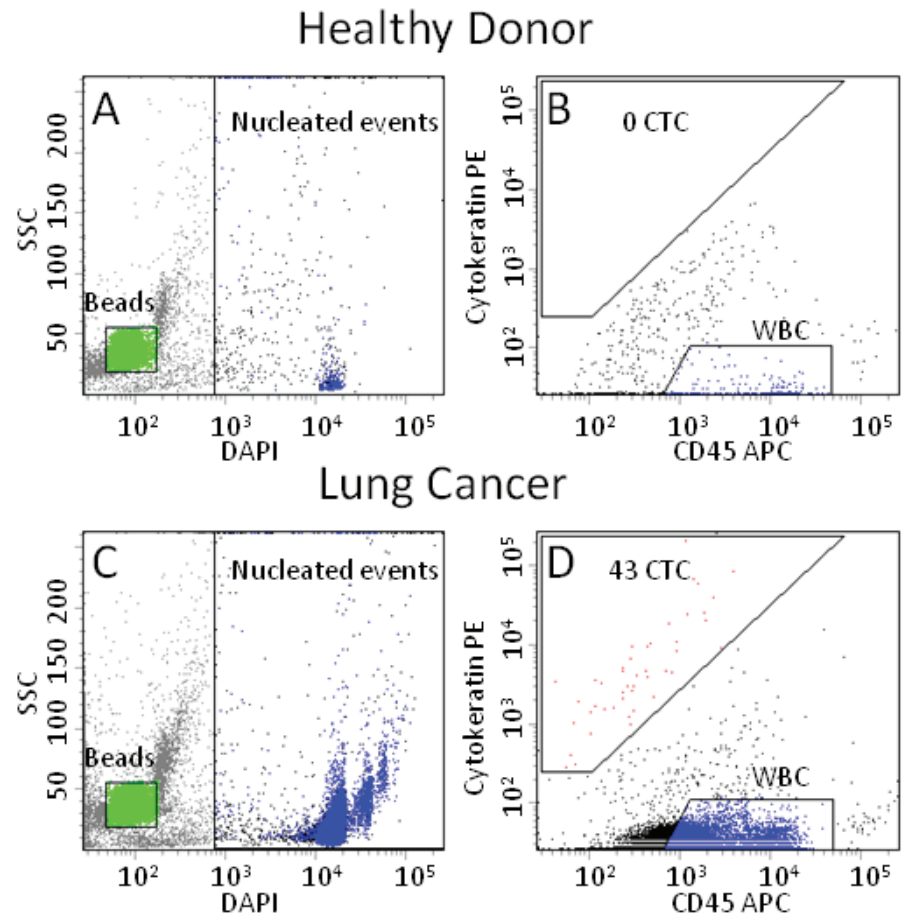

Figure 3.1. Flowcytometric analysis of a sample after processing $7.5 \mathrm{ml}$ blood by the CellSearch system from a healthy donor Panels A, B and a lung cancer patient Panels C, D. Zero CTC were detected by the CellSearch system and 0 CTC were present in the CTC gate of the healthy donor (Panel B). The CellSearch system detected 60 CTC in the patient sample and 43 of them were detected and sorted by flowcytometry (Panel D).

\subsubsection{Laser Capture Micro Dissection}

Laser Capture Micro Dissection can be used for the isolation of single cells from frozen or fixed tissue sections $[15,16]$. In practice, groups of cells are captured from tissues as they are usually in close association. Isolation of single cells works more efficient when cells are not in close proximity such as is the case for cytological samples after for example a cytospin. Caveat is that the cell density is not too high and target cells are still present. For isolation of CTC a pre enrichment is necessary as the cell density would otherwise be too high. CTC enriched samples can be cytospinned onto a LCM slide and the selected cells can be obtained. Several systems are available for LCM. The 
basic approaches used by these systems are illustrated in figure 3.2. The Palm system from Zeiss uses a PolyEthylene Naphtalate (PEN) or PolyPhenylene Sulfide (PPS) layer. This layer can subsequently be cut with a UV laser and the intended area can then be catapulted off with a high power laser pulse (figure 3.2A). The second possibility here is to catapult the cells with a high power laser without using the PEN or PPS layer. The latter can result in some remnants of the cells on the glass surface. Direct pulsing can be improved by using Director slides from Expression Pathology (cat: 50001-024, Expression Patholgy inc. Rockville, MD, USA). These slides have an energy transfer coating which transfers the power of the laser into kinetic energy and forces the cells into the analysis cap. Panel B of figure 3.2 shows the working principle of the Leica and Ion-LMD systems. The upright systems are able to cut out the selected cells, which are on top of a PEN layer. After the cells are cut by a high power pulse of a laser they are captured by gravity in a cap. Panel $\mathrm{C}$ of figure 3.2 shows the working principles of the laser micro-dissection from Life technologies system. A red laser is used to melt a polymeric film above the cells of interest. The cells will stick to this layer and can be transferred to the analysis tube. The last approach is the Cellector system from MMI shown in figure 3.2D. In this system, a laser cuts a membrane on top of the cells and the piece of membrane including the cells underneath will stick to a sticky cap that is pressed on the sample.

A combination of CTC enrichment and LCM has been shown by K.Helzer from ICx Biosystems in La Jolla, California [17]. Cells are captured on an anti EpCAM antibody coated layer in a microchip. The chip can be opened and the captured cells can be catapulted off with a LCM system. Another variation to this approach is to capture cells with anti-EpCAM antibodies but now on top of a PPS layer. The cells are now cut out with a UV laser and are being picked up by a so called sticky finger. This sticky finger is a polymer molten using a $805 \mathrm{~nm}$ laser from a capture cap which is placed in the vicinity of the cut cell. The capture cap with the cell sticking to the polymer can be placed into the downstream application [18].

The ability to visualize the target cells before capturing with LCM at a throughput of 10-100 cells per hour makes this technique attractive. The main cell loss can be contributed to the cytospin used to prepare the enriched cells for LCM. In some instances cells don't end up in the intended cap or cup as they are exposed to forces such as static electricity during the catapulting. 


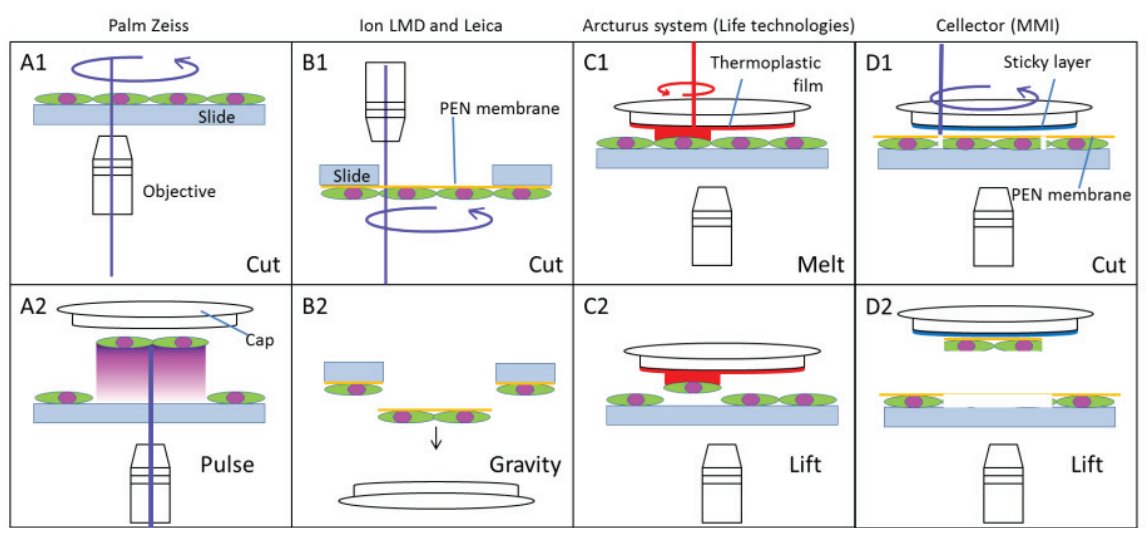

Figure 3.2. Approaches for Laser Capture Microdissection. Panel A, Palm system from Zeiss uses laser catapulting to get the cells into special designed caps. First the laser cuts around the cells of interest (A1) and second a high power pulse of this laser forces the cells into the cap (A2). Panel B, the ION LMD and the Leica systems both use gravity. Samples are placed on a PEN membrane and cut out with an UV laser (B1). Samples are captured by gravity (B2). Panel C, Arcturus system form Life Technologies uses a red laser to melt a polymeric layer on a special designed cap (C1). The molten polymer will stick to the selected cells which can be lifted off (C2) and transferred to the downstream process. Panel D, Cellector system from MMI overlays the cells with a thin membrane (D1). The membrane is cut by a laser and the selected cells are picked up by a cap with a sticky surface (D2).

\subsubsection{DEPArray}

The DEParray systems from Silicon Biosystems can automatically sort CTC from an enriched cell suspension that has been previously fluorescently labeled. The DEPArray system controls the movement of individual cells by dielectrophoretic (DEP) forces. A six color fluorescent computer controlled microscope is incorporated in the system to identify the cells of interest. The DEP is applied to areas or so called "cages" that contain, hold and move the cell of interest to an exit port. The DEPArray contains 16000 DEP cages restricting the total number of cells that can be processed. The time needed to select and isolate single CTC can takes up to 8 hours for one sample. The efficiency of the sorting process itself is very high with a specificity of $100 \%$, however there is quite a big loss of sample as there is a dead volume of around $50 \%$. For each chip a limited number of single cells can be sorted as there are a limited number of exit ports. It is however possible to sort multiple cells in one well to create a pool of selected cells. Some cells are lost during the sorting process and the quality of the cells do not permit amplification of DNA from all cells. In a study combining CellSearch and DEParray $16 \%$ of the CTC originally identified by CellSearch ended up in a WGA product. [19] Fabbri et al show the DEParray for isolating CTC from enriched peripheral blood from colon cancer patients. The sort efficiency is not mentioned in 
this paper and only in a few cases the isolated cells could be identified as CTC by detection of a mutation.[20] A main downside of this technique is the long sorting time. For DNA this is not necessarily a problem, but it can be expected that the quality of RNA will go down. The main advantages are the ease of use, the multi parameter imaging and the $100 \%$ specificity of sorted cells.

\subsubsection{Microchip WGA}

Selection, sorting and processing of single cells can also be done in a flow sorting microchip. Fluidigm now offers a system that is able to sort cells from a population based on size and subsequently process these cells for either DNA or RNA analysis. On one chip 96 samples can be amplified in parallel. The cell selection on this chip is not based on expression of cellular antigens but on cell size. CTC are described to be larger and more rigid than hematopoietic cells, however the size range described of CTC captured with the CellSearch system has a considerable overlap with the leukocytes $[21,22]$. Single cell capturing chips can be used to capture cells from different sizes: From $5-10 \mu \mathrm{m}, 10-17 \mu \mathrm{m}$ and $17-25 \mu \mathrm{m}$. Although no application from Fluidigm is yet available for WGA, Marcy et al already showed a MDA WGA on single bacterial cells using this system. [23] In this paper it was shown that a WGA reaction in small volumes yielded reduced amplification bias. A combination of the sorting of CTC and amplification technology can be a real benefit for single cell WGA applications, not only because of an easy workflow but also because of highly reduced reagent costs because of the small volumes used. Although more microfluidic devices have been developed for CTC isolation, all focus on the initial isolation of CTC from peripheral blood yielding only an enriched cell population. The final single cell isolation step is not yet included in these systems.[24, 25]

\subsection{Discussion}

All discussed systems come with their own specific drawbacks or limitations. Micromanipulation a cost effective way of sorting single cells, the microscope used for this is not dedicated and the tools are relatively inexpensive. The drawback from this system is that the operator needs to be very skilled. In fact, our experience is that not only skills but also frequent and recent use of this technique is necessary to reach optimal results. FACS and LMD require a good basic knowledge and some skills. DEParray and Fluidigm are designed in a very user friendly way. Table 3.1 gives an overview of the different systems and the most important properties. 


\begin{tabular}{|c|c|c|c|c|c|c|c|c|}
\hline method & Operator skills & $\begin{array}{l}\text { Time per } \\
\text { sample }\end{array}$ & $\begin{array}{c}\text { Efficiency from } \\
\text { CellSearch to WGA }\end{array}$ & $\begin{array}{l}\text { \# single } \\
\text { cells }\end{array}$ & $\begin{array}{l}\text { Live cell capturing } \\
\text { possibility }\end{array}$ & Cell ID & $\begin{array}{l}\text { Equipment costs } \\
\text { (estimate) }\end{array}$ & $\begin{array}{l}\text { Assay } \\
\text { costs }\end{array}$ \\
\hline Micromanipulation & High & $0.5-2 \mathrm{~h}$ & No data available & $<100$ & Yes & $\begin{array}{c}\text { Fluorescent immuno } \\
\text { staining }\end{array}$ & $€ 100 \mathrm{~K}$ & $<€ 10$, \\
\hline FACS & Medium & $0.5-1 \mathrm{~h}$ & $\sim 20 \%$ & $>100$ & Yes & Fluorescence intensity & $€ 300 \mathrm{~K}$ & $<€ 1,-$ \\
\hline $\begin{array}{l}\text { Laser Capture } \\
\text { Microdissection }\end{array}$ & Medium & $0.5-2 \mathrm{~h}$ & No data available & $<100$ & Some systems & $\begin{array}{l}\text { Fluorescent immuno } \\
\text { staining }\end{array}$ & $€ 120 \mathrm{~K}$ & $<€ 10,-$ \\
\hline DEParray & Low & $8 \mathrm{~h}$ & $\sim 16 \%$ & 22 & Yes & $\begin{array}{l}\text { Fluorescent immuno } \\
\text { staining }\end{array}$ & $€ 350 \mathrm{~K}$ & $€ 250$ \\
\hline Fluidigm & Low & $\begin{array}{l}\text { No data } \\
\text { available }\end{array}$ & No data available & 96 & Yes & Size based separation & $€ 120 \mathrm{~K}$ & $€ 700$ \\
\hline
\end{tabular}

Table 3.1. Comparison of the available single cell separation methods. For the time per sample estimation is made to isolate the cells of a CellSearch cartridge. Efficiency is determined for FACS and DEParray but not for the other techniques. Number of single cells is set to $<100$ for Micromanipulation and LCM because of hands on time and for micromanipulation also evaporation of the sample volume.

The time needed to get the isolated cells in a cup is for most systems the same: $0.5-2$ hours to isolate a reasonable amount of cells (20-30) from a CellSearch cartridge. Only the DEParray needs more time, but this is no hands on time. It does limit the frequency to 1 sample per day. A recent paper showed that it is possible to amplify DNA of good quality from single cells from 15 day old cartridges making it possible to spread the samples over a longer period [26].

The efficiencies of the systems are not yet decently established on patient material. In most cases, studies have been done on a large cohort of patients and only those cells and patients have been reported that ended in a WGA product. FACS has a high loss because of the single attempt that can be made to sort the cells. The DEParray deals with a very small sample volume $(14 \mu \mathrm{l})$. Cells have to be concentrated to reach this volume and a large part of this volume goes into the dead volume of the chip. With micromanipulation and LCM there is more manual control over the cells although with these techniques it is difficult and time consuming to verify the isolated single cell for being deposited and being single. Automation will resolve some of these issues but immediately makes the equipment much more expensive.

The number of cells is in most cases the problem since the cells are so rare. If more cells are required the micromanipulation and the laser capture techniques are not so convenient because of the high hands on time. The FACS can sort cells with a high precision in a 384 well plate so the number of cells is limited to that. The DEParray has 22 outlet ports and the Fluidigm has 96 capture positions. In most cases the 22 samples are enough but in samples with more cells it happens that many are likely apoptotic and contain unsuitable DNA. One solution could be to isolate many cells and try WGA on all of them. If, in case of the DEParray for example, not so many cells can be isolated and it could be useful to do a staining on the cells which detects apoptosis. 
All described systems are capable of doing a multiparametric analysis of the cells. This is also possible with FACS but here the morphological information is not entirely analyzed. With the Fluidigm system it is possible to analyze the cells for multiple dyes but the selection is purely based on the size of the cell.

The costs of these techniques differ a lot. All equipment is very expensive and specific for this purpose. For Fluidigm and DEParray also the single use cartridges are very costly. On the other hand, the downstream processing steps are WGA, a quality check and in most cases a qPCR, CGH or (next Gen) sequencing. These steps will be by far the most expensive part of this process.

\subsection{References}

1. Aggarwal S: Targeted cancer therapies. Nat Rev Drug Discov 2010, 9:427-8.

2. Meads MB, Gatenby RA, Dalton WS: Environment-mediated drug resistance: a major contributor to minimal residual disease. Nat Rev Cancer 2009, 9:665-74.

3. Pantel K, Alix-Panabières C: Real-time liquid biopsy in cancer patients: fact or fiction? Cancer Res 2013, 73:6384-8.

4. Coumans F a W, Ligthart ST, Uhr JW, Terstappen LWMM: Challenges in the Enumeration and Phenotyping of CTC. Clin cancer Res 2012,18:5711-8.

5. Heitzer E, Auer M, Gasch C, Pichler M, Ulz P, Hoffmann EM, Lax S, Waldispuehl-Geigl J, Mauermann O, Lackner C, Höfler G, Eisner F, Sill H, Samonigg H, Pantel K, Riethdorf S, Bauernhofer T, Geigl JB, Speicher MR: Complex tumor genomes inferred from single circulating tumor cells by array-CGH and next-generation sequencing. Cancer Res 2013, 73:2965-75.

6. Mathiesen RR, Fjelldal R, Liestøl K, Due EU, Geigl JB, Riethdorf S, Borgen E, Rye IH, Schneider IJ, Obenauf AC, Mauermann O, Nilsen G, Christian Lingjaerde O, BørresenDale A-L, Pantel K, Speicher MR, Naume B, Baumbusch LO: High-resolution analyses of copy number changes in disseminated tumor cells of patients with breast cancer. Int J Cancer 2012, 131:E405-15.

7. Klein CA, Blankenstein TJF, Schmidt-Kittler O, Petronio M, Polzer B, Stoecklein NH, Riethmüller G: Genetic heterogeneity of single disseminated tumour cells in minimal residual cancer. Lancet 2002, 360:683-9. 
8. Stoecklein NH, Hosch SB, Bezler M, Stern F, Hartmann CH, Vay C, Siegmund A, Scheunemann P, Schurr P, Knoefel WT, Verde PE, Reichelt U, Erbersdobler A, Grau R, Ullrich A, Izbicki JR, Klein C a: Direct genetic analysis of single disseminated cancer cells for prediction of outcome and therapy selection in esophageal cancer. Cancer Cell 2008, 13:441-53.

9. Schmidt-Kittler O, Ragg T, Daskalakis A, Granzow M, Ahr A, Blankenstein TJF, Kaufmann M, Diebold J, Arnholdt H, Muller P, Bischoff J, Harich D, Schlimok G, Riethmuller G, Eils R, Klein CA: From latent disseminated cells to overt metastasis: genetic analysis of systemic breast cancer progression. Proc Natl Acad Sci U S A 2003, 100:7737-42.

10. Lohr JG, Adalsteinsson VA, Cibulskis K, Choudhury AD, Rosenberg M, Cruz-Gordillo P, Francis JM, Zhang C-Z, Shalek AK, Satija R, Trombetta JJ, Lu D, Tallapragada N, Tahirova N, Kim S, Blumenstiel B, Sougnez C, Lowe A, Wong B, Auclair D, Van Allen EM, Nakabayashi M, Lis RT, Lee G-SM, Li T, Chabot MS, Ly A, Taplin M-E, Clancy TE, Loda M, et al.: Whole-exome sequencing of circulating tumor cells provides a window into metastatic prostate cancer. Nat Biotechnol 2014, advance on.

11. Yoshimoto N, Kida A, Jie X, Kurokawa M, Iijima M, Niimi T, Maturana AD, Nikaido I, Ueda HR, Tatematsu K, Tanizawa K, Kondo A, Fujii I, Kuroda S: An automated system for high-throughput single cell-based breeding. Sci Rep 2013, 3:1191.

12. Környei Z, Beke S, Mihálffy T, Jelitai M, Kovács KJ, Szabó Z, Szabó B: Cell sorting in a Petri dish controlled by computer vision. Sci Rep 2013, 3:1088.

13. Simpson SJ, Vachula M, Kennedy MJ, Kaizer H, Coon JS, Ghalie R, Williams S, Van Epps D: Detection of tumor cells in the bone marrow, peripheral blood, and apheresis products of breast cancer patients using flow cytometry. Exp Hematol 1995, 23:10628.

14. Swennenhuis JF, Reumers J, Thys K, Aerssens J, Terstappen LW: Efficiency of whole genome amplification of Single Circulating Tumor Cells enriched by CellSearch and sorted by FACS. Genome Med 2013, 5:106.

15. Schütze K, Lahr G: Identification of expressed genes by laser-mediated manipulation of single cells. Nat Biotechnol 1998, 16:737-742.

16. Emmertbuck M, Bonner R, Smith P, Chuaqui R, Zhuang Z, Goldstein S, Weiss R, Liotta L: Laser capture microdissection. Science (80- ) 1996, 274:998-1001. 
17. Helzer KT, Barnes HE, Day L, Harvey J, Billings PR, Forsyth A: Circulating tumor cells are transcriptionally similar to the primary tumor in a murine prostate model. Cancer Res 2009, 69:7860-6.

18. Zhao L, Lu Y-T, Li F, Wu K, Hou S, Yu J, Shen Q, Wu D, Song M, Ouyang W-H, Luo Z, Lee T, Fang X, Shao C, Xu X, Garcia M a, Chung LWK, Rettig M, Tseng H-R, Posadas EM: High-Purity Prostate Circulating Tumor Cell Isolation by a Polymer NanofiberEmbedded Microchip for Whole Exome Sequencing. Adv Mater 2013:2897-2902.

19. Molecular analysis of single circulating tumor cells (CTCs) isolated from metastatic breast cancer (mBC) patients (pts) | ONCOLOGYPRO [http://oncologypro.esmo.org/Meeting-Resources/IMPAKT-2013/Molecularanalysis-of-single-circulating-tumor-cells-CTCs-isolated-from-metastatic-breastcancer-mBC-patients-pts]

20. Fabbri F, Carloni S, Zoli W, Ulivi P, Gallerani G, Fici P, Chiadini E, Passardi A, Frassineti GL, Ragazzini A, Amadori D: Detection and recovery of circulating colon cancer cells using a dielectrophoresis-based device: KRAS mutation status in pure CTCs. Cancer Lett 2013, 335:225-31.

21. Ligthart ST, Coumans FAW, Bidard F-C, Simkens LHJ, Punt CJA, de Groot MR, Attard G, de Bono JS, Pierga J-Y, Terstappen LWMM: Circulating Tumor Cells Count and Morphological Features in Breast, Colorectal and Prostate Cancer. PLoS One 2013, 8:e67148.

22. Coumans FAW, van Dalum G, Beck M, Terstappen LWMM: Filtration parameters influencing circulating tumor cell enrichment from whole blood. PLoS One 2013, 8:e61774.

23. Marcy Y, Ishoey T, Lasken RS, Stockwell TB, Walenz BP, Halpern AL, Beeson KY, Goldberg SMD, Quake SR: Nanoliter reactors improve multiple displacement amplification of genomes from single cells. PLoS Genet 2007, 3:1702-8.

24. Stott SL, Hsu C-H, Tsukrov DI, Yu M, Miyamoto DT, Waltman BA, Rothenberg SM, Shah AM, Smas ME, Korir GK, Floyd FP, Gilman AJ, Lord JB, Winokur D, Springer S, Irimia D, Nagrath S, Sequist L V, Lee RJ, Isselbacher KJ, Maheswaran S, Haber DA, Toner M: Isolation of circulating tumor cells using a microvortex-generating herringbone-chip. Proc Natl Acad Sci U S A 2010, 107:18392-7.

25. Saliba A-E, Saias L, Psychari E, Minc N, Simon D, Bidard F-C, Mathiot C, Pierga J-Y, Fraisier V, Salamero J, Saada V, Farace F, Vielh P, Malaquin L, Viovy J-L: Microfluidic 
sorting and multimodal typing of cancer cells in self-assembled magnetic arrays. Proc Natl Acad Sci U S A 2010, 107:14524-9.

26. Peeters DJE, De Laere B, Van den Eynden GG, Van Laere SJ, Rothé F, Ignatiadis M, Sieuwerts a M, Lambrechts D, Rutten a, van Dam P a, Pauwels P, Peeters M, Vermeulen PB, Dirix LY: Semiautomated isolation and molecular characterisation of single or highly purified tumour cells from CellSearch enriched blood samples using dielectrophoretic cell sorting. Br J Cancer 2013(November 2012):1-10. 
CHAPTER 3: SAMPLE PREP METHODS 


\section{CHAPTER 4: TECHNICAL OVERVIEW OF SINGLE CELL WHOLE GENOME AMPLIFICATION METHODS}

Authors: Joost F Swennenhuis, Leon WMM Terstappen

Published in: Not published

Running title: WGA methods.

Abstract

With the introduction of targeted therapy during the last decade the assessment of the heterogeneity of cancer cells has become of great importance for cancer research and therapy. Traditionally cells were always analyzed in pools where individual outliers were averaged out and often disappeared in the bulk. A large challenge for the assessment of heterogeneity in Circulating Tumor Cells (CTC) is the low number of cells that can be made available for analysis. For DNA analysis of single cells it is often necessary to amplify the complete genome to have enough input DNA for the downstream application. A number of different approaches are developed to amplify the DNA of single or small amounts of cells. In this chapter an overview is given of all commercially available kits and the technical procedure of each kit is explained. Also two slide based WGA techniques are described that were developed at MCBP. Downstream applications will be discussed in relation to the different WGA approaches in combination with CTC research.

\subsection{Introduction}

Whole Genome Amplification general categories.

Whole Genome Amplification kits can be divided in three categories. The first are the Multiple Displacement Amplification (MDA) kits. The second are the Ligation Mediated PCR based amplification kits and the third are the MDA - PCR combination 
kits. Table 4.1 gives an overview of all the commercially available WGA kits. The Multiple Displacement Amplification (MDA) kits are from Qiagen (RepliG), GE (GenomiPhi) and a recently released kit from Sygnis (TruePrime). The second category are the Ligation Mediated (LM) PCR based amplification methods. The first of these kits, the GenomePlex (Sigma) kit produces random fragments while the other kit, the Ampli-1 kit (Silicon Biosystems) produces specific fragments using a restriction enzyme. The kits that combine the two methods are the PicoPLEX (Rubicon) and the MALBAC (Yikon Genomics). Rubicon also licensed out their technology to several other companies as mentioned in table 4.1 .

\begin{tabular}{llllll}
\hline & company & Kit name & type & Fragmentation method & Product size \\
\hline $\mathbf{1}$ & Qiagen & Repli-G & MDA & Random priming & $10 \mathrm{~K}+$ \\
\hline $\mathbf{2}$ & GE healthcare & GenomiPhi & MDA & Random priming & $10 \mathrm{~K}+$ \\
\hline $\mathbf{3}$ & Sygnis & TruePrime & MDA & None & $?$ \\
\hline $\mathbf{4}$ & Sigma & GenomePlex & LM-PCR & Chemical/heat & $100-500 \mathrm{bp}$ \\
\hline $\mathbf{5}$ & Silicon Biosystems & Ampli-1 & LM-PCR & Restriction enzyme & $100-7000 \mathrm{bp}$ \\
\hline $\mathbf{6}$ & Rubicon Genomics & Picoplex & MDA/PCR & Quasi random priming & $100-500 \mathrm{bp}$ \\
\hline $\mathbf{7}$ & New England Biolabs* & scWGA* & MDA/PCR & Quasi random priming & $100-500 \mathrm{bp}$ \\
\hline $\mathbf{8}$ & BlueGnome* & SurePlex & MDA/PCR & Quasi random priming & $100-500 \mathrm{bp}$ \\
\hline $\mathbf{9}$ & Perkin Elmer* & EasyAmp & MDA/PCR & Quasi random priming & $100-500 \mathrm{bp}$ \\
\hline $\mathbf{1 0}$ & Yikon Genomics & MALBAC & MDA/PCR & Random priming & $?$ \\
\hline
\end{tabular}

Table 4.1: Single cell WGA kits. MDA=Multiple Displacement Amplification, LM = Ligation Mediated *New England Biolabs, BlueGnome and Perkin Elmer license the Rubicon genomics PicoPlex technology. **Full name of scWGA from New England Biolabs kit is: "Single Cell Whole Genome Amplification kit"

\subsection{Methods}

\subsubsection{GenomePlex kit (Sigma)}

The technology of the Sigma GenomePlex kit is licensed from Rubicon genomics. The kit uses four steps as displayed in figure 4.1. A: Cell lysis. B: DNA fragmentation. C. Linker ligation and D: Amplification. The cell lysis is done with a proteinase $\mathrm{K}$ step at $42^{\circ} \mathrm{C}$ followed by heat inactivation of the enzyme. DNA fragmentation is done by using a proprietary chemical combined with a short heat incubation step. This randomly fragments the DNA to 100-500 bp fragments. Both ends of these fragments then get a linker ligated which is then used to amplify the DNA in a PCR reaction. 


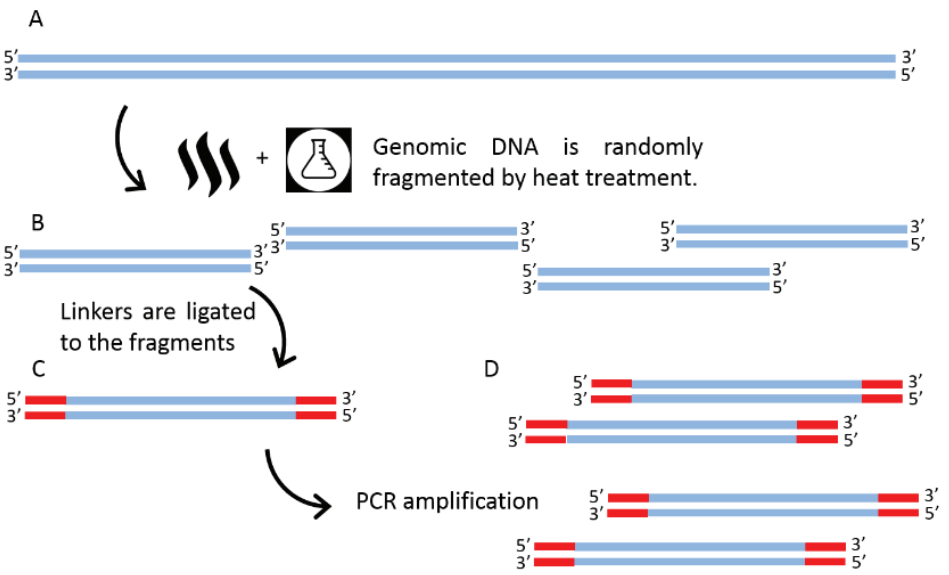

Figure 4.1. Sigma GenomePlex kit. A. Genomic DNA is prepared by lysis of a cell with proteinase K. B. The DNA is randomly fragmented by using heat and a proprietary chemical. C. Linkers are ligated to the ends of the fragments. D. The fragments are amplified in a PCR reaction.

\begin{tabular}{ll}
\hline Sigma GenomePlex kit \\
\hline Disadvantages & $\begin{array}{l}\text { Laborious protocol. } \\
\text { Kit produces random fragments. The quality of a single cell } \\
\text { amplification product is difficult to check. }\end{array}$ \\
\hline Advantages & $\begin{array}{l}\text { less sensitive to DNA damage since the protocol contains a random } \\
\text { fragmentation step }\end{array}$ \\
\hline Can be scaled down to low volumes. \\
\hline Applicability & $\begin{array}{l}\text { Not to use in targeted sequencing and PCR approaches since all } \\
\text { amplicons have the possibility to contain a breakpoint and } \\
\text { therefore cannot be amplified. }\end{array}$ \\
\hline
\end{tabular}

\subsubsection{Ampli-1 Kit (Silicon Biosystems)}

Just like the GenomePlex kit, The Ampli-1 kit is a Ligation Mediated PCR kit (LM-PCR). Again the process involves four steps as displayed in figure 4.2: A: Cell lysis. B: Fragmentation by restriction digestion. C. Linker ligation and D: Amplification. This kit also uses a proteinase K step to lyse the cells and release the DNA. The difference with the Sigma kit is that the fragmentation is done with MseI, a restriction enzyme recognizing TTAA and fragmenting the genome with an average fragment length of $126 \mathrm{bp}$. These fragments then get linkers ligated and will be amplified using a PCR amplification reaction. The big advantage is that this kit is deterministic. It is possible 
to design downstream tests based on the restriction fragments without having the possibility of unexpected DNA breaks caused by the kit.

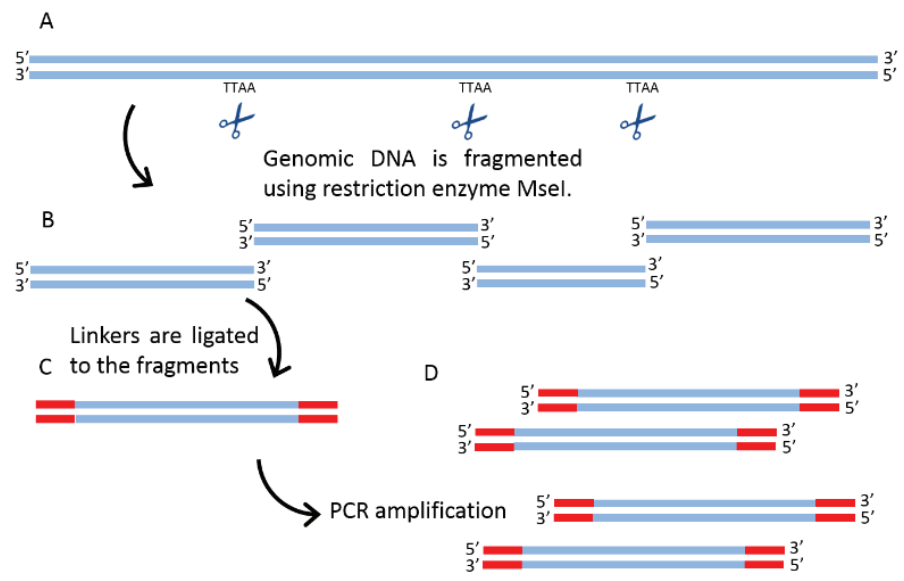

Figure 4.2. Ampli-1 Kit (Silicon Biosystems). A. Genomic DNA is prepared by lysis of a cell with proteinase $\mathrm{K}$. B. The DNA is fragmented by using a restriction enzyme (MseI). C. Linkers are ligated to the ends of the fragments. D. The fragments are amplified in a PCR reaction.

\section{Silicon Biosystems Ampli-1 Kit}

Disadvantages Long laborious protocol. Also the new and short version of the protocol takes a lot of hands-on time compared to other kits.

Short and long MseI fragments can get lost in the process or are not useable in downstream applications.

\begin{tabular}{ll}
\hline Advantages & $\begin{array}{l}\text { Kit produces predictable fragments making it easy to design } \\
\text { downstream applications and doing quality control. }\end{array}$ \\
\hline Applicability & $\begin{array}{l}\text { This kit can be used for all downstream applications unless the } \\
\text { sequence of interest is located on location with many MseI } \\
\text { restriction sites producing too short fragments. }\end{array}$ \\
\hline
\end{tabular}

\subsubsection{Multiple Displacement Amplification (MDA) kits}

The MDA based kits all make use of the Phi-29 DNA polymerase enzyme. This enzyme has an exceptional good strand displacement ability. When an actively copying Phi-29 polymerase meets a $5^{\prime}$ end of double stranded DNA, it separates the strands, continues to copy the template strand and produces, next to the double stranded DNA, single stranded template DNA. There are more enzymes with this ability such as Bst DNA polymerase and VentR® DNA polymerase. Phi-29 has by far the most efficient activity 
and is very fast even when it is displacing strands. And a third property is that it has 3'to 5'proofreading-exonuclease activity, checking just added nucleotides and replacing it when an incorrect nucleotide is built in.

When the Phi-29 polymerase is added to template DNA together with nucleotides it will start replicating the DNA while producing single stranded new template DNA (see figure 4.3). To initiate the polymerase, Qiagen and GE add random hexanucleotides to their reactions while Sygnis does not. The displaced strands form new target for the reaction. The reaction produces an ever increasing amount of template DNA and will only stop when the nucleotides are all used. This will, in general, be within a few hours in an isothermal reaction at $30-42^{\circ} \mathrm{C}$.

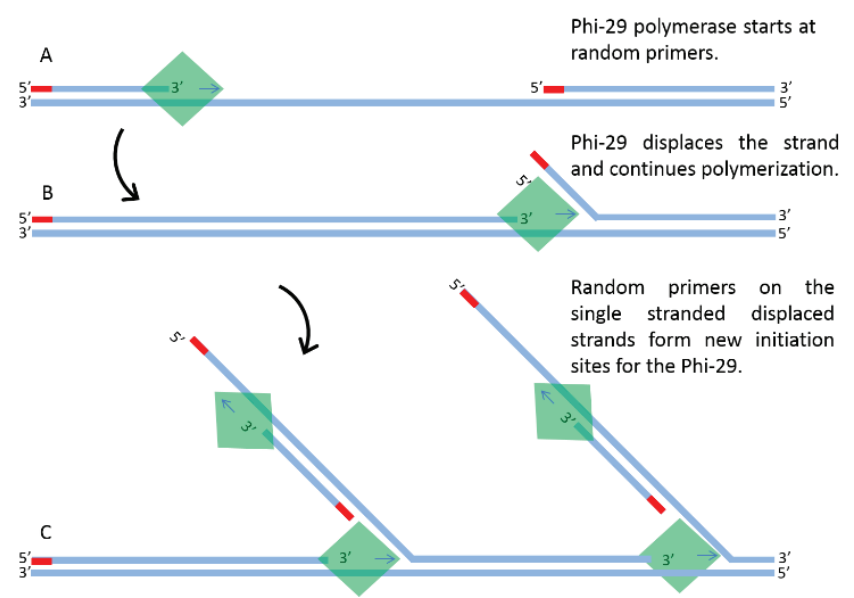

Figure 4.3. Schematic example of Multiple Displacement Amplification (MDA). A. The Phi-29 enzyme (green square) starts amplification at a 3 'end. B. When a $5^{\prime}$ end is met, the enzyme displaces the strand and continues the amplification. C. The displaced strands form new template DNA and are copied. 
MDA kits

Disadvantages The low temperature is especially a disadvantage for long GC stretches and parts of the genome forming secondary structures. Kits have variable highly non uniform amplification. Products are poorly suitable for CGH.

According to Qiagen these kits are not suitable for fixed or damaged cells.

Advantages Easy single step single temperature protocol. Very low hands-on time.

Phi-29 polymerase has high fidelity so kits are very well suited for snp detection

Applicability These kits can be used for all downstream analysis. The kits produce high molecular weight DNA fragments which can be treated as genomic DNA. The main restriction is upstream. The cells have to be unfixed which is a major limitation for CTC isolation techniques.

\subsubsection{Combinations of MDA and PCR}

\subsubsection{Rubicon Picoplex kit}

The Picoplex kit makes use of a heat stable, strand displacing enzyme: BstIpolymerase, producing PCR ready amplicons which are subsequently amplified in a PCR reaction. The protocol consists of three steps as displayed in figure 4.4: A: Cell Lysis. B: Preamplification. C. Amplification. After cell lysis using a proprietary enzyme (most probably also proteinase $\mathrm{K}$ ), a random primer is added together with BstI polymerase and the mix is subjected to cycles of denaturation and careful stepwise hybridization and strand displacing amplification. The random primer also contains a fixed sequence at the 5'side. Since the same primer also initiates the reaction on the displaced strand, both ends of the formed amplicons will have the same fixed sequence at the end. This sequence is used in the third part of the reaction to amplify the formed amplicons in a PCR reaction. Other vendors licensing and marketing the Picoplex technology are New England Biolabs (Single Cell WGA kit), BlueGnome (Sureplex kit) and Perkin Elmer (EasyAmp kit). 


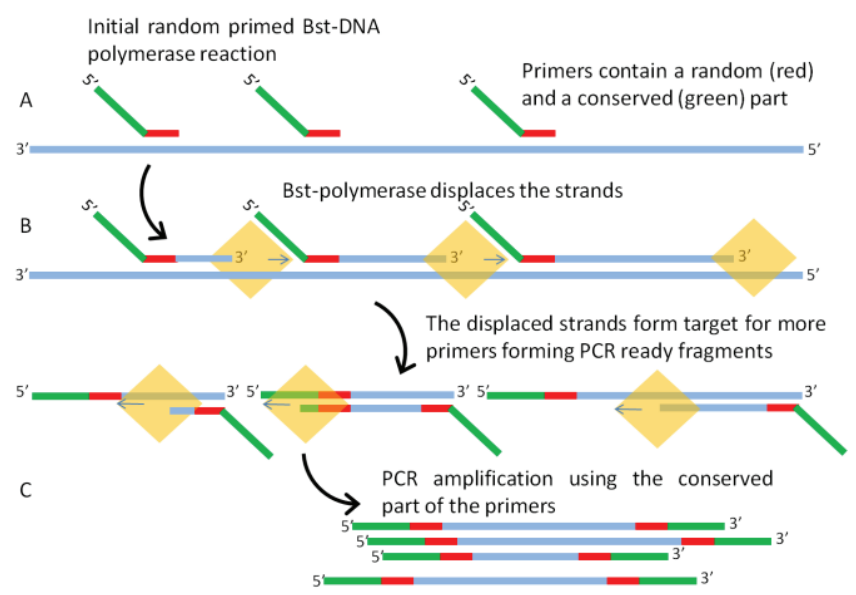

Figure 4.4. Schematic example of the Rubicon PicoPlex. A. The BstI enzyme (square) starts amplification at a $3^{\prime}$ end. B. When a $5^{\prime}$ end is met, the enzyme displaces the strand and continues the amplification. C. The displaced strands form new template DNA and are copied in a PCR reaction.

\begin{tabular}{ll}
\hline Rubicon Picoplex kit \\
\hline Disadvantages & $\begin{array}{l}\text { Since the first step uses BstI polymerase the kit is expected to be } \\
\text { sensitive for DNA damage since the enzyme cannot pass the } \\
\text { damaged sites. }\end{array}$ \\
\hline Advantages & $\begin{array}{l}\text { Easy and fast protocol. Low hands-on time. } \\
\text { Applicability }\end{array}$ \\
$\begin{array}{l}\text { This kit can be used for all downstream analysis. Although the kit } \\
\text { has a random amplification format, the initial multiple copies of } \\
\text { the template strands wil spread the risk of nicks in PCR amplicons. }\end{array}$ \\
\hline
\end{tabular}

\subsubsection{MALBAC}

Multiple Annealing and Looping Based Amplification Cycle (MALBAC) is next to the PicoPlex the second kit that combines both PCR amplification with a strand displacement pre-amplification. This kit however uses a more complex reaction where the primary product is produced in two steps (figure 4.5). The initial step uses again a random primed strand displacement step. The primer consists of a random as well as a conserved part. In the second part this initial product is used as a template for the production of complete amplicons. The nice thing about this reaction is that only the initial produced template can serve as template for this cycling. The finished amplicons are taken out of this loop because of the self-annealing ability of the primers. Third step is to amplify the formed amplicons in a PCR reaction. The MALBAC kit has not been tested at MCBP. 


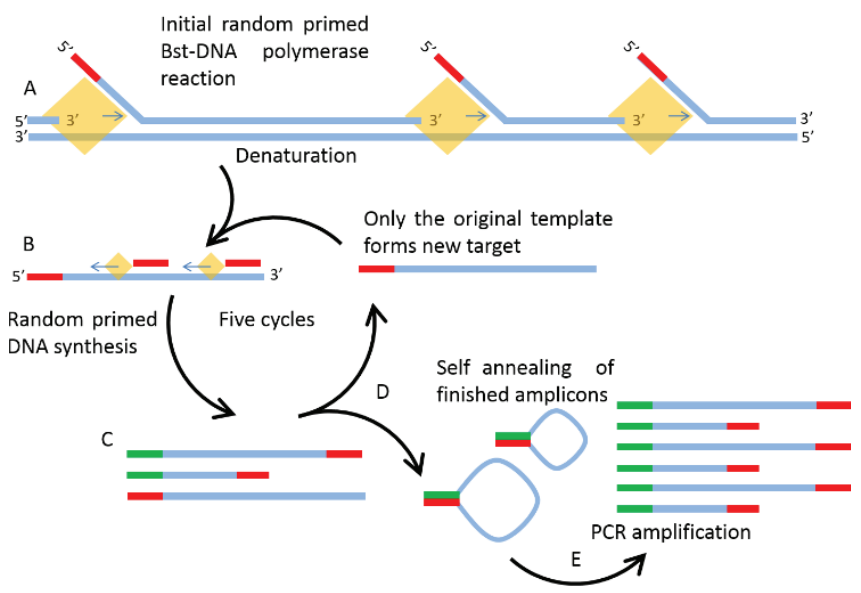

Figure 4.5. Schematic example of MALBAC. A. The BstI enzyme (green square) starts amplification at a $3^{\prime}$ end. B. When a $5^{\prime}$ end is met, the enzyme displaces the strand and continues the amplification. C. The displaced strands form new template DNA and are copied.

\begin{tabular}{ll}
\hline Yikon MALBAC kit \\
\hline Disadvantages & $\begin{array}{l}\text { This kit is strongly dependent on initial BstI amplification so } \\
\text { probably very sensitive for DNA damage. }\end{array}$ \\
\hline Advantages & Easy and fast protocol. Low hands-on time. \\
\hline Applicability & $\begin{array}{l}\text { This kit can be used for all downstream analysis. Although the kit } \\
\text { has a random amplification format, the initial multiple copies of } \\
\text { the template strands wil spread the risk of nicks in PCR amplicons. }\end{array}$ \\
\hline
\end{tabular}

\subsection{Downstream analysis}

To analyze the genome or exome of single CTC's a number of different tests could be applied which allow different kinds of cell purity, detect different sizes, types and numbers of aberrations and mutations with different sensitivity. Below an overview of the most common and clinically relevant tests that can be done on DNA or RNA of single CTC. 


\subsubsection{FISH}

FISH can be performed on a whole CellSearch enriched fraction of cells[1, 2]. With a FISH tests it is possible to look at structural variations like translocations, deletions, inversions and amplifications of sizes larger than $30 \mathrm{Kbp}$. Most fluorescent microscopes can handle up to five filters allowing four different FISH probes and a nuclear dye to be used at once. Translocation and inversion probes consist of two colors for each target. Deletion and amplification probes need a reference so that limits the number to two targets for each FISH test. Figure 4.6 shows an example of FISH on CTC's from Attard et al [2] of prostate cancer patients where the deletion, amplification and translocation status of the PTEN, ERG and AR genes is analyzed in one test in CTC's from the CellSearch system.

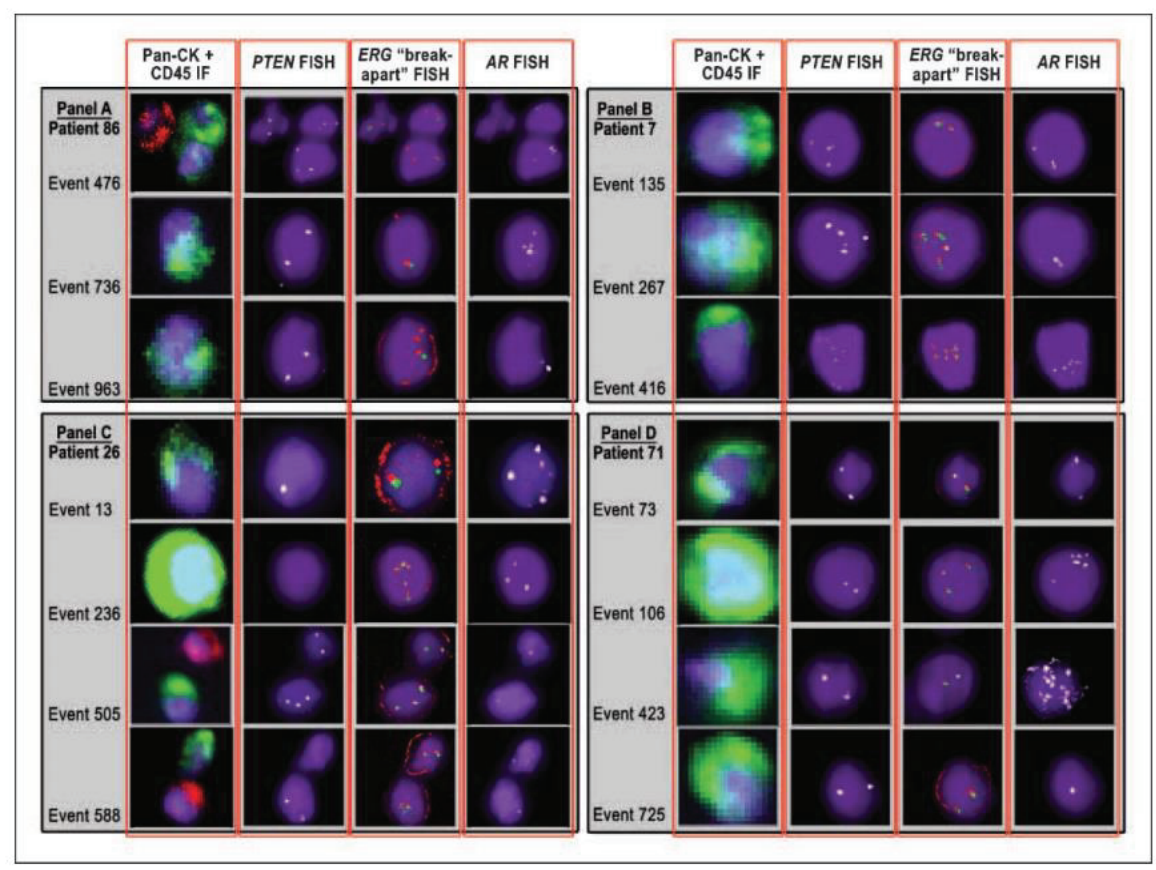

Figure 4.6. Molecular characterization of CTCs. CK (green) and CD45( red) immunofluorescence and PTEN, ERG break-apart, and AR FISH: Rhodamin-labeled PTEN probes, Dy647-labeled 3'ERG, F415-labeled 5'-ERG, and FITC-labeled AR. Examples of events from four patients that were CK positive (green) and had a DAPI stained nucleus (purple) are included. There are three examples of control leukocytes that stain positive for CD45( red) and negative for CK (no green); (A, event 46; C, events 505 and 588). Panel A shows cells from a patients with a deletion of ERG (green probe is missing). Panel B shows cells of a patient with a ploidy of the wild type gene (multiple copies of both green and red in each cell). Panel C shows a heterogeneous loss of the PTEN gene. Variable numbers of both copies together are found in the different CTC. Panel D shows heterogeneous AR gain. 


\subsubsection{RNA Microarray}

Microarray analysis can be done on extracted RNA from a complete CellSearch enriched cell fraction[3]. With this tests it is possible to detect the abundancy of genes that are differentially expressed by CTC's over WBC. Chips are available that cover the complete exome. The possibilities of this approach are limited because of the high background of WBC. Only genes that are not or very low expressed by the WBC's can be detected when expressed in CTC's. Downregulated genes in CTC cannot be found using this approach unless the CTC are individually isolated and the RNA from that single cell is amplified. RNA microarrays are slowly replaced by RNA sequencing. A technique that could give the same information together with detailed information on the sequence. At this moment a microarray is still a little bit cheaper and easier to analyze but it is expected that this will change in the near future.

\subsubsection{RT-PCR}

Reverse transcriptase PCR can be applied on extracted RNA from a complete CellSearch enriched cell fraction. This technique is used, just like the RNA microarray, to detect abundant genes expressed by CTC's[3, 4]. The extracted RNA could be amplified so the number of transcripts that can be analyzed is high. Since each PCR has to be done individually this technique is however labor intensive. Again, only high abundant genes and mainly genes that are differentially expressed by CTC's can be detected. Figure 4.7 shows RT-qPCR heat map results from Smirnov et al [3] where gene expression is analyzed from genes that were initially found to be differentially expressed by cancer cells by RNA microarrays. 
CHAPTER 4: WGA METHODS

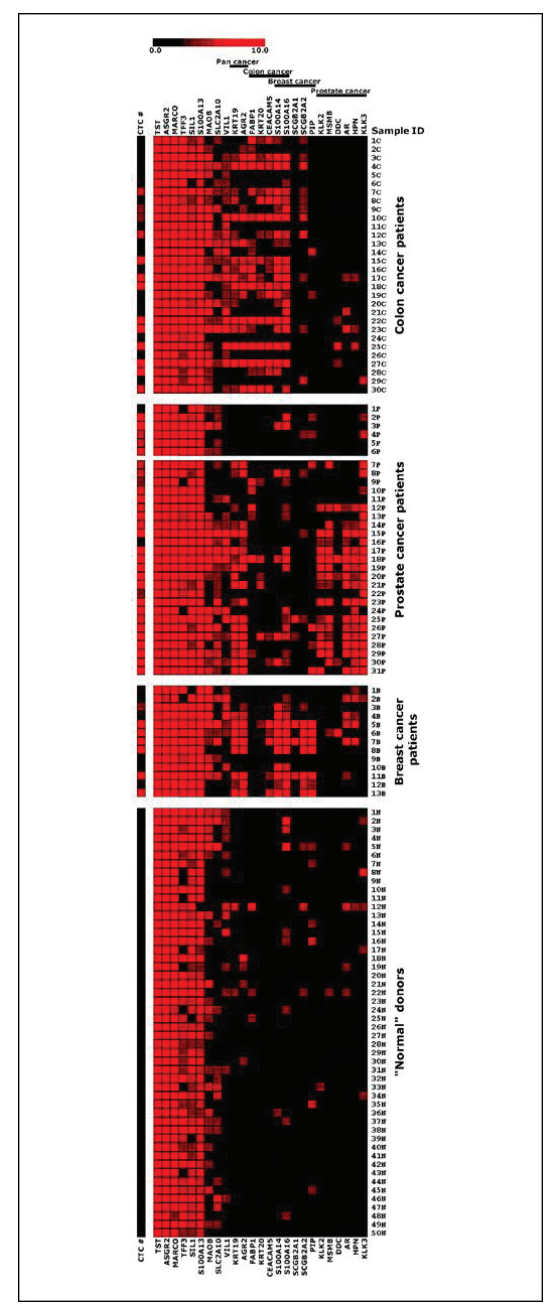

Figure 4.7. Results of global CTC expression profiling by microarrays. Log2-transformed fluorescent intensity ratios between CTC-enriched and corresponding CTC-depleted blood samples from a metastatic breast cancer, metastatic prostate cancer, and colorectal cancer patient are presented for selected genes in the form of a heatmap. Genes are grouped based on their expression pattern and selected for specificity to all CTCs regardless of cancer type (pan cancer group), metastatic breast cancer patient CTCs (breast cancer group), metastatic prostate cancer patient CTCs (prostate cancer group), and metastatic colon cancer patient CTCs (colon cancer group). Genes within each category are sorted in descending order by their log2transformed fluorescent intensity ratios. Fluorescent intensity ratios for the pan leukocyte marker CD45 and housekeeping (Hskp.) genes are also presented. 


\subsubsection{Single cell RTqPCR}

PCR analysis of the transcriptome of single CTC's is also possible using the SMART technology to amplify cDNA from a single CTC[5]. To do this it is first necessary to capture and isolate a single CTC from a pre-enriched fraction. The SMART technology amplifies the cDNA so the number of qPCR tests is not limited but again it is labor intensive. The sensitivity is very high but care should be taken that the targeted gene is not biased by the amplification during the SMART amplification.

\subsubsection{PCR}

PCR techniques on genomic DNA can be used to detect several aberrancies. On crude isolations of CellSearch enriched DNA, PCR tests for specific mutations will not work because of the low frequency of the mutated genes. To do this, at least a single cell isolation of the CTC is necessary. With a good PCR test it is then possible to detect a single mutation using a mutation specific PCR such as a Taqman assay. However in that case it is only possible to detect one mutation for each cell. Most PCR approaches therefore use a targeted or whole genome pre-amplification technique. The risk here is that these tests strongly depend on the reliability of the amplification reaction. qPCR can also be used to detect aberrancies in single isolated cells. Figure 4.8 shows combined FISH and qPCR results of cells with and without Erbb2 gene amplification from Yang et al.[6]
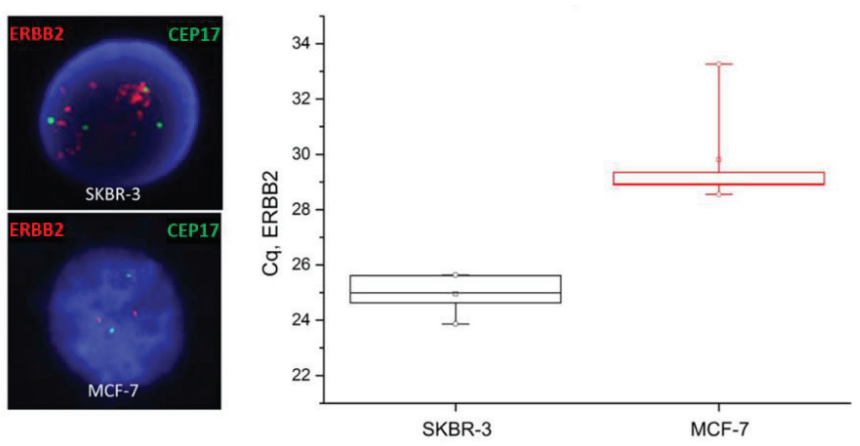

Figure 4.8. On-chip single cell whole genome amplification. On the left images of fluorescence in situ hybridization (FISH) with ERBB2 probes in red and centromere 17 probes (CEP17) in green for individual SKBR-3 and MCF-7. Nuclei were stained with Hoechst (blue). On the right Cq values of ERBB2 gene in a box plot. Cq values of ERBB2 were represented as black box in SKBR-3 $(n=6)$ and red box in MCF-7 showing a significantly lower Cq value for the SKBR-3 cells which have the ERBB2 gene amplification. 


\subsubsection{Sanger sequencing}

The Sanger sequencing approach has the same restrictions as the PCR since the product to be sequenced is a PCR amplified amplicon. It is again very labor intensive since each targeted mutation has to be amplified, purified and sequenced individually. The purity of the CTC with the targeted mutation has to be higher than $10 \%$ otherwise the mutation is not detectable. Figure 4.9 shows Sanger sequencing results for a mutation on the PTEN gene and the ROBO2 gene from three different cell lines. The detected mutations were used to identify each cell line: SKBR3 has none of both mutations, LNCaP has the PTEN tt deletion and PC-3 has the ROBO-2 G>A substitution.

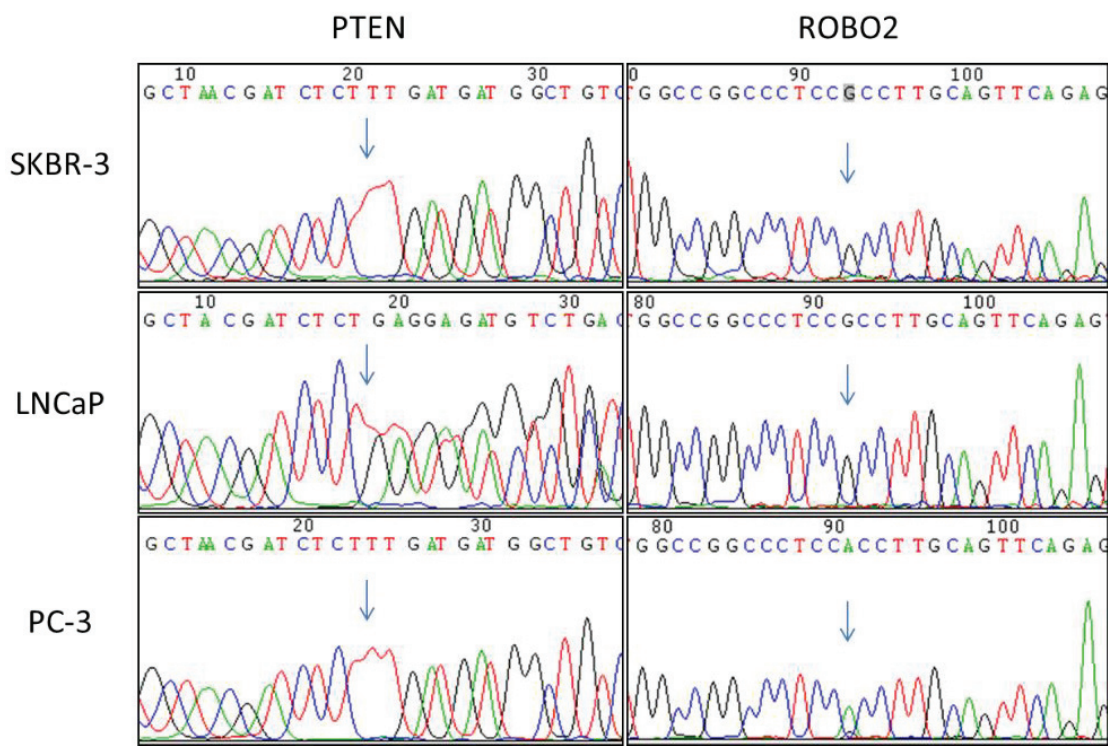

Figure 4.9. Sanger sequencing results from WGA amplified single cultured cells punched from the same VyCAP CUPS sieve. SKBR-3 cells have wild type for both PTEN and ROBO2 genes, LNCaP cells have a TT deletion in the PTEN gene and the PC-3 cells have a G>A substitution mutation in the ROBO-2 gene.

\subsection{7 $\mathrm{CGH}$}

Comparative Genomic Hybridization (CGH) also needs single purified CTC's whether or not pooled depending on the research question. CGH detects numerical variations in the DNA. It does not detect structural variations. The resolution of the detectable variations goes down to about $10 \mathrm{kbp}$. Just like most other single cell techniques CGH also depends on WGA. The homogeneity of this copy is very important for the end result. Figure 4.10 from Neves et al[7] shows a CGH profile of chromosome 11 of a single CTC on the left and a zoom in on the CCND1 gene genomic area 11q12.1 to 
11q14.1. It shows the variable amplification of this area in different single CTC's. To make these CGH profiles Neves et al enriched breast cancer CTC's from blood using CellSearch and FACS sorted the single CTC's into PCR tubes. The genome of the cells was subsequently amplified using the Ampli-1 kit and were hybridized in the CGH against Ampli-1 amplified material from single WBC's.

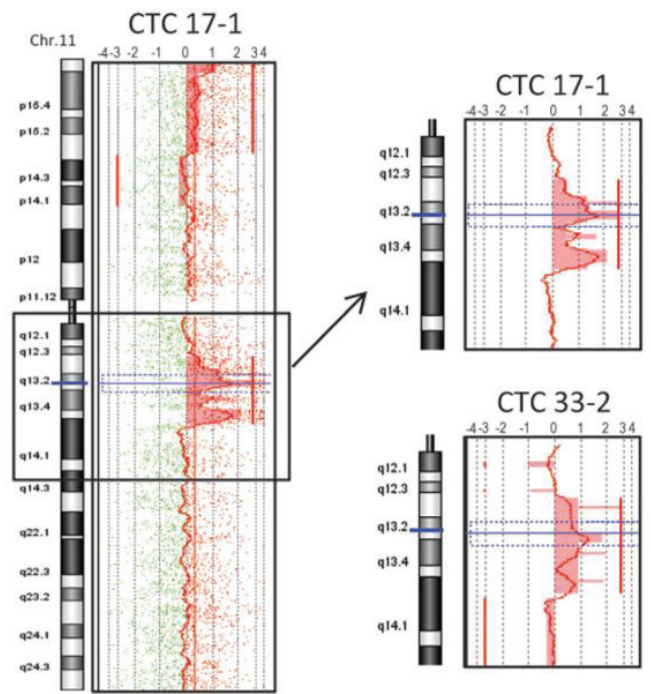

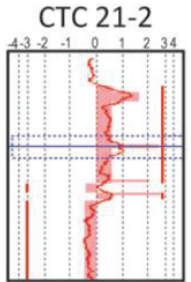

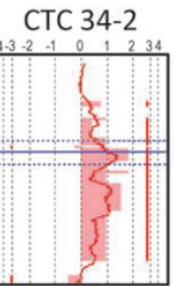

CTC 30-1

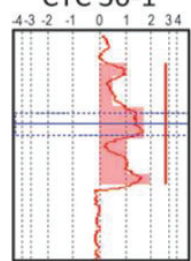

CTC 38-2

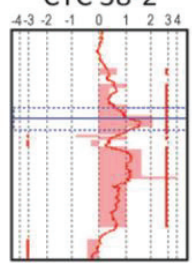

Figure 4.10. aCGH results obtained from individual breast cancer CTCs. Scatter plots (left panels) and histograms showing aCGH profiles of WGA products from individual CTCs with different degrees of gains in the CCND1 gene locus on 11q13.3. The position of the CCND1 gene locus is indicated by the blue horizontal solid line. Alterations are represented in each plot by vertical solid lines.

\subsection{8 mRNA seq}

For mRNA sequencing also single or pooled pure CTC's are required. To get enough input cDNA an amplification is again necessary. Here multiple approaches are possible. 5'end sequencing for gene quantification, which can be done with 96 cells in one reaction using barcodes[8] or sequencing the whole cDNA[5]. The first giving only quantitative information on the transcripts, the second giving both quantitative and sequence information where it is possible to also detect mutations in the sequence. The sensitivity of RNA seq depends on the depth of the sequencing reactions. 


\subsubsection{Targeted sequencing}

Targeted sequencing is an option where single isolated CTC's are preferred but not necessary. Because the target area is limited to a few hundred amplicons of around $200 \mathrm{bp}$, it is possible to sequence each amplicon to a depth of up to $1200 \mathrm{x}$. This means that even if one in every 50 cells would be a CTC, there still would be enough reads to reliably call mutations. With targeted sequencing it is not possible to detect structural or numerical variations.

\subsubsection{Exome sequencing}

For exome sequencing the targeted area is too big to allow any cells other than CTC. A single pure CTC or a pooled fraction needs to be the input of a WGA reaction[9]. Numerical and sequence mutations can be picked up by using this technique. The technique is very dependent on a homogenic amplification of the genome because of the large target area and therefore low depth of the sequencing. Figure 4.11 shows the result of an alignment of the reads of an exome sequencing reaction on the genomic DNA of the breast cancer cell line MDA-MB-468. The alignment is zoomed in to the base level onto a homozygous PTEN G>T substitution mutation harbored by the MDAMB-468 cell line. Position of a part of the reads is shown in the grey bars in the four samples $\mathrm{A}, \mathrm{B}, \mathrm{C}$ and $\mathrm{D}$. The red $\mathrm{T}$ indicates a deviation from the human genomic sequence (HG19) which is found in all reads that cover this base. The high variation in the number of reads is caused by the WGA reaction and the hybrid capture method that is used to enrich the DNA for the exomic sequences. 


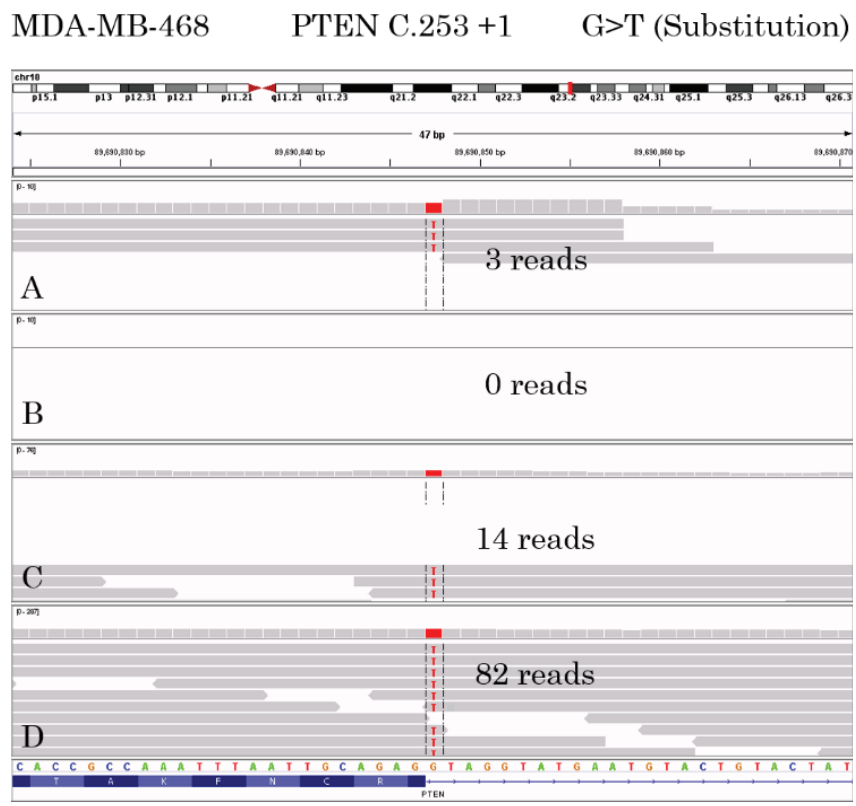

Figure 4.11. Results of the alignment of genomic DNA (A) , WGA amplified genomic DNA (B), WGA amplified single cell DNA (C and D) sequenced by exon sequencing. The alignment is zoomed in to the base level onto a homozygous PTEN G>T substitution mutation.

\subsection{WGA methods developed at MCBP.}

CTC are so rare in blood that no single existing technique is able to isolate a pure fraction of these cells from blood. All used methods have an enrichment step before the final individual cell isolation. At this point, CTC enrichment and single cell isolation, two expensive and in most cases labor intensive procedures, have been done already. The process of WGA and the quality control afterwards are also costly and time consuming. Especially when all cells will be treated and analyzed individually. It would be of great help when there is a possibility of a visual inspection of the cells just before WGA of the cells. This way the cell selection can be verified and no WGA and QC test will have to be wasted by amplifying empty wells. Another advantage could be that cells can be preselected on basis of their morphology. For this reason two protocols were developed at MCBP to enable Cell lysis and WGA on slides. The first is the Sigma GenomePlex kit in combination with the AmpliGrid system from Beckman Coulter. The second is a protocol to enable enzymatic lysis and isothermal strand displacement WGA using the GE GenomiPhi kit. 


\subsubsection{Sigma GenomePlex on AmpliGrid slides}

The Ampligrid technology (Beckmann Coulter) is based on small volume DNA reactions on a slide. $2 \mathrm{~mm}$ round wells are made on a glass slide surrounded by a hydrophobic ring. A max $2 \mu \mathrm{l}$ large reaction can be done underneath a dome of oil that stays in place due to the hydrophobic ring.

At MCBP we have been able to develop a WGA method using the reagents of the Sigma GenomePlex kit on an AmpliGrid slide using a maximum of $2 \mu \mathrm{l}$ volume. This project was preliminary terminated due to the fact that the AmpliGrid and its associated slide based PCR machine (the AmpliSpeed) were discontinued from sale. Also in the WGA field more methods were released to the market to reliably amplify the DNA of single cells. Based on theoretic grounds the Sigma GenomePlex method was inferior to a number of other methods that became available such as the Phi-29 based kits and the PicoPlex kit.

Since a low volume, and therefore low yield WGA could still be of use in the future for the even decreasing input requisite of the sequencing kits, the protocol as it was used is taken up in the supplementary protocols of this thesis. The method is an exact copy of the protocol described by Sigma but then reduced and simplified to 4 additions of $0.5 \mu \mathrm{l}$. All reagents are diluted in such way that the concentrations exactly match the concentrations of the original large volume protocol. The final PCR amplification of this kit is done in a larger volume in a regular PCR tube.

\subsubsection{GE GenomiPhi WGA on slide}

The GE GenomiPhi kit uses an isothermal amplification at $37^{\circ} \mathrm{C}$ making it possible using a water bath or hotplate as a heat source instead of a PCR machine. In the protocol section at the supplementary protocols of this thesis the protocol is given for the WGA method on single cells, using the GE Healthcare illustra GenomiPhi V2 DNA Amplification Kit. The protocol is developed with two lysis methods. The alkaline lysis or potassium hydroxide (KOH) lysis method is supplied with the GenomiPhi kit and works on fresh cells. The Protease K method is added to be able to amplify DNA from formalin or CellSave fixed cells but also works for fresh cells. After depositing the cells on a 30 well epoxy coated slide the cells are denatured either with $\mathrm{KOH}$ for 10 minutes on ice or with Proteinase $\mathrm{K}$ for 1 hour at $50^{\circ} \mathrm{C}$ followed by inactivation of the protK at $75^{\circ} \mathrm{C}$ for 20 minutes. The WGA reaction is done in a total volume of $5 \mu$ for $2-4$ hours in a humidified chamber in a waterbath. 


\subsection{Discussion}

\subsubsection{When to use what: Upstream WGA.}

The amplification of DNA from single CTC can only happen after a time consuming enrichment and single cell isolation process. Next to that, often, these isolations are part of multi-site studies obliging the samples to be fixed in order not to lose the CTC's during shipment. This fixation and the lengthy isolation process can damage the DNA. The effects of this DNA damage on the WGA process should be considered before selecting the WGA kit. WGA comparison papers all compare WGA kits used on unfixed, accessible and undamaged target material [10-13]. It can reasonably be expected that the different WGA approaches will have a different sensitivity for DNA nicks and fragmentation. A theoretical estimated applicability of the WGA kits on different DNA qualities is depicted in figure 4.12. The least sensitive for DNA damage is expected to be the GenomePlex kit. This because the first step in this kit is a random fragmentation of the DNA. For this kit intact DNA is not of importance. The Ampli-1 kit is a little more sensitive for DNA breaks. It also makes small fragments but then by cutting the DNA with a restriction enzyme. Therefore all fragments with a nick or break could get lost in the process but since small fragments are made a certain degree of fragmentation will only cause loss of small fragments and therefore not be of large influence. Malbac and Picoplex both use an initial BstI polymerase strand displacement step. The BstI polymerase will continue each amplification until a DNA end or nick in the template strand is met. The more nicks or breaks the less efficient this initial step will be. For the MDA kits it is most important that the DNA is undamaged since it completely depends on the long strand displacement reactions. Each nick or break will cause a disturbance in that particular genomic area and can have a large influence on the end product.

What the exact possibilities are of the different kits regarding degraded or damaged DNA will need to be examined because there is no literature available where this matter is addressed. 


\begin{tabular}{|r|c|c|c|c|}
\hline & Unfragmented & $\begin{array}{c}\text { Low } \\
\text { fragmented }\end{array}$ & $\begin{array}{c}\text { Moderate } \\
\text { fragmented }\end{array}$ & $\begin{array}{c}\text { Highly } \\
\text { fragmented }\end{array}$ \\
\hline MDA kits & & & & \\
\hline Malbac/Picoplex & & & & \\
\hline Ampli-1 & & & & \\
\hline Genome Plex & & & & \\
\hline
\end{tabular}

Figure 4.12. Predicted applicability of WGA kits on variable DNA quality. Genomeplex is expected to do best with fragmented DNA since the first step is random DNA fragmentation. Ampli-1 fragments the DNA to small pieces using a restriction enzyme. This makes that some fragment will get lost. Malbac and PicoPlex use Bst-1 polymerase as a first step. This enzyme is expected to stop at nicks or breaks but the small fragments that were formed will be amplified in second PCR step. The MDA kits completely depend on the long reactions of the Phi-29 polymerase which will stop at nick's or breaks.

\subsubsection{When to use what: Downstream WGA}

As discussed before, downstream WGA analysis could be PCR / Sanger, CGH or a number of different NGS approaches to reveal nucleotide substitutions, deletions, and insertions or copy number and structural variants. Next to the quality or fixation state of the template DNA the downstream application should be considered too when selecting a WGA method. For unfixed cells the MDA kits are very well suited for SNP calling because of the high fidelity of the Phi-29 enzyme [14]. MDA is less suited for CNV detection because of the variable highly non uniform amplification [15]. The ligation mediated and the combined MDA and PCR kits produce DNA better suited for CNV because of the more uniform amplification. Since these applications are only compared using unfixed single cells it is not yet possible to select the optimal amplification method until this has been compared directly. No matter which method is used, finding the same mutation twice independently of the other is the best proof and is even required when a real call for that variant has to be made. 


\subsection{References}

1. Swennenhuis JF, Tibbe AGJ, Levink R, Sipkema RCJ, Terstappen LWMM: Characterization of circulating tumor cells by fluorescence in situ hybridization. Cytometry A 2009, 75:520-7.

2. Attard G, Swennenhuis JF, Olmos D, Reid AHM, Vickers E, A'Hern R, Levink R, Coumans F, Moreira J, Riisnaes R, Oommen NB, Hawche G, Jameson C, Thompson E, Sipkema R, Carden CP, Parker C, Dearnaley D, Kaye SB, Cooper CS, Molina A, Cox ME, Terstappen LWMM, de Bono JS: Characterization of ERG, AR and PTEN gene status in circulating tumor cells from patients with castration-resistant prostate cancer. Cancer Res 2009, 69:2912-8.

3. Smirnov DA, Zweitzig DR, Foulk BW, Miller MC, Doyle G V, Pienta KJ, Meropol NJ, Weiner LM, Cohen SJ, Moreno JG, Connelly MC, Terstappen LWMM, O'Hara SM: Global gene expression profiling of circulating tumor cells. Cancer Res 2005, 65:4993-7.

4. Sieuwerts AM, Kraan J, Bolt-de Vries J, van der Spoel P, Mostert B, Martens JWM, Gratama J-W, Sleijfer S, Foekens JA: Molecular characterization of circulating tumor cells in large quantities of contaminating leukocytes by a multiplex real-time PCR. Breast Cancer Res Treat 2009, 118:455-68.

5. Ramsköld D, Luo S, Wang Y-C, Li R, Deng Q, Faridani OR, Daniels GA, Khrebtukova I, Loring JF, Laurent LC, Schroth GP, Sandberg R: Full-length mRNA-Seq from single-cell levels of RNA and individual circulating tumor cells. Nat Biotechnol 2012, 30:777-82.

6. Yang Y, Swennenhuis JF, Suk Rho H, Le Gac S, Terstappen LWMM: Parallel Single Cancer Cell Whole Genome Amplification Using Button-Valve Assisted Mixing In Nanoliter Chambers. PLoS One 2014.

7. Neves RPL, Raba K, Schmidt O, Honisch E, Meier-Stiegen F, Behrens B, Möhlendick B, Fehm T, Neubauer H, Klein CA, Polzer B, Sproll C, Fischer JC, Niederacher D, Stoecklein $\mathrm{NH}$ : Genomic high-resolution profiling of single CKpos/CD45neg flow-sorting purified circulating tumor cells from patients with metastatic breast cancer. Clin Chem 2014, 60:1290-7.

8. Islam S, Kjällquist U, Moliner A, Zajac P, Fan J-B, Lönnerberg P, Linnarsson S: Highly multiplexed and strand-specific single-cell RNA 5' end sequencing. Nat Protoc 2012, 7:813-28. 
9. Swennenhuis JF, Reumers J, Thys K, Aerssens J, Terstappen LW: Efficiency of whole genome amplification of single circulating tumor cells enriched by CellSearch and sorted by FACS. Genome Med 2013, 5:106.

10. Huang L, Ma F, Chapman A, Lu S, Xie XS: Single-Cell Whole-Genome Amplification and Sequencing: Methodology and Applications. Annu Rev Genomics Hum Genet 2015.

11. Hou Y, Wu K, Shi X, Li F, Song L, Wu H, Dean M, Li G, Tsang S, Jiang R, Zhang X, Li B, Liu G, Bedekar N, Lu N, Xie G, Liang H, Chang L, Wang T, Chen J, Li Y, Zhang X, Yang H, $\mathrm{Xu} \mathrm{X}$, Wang L, Wang J: Comparison of variations detection between whole-genome amplification methods used in single-cell resequencing. Gigascience 2015, 4:37.

12. de Bourcy CFA, De Vlaminck I, Kanbar JN, Wang J, Gawad C, Quake SR: A quantitative comparison of single-cell whole genome amplification methods. PLoS One 2014, 9:e105585.

13. Gawad C, Koh W, Quake SR: Single-cell genome sequencing: current state of the science. Nat Rev Genet 2016, advance on.

14. Paez JG, Lin M, Beroukhim R, Lee JC, Zhao X, Richter DJ, Gabriel S, Herman P, Sasaki H, Altshuler D, Li C, Meyerson M, Sellers WR: Genome coverage and sequence fidelity of phi29 polymerase-based multiple strand displacement whole genome amplification. Nucleic Acids Res 2004, 32:e71.

15. Grün D, van Oudenaarden A: Design and Analysis of Single-Cell Sequencing Experiments. Cell 2015, 163:799-810. 
CHAPTER 4: WGA METHODS 


\section{CHAPTER 5: QUALITY CONTROL ON SINGLE CELL WHOLE GENOME AMPLIFICATION PRODUCTS}

Authors: Joost F Swennenhuis, Leon WMM Terstappen

Published in: Not published

Running title: WGA quality control

Abstract

Single cell Whole Genome Amplification (WGA) is a method sensitive for input DNA quality and contamination. The procedure to get the single cells is often labourous and more important the downstream processes, like next gen sequencing, are often also long and expensive. Various measurescan be taken to check the quality of these WGA reactions during and after the procedure. This review will categorize and discuss the various methods that are used and will discuss the applicability of the quality control tests for downstream analysis.

\subsection{Introduction:}

DNA isolated from single cells can be used in a single PCR reaction to investigate the presence of a specific sequence. Such reactions can, after optimization be multiplexed but after doing the reaction no sample is left. For more comprehensive DNA analysis single cells do not contain enough DNA and the DNA needs to be amplified using a WGA reaction. The different WGA methods have been discussed in chapter 7 of this thesis. The quality of the products of whole genome amplification of single or low 
numbers of CTC's can vary due to several factors. First of all the quality and quantity of input material is not always stable. CTC's can be in apoptosis during which DNA is fragmented, or can be in the S or G2 phase of mitosis, where double amount of DNA is present. Another factor of influence of the final WGA product quality is the state of fixation of the CTC's. It is often necessary to use some kind of fixation to be able to reliably isolate the fragile rare cells from blood. The tougher the cells are fixed the lower the quality of the DNA. Fixation will cause DNA breaks and could cause difficulties in releasing the DNA from protein complexes, both having a negative effect on all different WGA procedures. The downstream DNA analysis applications are often labor intensive and expensive. Therefore the quality analysis of the WGA products is a very important step. Often there are multiple cells from a single patient that are amplified and depending on the downstream application not all WGA products can be analyzed because of time or costs.

Ideally the quality control should give information on the completeness of the copied genome including the regional bias of the amplification and the presence of both alleles. Since a quality control might be necessary on a lot of samples for one patient it is also necessary that it is not labor intensive or expensive. Best would be to combine some global and easy to apply checks with a more detailed and specific quality control where necessary. In this chapter an overview is given of global and specific quality control methods that are used on single cell WGA products.

\subsubsection{Global quality control.}

If the cell isolation method allows it, before starting WGA, a selection can be made based on cell and nuclear morphology. Large, regular stained cells have the highest success rate in downstream analysis. Large uneven stained or irregular shaped cells have a lower success rate in downstream applications and smaller cells even lower[1]. In practice there are in most patient samples a very low number of CTC so this would only apply if there are enough cells available. If there are enough cells and a selection is made one has to keep in mind that this might also select for CTC subgroups.

There are three global quality checks that can be done during or after WGA reactions. First, it is possible to monitor the amplification reactions in real-time. This can be done by adding Evagreen to the WGA mix and to run the amplification reaction on a real time PCR machine. Evagreen is a dye that fluoresces when bound to doublestranded DNA. This makes it possible to compare the different single cell reactions. A variation in starting material will result in a different $\mathrm{Ct}$ value. It will be possible to exclude the reactions that amplify too early or too late, indicating there is more or less than a single amplifiable genome in the reaction. Second, the amplification products 
could be run on a gel to exclude aberrant products and a third is that the concentration of the product can be measured after amplification. The latter two have as a downside that sometimes, depending on the kit, the negative or poor reactions also have a high DNA concentration after WGA. This is not an artifact or false positive, all WGA reactions will find in the end some DNA to amplify. The enzymes, other kit components or lab materials could have trace amounts of DNA which are then amplified. These trace amounts are in general so low that a single cell already provides large excess of target DNA so that it will not influence downstream analysis.

\subsubsection{Specific quality control}

To get more specific information about the amplified sequences a PCR can be done. To reduce costs and time multiple sequences can be analyzed at once by doing a multiplex PCR and subsequent analysis of the product on a gel. Several different PCR's have been developed and are used for this purpose. Below an overview of the most used quality control tests done on WGA products.

\subsubsection{16 plex STR test}

Kroneis et al shows the use of a commercial 16 plex Short Tandem Repeat (STR) kit (Promega Powerplex 16 system, Cat. DC6531) to check for quality[2]. This method allows identification of the cells to come from the intended patient since each individual has a specific set of STR fragment lengths. Also the Allele dropout (ADO) can be estimated by comparing the number of heterozygous loci that were found with the number of heterozygous loci of reference DNA of the patient. Disadvantage of this method is that a capillary analyzer is needed to be able to separate the short fragments.

\subsubsection{6-plex PCR}

A multiplex PCR with primers is designed by Knijnenburg et al [3] on 6 targets. Although this test is not developed for the Ampli-1 kit, 5 of 6 sequences that are used do not contain an MseI restriction site and one does. A good amplification therefore shows 5 bands and if the 6th band is visible it indicates that the restriction enzyme MseI did not work properly. Table 5.1 shows genes, genomic location, Msel fragmentand amplicon size of this multiplex PCR. The protocol can be found in the supplementary protocols of this thesis. 


\begin{tabular}{llll}
\hline Gene & $\begin{array}{l}\text { Genomic } \\
\text { location }\end{array}$ & $\begin{array}{l}\text { Original } \\
\text { MseI frag. }\end{array}$ & $\begin{array}{l}\text { PCR } \\
\text { Prod. Size (bps) }\end{array}$ \\
\hline DNAH9 & $17 \mathrm{p} 12$ & 625 & 401 \\
\hline PICK1 & $22 \mathrm{q} 13$ & 1111 & 358 \\
\hline NEK9 & $14 \mathrm{q} 24$ & 490 & 288 \\
\hline GRIK5 & $19 \mathrm{q} 13$ & 2520 & 222 \\
\hline CADPS & $3 \mathrm{p} 14$ & $717^{*}$ & 175 \\
\hline LAMC1 & $1 \mathrm{q} 31$ & 171 & 111 \\
\hline
\end{tabular}

Table 5.1. Details of the multiplex PCR with primers developed by Knijnenburg et al. First and second column show the targeted gene and the gene location. Third column shows the size of the MseI fragment as used in the AMpli- 1 kit. Fourth column gives the amplicon size. ${ }^{*}$ The original MseI fragment contains a MseI restriction site.

The MseI fragment size is important if this QC is used for the Ampli-1 kit where this enzyme is used for DNA fragmentation. For array CGH it is determined that Ampli-1 WGA samples qualify when three or more bands of this PCR are visible $[4,5]$. Figure 5.1 shows an example of a gel with different treated DNA samples during Ampli-1 WGA.

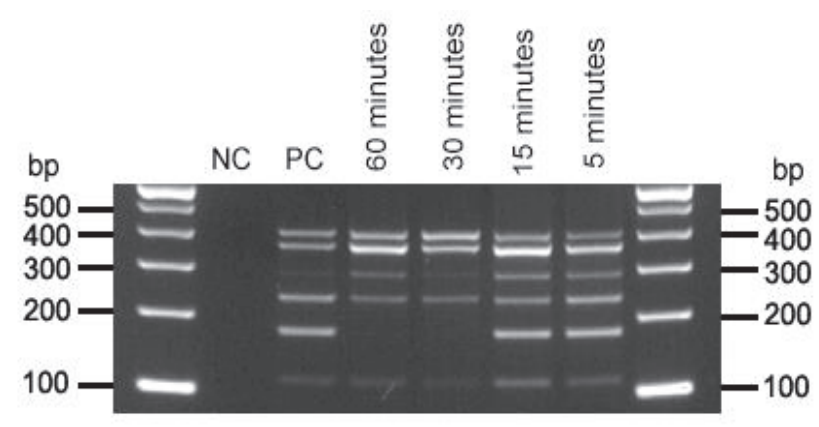

Figure 5.1. Example of a multiplex PCR with primers designed by Knijnenburg et al. on an Ampli-1 WGA product. Left the $100 \mathrm{bp}, \mathrm{NC}=$ negative control (water), $\mathrm{PC}=7.76 \mathrm{ng}$ LNCaP DNA, 603015 and 5 minutes = time MseI digestion within normal Ampli-1 procedure. Positive control shows the six expected products. The two longest digestion times miss the $175 \mathrm{bp}$ band indicating an effective restriction for this site. Picture provided by Lisa Oomens (MCBP).

\subsubsection{Ampli-I QC kit (Silicon Biosystems):}

Polzer et al. describe the development and evaluation of two QC procedures for Ampli1 amplified CellSearch cells [1]. The QC tests were tested on 507 amplified cells and predict the performance of the WGA products on qPCR assays and array CGH. Three 
singleplex PCR's and a 4-multiplex PCR show high concordance and both predict the performance. The multiplex PCR is commercially available at Silicon Biosystems.

\subsection{Quality monitoring methods developed at MCBP}

\subsubsection{Real time monitoring of WGA reactions}

To be able to monitor WGA reactions in real time a 40x dilution of Evagreen (Biotium cat.31000-T) was added to the reaction mixes. This resulted in all cases in an amplification profile of the single cells versus the multi-cell samples and no template controls as shown in figure 5.2. In most cases the single cell profiles (red) were separated from the multi-cell samples and the no-template controls.
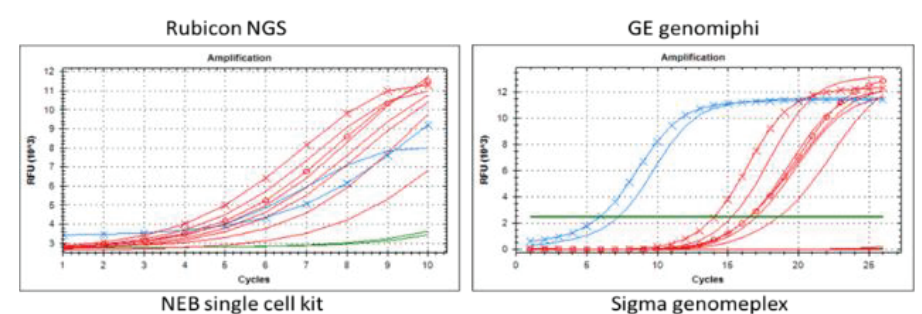

/ 50 cells

/ Single cells

Neg ctlr

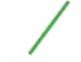

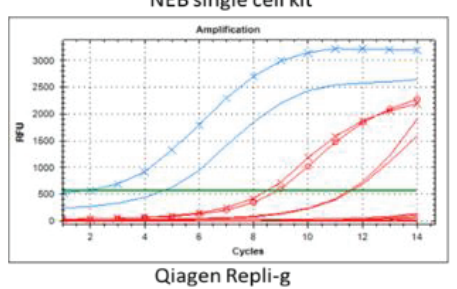
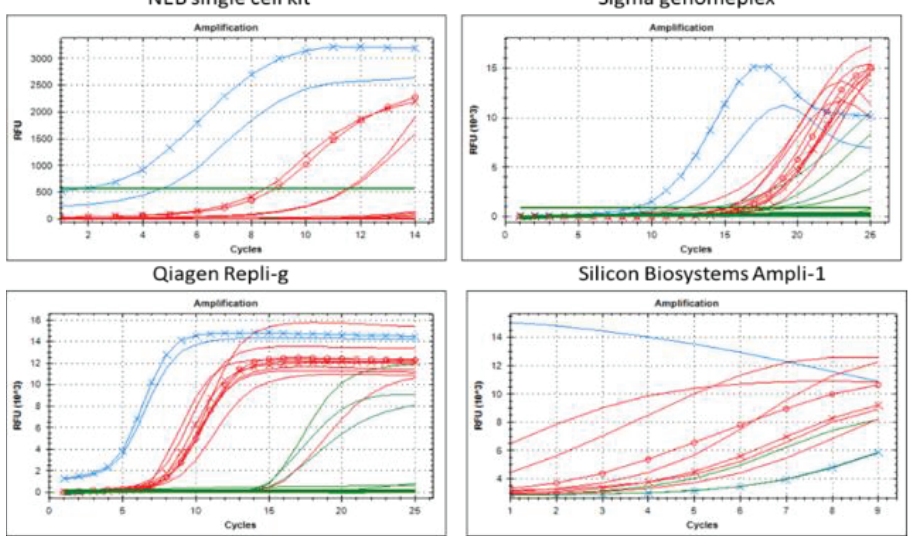

Figure 5.2: Real time monitoring of single cell WGA reactions. Controls in every reaction are samples with 50 cells (Blue lines) and negative (no template) reactions (Green lines). The red lines are single cell samples. Detailed protocol is described in the supplementary protocols of this thesis. 


\subsubsection{0 plex PCR}

At MCBP a 10 plex PCR was developed to get information on more genes in a single reaction. This test was designed on genomic areas on 10 different chromosomes. As targets, regions within reference genes were selected because these are less likely to be amplified or deleted in cancer cells than cancer related genes. The amplicon sizes range from $100 \mathrm{bp}$ to 1100 and are designed on MseI restriction fragments of $200 \mathrm{bp}$ to $4000 \mathrm{bp}$ which correspond to the amplicon size (see table 5.2 below). This makes the multiplex PCR also suitable for the Ampli-1 kit.

\begin{tabular}{llll}
\hline Gene & $\begin{array}{l}\text { Genomic } \\
\text { location }\end{array}$ & $\begin{array}{l}\text { Original } \\
\text { MseI frag. }\end{array}$ & $\begin{array}{l}\text { PCR Prod. } \\
\text { Size (bps) }\end{array}$ \\
\hline CUX1 & $7 q 22$ & 3434 & 1009 \\
\hline SCYL1 & $11 q 13$ & 2050 & 900 \\
\hline PPP5C & $19 q 13$ & 1292 & 800 \\
\hline JMJD6 & $17 q 25$ & $1592^{* *}$ & 720 \\
\hline ACTR10 & $14 q 23$ & $1840^{*}$ & 606 \\
\hline ROCK2 & $2 \mathrm{p} 24$ & 934 & 498 \\
\hline SCAP & $3 \mathrm{p} 21$ & 706 & 397 \\
\hline SCAMP3 & $1 \mathrm{q} 21$ & 500 & 301 \\
\hline SCARB2 & $4 \mathrm{q} 21$ & 300 & 197 \\
\hline XP0T & $12 \mathrm{q} 14$ & 172 & 94 \\
\hline
\end{tabular}

Table 5.2. Details of the multiplex PCR developed at MCBP. First and second column show the targeted gene and the gene location. Third column shows the size of the Msel fragment as used in the Ampli-1 kit. Fourth column gives the amplicon size. *The original MseI fragment contains one MseI restriction site. ${ }^{* *}$ The original MseI fragment contains two MseI restriction sites

For the quality control multiplex PCR reaction the Qiagen MP PCR kit is used. The protocol is developed but the validation of the test is still ongoing by collecting data of more single cell WGA reactions. Figure 5.3 (left) shows the 10 gene QC on Qiagen Repli-g amplified material. All ten bands are visible before and after WGA. In the last three lanes a small variation in band intensity is visible between the samples which were amplified from 10 MCF-7 cells each showing a small variation in the WGA. It can be expected that this variation becomes larger when single cells or low quality DNA is used. The right side of figure 5.3 shows the multiplex PCR done on Ampli-1 amplified material. While the positive controls show 10 bands, the Ampli-1 amplified products 
show at most 7 bands. Two bands are not visible because of the restriction digestion by MseI but also the largest band which comes from a $3434 \mathrm{bp}$ Msel fragment is not visible. Since this band is amplified in the positive controls (two lanes right on the right side of the ladder) this shows that the largest fragment was not properly amplified in the WGA reaction.

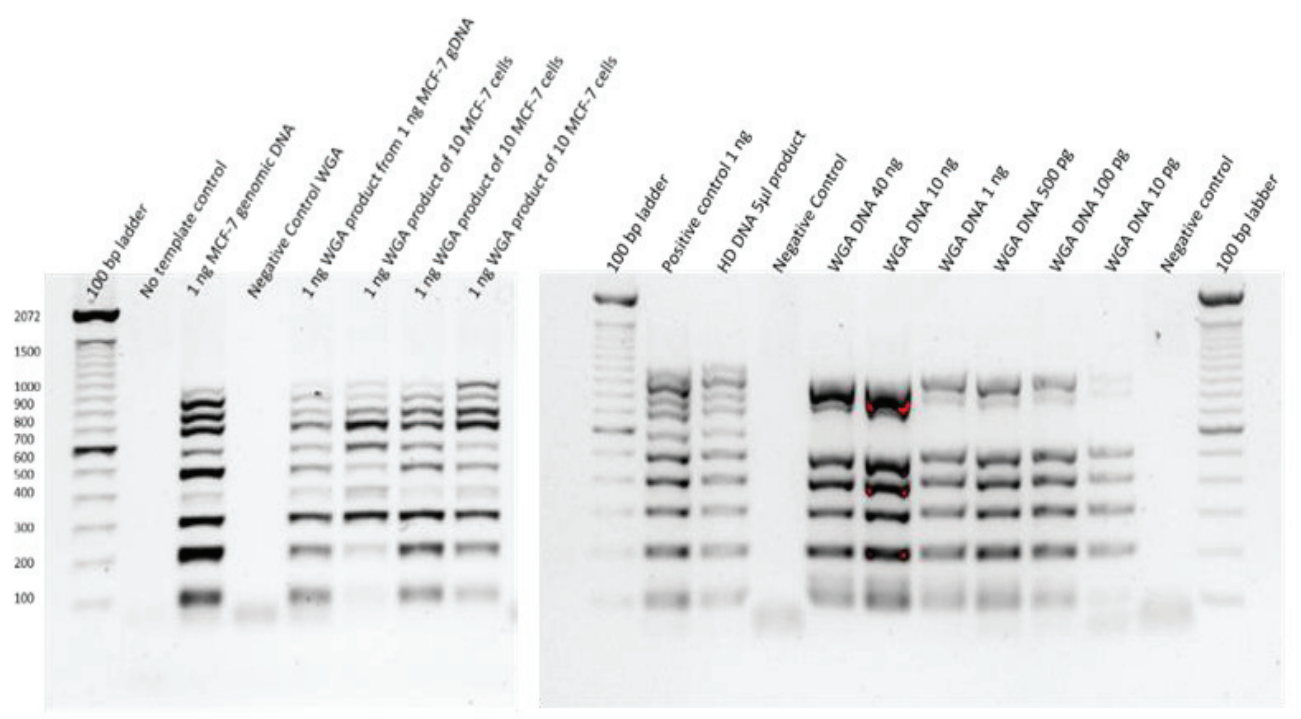

Figure 5.3. 10 gene multiplex QC on Qiagen Repli-g amplified genomic DNA (left) and Ampli-1 amplified genomic DNA (Right).

\subsubsection{0 gene qPCR QC}

A qPCR could provide additional quantitative information about specific sequences, releasing information on the uniformity of the amplification. For this purpose a qPCR was developed on 10 genes. For this qPCR test, ten frequently amplified or deleted cancer related gene regions were used. This was done to be able to detect these aberrancies in patient samples as well as in cell lines. This quantification could be very useful while optimizing the WGA procedure, it will give a measure of the homogeneity of amplification. The downside of a qPCR is that all reactions must be done separately and that the number of reactions will become very high if multiple products have to be screened. Next to the separate PCR's the WGA products do also have to be purified and measured before. Table 5.3 gives the result of this qPCR assay used on WGA material amplified with different kits starting from 50 cells and single cells. The protocol that was used is given in the supplementary protocols of this thesis. All amplifications that 
crossed that threshold were indicated green and the ones that failed to amplify were indicated red. The two yellow boxes at the Ampli-1 kit single cell amplification reaction are negative but should be negative because both contain an Msel restriction site. For this kit this is an indication that the restriction digestion was complete.

\begin{tabular}{|c|c|c|c|c|c|c|c|c|c|c|c|c|c|c|c|c|c|c|c|}
\hline \multirow[b]{2}{*}{ Gene } & \multicolumn{2}{|c|}{ S.B. Ampli 1 kit } & \multicolumn{3}{|c|}{ Rubicon NGS trial kit } & \multicolumn{3}{|c|}{ GE GenomiPhi kit } & \multicolumn{3}{|c|}{ NEB single cell WGA kit } & \multicolumn{3}{|c|}{ Sigma GenomePlex } & \multicolumn{3}{|c|}{ Qiagen RepliG } & \multicolumn{2}{|c|}{ gDNA } \\
\hline & 50Cells & 1 cells & 50 Cells & 1 cell & 1 cell & 50Cells & 1 cell & 1 cell & 50Cells & 1 cell & 1 cell & 50Cells & 1 cell & 1 cell & 50Cells & 1 cell & 1 cell & $100 \mathrm{pg}$ & $100 \mathrm{pg}$ \\
\hline ERBB2 & 28,2 & 16,3 & 22,6 & 18,9 & 19,6 & 25,4 & 33,1 & 26,1 & 20,3 & 19,2 & 17,7 & 20,8 & 18,6 & 18,6 & 26,0 & 26,7 & 35,1 & 18,3 & 16,4 \\
\hline CCND1 & 32,9 & 17,7 & $\mathrm{x}$ & 25,0 & 28,0 & 36,4 & $\mathrm{x}$ & $\mathrm{x}$ & 26,7 & $\mathrm{x}$ & 27,4 & 28,7 & $\mathrm{x}$ & $\mathrm{x}$ & $\mathrm{x}$ & $\mathrm{x}$ & 35,4 & 22,3 & 22,8 \\
\hline MYC & 31,2 & $\mathrm{x}$ & 23,0 & 20,1 & 18,1 & 26,5 & 42,4 & $\mathrm{x}$ & 18,4 & 17,9 & 14,5 & 19,3 & 21,2 & 21,0 & 27,0 & 33,0 & 33,9 & 18,4 & 17,2 \\
\hline PRMT2 & 32,4 & $\mathrm{x}$ & 28,3 & $\mathrm{x}$ & 28,5 & 29,5 & $\mathrm{x}$ & 34,0 & $\mathrm{x}$ & $\mathrm{x}$ & $\mathrm{x}$ & 25,4 & $\mathrm{x}$ & $\mathrm{x}$ & 33,1 & $\mathrm{x}$ & $\mathrm{x}$ & 22,9 & 20,2 \\
\hline URB2 & 30,5 & 17,0 & 25,4 & 25,0 & 23,9 & $\mathrm{x}$ & 33,7 & 31,9 & 24,6 & 34,1 & 29,8 & 22,8 & 22,4 & 29,0 & 30,5 & $\mathrm{x}$ & $\mathrm{x}$ & 22,8 & 21,2 \\
\hline FGFR1 & 36,2 & 29,1 & 26,4 & 20,8 & 19,9 & 31,7 & $\mathrm{x}$ & $\mathrm{x}$ & 20,7 & 18,7 & 17,9 & 26,2 & 42,0 & 28,3 & 35,5 & 48,9 & 47,6 & 25,7 & 23,4 \\
\hline P53 & 28,8 & 30,4 & 30,9 & 26,8 & 25,6 & 31,4 & 37,2 & 36,0 & 30,3 & 22,4 & 26,0 & 34,6 & 29,1 & 39,1 & 37,2 & 30,4 & $\mathrm{x}$ & 24,7 & 21,9 \\
\hline MUC1 & 34,1 & 27,0 & 32,4 & 21,4 & 20,2 & 34,9 & 39,1 & $\mathrm{x}$ & 20,9 & 20,3 & 19,3 & 26,2 & 25,0 & 22,8 & 37,0 & 43,4 & $\mathrm{x}$ & 24,2 & 22,2 \\
\hline TRAM & 31,9 & 17,2 & 20,4 & 19,2 & 20,8 & 26,0 & 33,4 & 32,2 & 18,7 & 20,0 & 25,1 & 19,6 & 18,9 & 19,1 & 23,1 & $\mathrm{x}$ & 29,5 & 21,5 & 18,2 \\
\hline PAK1 & 31,4 & 25,8 & 27,0 & 24,2 & 24,8 & 26,2 & 41,8 & 26,7 & 23,6 & 23,2 & 22,9 & 23,0 & 22,6 & $\mathrm{x}$ & 30,6 & 35,9 & 36,3 & 22,2 & 20,3 \\
\hline
\end{tabular}

Table 5.3. Ct values of the 10 gene qPCR test on DNA from 50 and single cells amplified with 6 different WGA kits. The $\mathrm{x}$ values did not cross the threshold value and were considered negative. The red color indicates low $\mathrm{Ct}$ value and the green a low $\mathrm{Ct}$ value. The $\mathrm{x}$ values at the single cell DNA from the ampli-1 kit should be negative because of an MseI restriction site in the amplicon.

\subsubsection{5 plex STS PCR}

Sigma Aldrich has a multiplex PCR test with the purpose for assessing the quality of DNA isolated from FFPE or other sources of damaged DNA. The tests consists of five STS (Sequence Tagged Site) primer pairs. A STS is a sequence in the DNA from which sequence and position in the genome is exactly known. This multiplex PCR is optimized for testing on Qiagen Repli-G and Sigma GenomiPhi samples and has not been tested on other kits. Figure 5.4 shows the 5 bands of this PCR on a $2 \%$ agarose gel. 


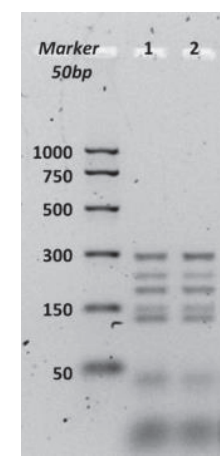

Figure 5.4. 5 plex STS multiplex PCR products on a $2 \%$ agarose gel. The five specific bands are visible from 132 to $300 \mathrm{bp}$. Below $50 \mathrm{bp}$ a dim band with primer-dimers is visible and below that the primer residue. Picture by Sanne de Wit.

\begin{tabular}{llll}
\hline Chr. & STS & $\begin{array}{l}\text { Ampl. } \\
\text { size (bp) }\end{array}$ & $\begin{array}{l}\text { Recommended } \\
\text { Primer } \\
\text { concentration }\end{array}$ \\
\hline $\mathbf{1 3}$ & SHGC105883 & 295 & $500 \mathrm{nM}$ \\
\hline $\mathbf{1 2}$ & SHGC147491 & 235 & $500 \mathrm{nM}$ \\
\hline $\mathbf{2}$ & CSNPHARP & 196 & $500 \mathrm{nM}$ \\
\hline $\mathbf{4}$ & STB39J12.SP6 & 132 & $500 \mathrm{nM}$ \\
\hline $\mathbf{2 2}$ & G50529 & 150 & $500 \mathrm{nM}$ \\
\hline
\end{tabular}

Table 5.4. STS name, location amplicon size and primer concentration of the STS 5plex PCR QC test.

\subsection{Discussion}

Several publications have already shown the usability and benefit of a multiplex PCR to determine the quality of a WGA product for specific downstream applications.[1, 2, $4,5]$ If a lot of reactions need to be tested it would be good to be able to test on the raw WGA product. Cleaning of the products is expensive and time consuming and it would be best if this can be limited to the higher quality samples that will be analyzed downstream. The 6 plex PCR and the Ampli-1 QC kit can be done on raw WGA products. The other mpPCR tests were not yet tested or optimized for raw products which might be useful to optimize and implement when many samples need to be tested. 
As a quality control of a WGA it would be best to have a procedure that takes as little time and effort as possible. Therefore it would be useful to evaluate the real-time monitoring of the WGA reactions. It seems reasonable that the better and more complete the DNA, the earlier the DNA will cross the threshold and that multiple cells will cross the threshold earlier. It will not take any extra time or effort and the analysis is fast and easy. Disadvantage is that the laboratory needs to have a qPCR machine with real-time capability and also in the reaction size of the kit. To be able to evaluate this real time monitoring it will need to be incorporated in a study where CGH or NGS is done on the products in combination with a regular approved QC method.

\subsection{References}

1. Polzer B, Medoro G, Pasch S, Fontana F, Zorzino L, Pestka A, Andergassen U, MeierStiegen F, Czyz ZT, Alberter B, Treitschke S, Schamberger T, Sergio M, Bregola G, Doffini A, Gianni S, Calanca A, Signorini G, Bolognesi C, Hartmann A, Fasching PA, Sandri MT, Rack B, Fehm T, Giorgini G, Manaresi N, Klein CA: Molecular profiling of single circulating tumor cells with diagnostic intention. EMBO Mol Med 2014, 6:137186.

2. Kroneis T, Geigl JB, El-Heliebi A, Auer M, Ulz P, Schwarzbraun T, Dohr G, Sedlmayr P: Combined molecular genetic and cytogenetic analysis from single cells after isothermal whole-genome amplification. Clin Chem 2011, 57:1032-41.

3. Knijnenburg J, van der Burg M, Tanke HJ, Szuhai K: Optimized amplification and fluorescent labeling of small cell samples for genomic array-CGH. Cytometry A 2007, 71:585-91.

4. Neves RPL, Raba K, Schmidt O, Honisch E, Meier-Stiegen F, Behrens B, Möhlendick B, Fehm T, Neubauer H, Klein CA, Polzer B, Sproll C, Fischer JC, Niederacher D, Stoecklein $\mathrm{NH}$ : Genomic high-resolution profiling of single CKpos/CD45neg flow-sorting purified circulating tumor cells from patients with metastatic breast cancer. Clin Chem 2014, 60:1290-7.

5. Möhlendick B, Bartenhagen C, Behrens B, Honisch E, Raba K, Knoefel WT, Stoecklein $\mathrm{NH}$ : A robust method to analyze copy number alterations of less than $100 \mathrm{~kb}$ in single cells using oligonucleotide array CGH. PLoS One 2013, 8:e67031. 


\section{CHAPTER 6: EFFICIENCY OF WHOLE GENOME AMPLIFICATION OF SINGLE CIRCULATING TUMOR CELLS ENRICHED BY CELLSEARCH AND SORTED BY FACS}

Joost F Swennenhuis a, Joke Reumers ${ }^{b}$, Kim Thys $^{\mathrm{b}}$, Jeroen Aerssens ${ }^{\mathrm{b}}$, Leon WMM Terstappen $^{\mathrm{a}}$

a Medical Cell BioPhysics, Faculty of Science and Technology, University of Twente, Enschede, The Netherlands.

b Janssen Research \& Development, Janssen Pharmaceutical Companies of Johnson \& Johnson, Beerse, Belgium.

Published in: Genome Medicine, doi:10.1186/gm510, 5:106, 2013.

Running title: Single cell Whole Genome Amplification.

Abstract

Background, Tumor cells in the blood of patients suffering from metastatic carcinomas are associated with poor survival. Knowledge of the cells' genetic make-up can help to guide targeted therapy. In this study we evaluate the efficiency and quality, of isolation and amplification, of DNA from single CTC; Methods, The efficiency of the procedure is determined by spiking blood with SKBR-3 cells, enrichment with the CellSearch system followed by single cell sorting by FACS and Whole Genome Amplification. A selection of single cell DNA from fixed and unfixed SKBR-3 cells is exome sequenced and the DNA quality is analyzed. Single CTC's from lung cancer patients are used to demonstrate the potential of single CTC molecular 
characterization; Results, The overall efficiency of the procedure from spiked cell to amplified DNA was $\sim 20 \%$. Losses attributed to the CellSearch system were about $20 \%$, transfer to FACS $\sim 25 \%$, sorting $\sim 5 \%$ and DNA amplification $\sim 25 \%$. Exome sequencing revealed that the quality of the DNA is affected by the fixation of the cells, the amplification and the low starting quantity of DNA. A single fixed cell has an average coverage at $20 x d$ epth of $30 \%$ when sequencing to an average of $40 x d e p$ th, whereas a single unfixed cell has a $45 \%$ coverage. Genomiphi-amplified genomic DNA has a coverage of $72 \%$ versus a coverage of $87 \%$ of genomic DNA. $21 \%$ of the CTC from lung cancer patients identified by the CellSearch system could be isolated individually and amplified; Conclusions, CTC's enriched by the CellSearch system can be sorted by FACS, and DNA retrieved and amplified with an overall efficiency of $20 \%$. Analysis of the sequencing data shows that this DNA can be used for variant calling, but not for quantitative measurements such as copy number detection. Close to $55 \%$ of the exome of single SKBR-3 cells can be successfully sequenced to 20x depth making it possible to call $72 \%$ of the variants. The overall coverage is reduced to $30 \%$ at $20 x$ depth making it possible to call $56 \%$ of the variants in CellSave fixed cells.

\subsection{Introduction}

Treatment options for patients with metastatic carcinomas are increasing rapidly and create a concomitant need for companion diagnostics to establish the therapy that is most likely to be effective. For a targeted therapy to be effective, its target needs to be present in the tumor cells. However, both within and between patients, the cancer cells are heterogeneous forcing the need for individual characterization of the tumor cells. Moreover, during the course of the disease resistance to the therapy can develop and a timely detection and search for alternative therapies is desirable. Tumor biopsies are difficult if not impossible to obtain at the time a new line of therapy is indicated. Tumor cells from solid tumors are shed into the circulation and these circulating tumor cells (CTC) may serve as a liquid biopsy to guide therapy. The presence and load of CTC in patients with metastatic carcinomas is associated with poor survival [1-5] and treatment targets can be assessed on CTC [6-9]. However the frequency of CTC is extremely low $[10,11]$ making it quite challenging to obtain a sufficient number of CTC's to evaluate all potential treatment targets. The ability to isolate and amplify DNA from the individual CTC's would overcome some of these challenges. In this paper we evaluate the feasibility of DNA amplification after FACS sorting of CTC obtained by what is currently the only clinically validated system for CTC enumeration [12] . 


\subsection{Methods}

\subsubsection{Patient and control samples}

$10 \mathrm{ml}$ of blood is drawn in a CellSave (Veridex LLC, Raritan, NJ) or EDTA (BD, Franklin Lanes, NJ) evacuated blood draw tubes from healthy volunteers and 10 patients with metastatic small cell lung cancer (SCLC) or metastatic non small cell lung cancer (NSCLC). Healthy volunteers aged 20-55 provided informed consent prior to donating blood under a study protocol approved by the Ethics Committee (METC Twente). All patients consented to provide blood for the study and approved by the ethics review committee from University Medical Center Groningen, The Netherlands.

\subsubsection{CTC identification and preparation for cell sorting}

Aliquots of $7.5 \mathrm{ml}$ of blood are processed on a CellTracks Autoprep using the CellSearch Circulating Tumor cell kit (Veridex LLC) [12]. The enriched cells are fluorescently labeled with the nucleic acid dye DAPI and the monoclonal antibodies directed against CD45 fluorescently labeled with APC and directed against cytokeratins labeled with PE. For CTC enumeration, the cartridges are placed on a CellTracks Analyzer II or CellSpotter for image acquisition and image review (Veridex LLC) $[11,12]$. After scanning, the cartridges are stored at $4^{\circ} \mathrm{C}$ for a maximum of 24 hours before further processing. The content of the cartridge is transferred to a $12 \mathrm{x}$ $35 \mathrm{~mm}$ flowtube and washed twice with $200 \mu \mathrm{l}$ dilution buffer to ensure removal of the majority of cells from the cartridge. To assure sufficient fluorescent nucleic acid signals, $2 \mu \mathrm{g} / \mathrm{ml}$ Hoechst 33342 (Mol Probes, Eugene, OR cat. H3570) is added for 15 minutes at $37^{\circ} \mathrm{C}$ prior to cell sorting. In addition, $2 * 104$ beads (BDBiosciences, cat. 345249) are added to ensure correct instrument settings and to serve as negative controls for cell sorting and DNA amplification.

\subsubsection{Single cell sorting}

A FACSARIA II (BD Biosciences, Jan Jose, CA) equipped with a $375 \mathrm{~nm}$, 488nm and $633 \mathrm{~nm}$ laser and single cell deposit unit was used for single CTC sorting. Cells were sorted into 384 well plates (BioRad, Hercules, US, Cat HSP3805). The instrument was calibrated using CS\&T beads (Beckton Dickinson, Franklin Lanes, cat. 641412) before use. Before sorting, the sort gates and the number of cells and beads to be sorted into the 384 wells were set. For single cell sorting, 20 beads were also sorted into the well. To serve as positive and negative controls for DNA amplification, for each patient, 10 single leukocytes (CD45+,Hoechst+), 5 wells with 20 beads were sorted and 5 wells 
were left empty. Wells that have DNA amplification initiation within 95 minutes are regared as positive.

A

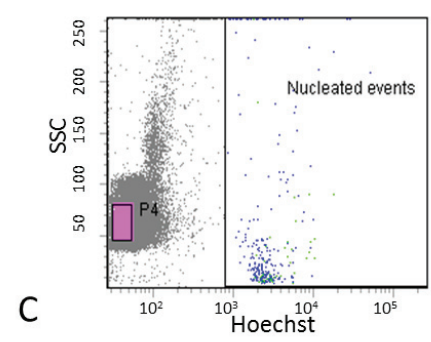

$\mathrm{E}$

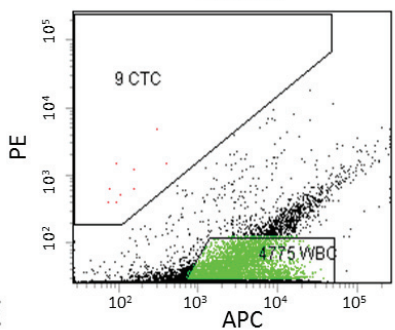

G
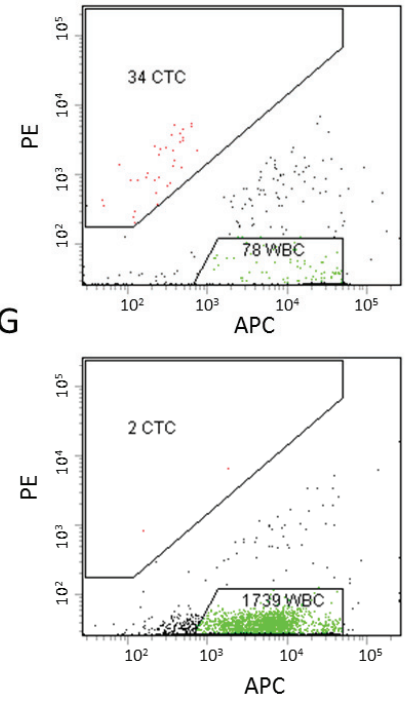

B
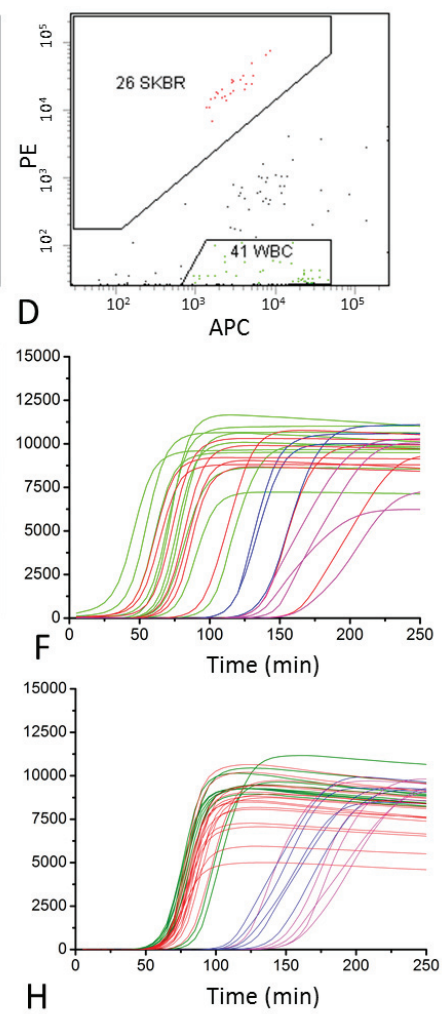

$\mathrm{H}$

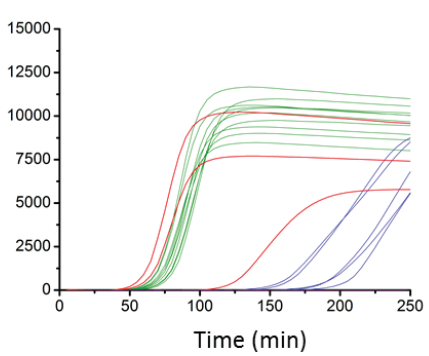

Figure 6.1. Flowcytometric analysis of CellSearch-enriched CTC and real-time PCR of singlesorted leukocytes and CTC. Panels A and B show the sort gates to identify and sort single CTC, single leukocytes and beads. Panels C (table 6.1, patient 7), E (table 6.1, patient 1 ) and G (table 6.1, patient 2) show the analysis and sort gates of three lung cancer patients and in Panels D, E and $\mathrm{F}$ the corresponding realtime DNA amplification of the individual sorted cells. The curves show the Evagreen fluorescence of the WGA reaction mixes in time. 


\subsubsection{Efficiency of DNA amplification}

Cells from the breast cancer cell line SKBR-3 were used to monitor the individual amplification reactions of both single and multiple cells compared to the amplification of background DNA. After trypsinization, the cells were suspended in $9 \mathrm{ml}$ of culture medium (DMEM, Sigma,D5796), 1\% Pen/strep (Sigma Aldrich, St Louis, US, cat. P4333), 2mM L-Glutamin (Sigma Aldrich, St Louis, US, cat.G7513), 10\%FCS (Sigma Aldrich, St Louis, US, cat. F4135). This suspension is transferred to a CellSave tube and left for 24 hours. $1 \mathrm{ml}$ of this suspension was stained with $2 \mu \mathrm{g} / \mathrm{ml}$ Hoechst 33342 (Invitrogen, Grand Island, US, cat. H3570) for 15 minutes at $37^{\circ} \mathrm{C} .2^{*} 104$ beads (BD, Franklin Lakes, US, cat. 345249) are added to the cells and 100, 10, 1, 0 SKBR-3 cells and 20 beads were sorted into a 384 well plate. Five experiments were performed for each spike level except for the single cells of which 10 were performed. After sorting, the wells are treated with proteinase K by incubating with $1 \mu \mathrm{l} 0.625 \%$ ProtK (Sigma Aldrich, St Louis, US, cat. P4850) in $10 \mathrm{mM}$ Tris-HCl pH7.4 for 1 hour at $50^{\circ} \mathrm{C}$. Proteinase $\mathrm{K}$ is inactivated by incubating for 10 minutes at $96^{\circ} \mathrm{C}$. After this step, $5 \mu \mathrm{l}$ of an amplification mix containing Evagreen a dsDNA dye is added to each well. The amplification mix consists of components from the GE Illustra Genomiphi DNA amplification kit (GE, Waukesha, US, cat. 25-6600-31) combined with Evagreen to monitor the reaction. The composition of the mix for each well is $1.75 \mu$ l Sample buffer,

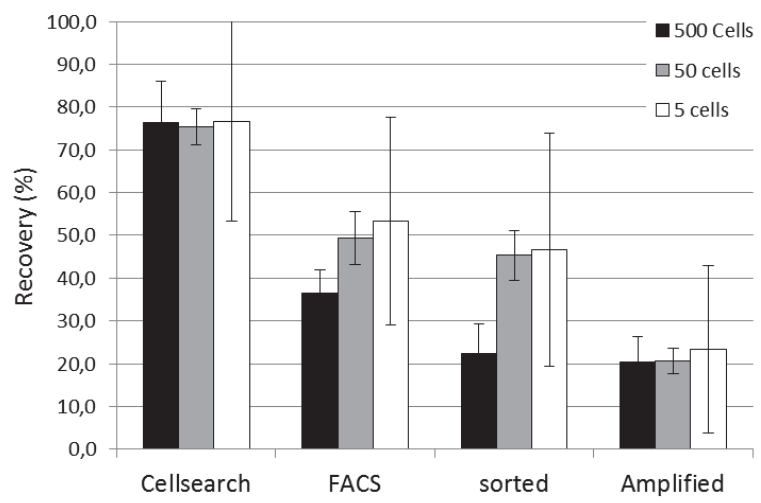

Figure 6.2. DNA amplification of 100 SKBR-3+20 beads (pink), 10 SKBR-3+20 beads (blue), 1 SKBR-3+ 20 beads (red), 20 beads (green), empty (black) sorted into a 384 well plate. Cells were lysed by treating for 1 hour at $50^{\circ} \mathrm{C}$ with $1 \mu \mathrm{l}$ protein $\mathrm{K}$ solution, 10 minutes inactivation at $96^{\circ} \mathrm{C}$ and cooled to $4^{\circ} \mathrm{C} .5 \mu \mathrm{l} \mathrm{WGA} \mathrm{mix} \mathrm{was} \mathrm{added} \mathrm{and} \mathrm{incubated} \mathrm{for} 250$ minutes at $30^{\circ} \mathrm{C}$ on a BioRad CFX 384 qPCR machine while measuring fluorescence every 5 minutes. The two arrows point to the amplification of two single cells that did not show any amplification.

2.25 $\mu$ l Reaction buffer, 0.25 Enzyme, 0.125 $\mu$ l Evagreen (Biotium, Hayward, US, cat. $31000), 0,625 \mu \mathrm{l} \mathrm{H} 20$. The plate is incubated for 250 minutes at $30^{\circ} \mathrm{C}$ in a BioRad CFX 
384 qPCR instrument while measuring the fluorescence every 5 minutes. After this, the Phi29 enzyme is inactivated for 10 minutes at $65^{\circ} \mathrm{C}$ and the plates are stored at $20^{\circ} \mathrm{C}$.

\subsubsection{Sample quality analysis of fixed cells, unfixed cells and isolated DNA by exome sequencing}

SKBR-3 cells are trypsinized and suspended in culture medium and the genomic DNA of these cells is isolated using the Promega Wizard SV genomic DNA purification system (cat A1120). The cells are stained with Hoechst 33342 and individually placed in a well of a 30 well epoxy-coated microscope slide (Menzel, Braunschweig, Germany, cat X1XER312B) using a micromanipulator (Eppendorf, Hamburg, Germany). Confirmation that the wells indeed contained a single cell was obtained by fluorescence microscopy. Control wells are filled with 50 cellsave fixed or 50 unfixed cells. Fixed cells are lysed by incubating with $1 \mu \mathrm{l}$ 0.625\% ProtK (Sigma Aldrich, St Louis, US, cat. P4850) in $10 \mathrm{mM}$ Tris-HCl pH7.4 for $1 \mathrm{~min}, 10 \mathrm{~min}, 30 \mathrm{~min}$ or 1 hour at $50^{\circ} \mathrm{C}$. Prot $\mathrm{K}$ is inactivated by incubating for 10 minutes at $96^{\circ} \mathrm{C}$. The unfixed cells are lysed by adding $1 \mu \mathrm{l}$ lysis buffer $(400 \mathrm{mM} \mathrm{KOH}, 25 \mathrm{mM}$ EDTA, $100 \mathrm{mM}$ Dithiotreitol) to the cells and are incubated 10 minutes on ice after which $1 \mu$ neutralization buffer $(0.4 \mu \mathrm{l} 1 \mathrm{M} \mathrm{HCl}+0.6 \mu \mathrm{l} 1 \mathrm{M}$ Tris $\mathrm{HCl}$ pH7.5, premixed) is added. DNA is amplified as described above except for the addition of evagreen. Samples are incubated for 2 hours at $30^{\circ} \mathrm{C}$ in a humidified chamber. Separately, $10 \mathrm{ng}$ of the genomic DNA is amplified in a tube in $5 \mu$ l amplification mixture. To obtain enough DNA for sequencing the initial amplifications samples are transferred to a vial and reamplified in a $100 \mu \mathrm{l}$ amplification mixture using the same kit and reagent composition for 2 hours at $30^{\circ} \mathrm{C}$. The final product is purified using the Qiagen PCR purification kit. Genomic DNA(1x), amplified genomic DNA(1x), amplified DNA of 50 cells(3x) and amplified DNA of single cells (7x) are used for Illumina sequencing (GAIIx).

\subsubsection{Exome Sequencing}

Exomes are captured using Illumina's TruSeq Exome Enrichment Kit. The TruSeq capture regions encompass $62 \mathrm{Mb}$, including 20,794 genes (201,121 exons). According to the RefGene definitions, $94.4 \%, 83.9 \%$ and $91.9 \%$ of the exonic regions, 5'UTR and 3'UTR respectively are included in the targeted capture. Pre-enrichment DNA libraries are constructed according to the standard protocol from Illumina's TruSeq DNA Sample Preparation Guide. A 200- to 300-bp band is gel-selected for each library and exome enrichment is performed according to Illumina's TruSeq Exome Enrichment Guide. Two rounds of biotinylated bait-based hybridizations are performed, followed by Streptavidin Magnetic Beads binding, a washing step and an elution step. A 10 - 
cycle PCR enrichment is performed after the second elution and the enriched libraries are subjected to Illumina sequencing (GAIIx). Libraries are denatured with sodium hydroxide and loaded onto an Illumina cBot for cluster generation according to the manufacturer's recommended protocols. Paired-end sequencing (2x75bp) is performed using TruSeq SBS kits. For each sample a single lane is used. BWA[13] is used to align the raw reads from each sequencing lane (in fastq format) to the human reference genome (NCBI37/hg19) using default parameters. Aligned reads are processed and sorted using SAMtools[14] and PCR duplicates are marked with Picard MarkDuplicates [15]. Base recalibration, local realignment around indels and single nucleotide variant calling are performed using the GenomeAnalysis ToolKit[16]. Basic statistics for coverage depth and variant composition are performed using the bedtools suite[17], vcftools[18] and custom Perl scripts.

\subsection{Results}

\subsubsection{Single cell sorting}

Figure 6.1 shows typical scatter plots from a flowcytometric measurement of the contents of a CellSearch cartridge after processing $7.5 \mathrm{ml}$ of blood spiked with 50 SKBR-3 cells. Panel A shows the DAPI/Hoechst staining and the gate to identify the beads is depicted in pink and the gate used to identify nucleated cells is also indicated. Panel B shows the CD45-APC staining versus the Cytokeratin-PE staining of the DAPI/Hoechst+ events. In this panel, the gates used to identify CTC (depicted in red) and leukocytes (depicted in green) are indicated. In this example 41 events are identified as CD45+, CK-, DAPI+ leukocytes and 26 events as CD45-, CK+, DAPI+ CTC. In this case, the CTC are the SKBR-3 cells that were spiked into the blood and 26 of the $50(52 \%)$ spiked SKBR-3 cells were recovered. The shape and position of the CTC gate are set such that as low as possible DAPI+ events appear in this gate when processing the blood of healthy donors while capturing as many as possible CTC from positive patient samples. Table S6.5 contains the results of 8 healthy control samples analysed with these settings after a CellSearch run. On average these samples have $1.6 \pm 1.1$ events in the CTC gate. In Panels C, E and G the CD45-APC,CK-PE scatterplots of 3 metastatic lung cancer patients are shown. A large variation in the number of CTC as well as the number of leukocytes in these samples can be observed. In addition, a population of CD45+,CK+, DAPI+ events can be observed between the leukocytes and the CTC gates that vary in frequency.

\subsubsection{Efficiency of DNA amplification}

One of the main challenges in single-cell whole genome amplification is quality control. Most amplification reactions are so sensitive that any trace of DNA in wells not 
containing a cell will be amplified to a maximum yield which is often indistinguishable from wells containing cells even when using quality control methods such as gel electrophoresis or (q)PCR. However, a simple method to check for the presence of a cell in a well is the addition of a fluorescent nucleic acid dye to the amplification reaction that can be followed in real time as shown in Figure 6.2. This figure shows the real-time monitoring of DNA amplifications in wells into which 100,10, 1 and 0 SKBR-3 cells were sorted. Into each well 20 beads were also sorted. Besides serving as a control, the volume of the droplets serve as a carrier for the cell to move to the bottom of the well. The higher amount of DNA in wells with more cells can be clearly distinguished and most importantly the wells containing 1 cell can easily be distinguished from the negative controls. In two of the 10 wells (indicated by arrows) in which a single SKBR-3 cell was sorted, the amplification occurred at the same time as the negative controls indicating that either the cell was not sorted or not lysed correctly. The negative controls all amplified at $~ 90$ minutes regardless of whether they contained beads or not. One well with a single SKBR-3 did not show any amplification.

\subsubsection{Yield and reproducibility of CTC isolation and WGA amplification of spiked samples}

Since CTC's are rare in most patients, the goal is to keep the loss of cells during the procedure as small as possible. To quantify the yield and illustrate the reproducibility of each of the important steps, 500, 50 and 5 SKBR-3 cells were placed in $7.5 \mathrm{ml}$ of blood. The blood was processed by the CellSearch system, transferred and identified by FACS, sorted by FACS and DNA isolated and amplified by WGA. Figure 6.3 shows the yield of each of these steps. The efficiency of the CellSearch system to recover SKBR-3 cells was $\sim 80 \%$ and close to the reported recovery of SKBR-3 cells $[11,12]$. $\sim 50 \%$ of the spiked SKBR-3 cells were then found back in the DAPI+,CK+,CD45- gate and $\sim 40 \%$ of the spiked SKBR-3 cells were sorted. The yield at the 500 spikes was lower as compared to the 50 and 5 cell spikes. The percentage of wells that resulted in an efficient amplification by WGA was $\sim 20 \%$ with the largest variation at the 5 cell spike level. More detailed information on the yield and reproducibility tests can be found in the supplementary data table S6.1 of the original publication [19]. 


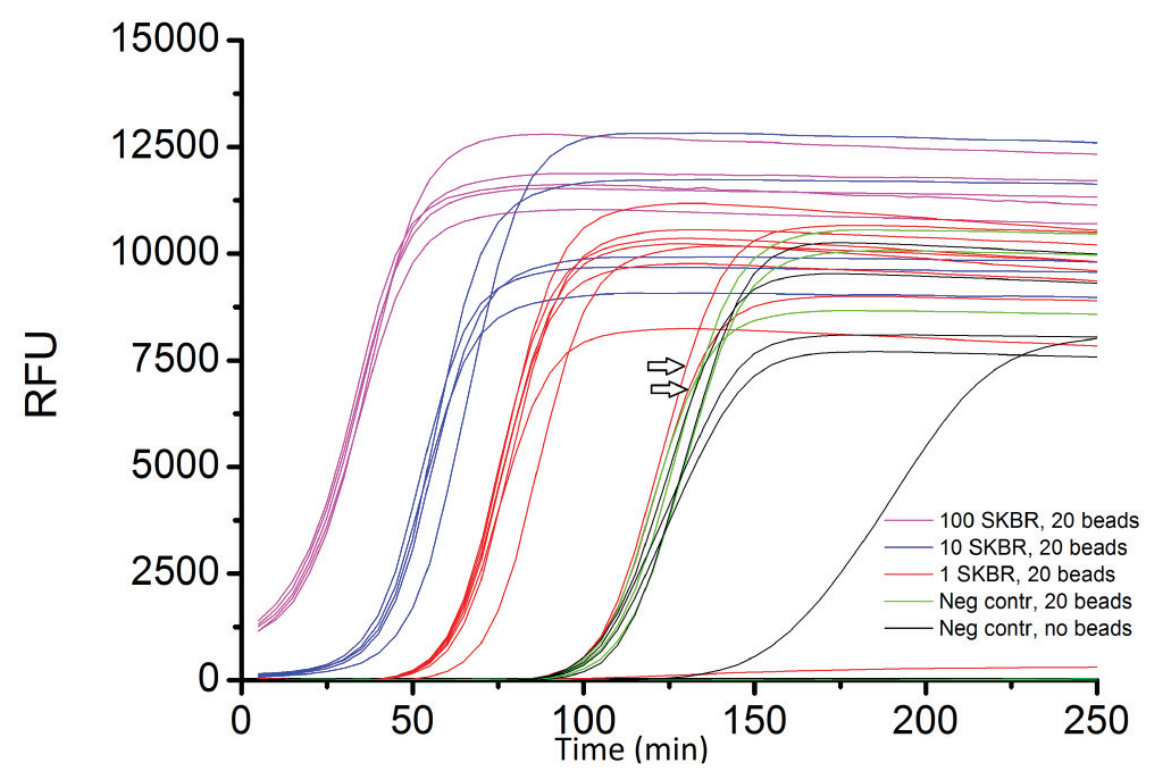

Figure 6.3. Yields of each of the steps for WGA amplification. 500, 50 and 5 SKBR-3 cells were sorted into aliqouts of $7.5 \mathrm{ml}$ of blood and enriched and enumerated by Cellsearch. The content of the CellSearch cartridge is placed in a FACS tube and SKBR-3 cells are sorted into a 384 well plate. On each well, a GE genomiphi amplification reaction is performed in the prescence of Evagreen. Yield of each step in the procedure is determined and plotted as a percentage of the starting amount. Each experiment was performed in triplicate except for the 5-cell sort which was done six times.

\subsubsection{Efficiency of CTC isolation and WGA amplification in non small cell lung cancer patients}

The number of CTC in metastatic SCL and NCLC patients varies greatly.[1, 20] To determine the efficiency at which CTC can be isolated, individually sorted and the DNA amplified, blood samples from 10 lung cancer patients were processed by using the CellSearch system. The number of CTC identified in $7.5 \mathrm{ml}$ of blood, the percentage of those cells that were identified as CTC by FACS and sorted as well as the number of single CTC successfully amplified are determined and the results are shown in table 6.1. An amplification was regarded as successful when a well has a Ct lower than the cutoff of 95 minutes. From the control samples that were done, 2 out of 50 negative controls with 20 beads sorted from the same samples were below this cutoff. None of 
the 50 empty negative controls was below this cutoff. 85\% ( $n=100)$ of the single leukocyte controls from the same patients was below this cutoff. Figure 6.1 C, E and G shows three examples of the sort gates used and the real-time DNA amplification plots from these patients are shown in panels D, F and H. From the nine CTC's identified by FACS in panel C, six showed a successful DNA amplification whereas nine of the ten leukocytes amplified successfully, as shown in panel D. From the 34 CTC's identified by FACS in panel E, 17 showed a succesfull DNA amplification whereas all of the ten leukocytes amplified successfully, as shown in panel F. From the two CTC identified by FACS in panel G 2 showed a successful DNA amplification and also all of the ten leukocytes amplified successfully, as shown in panel $\mathrm{H}$.

\subsubsection{Quality of the WGA amplified DNA by exome sequencing}

DNA produced by whole genome amplification kits is likely to contain aberrations introduced by the amplification method. The amplified genome of single cells is even more prone to aberrations because of the low starting copy number. DNA derived from single, multiple and genomic DNA from SKBR-3 cells was used for exome sequencing and analysis to check for the quality and representation of the exome. The fraction of bases mapping to the targeted exonic regions was fairly stable for all samples $(\sim 60 \%)$ and the overall coverage depth per sample was sufficient for reliable variant calling. The coverage depth distribution is shown in figure $6.4 \mathrm{~A}$ and shows that the fraction of uncovered bases at low coverage depth increases dramatically in all samples that have undergone WGA. For samples amplified from 50 cells there is no difference in coverage from fixed and unfixed cells. For samples amplified from single cells, there is a higher fraction of low or uncovered bases and highest for the DNA amplified from fixed single cells. Figure 6.4B shows the total coverage above specific coverage depths.

In the Genomic SKBR-3 DNA, 42225 variants to the human reference genome (NCBI37/hg19) are found. In the WGA of this DNA 36339 variants are found of which $75.3 \%$ are matching the variants also found in the isolated gDNA (figure 6.5A/C). Also in the DNA produced from 50 cells about the same number (38752) of variants can be found of which $78.1 \%$ are matching the gDNA. In the single-cell samples, the number of matching variants decreases to 23847 (56,5\% matching) for unfixed cells and 15071 (35,7\% matching) for fixed cells. The false discovery (FD) is around 6000 (range 4534-6438) for the multi cell samples and the single-cell unfixed samples (Figure 6.5B). The single-cell fixed samples all have a clearly higher FD (range 82679211). In the single-cell samples the ratio heterozygous/homozygous variants also decreased (figure 6.5D). In the supplementary data, tables S6.2 and S6.3 of the original 
publication [19], more detailed information is provided on the variant calling and the false negatives.
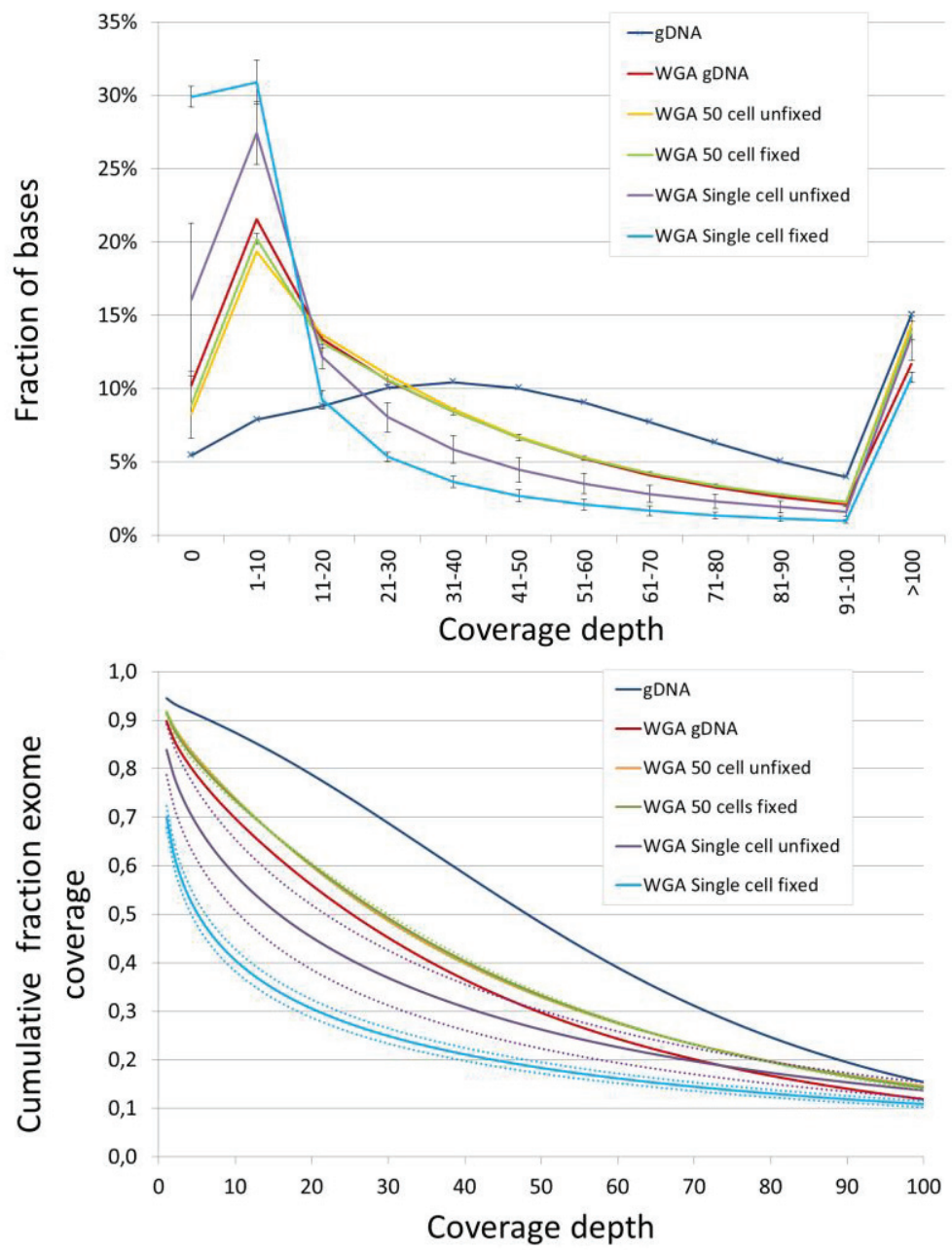

Figure 6.4. A: Fraction of bases with indicated coverage depth of gDNA (dark blue with mark, $\mathrm{n}=1$ ), Amplified gDNA (red, $\mathrm{n}=1$ ), amplified DNA from multiple unfixed cells (yellow, $n=1$ ), amplified DNA from multiple fixed cells (green, $n=2$ ), and single unfixed (purple, $n=3$ ) and fixed cells (blue, $n=4$ ). Figure 4B shows the cumulative fraction of the exome that was covered above coverage depths for the same samples as fig 4A. The dotted lines indicate the standard deviations. The lines from 50 cells fixed (green) and 50 cells unfixed (yellow) mostly overlap. 


\subsection{Discussion}

Availability of tumor cells representative of the cancer at the time of therapy administration of therapy is imperative to choose the therapy with the highest likelihood of success. Especially for targeted treatment, knowledge of the heterogeneity of tumor cells with respect to the treatment targets is of great importance. Characterization at the single-cell level thus will be important to determine the extent of this heterogeneity. The availability of tumor cells through the isolation of tumor cells circulating in the blood represents an opportunity for a liquid biopsy throughout the course of the disease and has spurred the development of a variety of technologies for such cells' isolation. However, these CTC's are extremely rare and the only clinically validated system to capture these cells is the CellSearch system. After CTC enrichment 100-10000 leukocytes remain next to the CTC and various techniques can be used to isolate single CTC from these enriched cell suspensions. Examples are the use of a micromanipulator [21] and the use of a DEParray [22] after the cells have been removed from the cartridge and identified by fluorescence microscopy. Laser microdissection of single cells [23] is also an option, but no reported studies using this in combination with CellSearch exist to our knowledge. In our study, we have evaluated the use of FACS to isolate single CTC's from the CTC-enriched cell suspensions. Each of these techniques has its advantages and disadvantages, and the choice is dictated by the availability of the equipment in the laboratory, the time and experience needed to isolate the single cells, the costs and the efficiency at which CTC can be obtained from an enriched cell population. All the techniques suffer from cell loss during the transfer steps. In our experiments we lost $\sim 40-50 \%$ of the cells identified by the CellSearch system as CTC by FACS. In our hands this still performed favorably by the cell losses we incurred by the use of a micromanipulator (data not shown). The cell losses described are in a model system in which a known number of tumor cells are spiked in blood and the losses at each step can be determined. Using blood of patients this is difficult if not impossible to determine as the number of CTC in the blood is not known. However we can assess the number of CTC's detected by the CellSearch system and determine the percentage of CTC's recovered and the number of CTC's from which the DNA can be successfully amplified. Successful amplification of the individually sorted CTC in the lung cancer patients varied greatly, suggesting that the "quality" of the CTC's is an important factor. A likely cause is that the DNA cannot be successfully amplified when the CTC's are undergoing apoptosis. A similar observation was made for CTC's that were examined by fluorescence-in-situ hybridization [8]. The consequence of this observation is that additional markers will need to be developed that can ensure that the identified CTC have a high likelihood of achieving successful DNA/RNA isolation and amplification. 


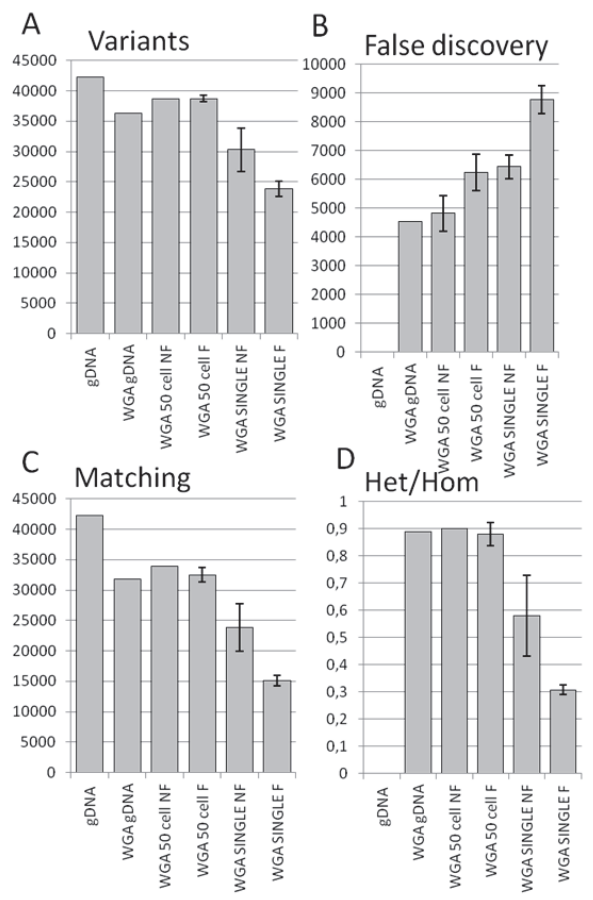

Figure 6.5. Plots of the variants called in the DNA samples. A. Total number of variants found in the samples. B. False discovery: The number of variants that were not in the gDNA. C. The number of variants that match with the gDNA. D. Heterogeneity /Homogeneity ratio of the variants found.

The processing time to obtain amplified DNA from single cells in general is around 48 hours. Since CTC are rare and in some cases fragile, EDTA blood is not optimal for conservation of such cells. For this reason, the CellSave tube was developed to keep the CTC stable before processing for up to 96 hours. The disadvantage of this fixation method is that DNA needs to be released from the fixed proteins of the cell for an optimal amplification of the generated products. We use various incubation times for proteinase $\mathrm{K}$ treatment to optimize the sample pretreatment measured in the quality of single-cell whole genome amplified DNA from cells exposed to CellSave by exome sequencing. However this did not lead to any difference in the DNA sequence data. From earlier experiments, we know that treatment with proteinase $\mathrm{K}$ is necessary to achieve any amplification product from the single fixed cells. From this, we conclude that any further proteinase $\mathrm{K}$ treatment will not lead to further improvements. 
To characterize the DNA content of individual cells' amplification of the genome without loss of representation of the original DNA is desirable. A variety of kits for DNA amplification are commercially available and can be divided into isothermal amplification kits (Phi-29 based GE genomiphi kit or the Qiagen RepliG kit) and linker adapter based kits such as the Silicon Biosystems Ampli1 and the Rubicon Picoplex series. The first two have the advantage of a highly user-friendly protocol with very short hands-on time and low costs. The Rubicon picoplex kit takes some more effort, but is as fast as the isothermal kits. The Ampli1 kit takes the most hands-on time and has a protocol that stretches over three days. In fact, all the possible amplification techniques could be applied on the single-cell sorted CellSearch CTC. To demonstrate the sorting, amplification and sequencing of the single CTC we adapted the GE Genomiphi kit.

The analyzed exomes of the single SKBR-3 cells are adversely affected by the amplification process but still contain useful information. If we look at the sharp increase in low or uncovered bases after whole genome amplification in all samples, it is clear that the amplification process itself causes a large bias. This makes this amplified DNA unsuitable for quantitative measurements. Furthermore the starting amount of one cell and the cell fixation also have a substantial influence on the final DNA quality. A part of the variants could be recovered and this could be increased when combining the DNA of individual amplified cells.

From figure 6.3 it is clear that there is a large difference in the number of detected cells in CellSearch and the subsequent number of CTC's detected using the FACS from the same samples. It could be that the cells are lost due to the cells' fragility in turn due to the permeabilization process in the CellSearch protocol or by nonspecific sticking of the cells to surfaces of pipettes and the tube. Furthermore CTC's that are connected to a leukocyte might miss the CTC gate due to the level of CD45 APC staining being too high. We learned from earlier studies that in patients a variable amount of the CTC's are apoptotic [8] and the effect of this process on the genomic sequence needs to be investigated. The amplification method of choice described in this paper is just one of many available methods. The choice of the method depend on the sample type and quality but also depend on the type of output data that is required. The differences between these kits and the most optimal kit for single cell CTC DNA amplification has yet to be determined.

Concluding: We have shown that CTC's enriched by the CellSearch system can be single-cell sorted by FACS, and the DNA retrieved and amplified with an overall efficiency of $20 \%$. From patient samples that were positive for CTC, it was possible to 
sort and amplify $20.6 \%$ of the CTC found in CellSearch. Analysis of sequencing data shows that Genomiphi-amplified DNA can be used for variant calling, but not for quantitative measurements. Close to $45 \%$ of the exome of single cells can be successfully sequenced to $20 \mathrm{x}$ depth making it possible to call $72 \%$ of the variants. Overall coverage is reduced to $30 \%$ at $20 \mathrm{x}$ depth making it possible to call $56 \%$ of the variants in CellSave fixed tumor cells.

\section{Acknowledgments}

This work was supported in part by a grant from Centocor (Malvern,PA, USA) and FP7-Health.2012.1.2-1 CTCTrap \#305341. The sponsors of this study had no role in study design, data analysis, data interpretation, or writing of the report. The authors thank Dr. J. Hilterman and Prof. H. Groen from University Medical Center Groningen for providing blood samples from lung cancer patients for this study, K.C. Andree from Twente University for the help in preparation of the single-cell samples and the development of the protocols, and Carl Van Hove, Elizabeth Van Rossem and Yves Wetzels for assistance with the sequencing experiments.

\subsection{References}

1. Hiltermann TJN, Pore MM, van den Berg A, Timens W, Boezen HM, Liesker JJW, Schouwink JH, Wijnands WJ a, Kerner GSM a, Kruyt F a E, Tissing H, Tibbe a GJ, Terstappen LWMM, Groen HJM: Circulating tumor cells in small-cell lung cancer: a predictive and prognostic factor. Ann Oncol 2012, 23:2937-42.

2. Krebs MG, Sloane R, Priest L, Lancashire L, Hou J-M, Greystoke A, Ward TH, Ferraldeschi R, Hughes A, Clack G, Ranson M, Dive C, Blackhall FH: Evaluation and prognostic significance of circulating tumor cells in patients with non-small-cell lung cancer. J Clin Oncol 2011, 29:1556-63.

3. de Bono JS, Parker C, Scher HI, Montgomery RB, Miller MC, Tissing H, Doyle G V., Terstappen LWWM, Pienta KJ, Raghavan D: Quantitative Analysis of Circulating Tumor Cells as a Survival Predictor in Metastatic Castration-Resistant Prostate Cancer: Missing Parts in a Superb Study. Clin Cancer Res 2009, 15:1504-1505.

4. Cohen SJ, Punt CJ a, Iannotti N, Saidman BH, Sabbath KD, Gabrail NY, Picus J, Morse M, Mitchell E, Miller MC, Doyle G V, Tissing H, Terstappen LWMM, Meropol NJ: Relationship of circulating tumor cells to tumor response, progression-free survival, 
and overall survival in patients with metastatic colorectal cancer. J Clin Oncol 2008, 26:3213-21.

5. Cristofanilli M, Budd GT, Ellis MJM, A, Stopeck A, Matera J, Miller MC, Reuben JM, Doyle G V, Allard WJ, Terstappen LWMM, Hayes DF, et al.: Circulating tumor cells, disease progression, and survival in metastatic breast cancer. Semin Oncol 2004, 351:781-791.

6. Attard G, Swennenhuis JF, Olmos D, Reid AHM, Vickers E, A'Hern R, Levink R, Coumans F, Moreira J, Riisnaes R, Oommen NB, Hawche G, James on C, Thompson EE, Sipkema R, Carden CP, Parker C, Dearnaley D, Kaye SB, Cooper CS, Molina A, Cox ME, Terstappen LWMM, de Bono JS: Characterization of ERG, AR and PTEN gene status in circulating tumor cells from patients with castration-resistant prostate cancer. Cancer Res 2009, 69:2912-8.

7. de Bono JS, Attard G, Adjei A, Pollak MN, Fong PC, Haluska P, Roberts L, Melvin C, Repollet M, Chianese D, Connely M, Terstappen LWMM, Gualberto A: Potential applications for circulating tumor cells expressing the insulin-like growth factor-I receptor. 2007, 13:3611-6.

8. Swennenhuis JF, Tibbe AGJ, Levink R, Sipkema RCJ, Terstappen LWMM: Characterization of circulating tumor cells by fluorescence in situ hybridization. Cytometry A 2009, 75:520-7.

9. Hayes DF, Walker TM, Singh B, Vitetta ES, Uhr JW, Gross S, Rao C, Doyle G V, Terstappen LWMM: Monitoring expression of HER-2 on circulating epithelial cells in patients with advanced breast cancer. Int J Oncol 2002, 21:1111-7.

10. Coumans FAW, Ligthart ST, Uhr JW, Terstappen LWMM: Challenges in the enumeration and phenotyping of CTC. Clin Cancer Res 2012, 18:5711-8.

11. Allard WJ, Matera J, Miller MC, Repollet M, Connelly MC, Rao C, Tibbe AGJ, Uhr JW, Terstappen LWMM: Tumor cells circulate in the peripheral blood of all major carcinomas but not in healthy subjects or patients with nonmalignant diseases. Clin Cancer Res 2004, 10:6897-904.

12. Kagan M, Howard D, Bendele T, Rao C, Terstappen L: Circulating tumor cells as cancer markers, a sample preparation and analysis system. Tumor markers Physiol Pathobiol Technol Clin Appl Washington, DC AACC Press 2002495-8 2002, 16:3-6. 
13. Li H, Durbin R: Fast and accurate long-read alignment with Burrows-Wheeler transform. Bioinformatics 2010, 26:589-595.

14. Li H, Handsaker B, Wysoker A, Fennell T: The sequence alignment/map format and SAMtools. 2009, 25:2078-2079.

\section{Picard MarkDuplicates [http://picard.sourceforge.net]}

16. Depristo MA, Banks E, Poplin R, Garimella K V, Maguire JR, Hartl C, Philippakis AA, Del Angel G, Rivas MA, Hanna M, McKenna A, Fennell TJ, Kernytsky AM, Sivachenko AY, Cibulskis K, Gabriel SB, Altshuler D, Daly MJ: A framework for variation discovery and genotyping using next-generation DNA sequencing data. Nat Genet 2011, 43:491-498.

17. Quinlan AR, Hall IM: BEDTools: a flexible suite of utilities for comparing genomic features. Bioinformatics 2010, 26:841-842.

18. Danecek P, Auton A, Abecasis G, Albers C a, Banks E, DePristo M a, Handsaker RE, Lunter G, Marth GT, Sherry ST, McVean G, Durbin R: The variant call format and VCFtools. Bioinformatics 2011, 27:2156-8.

19. Swennenhuis JF, Reumers J, Thys K, Aerssens J, Terstappen LW: Efficiency of whole genome amplification of single circulating tumor cells enriched by CellSearch and sorted by FACS. Genome Med 2013, 5:106.

20. Krebs M, Sloane R: Evaluation and prognostic significance of circulating tumor cells in patients with non-small-cell lung cancer. J Clin Oncol 2011, 29:1556-1563.

21. Stoecklein NH, Hosch SB, Bezler M, Stern F, Hartmann CH, Vay C, Siegmund A, Scheunemann P, Schurr P, Knoefel WT, Verde PE, Reichelt U, Erbersdobler A, Grau R, Ullrich A, Izbicki JR, Klein C a: Direct genetic analysis of single disseminated cancer cells for prediction of outcome and therapy selection in esophageal cancer. Cancer Cell 2008, 13:441-53.

22. Peeters DJE, De Laere B, Van den Eynden GG, Van Laere SJ, Rothé F, Ignatiadis $M$, Sieuwerts a M, Lambrechts D, Rutten a, van Dam P a, Pauwels P, Peeters M, Vermeulen PB, Dirix LY: Semiautomated isolation and molecular characterisation of single or highly purified tumour cells from CellSearch enriched blood samples using dielectrophoretic cell sorting. Br J Cancer 2013(November 2012):1-10. 
23. Kroneis T, Geigl JB, El-Heliebi A, Auer M, Ulz P, Schwarzbraun T, Dohr G, Sedlmayr P: Combined molecular genetic and cytogenetic analysis from single cells after isothermal whole-genome amplification. Clin Chem 2011, 57:1032-41.

\subsection{Supplementary data}

\begin{tabular}{|c|c|c|c|c|c|c|c|c|c|}
\hline \multirow[t]{2}{*}{ Cartridge } & \multirow[t]{2}{*}{ Start } & \multicolumn{2}{|l|}{ CellSearch } & \multicolumn{2}{|l|}{ FACS Detected } & \multicolumn{2}{|c|}{ Single cell sorted } & \multirow{2}{*}{$\begin{array}{r}\text { Amplified } \\
\text { (\%step) }\end{array}$} & \multirow{2}{*}{$\begin{array}{l}\text { Total } \\
\text { \%total }\end{array}$} \\
\hline & & (\%step) & \%total & (\%step) & \%total & (\%step) & \%total & & \\
\hline 01030300 & 500 & $404(80.8 \%)$ & $80.8 \%$ & $203(50.2 \%)$ & $40.6 \%$ & $86(42.4 \%)$ & $17.2 \%$ & $30 / 30(100 \%)$ & $17.2 \%$ \\
\hline 01030301 & 500 & $327(65.4 \%)$ & $65.4 \%$ & $152(46.5 \%)$ & $30.4 \%$ & $100(65.6 \%)$ & $20.0 \%$ & $25 / 30(83.3 \%)$ & $16.7 \%$ \\
\hline 01030302 & 500 & $416(83.2 \%)$ & $83.2 \%$ & $192(46.1 \%)$ & $38.4 \%$ & $151(78.6 \%)$ & $30.2 \%$ & $27 / 30(90.0 \%)$ & $27.2 \%$ \\
\hline Average & 500 & $382(76.5 \%)$ & $76.5 \%$ & $182(47.6 \%)$ & $36.5 \%$ & $112(61.5 \%)$ & $22.5 \%$ & $27 / 30(90.0 \%)$ & $20.4 \%$ \\
\hline Cartridge & Start & CellSearch & & FACS Detectec & & Single cell so & rted & Amplified & \\
\hline 01046645 & 50 & $36(72.0 \%)$ & $72.0 \%$ & $22(61.1 \%)$ & $48 \%$ & $21(95.4 \%)$ & $42 \%$ & $9(42.8 \%)$ & $18.0 \%$ \\
\hline 01046646 & 50 & $37(74.0 \%)$ & $74.0 \%$ & $24(64.9 \%)$ & $48 \%$ & $21(87.5 \%)$ & $42 \%$ & $12(57.1 \%)$ & $24.0 \%$ \\
\hline 01046647 & 50 & $40(80.0 \%)$ & $80.0 \%$ & $28(70.0 \%)$ & $56 \%$ & $26(92.9 \%)$ & $52 \%$ & $10(34.6 \%)$ & $18.0 \%$ \\
\hline Average & 50 & $37.7(75.3 \%)$ & $75.3 \%$ & $25.3(67.1 \%)$ & $50.7 \%$ & $22.7(30.2 \%)$ & $45 \%$ & $10.3(20.6 \%)$ & $20 \%$ \\
\hline Cartridge & Start & CellSearch & & FACS Detectec & & Single cell so & rted & Amplified & \\
\hline 01046569 & 5 & $5(100 \%)$ & $100 \%$ & $4(80 \%)$ & $80 \%$ & $4(100 \%)$ & $80 \%$ & $0(0 \%)$ & $0 \%$ \\
\hline 01046570 & 5 & $3(60 \%)$ & $60 \%$ & $3(100 \%)^{*}$ & $100 \% *$ & $2(66 \%)$ & $40 \%$ & $2(100 \%)$ & $40 \%$ \\
\hline 01046572 & 5 & $4(80 \%)$ & $80 \%$ & $4(80 \%)$ & $100 \%$ & $4(100 \%)$ & $80 \%$ & $2(50 \%)$ & $40 \%$ \\
\hline 01046573 & 5 & $4(80 \%)$ & $80 \%$ & $2(50 \%)$ & $40 \%$ & $1(50 \%)$ & $20 \%$ & $1(100 \%)$ & $20 \%$ \\
\hline 01046575 & 5 & $5(100 \%)$ & $100 \%$ & $2(40 \%)$ & $40 \%$ & $2(100 \%)$ & $40 \%$ & $2(100 \%)$ & $40 \%$ \\
\hline 01046576 & 5 & $2(40 \%)$ & $40 \%$ & $1(50 \%)$ & $20 \%$ & $1(100 \%)$ & $20 \%$ & $0(0 \%)$ & $0 \%$ \\
\hline Average & 5 & $3.8(76.7 \%)$ & $76.7 \%$ & $2.6(53.3 \%)$ & $63.3 \%$ & $2.3(86 \%)$ & $47 \%$ & $1.2(23.3 \%)$ & $20 \%$ \\
\hline
\end{tabular}

Table S6.1 efficiency data *2 events were sorted which were just inside the gate but are probably no SKBR-3 cells judged by the lower cytokeratin level. 
CHAPTER 6: SINGLE CELL WHOLE GENOME AMPLIFICATION

\begin{tabular}{|c|c|c|c|c|c|c|c|c|}
\hline \multirow{2}{*}{$\begin{array}{l}\text { Sample } \\
\text { REF }\end{array}$} & \multirow{2}{*}{$\begin{array}{l}\text { Fixation } \\
\text { Unfixed }\end{array}$} & \multirow{2}{*}{$\begin{array}{l}\text { Variants } \\
42225\end{array}$} & \multicolumn{4}{|c|}{ Matching sites } & \multicolumn{2}{|c|}{ False discovery rate } \\
\hline & & & Total & \% Matching & Homozygous & Heterozygous & FD & wrt exome \\
\hline WGA & Unfixed & 36339 & 31805 & $75,32 \%$ & 16818 & 14978 & 4534 & $0,007 \%$ \\
\hline 50CELL_02 & Unfixed & 38749 & 33929 & $80,35 \%$ & 17847 & 16074 & 4820 & $0,008 \%$ \\
\hline 50CELL_03 & Fixed & 39146 & 33335 & $78,95 \%$ & 17401 & 15925 & 5811 & $0,009 \%$ \\
\hline 50CELL_04 & Fixed & 38362 & 31684 & $75,04 \%$ & 17160 & 14516 & 6678 & $0,011 \%$ \\
\hline SINGLE_01 & Unfixed & 32505 & 26799 & $63,47 \%$ & 15617 & 11176 & 5706 & $0,009 \%$ \\
\hline SINGLE_02 & Unfixed & 26210 & 19345 & $45,81 \%$ & 13221 & 6122 & 6865 & $0,011 \%$ \\
\hline SINGLE_03 & Unfixed & 32142 & 25398 & $60,15 \%$ & 16411 & 8982 & 6744 & $0,011 \%$ \\
\hline SINGLE_04 & Fixed & 24920 & 15986 & $37,86 \%$ & 12112 & 3872 & 8934 & $0,014 \%$ \\
\hline SINGLE_05 & Fixed & 24835 & 15624 & $37,00 \%$ & 11931 & 3692 & 9211 & $0,015 \%$ \\
\hline SINGLE_06 & Fixed & 23031 & 14378 & $34,05 \%$ & 10979 & 3395 & 8653 & $0,014 \%$ \\
\hline SINGLE_07 & Fixed & 22562 & 14295 & $33,85 \%$ & 11101 & 3191 & 8267 & $0,013 \%$ \\
\hline
\end{tabular}

Table S6.2: Variant calling data

\begin{tabular}{lllllll}
\hline Sample & Fixation & Variants & Matching sites & False negatives \\
\hline REF & Unfixed & 42225 & Total & $\%$ Matching & (FN) & $\%$ FN \\
\hline WGA & Unfixed & 36339 & 31805 & $75,32 \%$ & 6943 & $16,44 \%$ \\
\hline 50CELL_02 & Unfixed & 38749 & 33929 & $80,35 \%$ & 4433 & $10,50 \%$ \\
\hline 50CELL_03 & Fixed & 39146 & 33335 & $78,95 \%$ & 3874 & $9,17 \%$ \\
\hline 50CELL_04 & Fixed & 38362 & 31684 & $75,04 \%$ & 5139 & $12,17 \%$ \\
\hline SINGLE_01 & Unfixed & 32505 & 26799 & $63,47 \%$ & 12174 & $28,83 \%$ \\
\hline SINGLE_02 & Unfixed & 26210 & 19345 & $45,81 \%$ & 20123 & $47,66 \%$ \\
\hline SINGLE_03 & Unfixed & 32142 & 25398 & $60,15 \%$ & 13780 & $32,63 \%$ \\
\hline SINGLE_04 & Fixed & 24920 & 15986 & $37,86 \%$ & 21994 & $52,09 \%$ \\
\hline SINGLE_05 & Fixed & 24835 & 15624 & $37,00 \%$ & 22160 & $52,48 \%$ \\
\hline SINGLE_06 & Fixed & 23031 & 14378 & $34,05 \%$ & 23641 & $55,99 \%$ \\
\hline & & & & & & \\
\hline
\end{tabular}

Table S6.3: variant calling, false negatives 


\begin{tabular}{lcc}
\hline Variants not present in reference sample & Number of variants & FNR(\%) \\
\hline $\mathbf{5 0}$-cell samples $(\mathbf{n}=\mathbf{4})$ & 905 & $2.1 \%$ \\
\hline $\mathbf{5 0}$-cell not fixed samples $(\mathbf{n}=\mathbf{2})$ & 1740 & $4.0 \%$ \\
\hline $\mathbf{5 0}$-cell fixed samples $(\mathbf{n}=\mathbf{2})$ & 1663 & $3.8 \%$ \\
\hline Single-cell samples $(\mathbf{n}=\mathbf{7})$ & 15 & $0.0 \%$ \\
\hline Single-cell not fixed samples $(\mathbf{n}=\mathbf{3})$ & 407 & $1.0 \%$ \\
\hline Single-cell fixed samples $(\mathbf{n}=\mathbf{4})$ & 60 & $0.1 \%$ \\
\hline
\end{tabular}

Table S6.4. False negatives in the reference sample. Variants not detected in the reference sample but consistenly detected in the 50- or single-cell samples may represent false negatives in the reference samples. Variants present in different sample groups are listed below and for each set of detected variants an estimate for the false negative rate (FNR) in the reference sample is given.

\begin{tabular}{lllll}
\hline Patient \# & \# CTC CellSearch & & Unassigned events CellSearch & \\
\hline $\mathbf{1}$ & 0 & 18 & 0 & 1496 \\
\hline $\mathbf{2}$ & 0 & 225 & 1 & 14953 \\
\hline $\mathbf{3}$ & 0 & 19 & 3 & 332 \\
\hline $\mathbf{4}$ & 0 & 30 & 1 & 295 \\
\hline $\mathbf{5}$ & 0 & 50 & 3 & 311 \\
\hline $\mathbf{6}$ & 0 & 5 & 1 & 485 \\
\hline $\mathbf{7}$ & 0 & 16 & 2 & 279 \\
\hline $\mathbf{8}$ & 0 & 28 & 1.6 & 2341 \\
\hline average & 0 & 49.1 & & WBC Gated \\
\hline
\end{tabular}

Table S6.5. FACS data negative healthy control samples. Events detected in the CTC and the WBC gates from CellSearch prepped healthy control samples. Column \# CTC CellSearch sums the number of CTC found in the CellSearch test. The Unassigned events are the number events selected by CellSearch but were no CTC. The CTC and WBC gated events are the events gated in the FACS. 


\section{CHAPTER 7: CHARACTERIZATION OF CIRCULATING TUMOR CELLS BY FLUORESCENCE IN-SITU HYBRIDIZATION}

Joost F Swennenhuis ${ }^{a}$, Arjan GJ Tibbe ${ }^{b}$, Rianne Levink ${ }^{a}$, Ronald CJ Sipkema, Leon WMM Terstappen ${ }^{\mathrm{a}}$

a: Department of Medical Cell BioPhysics, MIRA Research Institute, Faculty of Science and Technology, University of Twente, Enschede, The Netherlands

b: Veridex LLC, Enschede, Netherlands

Published in: Cytometry part A, Doi: 10.1002/cyto.a.20718, 75A: 520-527, 2009.

Running title: FISH on CTC.

Abstract

Tumor cells in blood of patients with metastatic carcinomas have been associated with poor survival prospects. Further characterization of these cells may provide further insights into the metastatic process. Circulating Tumor Cells (CTC) were enumerated in $7.5 \mathrm{~mL}$ of blood with the CellSearch ${ }^{\mathrm{TM}}$ system. After enumeration of Cytokeratin+, CD45-, nucleated cells, the cells are fixed in the cartridge while maintaining their original position. Cartridges were hybridized with FISH probes against the centromeric regions of chromosome 1, 7, 8 and 17. Next fluorescence images of the FISH probes of the previous identified CTC were acquired. Leukocytes surrounding the CTC were used as internal controls. The number of copies of chromosome 1, 7, 8 and 17 could be determined in 118 CTC containing blood samples from 59 metastatic prostate cancer patients. The samples contained a total of 21,751 
CTC (mean 184, median 16, SD 650). Chromosome counts were obtained in $61 \%$ of the relocated CTC. On average these CTC contained 2.8 copies of chromosome 1, 2.7 copies of chromosome 7, 3.1 copies of chromosome 8 and 2.3 copies of chromosome 17. CTC in which no chromosome count was obtained most likely underwent apoptosis indicated by the expression of M30. In 6/59 patients only diploid CTC were detected these samples however only contained 1 - 5 CTC. Heterogeneity in the chromosomal abnormalities was observed between CTC of different patients as well as among CTC of the same patient. Cytogenetic composition of CTC can be reliably assessed after they have been identified by the CellSearch ${ }^{\mathrm{TM}}$ system. The majority of CTC in hormone refractory prostate cancer are aneuploid confirming that they indeed are cancer cells. An extensive heterogeneity in the copy number of each of the chromosomes was observed.

\subsection{Introduction}

The need for biomarkers to guide treatment of patients with metastatic carcinomas is increasing with the growing number of available treatment options. Tumor cells shed into the blood during metastasis have the promise to become generic biomarkers for a variety of carcinomas. In multicenter prospective studies the presence of circulating tumor cells (CTC) have been associated with poor progression free and overall survival in metastatic breast (MBC), colorectal (MCRC), and prostate cancer (MPC)[16]. In these studies a standardized method for the enumeration and characterization of CTC was utilized[7, 8]. The presence of specific antigens or the amplification of specific genes in these CTC may help in selecting specific therapies or families of therapies[9-14]. In this study we introduce a method that permits FISH analysis on the CTC that have previously be identified by immunofluorescent staining in a standardized and automated fashion. The method was demonstrated by assessment of chromosome 1, 7, 8, and 17 copy number on CTC from samples from metastatic castration resistant prostate cancer patients enrolled in a recently completed multicenter study that demonstrated the relation between presence of CTC and poor outcome[6]. 


\subsection{Methods}

\subsubsection{Patient samples}

A prospective multi center clinical trial that evaluated the utility of counting CTC for predicting response to therapy, progression-free survival, and overall survival in metastatic castration resistant prostate cancer patients was conducted[6]. A total of 65 clinical centers throughout the United States and Europe participated in this study after formal institutional review board approval. All patients were required to provide written informed consent. Blood was collected before starting a new treatment and at monthly intervals prior to the next cycle of therapy. CTC were enumerated in $7.5 \mathrm{ml}$ of blood using the CellSearch ${ }^{\mathrm{TM}}$ system (Veridex Raritan, NJ) and sample cartridges were stored for later FISH analysis as described below. In this study a total of 178 cartridges containing CTC of 70 patients from blood samples taken after initiation of therapy were used.

\subsubsection{Enumeration of circulating tumor cells}

The CellTracks Autoprep (Veridex, Raritan, NJ) was used to immunomagnetically enrich epithelial cells from $7.5 \mathrm{~mL}$ of blood using ferrofluids coated with epithelial cell specific EpCAM antibodies and stain the CTC enriched samples with phycoerythrin conjugated antibodies directed against cytokeratins 8, 18 and 19, an allophycocyanin conjugated antibody to CD45 and the nuclear dye DAPI. After enrichment and staining the volume is reduced to $300 \mu \mathrm{l}$ and this volume, containing all isolated CTC, is transferred to a cartridge that is present inside the MagNest ${ }^{\mathrm{TM}}$ Cell Presentation Device. Next, the cartridge is analyzed on the CellTracks Analyzer II, a four color semiautomated fluorescence microscope (Veridex, Raritan, NJ). Image frames covering the entire surface of the cartridge for each of the four fluorescence filter cubes are captured. From the captured images, a gallery of objects meeting pre-determined criteria is presented in a web-enabled browser for interpretation by a trained operator who makes the final cell identification of the CTC. The criteria for an object to be defined as a CTC include round to oval morphology, a visible nucleus (DAPI positive), positive staining for cytokeratin and negative staining for CD45. Results of cell enumeration are expressed as the number of cells per $7.5 \mathrm{~mL}$ of blood. The performance of the assay system is described in detail elsewhere[8, 15]. 


\subsubsection{Preservation of CTC for FISH analysis}

CTC that have been analyzed on the CellTracks Analyzer are contained in $300 \mu$ buffer inside a cartridge and held in position against the analysis surface by magnetic forces $[16,17]$. To preserve the location of the CTC for future interrogation the buffer inside the cartridge has to be aspirated from the cartridge without cell movement. The cartridge contained within the MagNest ${ }^{\mathrm{TM}}$ Cell Presentation Device is placed upright with the glass on which the cells reside vertically. Manual aspiration of the buffer and introduction of the fixative resulted in variable loss or movement of CTC making the need for an automated buffer aspiration and cell fixation necessary. A device was constructed using a CavroXE1000 digital syringe pump for fluid transport and transfer probes that were fabricated from 13AWG Inconel (Cavro, Sunnyvale, CA). This nonmagnetic material was required to avoid movement of the probe under the influence of the magnetic field used to contain the cells in the sample cartridge in position. Aspiration and fixation steps were optimized and in the final protocol $250 \mu \mathrm{l}$ methanol:acetic acid (3:1) is carefully injected at the bottom of the cartridge. The difference in density causes the methanol/acetic acid to swirl up along the glass to the top of the cartridge. After 2 minutes, $250 \mu$ is removed from the cartridge followed by another injection of $250 \mu \mathrm{l}$ methanol:acetic acid. After another two minutes the whole volume is aspirated followed by immediate drying using a forced air flow. Fixed and dried cartridges can be processed for FISH immediately or stored at $-20{ }^{\circ} \mathrm{C}$ for later use. Stability studies showed that the cartridges could be stored for at least two years before hybridization.

\subsubsection{Hybridization of CTC}

FISH probes specific for the centromeric regions of chromosome 1, 7, 8 and 17 labeled with PlatinumBright-647, $-550,-505$ and 415 respectively, were used in this study (Kreatech, Amsterdam, The Netherlands). Cells of the tumor cell line SKBR-3 and MCF7 were used to optimize the volume and concentrations of the probes. The optimized probe mixture constisted of $50 \mu$ of hybridization buffer (50\% Formamide / 1xSSC / 10\%Dextran Sulfate) containing FISH probes against 1, 7, 8 and 17 at 2 ng / $\mu \mathrm{l}$ each. Probe mixture was added such that it covers the whole glass surface on which the cells are fixed. The cartridges were placed on a $80^{\circ} \mathrm{C}$ hotplate for $2 \mathrm{~min}$, with the glass facing towards the hotplate, and next hybridized at $42^{\circ} \mathrm{C}$ for 16 hours (Boekel Scientific, Feasterville, PA, USA). After hybridization the cartridge is washed with PBS containing 4',6-diamidino-2-phenylindole (DAPI) as a nuclear counter stain. 


\subsubsection{Fluorescent Microscope for CTC FISH analysis}

The CellTracks Analyzer II is equipped with a 10X objective (NA of 0.45). For FISH analysis the analyzer was modified and equipped with a 40X objective ( NA of 0.63 ) (Nikon Instruments Europe, the Netherlands) to improve the resolution and light collection of the fluorescent FISH signals and was equipped with filter cubes that permitted the acquisition of the fluorescence signals from DAPI and PlatinumBright$647,-550,-505$ and 415 . The Linux based operating system was modified such that it could: 1. read stored data and the location of the previously identified CTC, 2. relocate the previous identified CTC after the FISH procedure by correlating the location of the cells in the stored data with the new location acquired on the fluorescent DAPI signal acquired with the $40 \mathrm{X}$ objective, 3. acquire a Z-stack of 5 fluorescence images of the FISH signals of CTC of interest, 4. present the acquired images to the reader for FISH analysis, 5. generate a report of the result. CD45+ leukocytes, that are co-isolated during the magnetic isolation of the CTC and present in the cartridge, serve as internal controls for the FISH procedure and for the local signal quality for each CTC.

\subsection{Results}

\subsubsection{Preservation of CTC for FISH analysis}

The protocol to aspirate the fluid from the cartridges and fix the cells in position was verified by assessment of the number of nucleated cells on the analysis surface that either moved or disappeared from the original location. For CTC identification the 10X objective is used, and 175 images need to be acquired to cover the whole glass surface. Panel A of Figure 7.1 displays one of the 175 frames for the DAPI signal. One DAPI stained nucleus is enlarged to illustrate the resolution that is used for the identification of CTCs. Panel B of Figure 7.1 displays the DAPI fluorescence image acquired with the modified instrument using a 40X objective of the area indicated by the green box in Panel A after hybridization. The field of view is 1/16 of the $10 \mathrm{X}$ image. The nucleus of the same cell is enlarged and illustrates the higher resolution obtained with the higher NA objective. Furthermore it can be observed that the majority of the cells remain intact and stay in position. During the fixation and FISH procedure all immunofluorescence signals used to identify the CTC disappear which permit the use of fluorescence labels for FISH that overlap the spectra of the fluorescence labels used for immunofluorescence detection. Small differences in the protocol used for aspiration can have large impact on the percentage of cells that can be retrieved and analyzed. In this study two fixation protocols were used which differed in: 1) the aspiration speed of the methanol:acetic acid in the final step of the fixation, 2) the air 
flow through the cartridge during drying of the cartridge after removal of the fixation reagents. Of the 2932 CTC analyzed with one protocol 2707 (91\%) could be relocated after FISH whereas with the other protocol 1721 of the 3204 CTC (53\%) could be relocated. In total 4482 of the 6130 CTC (76\%) were relocated for FISH analysis. The difference in protocol did not have an effect on the quality of the FISH signals nor did it influence the analysis.

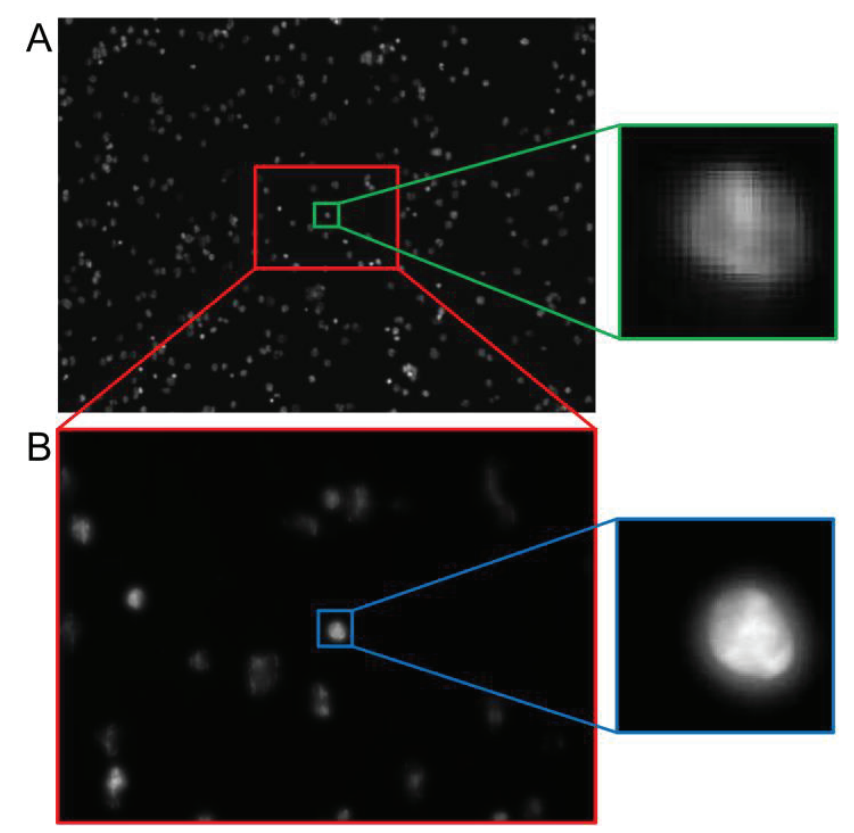

Figure 7.1. Fluorescence image of DAPI stained nuclei. A: Fluorescence image acquired with a 10X, NA 0.45 objective. The highlighted cell in the center of the image is displayed enlarged on the right side. B: Image acquired by a 40X, NA 0.63 of the area highlighted green in panel A. The field of view is $1 / 16$ th of the $10 \mathrm{X}$ area. The center cell, marked by the red box is the same cell as the enlarged cell in panel A and is displayed enlarged to the right.

\subsubsection{FISH analysis of CTC and leukocytes}

After the FISH hybridization is completed the cartridge is placed into the modified analyzer with the 40X objective. Fluorescence images acquired for CTC identification before FISH are imported onto the modified analyzer. To match the location of the cells before and after FISH the modified analyzer acquires DAPI images of the cartridge using the $40 \mathrm{X}$ objective and correlates these images with the DAPI images acquired using the $10 \mathrm{X}$ in the first scan of the cartridge. Next the system revisits all 
events that have been identified as CTC in the first scan. A Z-stack of 5 images with a spacing of 2 - $\mathrm{m}$ for each of the four FISH probes are acquired. The Z-stack images are collapsed into one image and presented to the reader. Figure 7.2 shows an example of DAPI, CD45-APC and CK-PE images of 9 CTC from the original identification and the corresponding DAPI, Chromosome 1, 7, 8, 17 images. Few of the images showed two copies of the chromosomes and each of the 9 CTC showed at least an aberrancy of one of the chromosomes. Leukocytes surrounding the CTC serve as internal control for the FISH. The numbers of leukocytes in the cartridge vary from samples to sample. If leukocytes are present within the frame of the CTC, 1-2 leukocytes are selected as a control. In case no leukocytes are present in close proximity a larger area around the CTC is scanned. If still no controls can be selected, the quality of the FISH is judged on the leukocytes that are present at other locations. Figure 7.3 displays 9 leukocytes that were selected as controls. The majority of the leukocytes show two copies of chromosome 1, 7, 8 and 17 in contrast with the larger heterogeneity observed in the copy numbers of chromosome 1, 7, 8 and 17 in the CTC.

Hundred seventy eight cartridges containing CTC from 70 prostate cancer patients were analyzed for FISH analysis. To limit the analysis time, a maximum of 125 CTC were analyzed per cartridge. From the 23,341 CTC present in these cartridges 6136 (26\%) were analyzed and 4428 (72\%) could be relocated. From the 4428 relocated CTC 2708 (61\%) did not provide FISH signals in contrast to the surrounding leukocytes that showed good quality FISH signals. The morphologic appearance of CTC that did not provide FISH signals suggested that these cells might be disintegrating and or undergoing apoptosis. The percentage of relocated CTC per cartridge that did not provide adequate FISH signals ranged from 0-100 \% (mean 59\%, median $62 \%$, SD 35\%). In 48 of the 178 cartridges $100 \%$ of the CTC did not provide evaluable FISH signals and in 12 of the 178 cartridges no CTC good be relocated because of different reasons, resulting in 118 evaluable cartridges from 59 patients. 


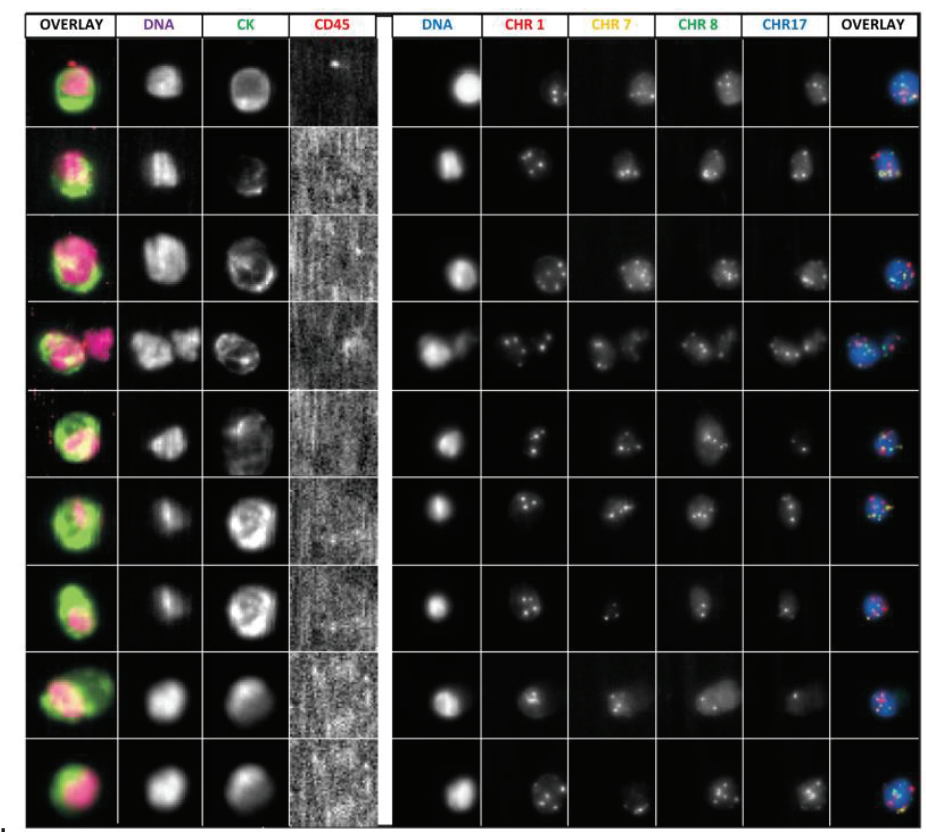

Figure 7.2. Fluorescence images of CTC. The 4 columns on the left are obtained with the 10X objective. Column "Overlay" displays the overlay of the columns "DNA" and "CK". The 6 columns on the right display the images of the same cells after FISH labeling using the 40X objective. Columns show the DAPI, Chromosome 1, 7, 8 and 17 signals and an overlay of DAPI with each of the four chromosomal fluorescence signals.

\subsubsection{Apoptosis of CTC and FISH analysis}

To demonstrate the relation between CTC undergoing apoptosis and lack of FISH signals EpCAM enriched CTC from $7.5 \mathrm{~mL}$ of blood from patients with metastatic disease were stained with $\mathrm{M} 30$, an antibody recognizing caspase cleaved cytokeratin 18, in addition to DAPI, Cytokeratin and CD45. M30 was labeled with PE, Cytokeratin with FITC and CD45 with APC. For 24 CTC positive cartridges the cartridges were preserved and hybridized with probes identifying the centromeres of chromosome 1 , 7, and 17. Panel A in Figure 7.4, shows an example of a CTC identified DAPI+, Cytokeratin+, M30-, CD45-, as well as the corresponding DAPI, chromosome 1, 7, and 17 images of the same CTC after hybridization and relocation. Figure 7.4, Panel B shows a DAPI+, Cytokeratin+, M30+, CD45- CTC from a patient but although the DAPI signal revealed that the CTC was relocated no adequate FISH signals were observed. A total of 765 CTC from the 24 samples (mean 52, median 7, SD 111) were analyzed and evaluable FISH signals were obtained for 567/590 (96\%) of the M30 negative CTC but 
only 101/175 (58\%) of the M30 positive CTC. Only CTC that were surrounded with leukocytes that contained at least one copy of each of the chromosomes were included in this analysis.

\subsubsection{Aneuploidy of CTC in hormone refractory prostate cancer.}

Copies of chromosomes 1, 7, 8 and 17 could be determined in 1720 CTC of 118 samples from 59 patients. In total 537 leukocytes were analyzed as internal controls. Figure 7.5, Panel A displays a histogram of the copy number of chromosome 1 in 1720 CTC (red bars) and 537 leukocytes surrounding the CTC (green bars). Panel B, C and D display the copy numbers of chromosome 7, 8 and 17 plus the surrounding leukocytes respectively. On average the leukocytes shows 2 copies in $86 \%$ of the cases, in $10 \%$ less than two and in 4\% more than two copies. The distribution of the number of chromosome copies found in CTC is different for each chromosome. The copy number of chromosome 8 (panel $\mathrm{C}$ ) is deviating most from normal, $8 \%$ had less than 2, 38\% had 2 copies and $54 \%$ had more than 2 copies. All chromosomes with more than 7 copies were reported as 7 copies. In 10 / 118 (9\%) samples from 6 patients CTC were diploid. The number of CTC in these samples was low and ranged from 1-5 CTC. To arrive at a numerical value for the deviation of the chromosome copy number from normal, we defined the chromosomal composition by: ((fraction of cells with 1 copy * $1)+($ fraction of cells with 2 copies $* 2$ ) $+\ldots+$ (fraction of cells with 6 copies * 6 ) + (fraction of cells with $\geq 7$ copies *7))-2. For normal cells the numerical value for the deviation is thus equal to 0 . In reality 2 copies will not be found in all the cells and in the 537 leukocytes that were used as controls a deviation from the normal chromosomal copy number of -0.07 was found for chromosome 1, -0.02 for chromosome $7,-0.06$ for chromosome 8 and -0.10 for chromosome 17 . A significant larger deviation was found in CTC. For chromosome 1, the deviation ranged from -2 to 5 with an average of 0.57 (median 0.23 , SD 1.04). For chromosome 7 , the deviation ranged from -2 to 5 with an average of 0.66 (median 0.50 , SD 1.06). For chromosome 8 , the deviation ranged from -2 to 4.61 with an average of 0.85 (median 0.75, SD 1.26) and for chromosome 17, the deviation ranged from -2 to 3.33 with an average of 0.44 (median 0.09, SD 0.82). Figure 7.6 shows a graphical representation of the deviation of chromosome 1, 7, 8 and 17 copy number for the 118 samples from the 59 patients. In addition the deviation of the chromosome copy number for leukocytes is provided. 


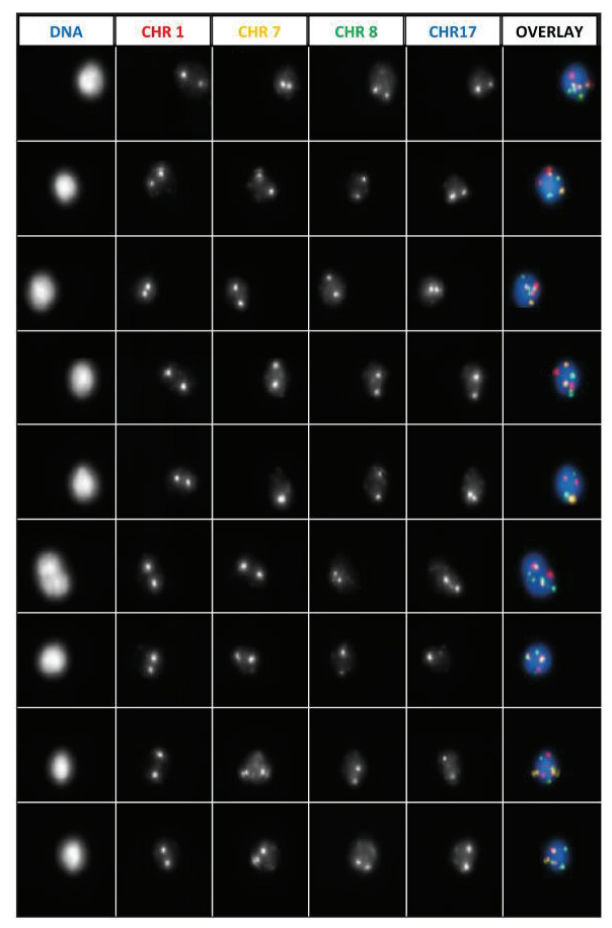

Figure 7.3. Fluorescence signals of leukocytes that surrounded the CTC. Column 1 displays the DAPI fluorescence signal of the nucleus. Fluorescence signals of chromosomes 1, 7, 8 and 17 and an overlay of DAPI with each of the four chromosomal fluorescence signals.

\subsection{Discussion}

Although case report studies have suggested that the presence of tumor cells in blood is associated with poor outcome their low frequency has hampered exploration of their clinical utility [18-25]. The recent introduction of a standardized assay has permitted the execution of prospective multicenter clinical trials in MBC, MCR and MPC. These studies showed that the presence of CTC indeed was associated with poor prognosis and their perseverance or occurrence after the first cycles of therapy strongly suggested that those patients were on a futile therapy [1-6]. The number of therapies available to treat patients with recurrent cancer is rapidly increasing. The challenge the oncologist is facing is to determine which therapy offers the most benefit with the fewest side effects. The shift towards targeted therapies has magnified the situation. Selecting the patient most likely to respond to a target directed drug requires a more in-depth characterization of the patient. Unfortunately, use of archival primary tumor tissues to determine target status may not represent the disease at the time of a recurrence. Due to genetic instability, a percentage of 
tumors continue to mutate giving rise to variants that are not expressed and/or resistant to a given therapeutic regimen[26-33]. Assessment of therapeutic targets on CTC constitutes may overcome this issue. The technological challenge of assessment of multiple analytes on CTC is that in most cases only few cells are available and repeated sampling or sampling of a larger blood volume are not realistic possibilities. In this study we explored the possibility to perform FISH after the original identification of CTC. In the CellSearch assay CTC are held by magnetic forces to an analysis surface and in this study we demonstrated that we were able to relocate more than $90 \%$ of the cells after hybridization. $61 \%$ of the CTC however did not provide FISH signals that could be counted in contrast to the leukocytes that surrounded the CTC. The morphological appearance of the CTC that did not provide FISH signals suggested that these cells were disintegrating to various degrees. To proof a relation between CTC undergoing apoptosis and lack of FISH signals we conducted a series of experiments in which CTC were characterized by the expression of caspase cleaved cytokeratin 18 followed by FISH analysis. Whereas $96 \%$ of the CTC that did not undergo apoptosis provided FISH signals only $58 \%$ of the CTC undergoing apoptosis did. It's not surprising that CTC shed into the circulation from primary or metastatic sites are undergoing apoptosis and the phenomenon has been reported earlier [34-37]. Drawback of this finding is that assessment of the genetic makeup of the tumor becomes less informative as fewer CTC are available and therapeutic targets can thus be assessed in fewer patients. Recent reports using alternative technologies suggest the presence of a significant larger number of CTC in carcinoma patients this however may well be contributed to the definition of what constitutes a CTC [38-45]. Still one would like to assess the presence or absence of therapeutic targets in as large a patient group as possible urging the need for technology that increase the yield of CTC. 

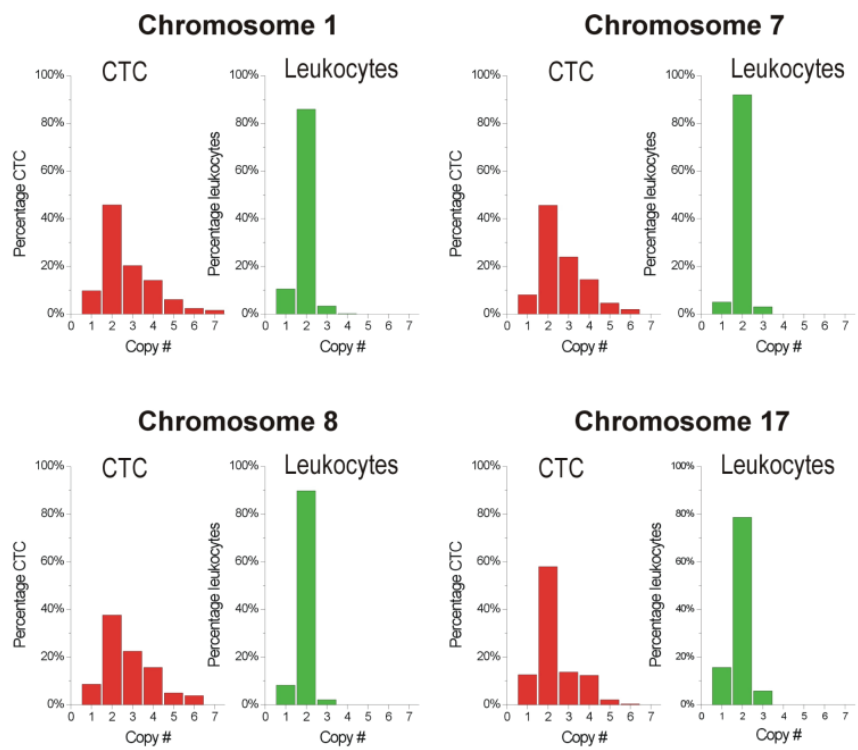

Figure 7.5. Four panels display the histogram of the copy number of chromosomes 1, 7, 8 and 17 of 1793 CTC (red bars) and 537 leukocytes surrounding the CTC (green bars).

The choice of the probes for the centromeres of chromosome 1, 7, 8 and 17 was not to examine prostate cancer, but merely served to demonstrate the reliability of the method. This combination of four probes was also the most aberrant across carcinomas in cytogenetic databases. With this set of probes we confirmed earlier studies that CTC are indeed cancerous[13, 46]. Surprisingly an extreme heterogeneity was observed with respect to the aberrancy of the copy number of chromosome 1, 7, 8 and 17 between patients, but also between CTC in the individual prostate cancer patients. In the few samples with only diploid CTC less than 5 CTC were detected. To quantify the deviation from normal a numerical value was derived and determined for each sample. The value zero represents diploid cells and values obtained for leukocytes indeed were close to zero in contrast large deviations were observed for CTC. The largest deviation from normal was observed for chromosome 8 whereas the smallest deviation was observed for chromosome 1, Figure 7.6. 

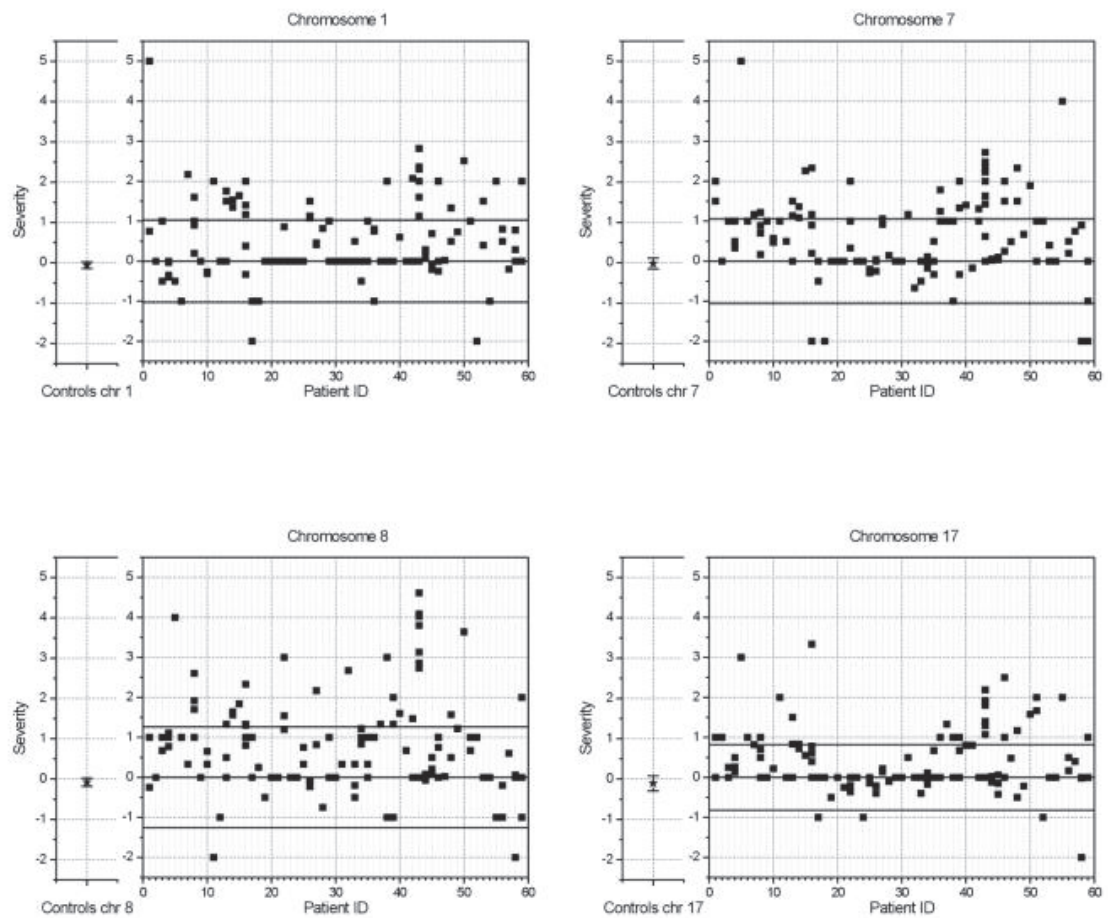

Figure 7.6. Four panels display the deviation from diploid cells in CTC and leukocytes for each sample in each patient of chromosome 1, 7, 8 and 17. The standard deviation for the severity factor is represented by the error bars for the controls and by the solid line in case of patients.

In this study we used DAPI and the fluorochromes PlatinumBright-647, -550, -505 and 415 limiting the number of probes that can be simultaneously assessed to four. The number of treatment targets already exceeds four urging the future expansion to more probes. This may be achieved by increasing the combination of fluorochromes and or explore the feasibility of repeated FISH analysis on the same CTC.

\subsection{References}

1. Cristofanilli M, Budd GT, Ellis MJM, A, Stopeck A, Matera J, Miller MC, Reuben JM, Doyle G V, Allard WJ, Terstappen LWMM, Hayes DF, et al.: Circulating tumor cells, disease progression, and survival in metastatic breast cancer. Semin Oncol 2004, 351:781-791. 
2. Cristofanilli M, Hayes DF, Budd GT, Ellis MJ, Stopeck A, Reuben JM, Doyle G V, Matera J, Allard WJ, Miller MC, Fritsche HA, Hortobagyi GN, Terstappen LWMM: Circulating tumor cells: a novel prognostic factor for newly diagnosed metastatic breast cancer. J Clin Oncol 2005, 23:1420-30.

3. Budd GT, Cristofanilli M, Ellis MJ, Stopeck A, Borden E, Miller MC, Matera J, Repollet M, Doyle G V, Terstappen LWMM, Hayes DF: Circulating tumor cells versus imaging-predicting overall survival in metastatic breast cancer. Clin Cancer Res 2006, 12:6403-9.

4. Hayes DF, Cristofanilli M, Budd GT, Ellis MJ, Stopeck A, Miller MC, Matera J, Allard WJ, Doyle G V, Terstappen LWWM: Circulating tumor cells at each follow-up time point during therapy of metastatic breast cancer patients predict progression-free and overall survival. Clin Cancer Res 2006, 12(14 Pt 1):4218-24.

5. Cohen SJ, Punt CJ a, Iannotti N, Saidman BH, Sabbath KD, Gabrail NY, Picus J, Morse M, Mitchell E, Miller MC, Doyle G V, Tissing H, Terstappen LWMM, Meropol NJ: Relationship of circulating tumor cells to tumor response, progression-free survival, and overall survival in patients with metastatic colorectal cancer. J Clin Oncol 2008, 26:3213-21.

6. de Bono JS, Scher HI, Montgomery RB, Parker C, Miller MC, Tissing H, Doyle G V, Terstappen LWWM, Pienta KJ, Raghavan D: Circulating tumor cells predict survival benefit from treatment in metastatic castration-resistant prostate cancer. Clin Cancer Res 2008, 14:6302-9.

7. Kagan M, Howard D, Bendele T, Rao C, Terstappen L: Circulating tumor cells as cancer markers, a sample preparation and analysis system. Tumor markers Physiol Pathobiol Technol Clin Appl Washington, DC AACC Press 2002495-8 2002, 16:3-6.

8. Allard WJ, Matera J, Miller MC, Repollet M, Connelly MC, Rao C, Tibbe AGJ, Uhr JW, Terstappen LWMM: Tumor cells circulate in the peripheral blood of all major carcinomas but not in healthy subjects or patients with nonmalignant diseases. Clin Cancer Res 2004, 10:6897-904.

9. Hayes DF, Walker TM, Singh B, Vitetta ES, Uhr JW, Gross S, Rao C, Doyle G V, Terstappen LWMM: Monitoring expression of HER-2 on circulating epithelial cells in patients with advanced breast cancer. Int J Oncol 2002, 21:1111-7.

10. Meng S, Tripathy D, Shete S, Ashfaq R, Haley B, Perkins S, Beitsch P, Khan A, Euhus D, Osborne C, Frenkel E, Hoover S, Leitch M, Clifford E, Vitetta E, Morrison L, Herlyn D, 
Terstappen LWMM, Fleming T, Fehm T, Tucker T, Lane N, Wang J, Uhr J: HER-2 gene amplification can be acquired as breast cancer progresses. Proc Natl Acad Sci U S A 2004, 101:9393-8.

11. Meng S, Tripathy D, Shete S, Ashfaq R, Saboorian H, Haley B, Frenkel E, Euhus D, Leitch M, Osborne C, Clifford E, Perkins S, Beitsch P, Khan A, Morrison L, Herlyn D, Terstappen LWMM, Lane N, Wang J, Uhr J: UPAR and HER-2 gene status in individual breast cancer cells from blood and tissues. Proc Natl Acad Sci U S A 2006, 103:173615.

12. Meng S, Tripathy D, Frenkel EP, Shete S, Naftalis EZ, Huth JF, Beitsch PD, Leitch M, Hoover S, Euhus D, Haley B, Morrison L, Fleming TP, Herlyn D, Terstappen LWMM, Fehm T, Tucker TF, Lane N, Wang J, Uhr JW: Circulating tumor cells in patients with breast cancer dormancy. Clin Cancer Res 2004, 10:8152-62.

13. Shaffer DR, Leversha MA, Danila DC, Lin O, Gonzalez-Espinoza R, Gu B, Anand A, Smith K, Maslak P, Doyle G V, Terstappen LWMM, Lilja H, Heller G, Fleisher M, Scher HI: Circulating tumor cell analysis in patients with progressive castration-resistant prostate cancer. Clin Cancer Res 2007, 13:2023-9.

14. de Bono JS, Attard G, Adjei A, Pollak MN, Fong PC, Haluska P, Roberts L, Melvin C, Repollet M, Chianese D, Connely M, Terstappen LWMM, Gualberto A: Potential applications for circulating tumor cells expressing the insulin-like growth factor-I receptor. 2007, 13:3611-6.

15. Tibbe AGJ, Miller MC, Terstappen LWMM: Statistical considerations for enumeration of circulating tumor cells. Cytometry A 2007, 71:154-62.

16. Terstappen LWWM, G.J. D: Magnetic separation apparatus and methods. 2003:United States Patent No: 6,660,159 B1, December 9,.

17. Tibbe AGJ, de Grooth BG, Greve J, Dolan GJ, Rao C, Terstappen LWMM: Magnetic field design for selecting and aligning immunomagnetic labeled cells. Cytometry 2002, 47:163-72.

18. Recamier JCA: L'histoire de le Meme Maladie. Gabor 1829, 2:110.

19. Ashworth TR: A case of cancer in which cells similar to those in the tumours were seen in the blood after death. Aust Med J 1869, 14:146-147. 
20. ENGELL HC: Cancer cells in the circulating blood; a clinical study on the occurrence of cancer cells in the peripheral blood and in venous blood draining the tumour area at operation. Acta Chir Scand Suppl 1955, 201:1-70.

21. Carey RW, Taft PD, Bennett JM, Kaufman S: Carcinocythemia (carcinoma cell leukemia). An acute leukemia-like picture due to metastatic carcinoma cells. Am J Med 1976, 60:273-8.

22. Myerowitz RL, Edwards PA, Sartiano GP: Carcinocythemia (carcinoma cell leukemia) due to metastatic carcinoma of the breast: report of a case. Cancer 1977, 40:3107-11.

23. Gallivan M V, Lokich JJ: Carcinocythemia (carcinoma cell leukemia). Report of two cases with English literature review. Cancer 1984, 53:1100-2.

24. Sile CC, Perry DJ, Nam L: Small cell carcinocythemia. Arch Pathol Lab Med 1999, 123:426-8.

25. Seronie-Vivien S, Mery E, Delord JP, Fillola G, Tkaczuk J, Voigt JJ, Bugat R: Carcinocythemia as the single extension of breast cancer: report of a case and review of the literature. Ann Oncol 2001, 12:1019-22.

26. Ross BAA, Cooper BW, Lazarus HM, Mackay W, Moss TJ, Ciobanu N, Tallman MS, Kennedy MJ, Davidson NE, Sweet D, Winter C, Akard L, Jansen J, Copelan E, Meagher RC, Herzig RH, Klumpp TR, Kahn DG, Warner NE: Detection and viability of tumor cells in peripheral blood stem cell collections from breast cancer patients using immunocytochemical and clonogenic assay techniques [see comments]. 2013:26052610.

27. Vogelstein B, Fearon ER, Hamilton SR, Kern SE, Preisinger AC, Leppert M, Nakamura Y, White R, Smits AM, Bos JL: Genetic alterations during colorectal-tumor development. N Engl J Med 1988, 319:525-32.

28. Ingvarsson S: Molecular genetics of breast cancer progression. Semin Cancer Biol 1999, 9:277-88.

29. Pihan GA, Purohit A, Wallace J, Malhotra R, Liotta L, Doxsey SJ: Centrosome defects can account for cellular and genetic changes that characterize prostate cancer progression. Cancer Res 2001, 61:2212-9. 
30. Kleer CG, Bryant BR, Giordano TJ, Sobel M, Merino MJ: Genetic Changes in Chromosomes 1p and 17p in Thyroid Cancer Progression. Endocr Pathol 2000, 11:137-143.

31. Alers JC, Rochat J, Krijtenburg PJ, Hop WC, Kranse R, Rosenberg C, Tanke HJ, Schröder FH, van Dekken H: Identification of genetic markers for prostatic cancer progression. Lab Invest 2000, 80:931-42.

32. Endo C, Sagawa M, Sato M, Chen Y, Sakurada A, Aikawa H, Takahashi S, Usuda K, Saito Y, Fujimura S: Sequential loss of heterozygosity in the progression of squamous cell carcinoma of the lung. Br J Cancer 1998, 78:612-5.

33. Simon R, Nocito A, Hübscher T, Bucher C, Torhorst J, Schraml P, Bubendorf L, Mihatsch MM, Moch H, Wilber K, Schötzau A, Kononen J, Sauter G: Patterns of her$2 /$ neu amplification and overexpression in primary and metastatic breast cancer. J Natl Cancer Inst 2001, 93:1141-6.

34. Larson CJ, Moreno JG, Pienta KJ, Gross S, Repollet M, O’hara SM, Russell T, Terstappen LWMM: Apoptosis of circulating tumor cells in prostate cancer patients. Cytometry A 2004, 62:46-53.

35. Wang ZP, Eisenberger MA, Carducci MA, Partin AW, Scher HI, Ts'o PO: Identification and characterization of circulating prostate carcinoma cells. Cancer 2000, 88:2787-95.

36. Suriano G, Oliveira MJ, Huntsman D, Mateus AR, Ferreira P, Casares F, Oliveira C, Carneiro F, Machado JC, Mareel M, Seruca R: E-cadherin germline missense mutations and cell phenotype: evidence for the independence of cell invasion on the motile capabilities of the cells. Hum Mol Genet 2003, 12:3007-16.

37. Racila E, Euhus D, Weiss AJ, Rao C, McConnell J, Terstappen LW, Uhr JW: Detection and characterization of carcinoma cells in the blood. Proc Natl Acad Sci U S A 1998, 95:4589-94.

38. Adams AA, Okagbare PI, Feng J, Hupert ML, Patterson D, Göttert J, McCarley RL, Nikitopoulos D, Murphy MC, Soper SA: Highly efficient circulating tumor cell isolation from whole blood and label-free enumeration using polymer-based microfluidics with an integrated conductivity sensor. J Am Chem Soc 2008, 130:8633-41.

39. Campos M, Prior C, Warleta F, Zudaire I, Ruíz-Mora J, Catena R, Calvo A, Gaforio JJ: Phenotypic and genetic characterization of circulating tumor cells by combining 
immunomagnetic selection and FICTION techniques. J Histochem Cytochem 2008, 56:667-75.

40. Pachmann K, Camara O, Kavallaris A, Krauspe S, Malarski N, Gajda M, Kroll T, Jörke C, Hammer U, Altendorf-Hofmann A, Rabenstein C, Pachmann U, Runnebaum I, Höffken K: Monitoring the response of circulating epithelial tumor cells to adjuvant chemotherapy in breast cancer allows detection of patients at risk of early relapse. J Clin Oncol 2008, 26:1208-15.

41. Schindlbeck C, Stellwagen J, Jeschke U, Karsten U, Rack B, Janni W, Jückstock J, Tulusan A, Sommer H, Friese K: Immunomagnetic enrichment of disseminated tumor cells in bone marrow and blood of breast cancer patients by the ThomsenFriedenreich-Antigen. Clin Exp Metastasis 2008, 25:233-40.

42. Nagrath S, Sequist L V, Maheswaran S, Bell DW, Irimia D, Ulkus L, Smith MR, Kwak EL, Digumarthy S, Muzikansky A, Ryan P, Balis UJ, Tompkins RG, Haber DA, Toner M: Isolation of rare circulating tumour cells in cancer patients by microchip technology. Nature 2007, 450:1235-9.

43. Roeser T, Ritzi M, Drese KS, Laureyn W, Liu C, O’Sullivan CK, Ozalp VC, Fermer C, Nilsson O, Hauch S, Albert W, Borgen E, Nygre AOH: Lab-on-chip for the isolation and characterization of circulating tumor cells. Conf Proc . Annu Int Conf IEEE Eng Med Biol Soc IEEE Eng Med Biol Soc Annu Conf 2007, 2007:6447-9.

44. Zheng S, Lin H, Liu J-Q, Balic M, Datar R, Cote RJ, Tai Y-C: Membrane microfilter device for selective capture, electrolysis and genomic analysis of human circulating tumor cells. J Chromatogr A 2007, 1162:154-61.

45. Tveito S, Maelandsmo GM, Hoifodt HK, Rasmussen H, Fodstad O: Specific isolation of disseminated cancer cells: a new method permitting sensitive detection of target molecules of diagnostic and therapeutic value. Clin Exp Metastasis 2007, 24:317-27.

46. Fehm T, Sagalowsky A, Clifford E, Beitsch P, Saboorian H, Euhus D, Meng S, Morrison L, Tucker T, Lane N, Ghadimi BM, Heselmeyer-haddad K, Ried T, Rao C, Uhr J: Cytogenetic Evidence That Circulating Epithelial Cells in Patients with Carcinoma Are Malignant Advances in Brief Cytogenetic Evidence That Circulating Epithelial Cells in Patients with Carcinoma Are Malignant 1. 2002:2073-2084. 


\section{CHAPTER 8: CONSTRUCTION OF REPEAT FREE FLUORESCENCE IN-SITU HYBRIDIZATION (FISH) PROBES}

Joost F Swennenhuis ${ }^{a *}$, Brad Foulk ${ }^{\mathrm{b} *}$, Frank A.W. Coumans ${ }^{\mathrm{a}}$, Leon WMM Terstappen ${ }^{\mathrm{a}}$

a: Department of Medical Cell BioPhysics, MIRA Research Institute, Faculty of Science and Technology, University of Twente , Enschede, The Netherlands;

b: Veridex LLC, Huntingdon Valley , USA.

* Both authors contributed equally

Published in: Nucleic Acids Research, 40, (3) e20. doi: 10.1093/nar/gkr1123, 2012.

Running title: Repeat free FISH probes

Abstract

FISH probes are generally made out of BAC clones with genomic DNA containing a variable amount of repetitive DNA that will need to be removed or blocked for FISH analysis. To generate Repeat Free Probes (RFP) without loss in genomic coverage, a random library is made from BAC clones by Whole Genome Amplification (WGA). Libraries are denatured in the presence of excess Cot-1 DNA and allowed to re-anneal followed by digestion of all double stranded elements by Duplex Specific Nuclease (DSN). Selective amplification of all elements not containing repetitive sequences is realized by a sequential amplification. The final repeat free products can be reamplified and used as a stock for future probe production. The RFP have a lower background, the signal intensity build up is faster and there is no need for blocking 
DNA. The signal intensity of the RFP was equal or higher as compared to repeat containing probes.

\subsection{Introduction}

FISH is a powerful technique for detection of RNA or DNA sequences in cells[1-3]. FISH is applied for gene mapping, diagnosis of chromosomal abnormalities and studies of cellular structure and function. In most cases FISH probes are made out of BAC, YAC or cosmid clones which contain mapped random pieces of genomic DNA. As these probes contain a variable amount of repetitive DNA the hybridization needs to be blocked by a large excess of non-labeled repetitive DNA. To simplify and improve FISH assays several attempts have been made to remove repetitive sequences from isolated genomic sequences[4-7]. Although successful, these techniques are labor intensive and do not provide a source of probes that can be used for the simple production of repeat free FISH probes. Here we introduce a simple and reliable method to remove the repetitive DNA from the FISH probes resulting in an easy PCR amplifiable product without a loss in genomic coverage and probe performance.

\subsection{Methods}

\subsubsection{BAC clones}

Three BAC clones were chosen in the 17q12-17q21.1 region, spanning 454kb of the ERBb2 gene. The BAC clones have a total length of $541 \mathrm{~kb}$. Clones were analyzed using RepeatMasker version 3.2.8 with repeat library RM-20090604 (Smit, AFA, Hubley, R \& Green, P. RepeatMasker Open-3.0. 1996-2010 http://www.repeatmasker.org). A total of $40.2 \%$ of this sequence consists of interspersed repeats from which $52 \%$ is Alu repeat.

\subsubsection{Repeat free procedure}

Three BAC clones spanning a 454kb region over the Erbb2 gene were isolated from the bacterial culture using a Qiagen Large Construct Kit (Qiagen, Hilden, Germany, Cat 12462) minimizing the bacterial genomic DNA in the sample. BAC clones were randomly fragmented according to manufacturer's instructions of the WGA1 kit (Sigma, St Louis, MO, cat WGA-1) linkers were attached and a first round of amplification was performed according to the same manufacturer's instructions. The PCR product was purified with the Qiagen PCR purification kit and quantified using a 
Nanodrop ND1000 (Thermo scientific, Wilmington, DE). 50 ng of this material was added to a 40x excess of C0t-1 DNA (Invitrogen, Carlsbad, CA, cat 15279-011) in $300 \mathrm{mM} \mathrm{NaCl}$ in a total volume of $10 \mu \mathrm{l}$ and denatured for 10 minutes at $95^{\circ} \mathrm{C}$. The mixture was cooled to $65^{\circ} \mathrm{C}$ and allowed to hybridize in the presence of $2 \mathrm{U}$ Duplex specific Nuclease (DSN) (Evrogen, Moscow, Russia, cat EA001) for 90 minutes in 1x DSN buffer in a total volume of $20 \mu \mathrm{l}$. After digestion of the duplex DNA formed during hybridization, the non-restricted fragments of the original BAC clones in the mixture were re-amplified with the WGA-3 kit (Sigma, St Louis, MO,cat WGA-3). From this material $10 \mathrm{ng}$ is used to reamplify to larger quantities with the WGA-3 kit.

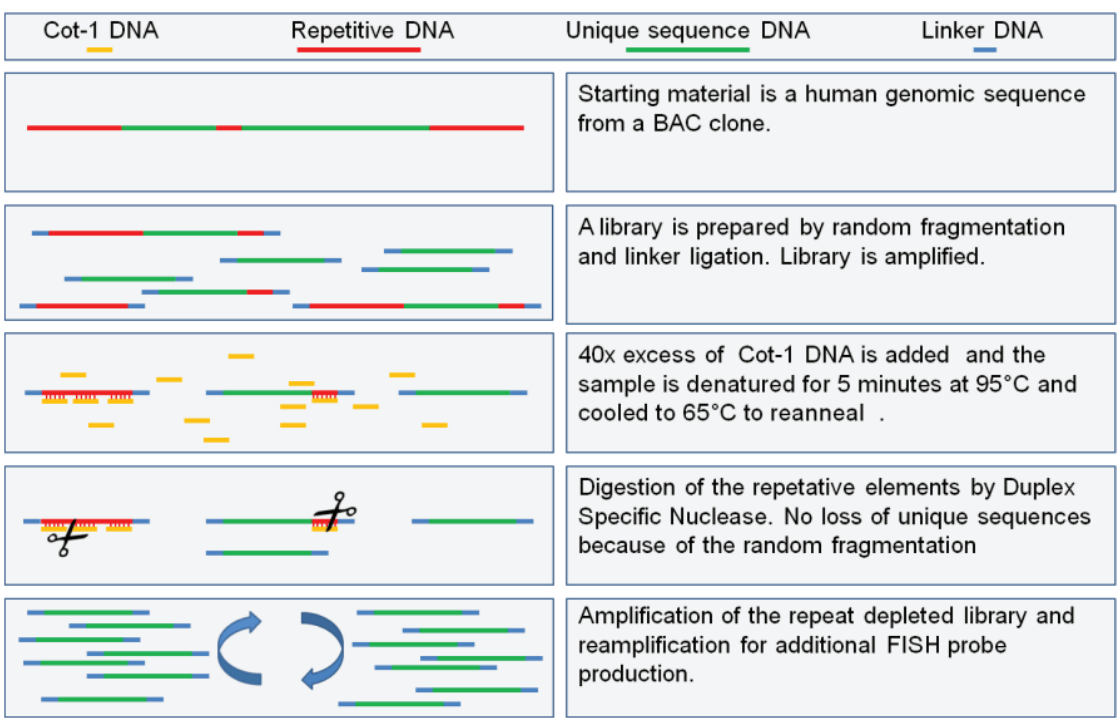

Figure 8.1. Schematic overview for the generation of repeat free FISH probes.

\subsection{3 qPCR}

qPCR was used to measure the depletion of repetitive elements from the WGA BAC DNA by the duplex specific nuclease treatment. PCR primers were designed to amplify a segment of an alu family repeat sequence present in parental BAC clone to obtain a representative repeat sequence (primers: forward CCAGCCTGACCAACATGGA, reverse CCACGCCTGGCTAATTTTGT). As a reference gene, a primer pair was designed to amplify a unique fragment of the coding sequence of Her-2/neu gene also present on the BAC (primers: forward CTGGCCCTGAAAGGGAGTATG, reverse GGACCAAGCTGCTGGGATT). Pre-depletion DNA consisted of the products of the initial whole genome amplification reaction (figure 8.1). Post-depletion samples were DNA samples from the third sequential PCR following repeat depletion. Ct values reflect the 
average Ct of duplicate PCR measurements using one nanogram of DNA as template in each reaction. Time of exposure to Duplex specific Nuclease was also measured by qPCR for time points from 0 to 90 minutes. $\Delta C t$ was defined as the $\mathrm{Ct}$ of the reference primer pair minus the CT of the repetitive primer pair. $\Delta \Delta \mathrm{Ct}$ is defined as the $\Delta \mathrm{Ct}$ of the pre depletion samples minus the $\Delta$ Ct of the post DSN depletion samples. A log Delta RN value of 60 was set as the threshold foc Ct calculations.

\subsubsection{FISH Probe labeling}

Repeat free and non-repeat free PCR products were purified with the Qiagen PCR purification kit (Qiagen, cat 28106), fragmented by sonification to a size of 100-400 bp and quantified using a Nanodrop ND1000. Fragmented PCR products were labeled with dy550-ULS (Kreatech, Amsterdam, The Netherlands) according to manufacturer's instructions.

\subsubsection{Hybmix}

Labeled probes were diluted to a final concentration of $4 \mathrm{ng} / \mu \mathrm{l}$ in a mixture of $50 \%$ deionized formamide (Invitrogen, Carlsbad, CA, cat.AM9342), 1xSSC (Sigma, St Louis, M0,cat S6639) and 10\% dextran sulfate(Sigma, St Louis, M0,catD8906). Labeled repetitive sequences in the non-repeat free probes were blocked with a $25 \mathrm{x}$ excess of C0t-1 DNA (Invitrogen, Carlsbad, CA, cat 15279-011)).

\subsubsection{FISH}

Formalin fixed and paraffin embedded MCF7 cells were sectioned at $5 \mu \mathrm{m}$, mounted to microscope slides (Menzel, Braunschweig, Germany cat.J3800AMNZ) and were baked overnight at $50^{\circ} \mathrm{C}$. Slides were pretreated with the Poseidon tissue pretreatment kit (Kreatech, Amsterdam, The Netherlands) according to the package insert with a 15 minute pepsin treatment. $10 \mu \mathrm{l}$ hybmix was applied under an $18 x 18 \mathrm{~mm}$ coverslip and sealed with rubber cement (Kreatech, Amsterdam, The Netherlands). Samples were co-denatured for 5 minutes at $80^{\circ} \mathrm{C}$ and hybridized at $42^{\circ} \mathrm{C}$. After hybridization the rubber cement and coverslips were removed and slides were washed for 10 minutes at $37^{\circ} \mathrm{C}$ and for 2 minutes at $72^{\circ} \mathrm{C}$ in $0.4 \mathrm{xSSC} / 0.1 \%$ tween 20 . Next slides were dehydrated and dried. $10 \mu \mathrm{l}$ Vectashield/DAPI (Vector labs, Burlingame, CA, cat H1200) was applied and covered with a coverslip. 


\subsubsection{Signal and background measurements}

Slides were analyzed under a Nikon Eclipse E200 microscope using a 100x oil 1.3NA objective (Nikon, Amstelveen, the Netherlands) For each slide 5 non-saturated frames were captured using a 12 bit camera (Hamamatsu, Hamamatsu city, Japan).

\subsection{Results}

\subsubsection{Repeat removal process}

A schematic overview for the generation of repeat free FISH probes is illustrated in Figure 8.1. A library from three BAC clones spanning a $454 \mathrm{~kb}$ region over the Erbb2 gene was generated by Whole Genome Amplification (WGA). After purification and quantification of the PCR product a 40x Excess of C0t-1 DNA was added and denatured at $95^{\circ} \mathrm{C}$. The mixture was cooled to $65^{\circ} \mathrm{C}$ and allowed to hybridize in the presence of 2U Duplex Specific Nuclease (DSN). After digestion of the duplex DNA formed during hybridization, the non-restricted fragments of the original WGA library were reamplified by three sequential WGA reamplifications. DNA from the third round WGA reamplification was sonicated, fluorescently labeled, and used as FISH probe without the use of blocking DNA.

\subsubsection{Measurement of repetitive sequence removal}

Real time qPCR was used to measure the depletion of repetitive elements from the WGA BAC DNA by the DSN treatment. As a representative repeat sequence, PCR primers were designed to amplify a segment of an alu family repeat sequence present in the parental BAC clone. As a reference gene, a primer pair was designed to amplify a unique fragment of the coding sequence of Her-2/neu gene also present on the BAC. 


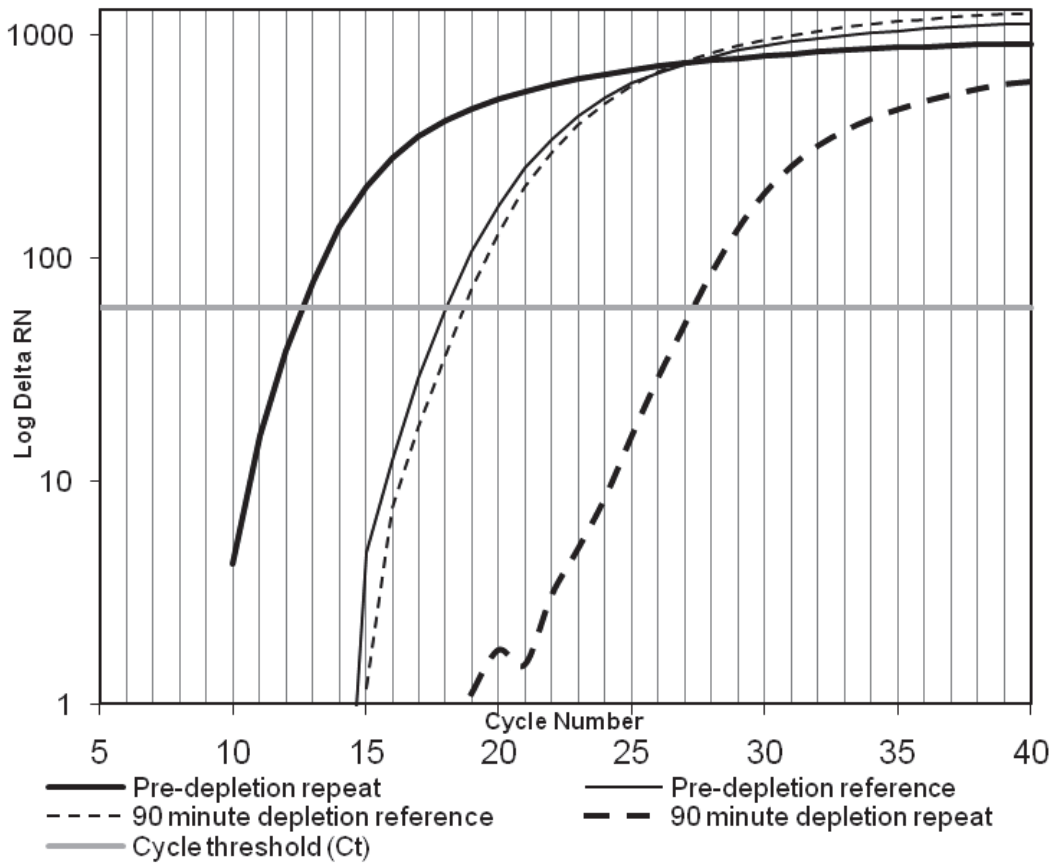

Figure 8.2. Quantitative PCR measurement of repeat depletion after 90 minutes Duplex Specific Nuclease treatment. Real-time qPCR was used to measure the depletion of repetitive elements from the WGA BAC DNA by the duplex specific nuclease treatment. As a representative repeat sequence, PCR primers were designed to amplify a segment of an alu family repeat sequence present in parental BAC clone. As a reference gene, a primer pair was designed to amplify a unique fragment of the coding sequence of Her-2/neu gene also present on the BAC. Predepletion DNA consisted of the products of the initial whole genome amplification reaction (figure 8.1). Post-depletion samples were DNA from the third sequential PCR following repeat depletion. Ct values reflect the average Ct of duplicate PCR measurements using one nanogram of DNA as template in each reaction.

Figure 8.2 shows the quantitative PCR measurement of repeat depletion after 90 minutes DSN treatment. It shows mass normalized PCR data for the reference and repeat sequence before and after repeat depletion with the described procedure. The Ct value of the repetitive sequence increased by 14.7 cycles after depletion whereas the $\mathrm{Ct}$ value for the reference sequence increased by only 0.6 cycles. This demonstrates that the depletion reaction heavily favors removal of a representative repetitive sequence compared to unique sequences. Normalization of the repetitive primer pair to the reference primer pair yielded a $\Delta \Delta \mathrm{Ct}$ value of 14.1 cycles for the sample treated for 90 minutes with duplex specific nuclease. Aliquots of this reaction 
were removed at 30 and 60 minutes and these samples showed $\Delta \Delta \mathrm{Ct}$ values of 9.2 and 11.4, respectively (data not plotted). This illustrates that increasing the amount of time of exposure to DSN results in increased relative depletion of the repeat sequences.
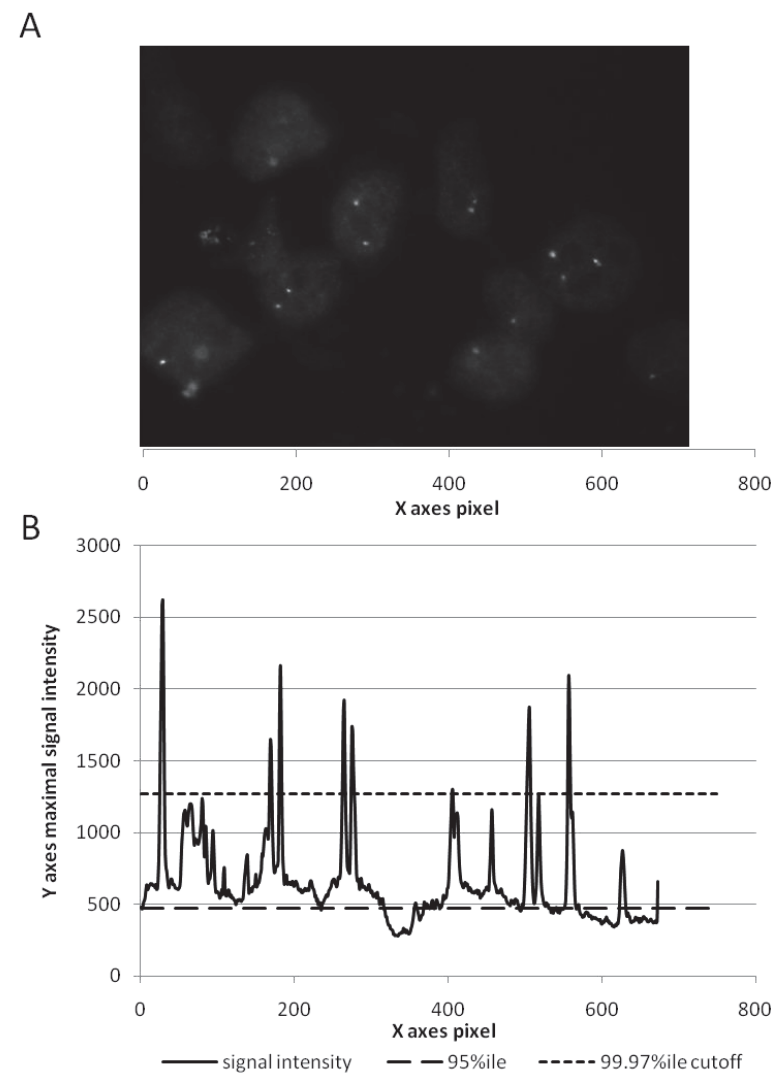

Figure 8.3. $5 \mu \mathrm{m}$ thick Formalin fixed paraffin embedded (FFPE) MCF7 cells hybridized with probes directed against the Her2/neu (17q21) region were analyzed in time for signal and background intensities. 3A) Example of a picture of the 8 hour hybridization of the repeat containing probe. For each probe and time point 5 different unsaturated pictures were taken. 3B) Maximum signal intensity profile of the picture 3A with the $99.97 \%$ ile line cutoff for the signal intensity and the $95 \%$ ile line for the background value. Signal value is determined by taking the mean of the mean of the values above the 99.97\%ile line. Background is the $95 \%$ ile level.

To obtain an objective measure of the fluorescence background and signals obtained from FISH probes after hybridization with the tissue, quantitative fluorescence 
measurements were extracted from the images. Figure 8.3 shows the principles of these measurements using an image taken with a 100x oil 1.3NA objective from a tissue sample hybridized with dy550 labeled Her2 probe. The pictures contain either out-of-focus signals as well as dark areas in between the cells. Since only the in-focus signals and the background inside the nuclei are of interest we used the mean of the mean of the signals above the 99.97 percentile (\%ile) line to determine the signal intensity. The pictures contained on average 10.8 signals in a range of 7 to 18 signals. Since the FISH signals are small all peaks will fall into the highest 5 \%ile. The $95 \%$ ile value will therefore reflect the background signal in the nuclei for pictures with a lower background signal in between the nuclei. All pictures that were taken have a low background signal in between the nuclei.

To compare the signal to background of repeat containing and repeat free probes $5 \mu \mathrm{m}$ thick sections of formalin fixed paraffin embedded cells from the breast cancer tumor cell line MCF7 were hybridized with repeat free and repeat containing probes directed against the Her2/neu (17q21) region. The assays were performed at different hybridization times to uncover differences in the kinetics of the probes. For each experiment the signal and background values of five different images were evaluated for each time point. As is shown in Figure 8.4 the optimal signal to background is already achieved after a couple of hours for the repeat free probes whereas the signal to background still rises for the repeat containing probes but never reached the maximum that was reached for the repeat free probes. Figure 8.5 shows repeat free probes made against different targets and labeled with different fluorochromes on normal metaphase spreads and hybridized without the use of Cot-DNA. 


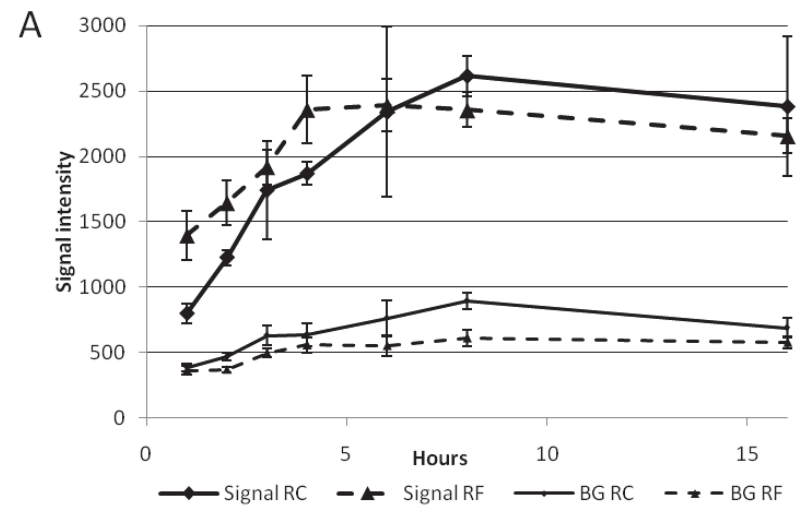

B

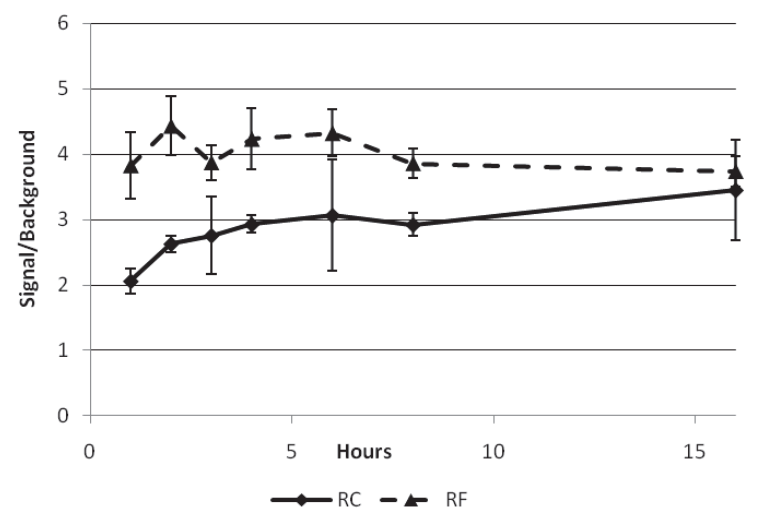

Figure 8.4. Performance of FISH probe with and devoid of repetitive sequences. $5 \mu \mathrm{m}$ thick Formalin fixed paraffin embedded (FFPE) MCF7 cells hybridized with probes directed against the Her2/neu (17q21) region were analyzed in time for signal and background intensities. 4A) Background and signal intensities of the Repeat Free (RF) and Repeat Containing (RC) probes. 4B) The signal/background ratio of the values shown in $4 \mathrm{~A}$. 

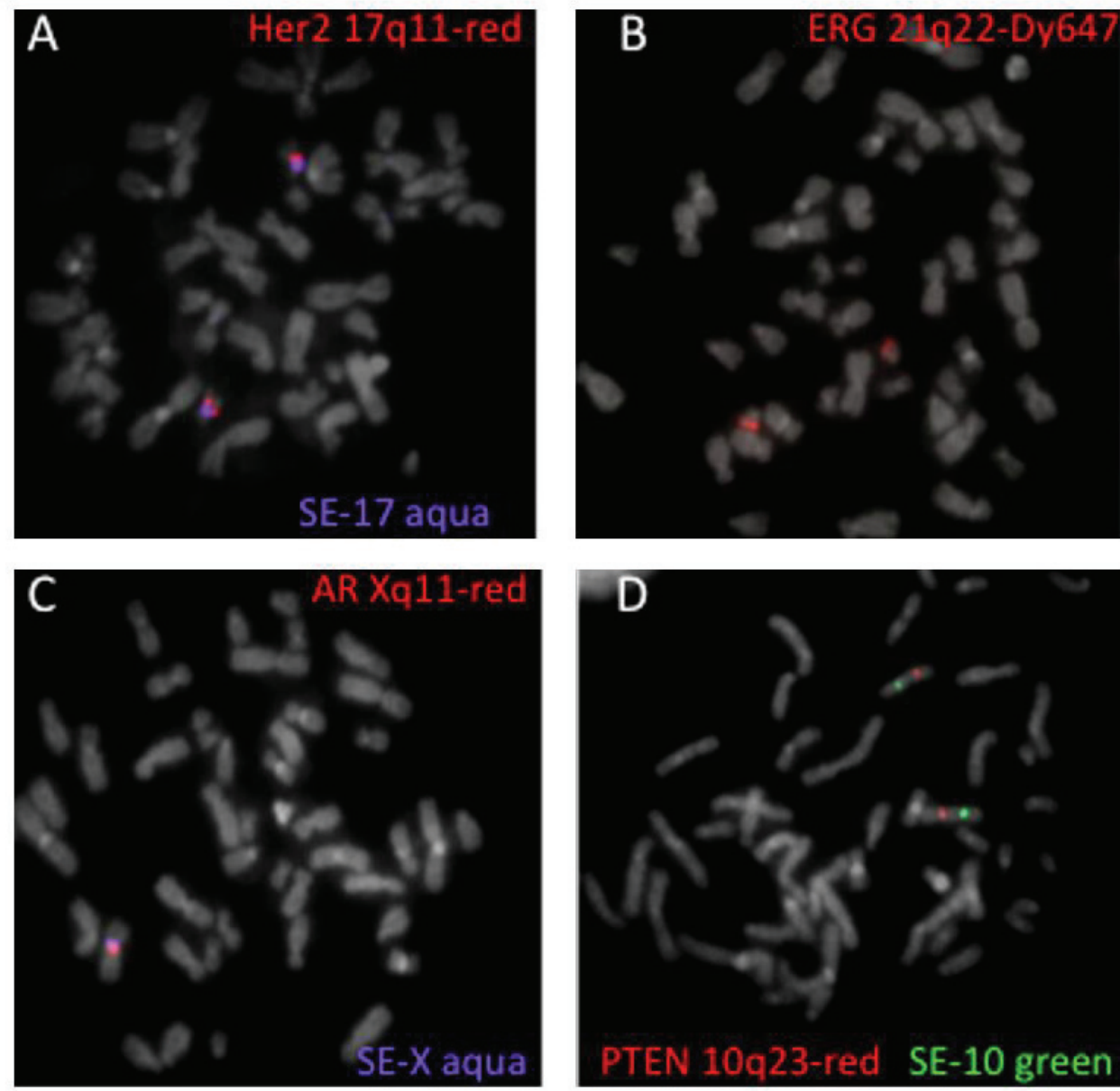

Figure 8.5. Examples of hybridizations of four different FISH probes after hybridization on metaphase spreads without the use of blocking DNA.

\subsection{Discussion}

A method is introduced for the generation and production of repeat free FISH probes. A library is prepared from a BAC clone containing a human genomic sequence by random fragmentation and linker ligation followed by amplification of the library. By allowing Cot-1 DNA to anneal to the repetitive sequences, double stranded DNA is generated that now can be digested by Duplex Specific Nuclease. Due to the random fragmentation of the library all unique sequences will still be represented. The resulting product can now serve as a source for the production of unlimited amount of repeat free FISH probes. 
BAC or YAC isolations contain an unpredictable amount of genomic DNA from the host depending on the individual culture, isolation method and user. The repetitive DNA contributes on average around $50 \%$ of the genomic DNA and will be labeled when it is not removed. The same happens with the variable amount of bacterial genomic DNA co-isolated in the classical BAC isolation procedures. The removal of the repeats therefore leads to a more efficient probe labeling. By excluding the variability in probe production, the individual probes do not need extensive validation and optimization for every production batch. The method is not restricted to the target area or size of the probes and already have been successfully applied for a large number of FISH probes [8] and has been validated in an independent study for the Her2 amplification[9].

Elimination of the necessity to add blocking DNA in a FISH assay simplifies the assay procedure, reduces the assay time, cost and background fluorescence signals while maintaining the specificity and signal to noise ratio of the FISH probes.

\subsection{References}

1. Bauman JG, Wiegant J, Borst P, van Duijn P: A new method for fluorescence microscopical localization of specific DNA sequences by in situ hybridization of fluorochromelabelled RNA. Exp Cell Res 1980, 128:485-490.

2. Tkachuk DC, Pinkel D, Kuo WL, Weier HU, Gray JW: Clinical applications of fluorescence in situ hybridization. Genet Anal Tech Appl 1991:67-74.

3. Arnoldus EP, Wiegant J, Noordermeer IA, Wessels JW, Beverstock GC, Grosveld GC, van der Ploeg M, Raap AK: Detection of the Philadelphia chromosome in interphase nuclei. Cytogenet Cell Genet 1990, 54:108-111.

4. Rogan PK, Cazcarro PM, Knoll JHM: Sequence-based design of single-copy genomic DNA probes for fluorescence in situ hybridization. Genome Res 2001, 11:1086-1094.

5. Craig JM, Kraus J, Cremer T: Removal of repetitive sequences from FISH probes using PCR-assisted affinity chromatography. Hum Genet 1997, 100:472-476.

6. Fuscoe JC, Collins CC, Pinkel D, Gray JW: An efficient method for selecting uniquesequence clones from DNA libraries and its application to fluorescent staining of human chromosome 21 using in situ hybridization. Genomics 1989, 5:100-109. 
7. Milner JJ, Cecchini E, Dominy PJ: A kinetic model for subtractive hybridization. Nucleic Acids Res 1995, 23:176-187.

8. Attard G, Swennenhuis JF, Olmos D, Reid AHM, Vickers E, A'Hern R, Levink R, Coumans F, Moreira J, Riisnaes R, Oommen NB, Hawche G, Jameson C, Thompson EE, Sipkema R, Carden CP, Parker C, Dearnaley D, Kaye SB, Cooper CS, Molina A, Cox ME, Terstappen LWMM, de Bono JS: Characterization of ERG, AR and PTEN gene status in circulating tumor cells from patients with castration-resistant prostate cancer. Cancer Res 2009, 69:2912-8.

9. Francz M, Egervari K, Kardos L, Toth J, Nemes Z, Szanto J, Szollosi Z: Comparison of Pathvysion and Poseidon HER2 FISH assays in measuring HER2 amplification in breast cancer: a validation study. J Clin Pathol 2010, 63:341-346. 


\section{CHAPTER 9: SELF-SEEDING MICROWELL CHIP FOR THE ISOLATION AND CHARACTERIZATION OF SINGLE CELLS}

Joost F Swennenhuis ${ }^{a}$, Arjan GJ Tibbe ${ }^{b}$, Michiel Stevens ${ }^{b}$, Madhumohan Rao Katikaa, Joost van Daluma, Hien Duy Tongc, Cees JM van Rijnd, Leon WMM Terstappena

a: Medical Cell BioPhysics group, MIRA Institute, University of Twente, Hallenweg 23, 7522 NH, Enschede, The Netherlands

b: VyCAP, Abraham Rademakerstraat 41, 7425PG Deventer,, The Netherlands

c: Laboratory for Nanotechnology, Vietnam National University, HoChiMinh, Vietnam

d: Laboratory of Organic Chemistry, Dreijenplein 8, University of Wageningen, Wageningen, the Netherlands

Published in: Lab on a Chip, doi: 10.1039/C5LC00304K, 2015

Running Title: Microwell single cell isolation

Abstract

A self-seeding microwell chip is introduced for the isolation and interrogation of single cells. A cell suspension is transferred to a microwell chip containing 6400 microwells, each microwell with a single $523 \mu \mathrm{m}$ pore in the bottom. The fluid enters the microwell and drags a cell onto the pore. After a cell has landed onto the pore, it will stop the fluid flow through this microwell. The remaining fluid and cells will be 
diverted to next available microwell. This results in a fast and efficient distribution of single cells in individual microwells. After identification by fluorescence microscopy, the cells of interest are isolated from the microwell by punching the bottom together with the cell. The overall single cell recovery of seeding followed by isolation of the single cell, is $>70 \%$ with a specificity of $100 \%$ as confirmed by the genetic make-up of the isolated cells.

\subsection{Introduction}

Cell populations can be very heterogeneous and to study this heterogeneity in any given cell population is a complex task, for which efficient screening methods are needed. Understanding how cells function transform and react to different stimuli and how this relates to genetic and epigenetic changes requires isolation, characterization and interrogation of single cells. This has led to a large variety of technologies to isolate and investigate single cells, which include limited dilution sedimentation in microwells[1], cell picking using micropipettes[2, 3], magnetic rafts[4], fluorescence activated cell sorting (FACS)[5], laser-capture microdissection[6], dielectrophoresis[7] and a variety of microfluidic chips with different structures and different underlying cell isolation principles[8-10]. Recent simplification of methodologies and improvement of reagents to amplify DNA at the single cell level, allowed single cell Whole Genome Amplification (WGA) on a single microfluidic chip followed by a transfer of the amplified DNA to a sequencing platform[11, 12]. Although these technologies have proven their value within the field of single cell analysis, they are hampered typically by low throughput, labor intensiveness, and high cell losses. The first two arguments avoid the use of these technologies on a large scale and will limit their use in the clinic, while high cell loss is unacceptable in cases where only very few cells are present. An example of such is the detection and characterization of Circulating Tumor Cells (CTC) in the blood of cancer patients with disseminated disease.

Although the number of tumor cells circulating in the blood within these patients is very low (0 - 10 per $\mathrm{ml}$ ) the number of cells present is inversely proportional to overall survival chances[13-15]. Next breakthrough in the promise of CTC research is to uncover treatment targets enabling the administration of a therapy with a high likelihood of being effective. The extremely low frequency of CTC appearance and its inherent heterogeneity dictates the need for an efficient analysis method at the single cell level. A variety of technologies have been introduced to enrich and count CTC 
from blood[16] but these are restricted by inefficiency to isolate individual CTC for further molecular characterization to unveil the best treatment strategy.

Here we introduce a simple solution that combines single cells seeding in individual microwells in combination with an efficient method to isolate these single cells characterization by fluorescence microscopy.

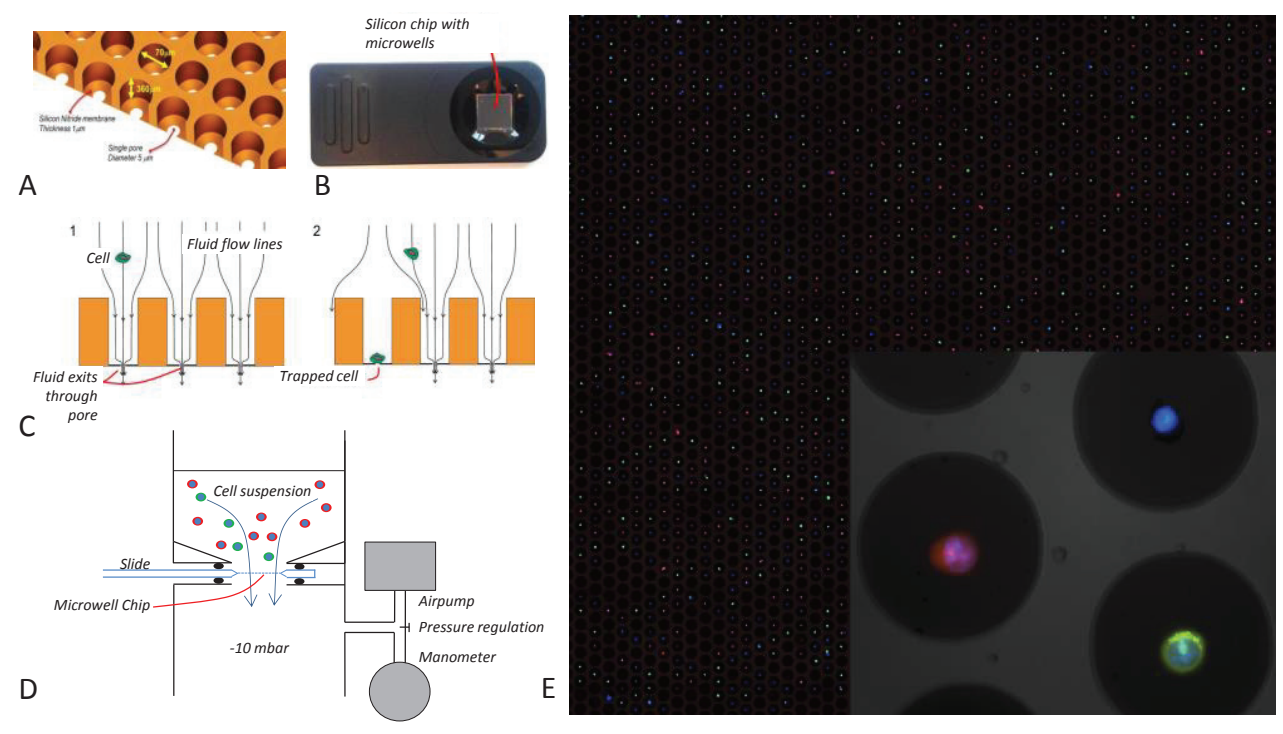

Figure 9.1. Self-seeding microwells. A) Impression of the microwells. Microwells have a diameter of $70 \mu \mathrm{m}$ and depth of $360 \mu \mathrm{m}$. The bottom consists of $1 \mu \mathrm{m}$ SiNi with a pore in the center of the microwell. B) The microwells are present in a $10 \times 10 \mathrm{~mm}$ Silicon chip that is mounted in a plastic slide to facilitate handling and seeding. C) Fluid enters the microwells from the top and exits the microwells through the pore in the bottom. Cells are dragged inside the microwell and land onto the pore at the bottom of the microwell. D) Schematic representation of the filtration system. The slide with the microwell chip is inserted into a holder and the cellsuspension is applied on top of the slide. Cells are forced into the microwells by applying a negative pressure of 10 mbar under the slide using an air pump, manometer and a pressure regulator. E) Microwell containing cells from the prostate cancer cell lines LNCaP (Hoechst (blue), CellTracker Green (green)) and PC3 (Hoechst, CellTracker Orange (red)) and cells from the breast cancer cell line SKBR3 (Hoechst). Insert presents a magnification of the microwells. 


\subsection{Methods}

\subsubsection{Microwell chip fabrication}

Basic process steps to produce a microwell chip. A low stress silicon nitride layer with a thickness of $900 \mathrm{~nm}$ is deposited on a $360 \mu \mathrm{m}$ thick polished mono crystalline silicon wafer by means of LPCVD (Low-Pressure Chemical Vapour Deposition). A photosensitive lacquer layer is applied by spincoating on the silicon nitride layer and patterned with pores of $5 \mu \mathrm{m}$ with an interpore spacing of $100 \mu \mathrm{m}$ by exposing it to UV light through a photo mask. The pattern in the photosensitive layer is transferred into the silicon nitride membrane by means of RIE (Reactive Ion Etching) with a CHF3/02-plasma. Next the backside of the wafer is patterned with openings with a diameter of $70 \mu \mathrm{m}$ with an interpore spacing of $100 \mu \mathrm{m}$. Subsequently this pattern is first transferred into the silicon nitride membrane and next in the silicon wafer by means of DRIE (Deep Reactive Ion Etching) with a SF6/02-plasma and cryogenic substrate cooling. Herewith microwells are obtained with straight walls with a depth of $360 \mu \mathrm{m}$ and a diameter of $70 \mu \mathrm{m}$.

\subsubsection{Cell lines}

The PC3 and the LNCaP cell line were kindly provided by the Institute of Cancer Research, London, UK. Both cell lines were cultured using RPMI (Sigma, St. Louis, MO, USA) supplemented with 10\% fetal calf serum (Gibco, Invitrogen, Carlsbad, CA, USA), 1\% l-glutamin (Sigma) and 1\% penicillin-streptomycin (Gibco). SKBR-3 cell line was provided by Immunicon Corp (Huntingdon Valley, PA, USA) and were cultured in DMEM (Sigma, St. Louis, MO, USA) with the same additives. PC3 Cells were stained using anti-EpCaM-FITC antibody (Aczon, Bologna, Italy) and LNCaP cells were stained using anti-CK-PE (Janssen Diagnostics, Huntingdon Valley, PA, USA). Cells of all three cell lines were counterstained with $10 \mathrm{mM}$ Hoechst 33342 (Invitrogen). Cells were harvested after washing with $10 \mathrm{ml}$ PBS and using $0.05 \%$ trypsin (Gibco) for 5 minutes at $370 \mathrm{C}$.

For spiking experiments the exact number of spiked cells was determined by putting 10 drops, each $1 \mu \mathrm{l}$, of culture medium with the fluorescently labeled cells, on a microscope slide. The number of cells in each drop was counted and immediately washed of the slide into the sample volume. Next the slides were checked for any remaining cells and these are subtracted from the number of cells counted.

\subsubsection{Single cell isolation of viable cells}

Cells from the cancer cell lines SKBR-3, PC3 and LNCaP were fluorescently labeled by adding $10 \mu$ M Fluorescein Diacetate (FDA) (Sigma, St. Louis, MO, USA) to the culture 
medium (DMEM for SKBR3 / RPMI for PC3 and LNCaP) for 5 minutes at room temperature after which the cells were washed twice with culture medium. 24 hours after punching cells are also stained with Propidium Iodide (PI) (Sigma, St. Louis, MO, USA) at a concentration of $1 \mu \mathrm{g} / \mathrm{ml}$.

\subsubsection{Single Cell Seeding}

Self-sorting microwell chips were degassed in a vacuum chamber at -1.0 bar for 15 minutes in PBSt (PBS/0.1\% Triton-X-100). After degassing, the microwells were placed in a filtration holder (not shown, VyCAP, the Netherlands). A sample volume of $1 \mathrm{ml}$ with predetermined number of cells was was added on top of the microwell chip and a pressure of -10 mbar under was applied. After seeding was completed, the microwell chip was removed from the filtration device and scanned on the puncher microscope and fluorescence images were acquired using a 10x, N.A. 0.45 objective. After scanning, the microwells were left to dry in a laminar flow hood at room temperature.

\subsubsection{DNA WGA}

Five microliter of pure Ethanol was added to each of the PCR cups in which a cell or empty bottom was punched. Next, the PCR plate was put on a PCR plate mixer (Thermomixer C, Eppendorf, Germany) at $3000 \mathrm{rpm}$ for a few seconds followed by a short spin in a Labnet MPS1000 plate centrifuge. This will spin down all punched cells that might have ended on the walls of the PCR cups which would therefore not be accessable for the WGA reagents.

The reaction end volume of the WGA reaction of commercial available kits is larger than the volume of a cup of a 384 PCR plate. To reduce the end reaction volume the prescribed protocols of the used three WGA kits were slight modified.

\subsubsection{Genomiphi kit (GE, Buckinghamshire, UK)}

The prescribed cell lysis is replaced by proteinase $\mathrm{K}$ lysis. Proteinase-K (Sigma) solution ( $1 \mu \mathrm{l}, 5 \mathrm{U} / \mathrm{ml}$ in 10mMTris, pH8.0) was added to all PCR cups in which a cell was punched and to three empty cups as a negative control. The PCR cups were treated 1 hour at $50^{\circ} \mathrm{C}$ followed by a 10 minute inactivation of the proteinase $\mathrm{K}$ at $96^{\circ} \mathrm{C}$ and next cooling to $4^{\circ} \mathrm{C}$. WGA mix was prepared according to the manufacturer's instructions. Five $\mu \mathrm{l}$ of WGA mix was added to each PCR cup and the sample was incubated for 250 minutes at $30^{\circ} \mathrm{C}$ on a BioRad CFX 384 qPCR machine while measuring the fluorescence intensity every 5 minutes. 


\subsubsection{Ampli-1 (Silicon Biosystems, San Diego, CA, USA)}

The kit is applied to the PCR cups according to the manufacturer's prescription except that $1 / 3$ th of the reagent volume is used.

\subsubsection{NEB Single Cell Whole Genome Amplification kit (NEB, Ipswich, MA, USA)}

The kit is used according to the manufacturer's instructions except that $1 / 4$ th of the volume is used. To the amplification reaction volume of all three kits, $1 / 40$ th of the total WGA reaction volume of EvaGreen (Biotium, Hayward, CA, USA) was added to measure the amplification reactions in real-time.

\section{Sanger Sequencing}

After punching of SKBR-3, PC3 and LNCaP cells, WGA was applied using the Ampli-1 WGA kit. PCR reactions were performed on the WGA amplified DNA across the two specific mutations for the LNCaP and PC3 cell line. The LNCaP cell line has a heterozygous mutation in the PTEN gene (CR450306.1:c.16,17 delAA). The PC3 celline has a heterozygous mutation in the ROBO-2 gene (NM001128929.3:c. $508 \mathrm{C}>\mathrm{T}$ ). Primers used were Pten: forward: 5'AGTCCAGAGCCATTTCCATC3' reverse: 5'GTCTAAGTCGAATCCATCCTCTTG3' and ROBO2 forward: 5'GGAGCATCCTTCCGATGT3' and reverse: 5'CACGATGCGCAAGAAGAATAAG3'. PCR is performed using $1 \mu \mathrm{l}$ of a 100x dilution of the Ampli-1 amplified product. PCR products were Sanger sequenced.

\subsection{Results}

\subsubsection{Self Seeding Microwell Chip}

The self-seeding microwell chip comprises 6400 microwells in an effective area of 8x8 $\mathrm{mm} 2$. Each microwell has a diameter of $70 \pm 2 \cdot \mathrm{m}$, a depth of $360 \pm 10 \cdot \mathrm{m}$ and a volume of $1.4 \mathrm{~nL}$. The bottom of the microwell is a thin, optical transparent, silicon nitride ( $\mathrm{SiNi}$ ) membrane with a thickness of $1 \mu \mathrm{m}$, having a single pore with a diameter of $5 \mu \mathrm{m}$ in the center. An impression of the microwell chip is shown in figure 9.1 panel A. To facilitate the microfluidic handling and cell seeding, the chip is mounted in a plastic slide (Figure 9.1, panel B) that fits in a filtration disposable (not shown, VyCAP, the Netherlands). More fabrication details can be found in section 3 . The principle of the self-seeding microwell chip is depicted in panel C of figure 9.1. A cell suspension is transferred to the microwells, and a small negative pressure of 10 mbar is applied across the microwells (figure 9.1, panel D). The fluid enters the microwells from the supply side and leaves the microwells through the pore at the 
bottom of the well. Hydrodynamic forces drag individual cells into the wells towards the pore in the center of the bottom of the microwell. Simulation models of the pressure and flow in the microwells are available in the supplementary data S2. The diameter of the pore is smaller than the dimension of the cells of interest. After a cell has landed onto the pore the sample flow through that particular microwell stops and no other cell will enter the same microwell. The next cell is then diverted to a neighboring well. In this manner single cells are 2D seeded in individual wells across the entire microwell chip until all single cells occupy individual microwells. After the microwells are filled with single cells, these cells are imaged through the bottom of the optical transparent silicon nitride using an inverted fluorescence microscope that acquires images of the entire microwell chip in an automated fashion. Figure 9.1, panel E presents a fluorescence image of single cells collected in individual microwells. In this case a mixture of three cell lines, i.e. SKBR-3, LNCaP and PC3, that are labeled with a combination of fluorescent labels, are seeded into the microwells. In total 2400 cells were seeded, 800 of each cell line. The image shows that each of the microwells contains a single cell that is present at the pore in the center of the microwell. In some wells two cells are visible. Since these are cultured cells a portion of the cells will be present in cell clusters and these will block the pore and stop the flow. In experiments with polystyrene beads only wells with one bead are observed. The insert shows a magnification of three microwells with a single cell of one of these three cell lines.

\subsubsection{Single cell seeding efficiency.}

The graph of figure 9.2 shows the theoretical possibility of capturing a single cell in a microwell by flow through self-seeding, where the fluid exits the pore at the bottom, compared to gravity sedimentation, using microwells without a pore in the bottom of the microwell. The probabilities of having n cells in a well are calculated using Poisson

statistics $P(N=n)=e^{-\lambda} \frac{\lambda^{n}}{n^{!}}$. In case of gravity seeding $\lambda$ is equal to the number of cells in the sample divided by the number of available wells. In case of self seeding, $\lambda$ equals the number cells present in the sample divided by the number of volume units of $1.4 \mathrm{~nL}$ (volume of a single microwell) present in the total sample volume. The $\mathrm{x}$-axis displays the ratio number of cells / number of microwells. The y-axis displays the probability that a cell containing microwell contains just 1 cell. The solid lines represent the probability for a self-seeding microwell using a sample volume of $1 \mathrm{ml}$ and $0.1 \mathrm{ml}$. At high cell concentrations there is a larger possibility that more than one 
cell enters a microwell before a cell has landed on the pore and closed the sample fluid inlet, resulting in more than one cell per microwell. Although the effect of sample volume is small it may be advantageous to use large sample volumes when using the microfluidic cell seeding method. The dashed lines represent the situation in case the cells are seeded using gravity sedimentation. In contrast to the flow through selfseeding, the probability to obtain a single cell per microwell is highly depending on the ratio [number of cells] / [number of microwell] and this drops to 58\% when the number of cells is equal to the number of wells. The probability that a cell containing microwell contains more than 1 cell $(\mathrm{N}>1)$ starts at 0 and in case of sedimentation rises to $42 \%$. The probability of having more than one cell in a self-seeding microwell is $0.3 \%$ and cannot be visualized in this graph. In this theoretical situation it is assumed that the walls in between the microwells are infinite thin and that the area with microwells is equal to the footprint of the sample volume on top. In reality this however will never be the case and loss of cells that land on top of the walls in between the microwells is inevitable and this will result in additional cell losses in case sedimentation is used. Using the self-seeding microwells the single cells are not only directed to the next available microwell but it also forces the cells towards the area with the microwells herewith limiting the loss of cells that land on areas without microwells. Besides increasing the seeding efficiency, the pores in the bottom of the microwell act as well as a size discriminator. Only cells that are large enough to block the pore are captured. At a negative pressure difference across the pores of $10 \mathrm{mbar}$ the flow rate through the 6400 pores of the microwells is typically $1 \mathrm{~mL} / \mathrm{min}$. As more pores become occupied by events larger than the pore diameter the flow rate reduces linear with the percentage of blocked pores. At a negative pressure difference of 10 mbar across the pores, the capture efficiency of viable cells from the cell lines LNCaP (average diameter $15 \mu \mathrm{m}$ ), PC3 (average diameter $19.5 \mu \mathrm{m}$ ) and SKBR-3 (average diameter $19.1 \mu \mathrm{m}$ ) were respectively 58\%, 71\% and 73\%. Detailed data can be found in supplementary data S3. These capture percentages correspond with previous reported capture efficiencies for silicon microsieves with filtration pores of $5 \mu \mathrm{m}$ diameter in a similar $1 \mu \mathrm{m}$ thick SiNi membrane [17-19]. 


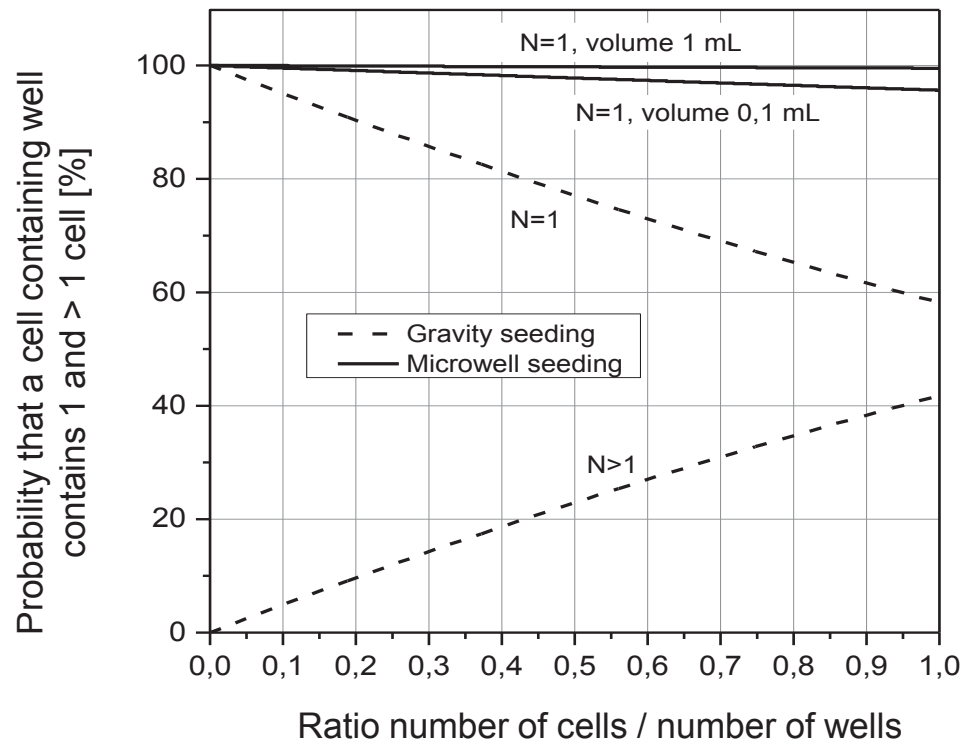

Figure 9.2. Probability for seeding single cells. The $\mathrm{x}$-axis displays the ratio number of cells / number of microwells. The y-axis displays the probability that a cell containing microwell contains 1 cell. Solid lines represent the probability for forced seeding for a sample volume of 1 and $0.1 \mathrm{~mL}$. The dashed lines present the probability for seeding by sedimentation.

\subsubsection{Single cell isolation}

A schematic representation of the single cell isolation method is presented in figure 9.3A. After the microwells are filled with cells the microwells are scanned on an inverted microscope (TE-2000, Nikon, Tokyo, Japan) and fluorescence images are acquired using a 10x/NA0.45 objective (Nikon, Tokyo, Japan) (figure 9.3B, step 1). The forces excreted by the surface tension of the cell buffer present in the microwells will reduce the punching efficiency. To increase the punching efficiency the microwell chip is dried after scanning. Based on the acquired fluorescence images, the single cells to be isolated are selected. Next, the stage that is used for scanning and acquisition of fluorescence images (MS-2500, ASI, Oregon, USA), brings the microwells to the position of the punch needle which is mounted on a Z-stage (LS-50, ASI) (figure 9.3 B, step 2). The punch needle is made of a $50 \mu \mathrm{m}$ Nickel Titanium (NiTi) wire (Flexmet BVBA, Aarschot, Belgium) and has a sharp $27^{\circ}$ tip mounted into a 30 gauge luer lock dispensing tip (TE730050PK, Technon Systems, Garden Grove, CA, USA). A 
microscope image of the tip of the needle is presented in figure 9.3. The center of the microwell with the cell that needs to be isolated is aligned with the center of the punch needle. Next the punch needle is lowered into the microwell to punch out the bottom together with the selected cell. The punched cell plus the bottom fragments of the microwell fall down into the designated cup of a 384 well PCR plate, that is placed on a different XY stage (MS-2000, ASI) which aligns the selected PCR cup with the microwell and punch needle (Figure 9.3A). To punch the next cell the punch needle is lifted, the next microwell is positioned underneath the punch needle, the selected PCR cup is placed underneath the microwell and the needle is lowered into the cup to punch the next bottom and cell. The end of the punch needle is shaped such that it only touches the bottom of the microwell at the edges of the microwell and never comes in contact with the cell that is positioned at the pore in the center of the microwell. This allows using the same punch needle for $>500$ punches. 


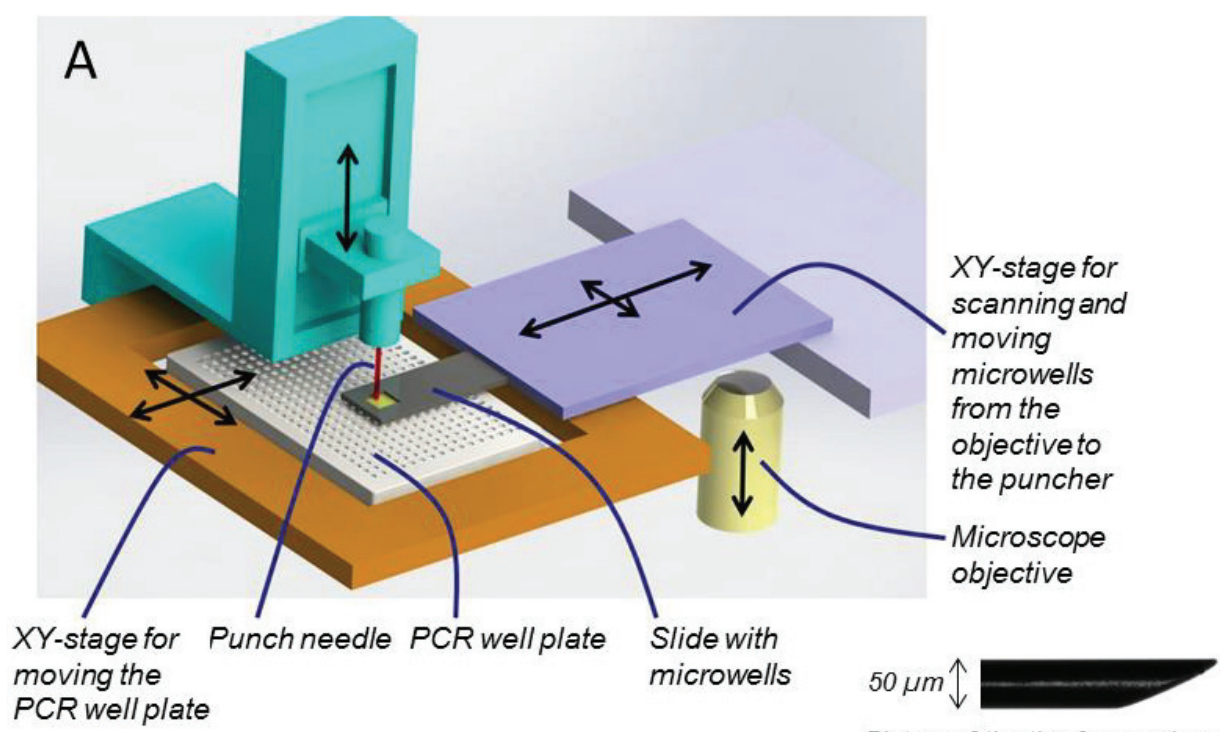

Picture of the tip of a punch needle

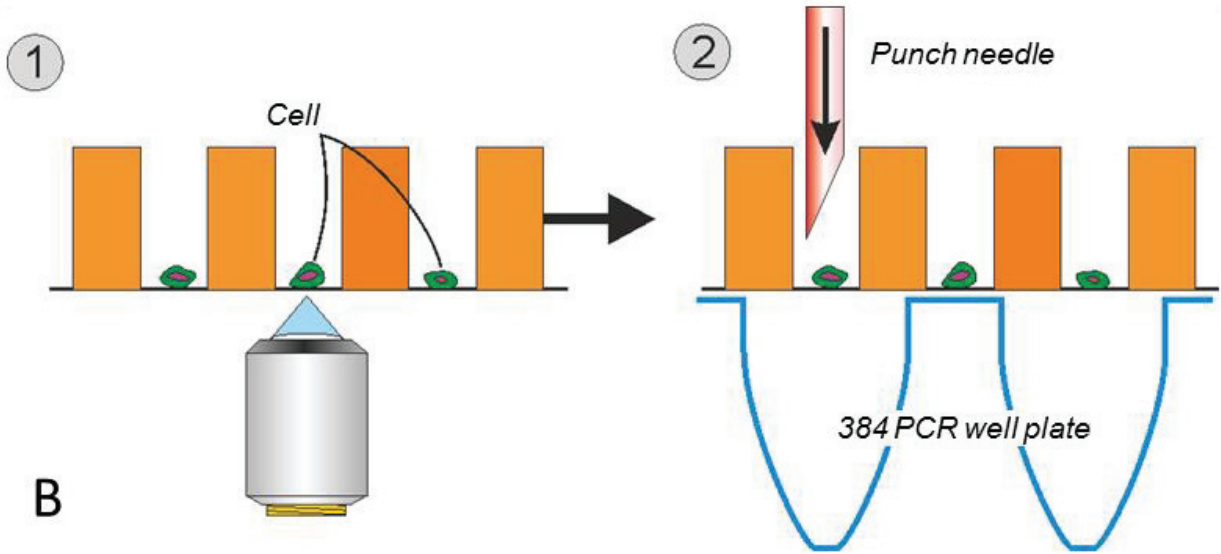

Figure 9.3. Single cell isolation using punching. A) Punching set-up. B) Punching principles. Panel 1: Fluorescence images of the seeded cells are acquired, through the SiNi bottom, using an inverted microscope, Panel B: The selected cells are removed from the microwell by lowering a NiTi wire into the microwell with the selected cell, that punches out the bottom plus the cell into a reaction tube that is positioned below the microwell. The insert shows a microscope image of the NiTi punch needle.

Panel A of figure 9.4 shows two single cells in two separate microwells, indicated with 1 and 2. Panel B of figure 9.4 shows the same two microwells after punching, the cells are no longer visible and few fragments of the bottom of the microwells can still be 
observed. Panel C of figure 9.4 shows an image of the two punched cells together with fragments of the SiNi microwell bottom. The isolation of single cells by punching these from the microwells into a PCR plate is fully automated and with the set-up as described, single cells are isolated with a rate of 1 cell / second. The two automated XY stages, the $\mathrm{Z}$ stage for the punch needle and the camera are controlled by custom made software using LabVIEW (National Instruments, Austin, TX, USA).

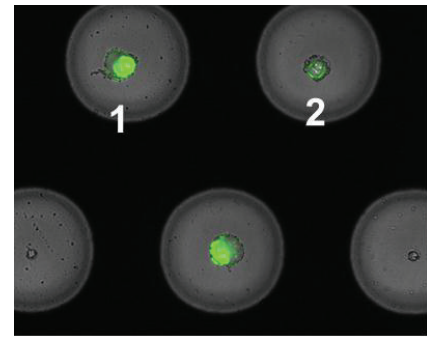

A

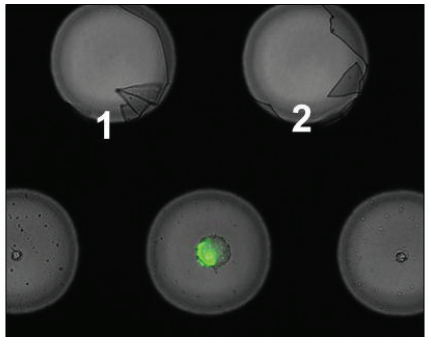

B

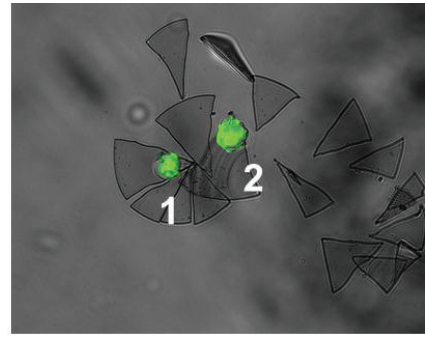

C

Figure 9.4. Example of 2 punched cells. A) Cells are selected based on their fluorescence image. B) The selected cells were punched from the microwell. C) Images of the cells plus bottoms after these have been removed from the microwell.

\subsubsection{Single cell isolation for DNA analysis}

The fluorescence image figure 9.1D was obtained by filling the microwells with a cell suspension with a total volume of $1 \mathrm{ml}$ that contained in total 2400 cells of the cell lines SKBR-3, PC3 and LNCaP in equal ratio. After the sample was transferred to the microwells a negative pressure 10 mbar across the microwell chip was applied. After 60 seconds the whole sample volume had passed through the pores of the microwell plate and filling of the microwells was completed. Next, the slide with microwells was transferred to the puncher microscope and fluorescence images of the microwells were acquired, figure 9.1D. To facilitate punching, the microwells were left to dry overnight before single cell punching. Next, the slide with the microwells are placed back onto the puncher microscope and automatically realigned with the previously acquired fluorescence scan. Using the fluorescence images captured before drying, 30 single cells of each cell line were selected and punched into individual cups of a 384 PCR well plate. Visual inspection of the PCR plate cups after punching revealed that $80 \%$ of the punched cells was successfully transferred and contained a single cell. In the other $20 \%$ of the PCR cups no cell could be observed. 
Next, WGA was applied to the PCR cups in which a single cell was punched. As a control, punched SiNi bottoms of empty microwells were used. Three different WGA kits were tested with comparable results. On average DNA was successfully amplified in $70 \%$ of the PCR cups in which a cell was punched. Figure 9.5A displays the qPCR curves for the DNA amplification using the Single Cell Whole Genome Amplification kit of NEB (NEB, Ipswich, MA, USA). The DNA signals of the cell containing cups of the PCR plate, rise earlier as compared to the empty PCR cups and PCR cups that contained punched microwell bottoms without a cell. After WGA, Sanger sequencing was applied to the ROBO2 and PTEN gene. Specific mutations within these genes allow conformation of the LnCAP, PC3 and SKBR-3 cells that were previously identified by their fluorescence signature (Fig 1D). The Sanger sequence data of the ROBO2 and PTEN gene of punched cells are presented in figure 9.5B. This data clearly demonstrates the differences between the cells lines and the observed changes correspond with previous reported sequencing data[20]. 


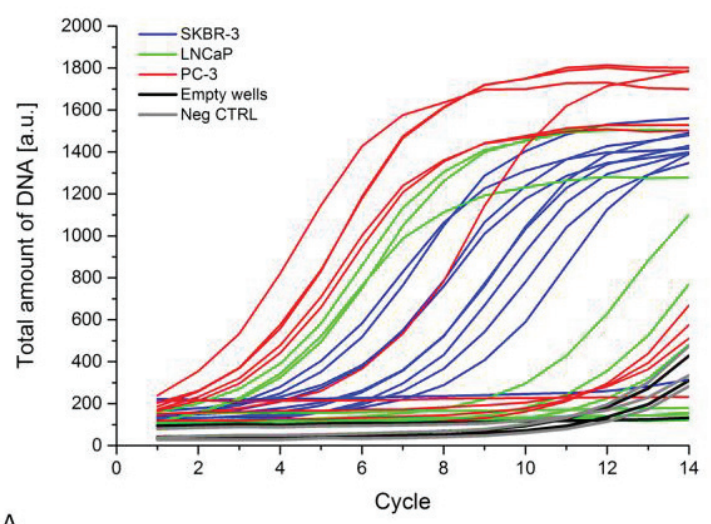

A

PTEN

ROBO2

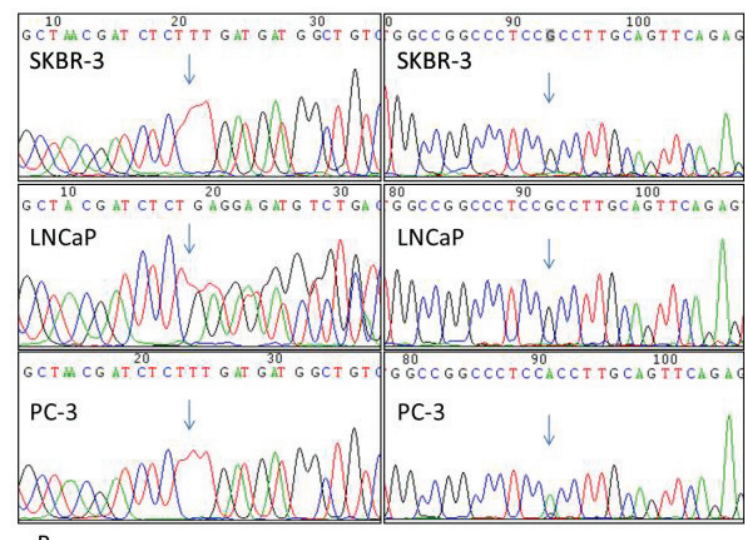

B

Figure 9.5. DNA amplification and Sanger sequencing. A) Graph displays the qPCR curves for the DNA amplification using the Single Cell Whole Genome Amplification kit of NEB (NEB, Ipswich, MA, USA). The DNA signals of the cell containing cups of the PCR plate, rise earlier as compared to the empty PCR cups and PCR cups that contained punched microwell bottoms without a cell.

B) Sanger sequence data of the ROBO2 and PTEN genes of punched cells are presented.

\subsubsection{Single cell isolation of viable cells.}

Cells from the cancer cell lines SKBR-3, PC3 and LNCaP were fluorescently labeled with Fluorescein Diacetate (FDA) (Sigma, St. Louis, MO, USA). FDA enters normal cells and becomes green fluorescent after being cleaved by esterases. Once cleaved, FDA can no longer permeate cell membranes. Dead cells will lose the fluorescence. Propidium Iodide (PI) is used as an extra marker at 24 hours. PI does not pass intact 
cell membranes and will only stain necrotic or apoptotic cell nuclei [21, 22]. Since FDA staining is reduced in apoptotic or dying cells but not immediately zero, only the bright stained cells are counted as FDA positive. A sample volume of $0.5 \mathrm{ml}$ containing 5000 cells was added to the microwell chip. A constant pressure of -10 mbar was applied across the microwells and the whole sample volume passed through the open pores of the microwells in less than 1 minute. After completion of the cell seeding the slide with microwells was transferred to the puncher set-up. While the microwells were still filled with medium, fluorescence images of the captured cells were acquired. For punching viable cells, the 384 PCR well plate, as was used for DNA analysis, was replaced by a 96 well culture plate. Before a selected cell was punched, the designated cup of the 96 well plate was slightly overfilled with a volume of $440 \mu \mathrm{l}$ of culture medium. The microwells were moved over to the punch needle such that the selected microwell was aligned with the punching needle and the prefilled well of the culture plate. Next, the 96 well culture plate was raised towards the membrane of the microwells until fluid contact between the membrane of the microwell and the culture medium was established. The bottom of the microwell with the cell was then punched causing the bottom of the microwell plus cell to sediment towards to bottom of the well of the 96 well plate. Establishing fluid contact between the bottom of the microwell and the culture medium in the well of the culture plate, facilitates the removal of the bottom of the microwells that is still filled with culture medium during punching, as well as keeping the cells in medium at all times during punching. As control experiments pipetted cells and FACS sorted cells were analyzed at the same time.

After punching, the cells were checked on viability by determining the presence of the green fluorescence of the FDA label inside the cell. Immediately after punching all punched cells display strong FDA fluorescence indicating that all cells were alive before punching 20,21. At 3 hours after punching, approximately $70 \%$ of the punched cells displayed FDA fluorescence which was comparable to what is observed in pipetted and FACS sorted control cells. After 24 hours an additional PI staining is performed to also stain dead or dying cells (FDA- /PI+), and to confirm live cells (FDA+/PI-). Approximately $20 \%$ of the cells were alive after punching, approximately $30 \%$ were alive after FACS sorting and approximately $35 \%$ were alive after pipetting.

\subsection{Discussion}

To increase our understanding of resistance to cancer therapy and search for alternative therapy targets, tools are needed to interrogate single cancer cells at 
different times during the course of the disease. This requires efficient, simple and fast methods to isolate and characterize single cancer cells that have the ability to be used in clinical diagnostics. Here, we present a novel technology that enables sorting of single cancer cells and demonstrate its efficiency by applying WGA to the isolated cells and verify their origin by cell type specific Single Nucleotide Polymorphisms (SNP's). Although this paper primarily focused on the seeding followed by punching the single cells and DNA analysis thereof, the efficient cell seeding in combination with fluorescence microscopy on its own holds many advantages in comparison to the currently used seeding methodologies and procedures.

The essence of the technology is a microwell chip with two functions. Firstly, single cells are self-seeded in individual microwells. Secondly, the fluid exit pore at the bottom acts as a size selection and only cells with dimensions larger than the pore diameter are captured. Although one could opt to add reagents for further characterization to the microwells we choose to punch the bottom of the microwell with the cell into a standard PCR plate. This has the advantage that the technology becomes less complex and is immediately compatible with standard lab protocols, reagents and technologies such as WGA of single cells.

The capture efficiency of the microwell plate was tested by spiking LNCaP, PC-3, and SKBR-3 into a buffer volume of $1 \mathrm{ml}$ and fill the microwells. It was observed that the capture efficiency was highest for the SKBR-3 cells (75\%) and PC3 cells (73\%) and lowest for the LNCaP cells (58\%), which is related to the different diameters of these cell types. If a sample contains only cells of interest or no more than 6400 cells and no further discrimination based on size is required, the pore size can be reduced to a diameter that no cell is able to pass and all cells are captured and available for further analysis.

The punching set-up consists of two connected XY stages and a stage that lowers a NiTi punch needle into the microwell to punch the bottom containing the cell. The whole set-up fits onto a standard inverted fluorescence microscope. The end of the NiTi wire is shaped such that it only touches the bottom of the microwell and not the captured cell in the center. Cross contamination between different microwells was checked by punching bottoms of microwells with and without a cell from a single microwell chip. In all cases no DNA could be detected in the microwells that had no cells (figure 9.5). Since no cross-contamination was observed between different microwells there is no need to replace the needle after each experiment, which further simplifies the use of the system. The punch needle can be used for $>500$ punches 
without any problem. The efficiency for punching dried cells from the microwell into cups of a 384 PCR well plate was over $80 \%$. For the 96 well plate used for live cell punching this efficiency was even over 90\%. To test the specificity of punched PC3, LNCaP and SKBR-3 cells the WGA material was sequenced for the ROBO and PTEN genes. The presence or absence of the specific mutations within these genes perfectly identified the specific cell line, which corresponded to their fluorescence signature on which basis these cells were selected for punching.

A small constant negative pressure of 10 mbar is used to fill the microwells. This puts a limited amount of stress on the cells. After filling of the microwells the collected cells are alive, as was visualized by the presence of FDA fluorescence. Also 24 hours after punching it is shown that about $20 \%$ of the cells is alive which is a bit lower than FACS sorting (30\%) or pipetting (35\%). During FACS, pipetting and punching the cells endure physical stress. Next to that these cells were seeded in very low densities: 100 to 1000 times lower than usually done for these cell lines. The physical stress in different grades is most probably the cause of the difference between the methods. The fact that most cells die, even after pipetting, is most probably due to the lack of neighboring cells.

This device is specially designed for a suspension of rare cells that have been pre enriched and need to be isolated at single cell level. Most microfluidic devices, designed to isolate single cells, isolate a number of single cells from a bulk and remove the excess of cells[8, 23, 24]. This makes those devices unsuitable for rare cell isolation. Other microfluidic devices are just designed to enrich a cell population and do not isolate single cells $[10,25]$. The presented workflow demands limited hands on time and fits within the daily routine within a clinical laboratory.

The self-seeding microwells in combination with the single cell isolation punching technology as presented, is simple, fast and efficient. Next step is to use the full potential of the microwell filtration property to isolate and capture single CTC, fast and efficient, directly from blood or from samples that are pre-enriched for CTC followed by determination of their genetic make-up. 
Concluding, we have demonstrated a new procedure for fast and efficient separation and isolation of single cells. The capture of cells into a self-sorting microwell chip was on average done with an efficiency of $67 \%$. We have shown that single cells can be punched from the chip into PCR plates from which in $70 \%$ the genomic DNA could be amplified. In all tested cases the amplified DNA was shown to be specific for the cells that were punched by Sanger sequencing of specific mutations.

\subsection{References}

1. Lindström S, Eriksson M, Vazin T, Sandberg J, Lundeberg J, Frisén J, AnderssonSvahn H: High-density microwell chip for culture and analysis of stem cells. PLoS One 2009, 4:e6997.

2. Környei Z, Beke S, Mihálffy T, Jelitai M, Kovács KJ, Szabó Z, Szabó B: Cell sorting in a Petri dish controlled by computer vision. Sci Rep 2013, 3:1088.

3. Haupt S, Grützner J, Thier M-C, Kallweit T, Rath BH, Laufenberg I, Forgber M, Eberhardt J, Edenhofer F, Brüstle O: Automated selection and harvesting of pluripotent stem cell colonies. Biotechnol Appl Biochem , 59:77-87.

4. Gach PC, Wang Y, Phillips C, Sims CE, Allbritton NL: Isolation and manipulation of living adherent cells by micromolded magnetic rafts. Biomicrofluidics 2011, 5:320023200212.

5. Fu AY, Spence C, Scherer A, Arnold FH, Quake SR: A microfabricated fluorescenceactivated cell sorter. Nat Biotechnol 1999, 17:1109-11.

6. Schütze K, Lahr G: Identification of expressed genes by laser-mediated manipulation of single cells. Nat Biotechnol 1998, 16:737-742.

7. Fuchs AB, Romani A, Freida D, Medoro G, Abonnenc M, Altomare L, Chartier I, Guergour D, Villiers C, Marche PN, Tartagni M, Guerrieri R, Chatelain F, Manaresi N: Electronic sorting and recovery of single live cells from microlitre sized samples. Lab Chip 2006, 6:121-6.

8. Wang X, Gou X, Chen S, Yan X, Sun D: Cell manipulation tool with combined microwell array and optical tweezers for cell isolation and deposition. J Micromechanics Microengineering 2013, 23:75006. 
9. Chen Y, Li P, Huang P-H, Xie Y, Mai JD, Wang L, Nguyen N-T, Huang TJ: Rare cell isolation and analysis in microfluidics. Lab Chip 2014, 14:626-45.

10. Riahi R, Gogoi P, Sepehri S, Zhou Y, Handique K, Godsey J, Wang Y: A novel microchannel-based device to capture and analyze circulating tumor cells (CTCs) of breast cancer. Int J Oncol 2014, 44:1870-8.

11. Powell A a, Talasaz AH, Zhang H, Coram M a, Reddy A, Deng G, Telli ML, Advani RH, Carlson RW, Mollick J a, Sheth S, Kurian AW, Ford JM, Stockdale FE, Quake SR, Pease RF, Mindrinos MN, Bhanot G, Dairkee SH, Davis RW, Jeffrey SS: Single cell profiling of circulating tumor cells: transcriptional heterogeneity and diversity from breast cancer cell lines. PLoS One 2012, 7:e33788.

12. Yang Y, Swennenhuis JF, Rho HS, Le Gac SS, Terstappen LWMM, Suk Rho H, Le Gac SS, Terstappen LWMM: Parallel Single Cancer Cell Whole Genome Amplification Using Button-Valve Assisted Mixing In Nanoliter Chambers. PLoS One 2014, 9:e107958.

13. Miller MC, Doyle G V, Terstappen LWMM: Significance of Circulating Tumor Cells Detected by the CellSearch System in Patients with Metastatic Breast Colorectal and Prostate Cancer. J Oncol 2010, 2010:617421.

14. Coumans FAW, Ligthart ST, Uhr JW, Terstappen LWMM: Challenges in the enumeration and phenotyping of CTC. Clin Cancer Res 2012, 18:5711-8.

15. Coumans F, Ligthart S, Terstappen L: Interpretation of change in circulating tumor cell counts. Transl Oncol 2012, 5:486-491.

16. Krebs MG, Metcalf RL, Carter L, Brady G, Blackhall FH, Dive C: Molecular analysis of circulating tumour cells-biology and biomarkers. Nat Rev Clin Oncol 2014, 11:129-44.

17. Coumans FAW, van Dalum G, Beck M, Terstappen LWMM: Filtration parameters influencing circulating tumor cell enrichment from whole blood. PLoS One 2013, 8:e61774.

18. Rijn CJM van, Nijdam W, Kuiper S, Veldhuis GJ, Wolferen H van, Elwenspoek M: Microsieves made with laser interference lithography for micro-filtration applications. J Micromechanics Microengineering 1999, 9:170-172.

19. Rijn CJM van, Veldhuis GJ, Kuiper S: Nanosieves with microsystem technology for microfiltration applications. Nanotechnology 1998, 9:343-345. 
20. Barretina J, Caponigro G, Stransky N, Venkatesan K, Margolin AA, Kim S, Wilson CJ, Lehár J, Kryukov G V, Sonkin D, Reddy A, Liu M, Murray L, Berger MF, Monahan JE, Morais P, Meltzer J, Korejwa A, Jané-Valbuena J, Mapa FA, Thibault J, Bric-Furlong E, Raman P, Shipway A, Engels IH, Cheng J, Yu GK, Yu J, Aspesi P, de Silva M, et al.: The Cancer Cell Line Encyclopedia enables predictive modelling of anticancer drug sensitivity. Nature 2012, 483:603-7.

21. Jones $\mathrm{KH}$, Senft JA: An improved method to determine cell viability by simultaneous staining with fluorescein diacetate-propidium iodide. J Histochem Cytochem 1985, 33:77-9.

22. Zhao X, Newcomb JK, Pike BR, Wang KK, d'Avella D, Hayes RL: Novel characteristics of glutamate-induced cell death in primary septohippocampal cultures: relationship to calpain and caspase-3 protease activation. J Cereb Blood Flow Metab 2000, 20:550-62.

23. Hsiao AP, Barbee KD, Huang X: Microfluidic Device for Capture and Isolation of Single Cells. Proc SPIE--the Int Soc Opt Eng 2010, 7759.

24. Yamaguchi Y, Arakawa T, Takeda N, Edagawa Y, Shoji S: Development of a polydimethylsiloxane microfluidic device for single cell isolation and incubation. Sensors Actuators B Chem 2009, 136:555-561.

25. Karabacak NM, Spuhler PS, Fachin F, Lim EJ, Pai V, Ozkumur E, Martel JM, Kojic N, Smith K, Chen P, Yang J, Hwang H, Morgan B, Trautwein J, Barber TA, Stott SL, Maheswaran S, Kapur R, Haber DA, Toner M: Microfluidic, marker-free isolation of circulating tumor cells from blood samples. Nat Protoc 2014, 9:694-710. 


\section{CHAPTER 10: OUTLOOK}

\subsection{CTC enumeration}

Circulating Tumor Cells can currently clinically be used by assessment of their number and determination whether the number is less than 5 CTC in $7.5 \mathrm{ml}$ of blood or 5 or more CTC. This divides the patients into those with a favorable $(<5$ CTC) and unfavorable prognosis ( $>5$ CTC). A reduction of CTC's after the first cycles of therapy indicates an effective treatment whereas an increase indicates a futile therapy. Clinical trials are being designed and conducted where CTC enumeration is being used to guide treatment decisions. The first large trial where a decision is made based on CTC enumeration has just been ended: The SWOG500 trial. In this trial breast cancer patients with a high number of CTC who remain high after first chemo were switched to a different chemo. For these patients the switching to a different cytotoxic therapy was not prolonging overall survival. At the time this trial was designed there were no possibilities yet to analyze the CTC for treatment targets. At present trials are being designed and conducted where a switch to a targeted therapy based on CTC enumeration is conducted. We can expect results of these trials in years to come.

\subsection{CTC from larger blood volumes}

For most types of cancer less than $50 \%$ of the metastatic patient samples contain CTC's. Currently studies are being done to access larger volumes of blood. One of the approaches is by using diagnostic LeukApheresis (DLA) to collect a large amount of mononuclear cells. Since the CellSearch system can only handle up to $\sim 2 * 10^{8}$ cells, other techniques will have to be used. Currently the Rosettesep negative selection technique is adapted to enrich the CTC's. This technique however has the disadvantage of a fycoll density gradient separation step, which is used to separate leukocyte-erythrocyte conjugates from unbound cells. CTC's with a higher density will get lost using this technique depending on the handling of the sample. This technique is hard to automate and will eventually only be able to isolate CTC above a specific density. Currently magnetic negative selection techniques are being developed to overcome these limitations.

\subsection{Single cell isolation progress}

Single cell isolation as discussed in chapter 2 and 8 is currently the limiting step in bringing the CTC molecular analysis further. This step has always been a bit ignored 
because of the use of cultured cells in the development of protocols. When there are enough cells available it is easy to make a limited dilution, simply sort some of the cells by FACS or use a micromanipulator. These techniques change fundamentally when only a small population of cells needs to be sorted. First of all, there is little room for cell loss. Each cell counts when only a few are found in a sample. For FACS this has been shown to be possible, however not without some cell loss (see also chapter 5). Others (Neves et al.) have reached a higher efficiency using breast cancer samples instead of lung cancer samples. The two commercialized systems the DEParray and the ALS CellCelector have been shown to be useable with CTC's. Both very promising techniques with for the ALS CellCelector even a reported single cell capture efficiency of $97 \%$ of the CellSearch identified patient CTC's [2]. The ideal capturing technology should be done as fast as possible after CTC enrichment, should be automated and provides the viability status, cell morphology and quantitative information on the gathered fluorescence parameters. The minimal time between blood draw and sample processing is beneficial for cell viability / integrity and optimal analysis for cell expansion, RNA and microRNA analysis. The morphology and fluorescence data can be used to identify subgroups of cells. It will depend on the necessary information needed how detailed the whole process has to be. It can range from global detection of aberrations in cfDNA to detailed analysis of multiple single CTC's in order to closely monitor the treatment effectiveness.

\subsection{Whole genome amplification}

Whole genome amplification is for the time being still necessary for the analysis of multiple targets on single CTC until sequencing techniques have progressed to the level where a single cell's DNA can be reliably sequenced without amplification. The choice for the method that can be used for the amplification should be based on the downstream application as discussed in Chapter 3. Improvements can be expected in the combined amplification of DNA, methylated DNA, RNA and microRNA to cover the complete downstream regulatory system of a cell. Single cell DNA methylation tools are available to separate methylated from unmethylated DNA. Using MBD (MethylCpG Binding Domain) proteins bound to a solid surface it is theoretically possible to separate both DNA fractions. This step is easy to build into the protocol of the Ampli-1 WGA kit after the fragmentation or after the linker ligation. If both fractions of amplified material are subsequently sequenced it is possible to get both negative and positive confirmation of hypermethylated promoter regions. It could be used to confirm the cancerous state of cells as well as making a genome wide methylation profile. Not much DNA is expected to get lost because no extensive isolation steps are 
needed. The amplified DNA will also be useable for targeted sequencing or CGH. The first experiments to develop this technique are currently being conducted.

\subsection{Targeted drugs}

With the rise of the targeted cancer therapies, the choice of drugs will be adapted to the current state of the cancer cells. It has to be continuously defined which growth signals the cell benefits from. An effective treatment blocking this growth signal will put an adaptive pressure on the cells and often a resistant clone will come forward due to a mutation in one of the signal transduction pathway genes. Cancer cells adapt to treatments in many different ways: alternative splicing of RNA, translocation of genes to a position behind a more active promoter, methylation of promoter sequences, deletion of genes, mutations leading to activation, inactivation or change of function of proteins or changing the expression of microRNA's. Many of these new adaptations of the cells are again potentially targetable. Yap et al. have showed that 44 out of the 62 most prevalent aberrations in prostate cancer are drugable [3]. Logically circulating biomarkers are a key to monitoring these changes since frequent sampling of the metastasis will be too invasive and stressful for the patient and it will be impossible to get a complete overview of all metastases. Unfortunately the different circulating sources of biomarkers have their own downsides. Circulating free DNA is easy to isolate but the composition is variable. From this DNA it is unable to say if the aberrations that were found are from one or multiple clones. As said, the CTC's still have the downside of their rarity in most patients. Amplification of the genomic DNA is still needed if single cells are to be analyzed.

Personalized therapy and therefore effective use of targeted drugs will be more and more based on genetic information. An example is a study from Bertotti et al. colorectal primary tumors, liver metastasis and xenografts before and after treatment with anti-EFGR (cetuximab and panitumumab) were extensively sequenced for DNA alterations [4]. This study identified resistance alterations in 10 different genes related to EGFR or its signaling pathway. It was found that besides the already known negative indicator for this therapy, KRAS mutations, an alteration (mutation or amplification) in IRS2 could act as a positive indicator. However no response was seen in tumors harboring IRS2 alterations together with known resistance indicators such as those in MET or BRAF. This shows an advantage of looking into individual cells instead of circulating DNA when accurate and complete information is needed. The combination of aberrations is essential in this case.

Currently most attention goes to those biomarkers where material is easily available and which can be analyzed with the standard laboratory techniques such as FISH, NGS 
or CGH. These are the DNA aberrations such as point mutations, translocations, deletions and copy number changes. To get a complete overview of a cells state, it will be necessary to include information from other regulatory levels in the cell such as DNA methylation, microRNA's or alternative RNA processing. Currently, in a research setting it is already possible to look at epigenetic regulatory changes in the form of DNA methylation or at microRNA mediated regulation changes in single cells. More information will be extracted from the single cells in the future. It is expected that al nucleic acid sequences including epigenetic modifications will be analyzed from the single cells at once in future sequencing technologies so that the complete biological state of each cell can become available.

\subsection{References}

1. Attard G, Swennenhuis JF, Olmos D, Reid AHM, Vickers E, A'Hern R, Levink R, Coumans F, Moreira J, Riisnaes R, Oommen NB, Hawche G, Jameson C, Thompson E, Sipkema R, Carden CP, Parker C, Dearnaley D, Kaye SB, Cooper CS, Molina A, Cox ME, Terstappen LWMM, de Bono JS: Characterization of ERG, AR and PTEN gene status in circulating tumor cells from patients with castration-resistant prostate cancer. Cancer Res 2009, 69:2912-8.

2. Neumann MHD, Schneck H, Decker Y, Schömer S, Franken A, Endris V, Pfarr N, Weichert W, Niederacher D, Fehm T, Neubauer H: Isolation and characterization of circulating tumor cells using a novel workflow combining the CellSearch® system and the CellCelectorTM. Biotechnol Prog 2016.

3. Yap TA, Smith AD, Ferraldeschi R, Al-Lazikani B, Workman P, de Bono JS: Drug discovery in advanced prostate cancer: translating biology into therapy. Nat Rev Drug Discov 2016.

4. Bertotti A, Papp E, Jones S, Adleff V, Anagnostou V, Lupo B, Sausen M, Phallen J, Hruban CA, Tokheim C, Niknafs N, Nesselbush M, Lytle K, Sassi F, Cottino F, Migliardi G, Zanella ER, Ribero D, Russolillo N, Mellano A, Muratore A, Paraluppi G, Salizzoni M, Marsoni S, Kragh M, Lantto J, Cassingena A, Li QK, Karchin R, Scharpf R, et al.: The genomic landscape of response to EGFR blockade in colorectal cancer. Nature 2015, 526:263-7. 


\section{Summary}

The number of Circulating Tumor Cells (CTCs) that can be isolated from blood of cancer patients is prognostic for the course of the disease. A higher number of CTCs correlates with a worse prognosis. A change from a higher number to a lower number of CTCs indicates a benefit of the current treatment for the patient and vice versa. For this reason the number of CTCs found with the CellSearch test can be used as a tool in the management of patient treatment.

Repeated molecular analysis of CTCs enables the detection of changes during the course of the disease. This analysis could unmask details on proliferation stimulating pathways in the cells, which can lead to a change to a more effective treatment. With this information, targeted drugs could effectively be used until new analysis shows resistance and discloses possible new druggable pathways.

This thesis covers the whole workflow from blood draw up to the analysis of single CTC genomes. We give an overview of all work done to analyze or unmask the cells captured with CellSearch tests and a review is included of single cell isolation methods suitable for sorting CTCs. In a review of Whole Genome Amplification (WGA) methods we show the technical details of the commercially available kits and the applicability is discussed on upstream target DNA quality and downstream applications.

Cancerous origin of the epithelial cells isolated with CellSearch was expected but has been conclusively proven by the development of a Fluorescence In Situ Hybridization (FISH) test. The analysis of a large number of CTC's from a series of prostate cancer patient samples clearly shows aberrant chromosome numbers. During development of FISH using unique sequence probes a highly efficient method was developed to remove repetitive DNA from these probes. We present the procedure to remove the repetitive DNA and show the quality and efficiency of the derived FISH probes.

The possibility of analyzing genomes of single CTCs after CellSearch shows to be informative but labour intensive. The presented method using Fluorescence Assisted Cell Sorting (FACS) is a multi step procedure suitable for research but needs to be optimized and simplified to be able to use in routine diagnostics. The microwell single cell isolation technique has the potential of automation, speed and still a high degree of multi marker confirmation to authenticate the CTCs. It is a promising step forward in handling and separating CTCs. 


\section{Summary in Dutch / Samenvatting}

Het aantal Circulerende Tumor Cellen (CTC's) dat geïsoleerd kan worden uit bloed van kankerpatiënten is prognostisch voor het verloop van de ziekte. Een groter aantal CTC's correleert met een slechtere prognose. Een verandering van een hoog naar een laag aantal CTC's indiceert een gunstig effect van de huidige behandeling en vice versa. Om deze reden kan het aantal CTC's dat geïsoleerd is met het CellSearch systeem gebruikt worden als een marker tijdens de behandeling van kanker patiënten.

Herhaaldelijke moleculaire analyses van CTC's zullen het mogelijk maken om veranderingen te volgen tijdens het ziekteverloop. Deze analyses kunnen details blootleggen over processen die de proliferatie van de tumorcellen stimuleren en welke ten gevolge van de behandeling kunnen veranderen. Met deze informatie kunnen specifieke medicijnen efficiënt worden ingezet, tot een nieuwe analyse resistentie laat zien, en mogelijk nieuwe behandelbare processen blootlegt.

Het werk wat beschreven wordt in dit proefschrift dekt het hele proces vanaf de bloedafname tot en met de analyse van een enkele CTC. We geven een overzicht van al het werk dat gedaan is om cellen, die met CellSearch geïsoleerd zijn, te analyseren en te ontmaskeren, alsmede een overzicht van alle cel isolatie methodes die geschikt zijn om CTC's te sorteren. In een overzicht van alle genoom amplificatie methodes laten we de technische details zien van alle commercieel verkrijgbare testen en de toepasbaarheid in relatie tot de kwaliteit van het CTC DNA en tot de DNA analyse technieken die erop gedaan kunnen worden.

Dat de epitheliale cellen die gevonden waren met de CellSearch test kankercellen waren werd wel verwacht maar is nu definitief bewezen door de ontwikkeling van een Fluorescente In Situ Hybridisatie (FISH) test. Een analyse van een groot aantal CTC's uit een serie monsters afkomstig van prostaatkankerpatiënten laat duidelijk een afwijkend aantal chromosomen zien. Tijdens de ontwikkeling van unieke sequentieprobes is een zeer efficiënte methode gevonden om FISH probes te ontdoen van repetitief DNA. We laten de procedure van verwijderen van het repetitieve DNA zien, alsmede de kwaliteit en efficiëntie van de ontwikkelde FISH probes.

De mogelijkheid om het genoom van enkele CTC's na CellSearch te analyseren is informatief maar vergt veel tijd. De methode die we laten zien met Fluoresence Assisted Cell Sorting (FACS) bevat veel stappen en is geschikt voor onderzoek maar 
moet nog worden geoptimaliseerd en vereenvoudigd om te kunnen gebruiken in de routine diagnostiek. De microwell cell isolatie techniek kan worden geautomatiseerd, is snel en biedt tegelijkertijd de mogelijkheid om meerdere markers te gebruiken om de CTC's te identificeren. Deze microwell techniek is een veelbelovende stap vooruit in het behandelen, verwerken en isoleren van CTC's. 
SUMMARY 


\section{Eenvoudige weergave van dit proefschrift}

In dit hoofdstuk vinden jullie een eenvoudige uitleg van het werk dat in dit proefschrift staat. Het werk wat gedaan is, is per hoofdstuk samengevat, eenvoudig en zo volledig mogelijk uitgelegd.

\section{In het kort:}

\section{Wat?}

Ik heb gewerkt aan een methode om tumorcellen die losgelaten zijn van een vaste tumor (zoals borst, prostaat of longtumoren) en door het bloed circuleren, te vangen, te bewerken en te analyseren. De methode om de cellen uit het bloed te halen bestond al. Mijn werk zit in het proces hierna, waar ik methodes heb onderzocht om de individuele cellen te kunnen analyseren.

\section{Waarom?}

Dit om te kunnen aantonen welke afwijkingen deze cellen hebben en om hiermee te kunnen bepalen welke behandeling er het beste gegeven kan worden aan de kankerpatiënt.

\section{Waarvoor?}

Dit heeft als voordeel dat niet alleen vóór de behandeling gekeken kan worden naar de status van de ziekte maar ook naar de veranderingen tijdens (en door) de behandeling. Zo kan een behandeling in de toekomst worden aangepast als het niet werkt of worden doorgezet als het nog langer nodig is.

\section{Indeling van het proefschrift}

Het proefschrift beschrijft verschillende stappen die zijn ontwikkeld of verbeterd om circulerende tumorcellen (vanaf nu CTC's genoemd) uit het bloed te isoleren en analyseren.

Omdat de werkwijze om de cellen uit het bloed te vangen, te bewerken en te analyseren in de basis altijd hetzelfde is, kan ik de hoofdstukken mooi langs deze lijn leggen om te laten zien waar ze ingepast moeten worden in het proces. 
Na de inleiding (hoofdstuk 1) volgen er in hoofdstuk 2 en 3 gepubliceerde beschouwende artikelen.

Hoofdstuk 4 en 5 zijn nog niet eerder gepubliceerd en bestaan uit achtergrond informatie aangevuld met eigen ontwikkelde technieken.

Hoofdstuk 6 beschrijft één van de methodes waarmee de CTC's geanalyseerd kunnen worden, van begin (het buisje bloed) tot eind (gegevens over de afwijking van de betreffende cellen), evenals hoofdstuk 7 waar een andere methode wordt toegepast.

Hoofdstuk 8 focust zich op een technisch onderdeel van hoofdstuk 7.

Hoofdstuk 9 beschrijft een derde en eigen ontwikkelde methode voor het verkrijgen van individuele circulerende tumor cellen.

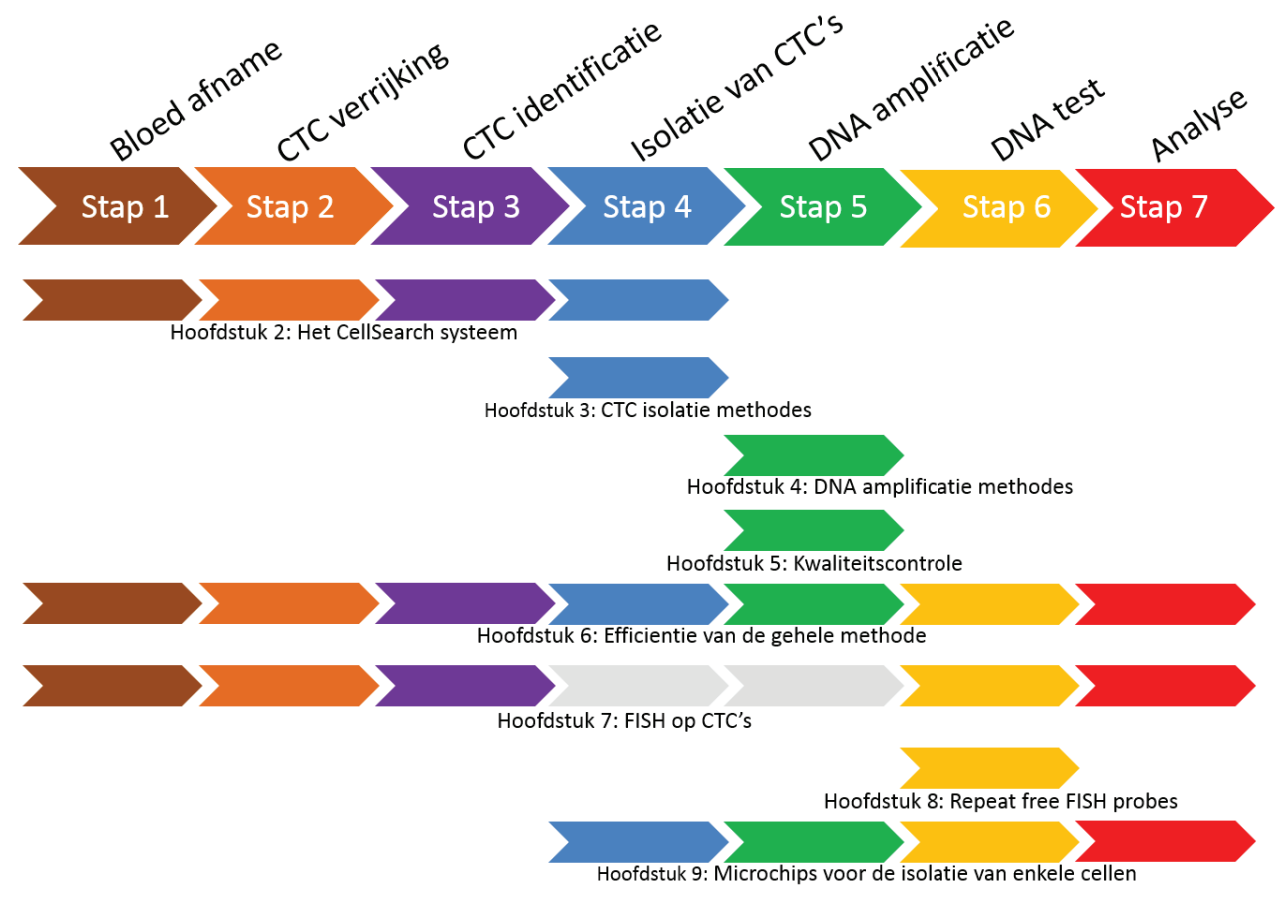

\section{Stap 1: Bloedafname}

Dit lijkt eenvoudig, maar de cellen die we zoeken zijn erg fragiel en het zijn er erg weinig. De afnamebuizen moeten een stabilisator bevatten, die er voor zorgt dat de 
cellen een aantal dagen stabiel blijven. Daarentegen mogen de cellen weer niet te hard gefixeerd worden omdat ze anders niet meer te analyseren zijn.

\section{Stap 2: CTC verrijking}

Met het verrijken van CTC's wordt bedoeld dat het overgrote deel van de andere cellen (de bloedcellen) worden verwijderd zonder de CTC's te verliezen. Dit is de grootste uitdaging met vele haken en ogen. Leon Terstappen is het gelukt om een groep CTC's te isoleren die kunnen worden gerelateerd aan het ziekteverloop van de patiënt. Er kunnen echter ook nog andere (tumor)cellen gevonden worden als er op een andere wijze geïsoleerd wordt.

\section{Stap 3: CTC identificatie}

Op dit moment tellen we alle cellen die ten eerste een kern (DNA), ten tweede een cytoskelet en ten derde geen witte bloedcelkleuring hebben. Ook hier kunnen door het anders kleuren van geïsoleerde cellen andere cellen gevonden worden.

\section{Stap 4: Isolatie van CTC's}

Als het DNA van de CTC's moet worden geanalyseerd dan moet er na de verrijking van deze cellen uit het bloed nog een laatste isolatiestap gedaan worden om alleen de CTC en geen enkele andere cel in een buisje te krijgen. Een erg lastige en tijdrovende bezigheid.

\section{Stap 5: DNA amplificatie}

Omdat een cel niet genoeg DNA bevat om een uitgebreide analyse op te doen is het nodig om dit DNA te kopiëren. Dit zal mooi gelijkmatig moeten gebeuren en zonder fouten.

\section{Stap 6: DNA test}

Hier kunnen erg veel verschillende DNA testen gedaan worden afhankelijk van hoeveel informatie er nodig is. In de toekomst zal deze test uitsluitsel moeten geven over de beste behandeling van de betreffende cel.

\section{Stap 7: De analyse}

De analyse van de DNA test kan erg gemakkelijk zijn voor een gerichte test tot zeer complex. Als we een bekende DNA mutatie willen weten kan de test en analyse erg gemakkelijk zijn, als er gezocht moet worden naar iets onbekends dan worden beiden erg complex. 
Ik hoop dat na het lezen van dit hoofdstuk het een beetje duidelijk is waar de belangrijkste uitdagingen liggen van het CTC werk.

\section{Hoofdstuk 2: Het CellSearch systeem}

\section{Het Cellsearch systeem}

Het CellSearch systeem is ontwikkeld om circulerende tumorcellen (CTC's) in het bloed te kunnen tellen. Om dit te doen wordt 99,999 procent van alle andere cellen verwijderd. Nog steeds blijven er dan 10.000 bloedcellen over. Dit aantal is echter zo klein dat het mogelijk is om de tumorcellen te tellen.

\section{De methode}

De cellen worden uit het bloed gehaald door ijzerdeeltjes aan de tumorcellen te koppelen en vervolgens veelvuldig te wassen in aanwezigheid van sterke magneten. Na deze verrijkingsstap worden de cellen ook nog eens gekleurd. De tumorcellen hebben een structuur in zich wat vorm geeft aan de cellen, genaamd een cytoskelet (celskelet). Dit cytoskelet is uniek voor de tumorcellen en kan worden gekleurd. Tegelijk worden in een andere kleur de witte bloedcellen gekleurd en de celkernen (het DNA) in een derde kleur. De cellen met een kern, die geen bloedcelkleuring hebben en wel een cytoskelet, worden geteld als tumorcellen.

\section{Gebruik van het CellSearch systeem}

De CellSearch test is één van vele manieren om de CTC's uit het bloed te isoleren. Het unieke van deze methode is dat het herhaalbaar is. We kunnen dus met redelijk grote zekerheid de cellen tellen in het bloed. De test is daarnaast ook nog eens goedgekeurd door de Amerikaanse Food and Drug Administration (FDA). Hiermee is deze test ook geschikt om patiënten mee te volgen tijdens een behandeling. Een arts zou de resultaten van deze test kunnen gebruiken om een behandeling te sturen. Tot dusverre is deze test de enige die goedgekeurd is voor klinisch gebruik. Alle overige tests zijn bedoeld voor onderzoek. 


\section{Hoofdstuk 3: Beschrijving van methodes om een enkele cel te kunnen isoleren}

\section{Achtergrond}

Dit hoofdstuk is gepubliceerd in een boek*. In dit boek worden methodes en technieken beschreven om het DNA van een enkele cel te kopiëren. Dit wordt gedaan omdat er in een cel slechts 7 picogram $(0,000000000007)$ gram DNA zit. Het is niet zo dat dit heel weinig is want met al 1000 tot 10.000 keer meer kunnen we al heel veel analyseren. Het is op het moment helaas nog zo dat de apparatuur om DNA te kunnen 'lezen' gewoon meer nodig heeft. Meer hierover in hoofdstuk 4 en 5. Het hoofdstuk uit dit boek beschrijft de methodes die er bestaan om cellen te isoleren uit een grotere verzameling van cellen. Er zijn in de wereld een aantal commerciële oplossingen hiervoor. Elk met hun eigen voordelen en beperkingen en deze worden in dit hoofdstuk beschreven.

* Boek: Whole Genome Amplification Methods and Protocols, editor Thomas Kroneis. Humana Press, USA ISBN 978-1-4939-2990-0, pp 57-67, 2015.

\section{Hoofdstuk 4 en 5: Methodes voor DNA amplificatie van een enkele cel}

\section{Achtergrond}

Deze twee hoofdstukken zijn geschreven omdat er in de tijd dat we onderzoek deden erg veel ervaring is opgedaan hiermee. Verschillende methodes zijn gebruikt en uitgeprobeerd en een aantal is aangepast naar onze eigen wensen.

\section{WGA (Whole Genome Amplification)}

Om al het DNA te vermeerderen van een enkele cel kunnen twee basisprincipes worden gebruikt en er is een aantal methodes dat gebruik maakt van een combinatie van de twee. Twee dingen zijn hierbij belangrijk: het eerste is dat er een gelijkmatige kopie gemaakt wordt van al het DNA. Bij kanker is het vaak van belang te weten welke delen van het DNA vermeerderd zijn en welke delen weg zijn. Analyse van een gelijkmatige kopie kan hier uitsluitsel over geven. Het tweede is dat er bij het kopiëren niet veel fouten worden gemaakt. De enzymen die gebruikt worden kunnen fouten maken welke dan kunnen worden aangezien voor fouten die aanwezig waren in de cel. 


\section{Inhoud van hoofdstuk 4 en 5}

Hoofdstuk 4 beschrijft alle methodes die er bestaan om DNA van één cel te amplificeren en wat de voor- en nadelen zijn van het gebruik van deze methodes.

Hoofdstuk 5 gaat in op de kwaliteitscontrole die gedaan kan worden op de producten die gemaakt zijn. Afhankelijk van welke methode is gebruikt, kunnen er verschillende methodes gebruikt worden om te controleren hoe goed de kwaliteit is. Een aantal van deze kwaliteit controle methodes is door ons ontwikkeld en deze worden beschreven naast de bestaande methodes.

\section{Hoofdstuk 6: Een methode om DNA te pakken te krijgen van enkele tumorcellen uit bloed}

\section{Achtergrond:}

Dit hoofdstuk beschrijft een volledige methode om DNA van CTC's te analyseren. Voor iedere stap is er een keuze gemaakt voor welke methode er gebruikt zou gaan worden. De keuze is gemaakt op basis van wat we op ons laboratorium aan mogelijkheden hebben, maar belangrijker nog was dat het op andere laboratoria exact zo herhaald kan worden. We hebben gekozen voor de CellSearch test omdat deze test exact kan worden herhaald op andere labs en voor het sorteren met een FACS (Fluorescence Assisted Cell Sorting) (zie onder) omdat deze machines op ieder ziekenhuislab staan voor de analyse van bloedcellen.

\section{FACS sorteren}

De belangrijkste stap die hier gebruikt is, is het sorteren van de enkele cellen in een buisje. Dit is gedaan met een FACS. Dit is een groot apparaat welke met behulp van lasers iedere cel scant. Op basis van de kleur van deze cellen wordt er dan een keuze gemaakt welke cellen vermoedelijk de CTC's zijn en kan er een paar microseconden later een cel tussenuit gepikt worden welke dan een reageerbuisje ingeschoten wordt.

\section{DNA analyse}

Na dit sorteren is er een DNA amplificatie gedaan waarna het DNA is geanalyseerd. Dit is op een uitgebreide manier gedaan om te kijken wat we kunnen verwachten van een cel die op deze manier is opgewerkt. We hebben geprobeerd om alleen het DNA te "lezen" wat belangrijk is, de genen. Al het andere DNA is er uit gehaald. Dit is gedaan omdat de hoeveelheid informatie uit een hele cel zo ontzettend groot is dat de kwaliteit van de mogelijk belangrijke stukken sterk af zou nemen. Ook wordt er in de 
genen zelf de belangrijkste informatie verwacht. We waren uiteindelijk in staat om $56 \%$ van de fouten in het DNA op te sporen in een enkele cel.

\section{Efficiëntie van de hele procedure}

Naast de analyse van het DNA hebben we ook gekeken hoe efficiënt de cellen uiteindelijk geïsoleerd konden worden op deze manier. We hebben uiteindelijk van longkankerpatiënten ongeveer 20 \% van de cellen kunnen sorteren in individuele buisjes.

\section{Hoofdstuk 7: FISH op CTC}

\section{Achtergrond:}

In dit hoofdstuk wordt de FISH (fluorescente in Situ Hybridisatie) techniek ingezet op de cellen die zijn geïsoleerd met het CellSearch systeem. Dit om te bewijzen dat het inderdaad om tumorcellen gaat. Zoals eerder beschreven isoleert het CellSearch systeem cellen uit het bloed die het eiwit EPCAM op de buitenkant van de cel hebben zitten. Omdat EPCAM op heel veel, ook normale cellen voorkomt, zouden deze geïsoleerde cellen ook normale cellen kunnen zijn. Uiteraard zien we een sterk verband tussen hoeveel cellen we vinden en de conditie van de patiënt en ligt het voor de hand dat het inderdaad om tumorcellen gaat maar dit was nog niet onomstotelijk bewezen. In dit hoofdstuk wordt bewezen dat deze cellen inderdaad tumorcellen zijn.

\section{FISH}

FISH staat voor Fluorescente in-situ hybridisatie: Fluorescentie: Een fluorescent label heeft als eigenschap dat het licht van de ene kleur opneemt en het in een andere kleur weer uitstraalt. Fluorescentiemicroscopen zijn uitgerust met speciale lichtfilters. Ze laten bijvoorbeeld groen licht op de cel vallen en vervolgens zit er voor het uitgaande licht een filter dat alles tegenhoudt behalve rood. In combinatie met zo'n filter is dan het enige wat er te zien is in de cel, de zelf aangebrachte fluorescente labels. In Situ: Betekent letterlijk ter plaatse. De kleuring wordt gedaan in de cel. Hybridisatie: Hybridisatie heeft te maken met het DNA waarop deze test wordt gedaan. DNA is onder normale omstandigheden dubbelstrengs. Een streng met acttgcgataacttgcgata zal als er een beetje zout aanwezig is (zoals in het lichaam) zijn complementaire partner tgaacgctattgaacgctat opzoeken. Dus: Tegenover iedere a komt altijd een $t$ en tegenover iedere c altijd een g. 
Gemakkelijk is op deze manier ook te zien dat het alleen zal "passen" als de match perfect is:

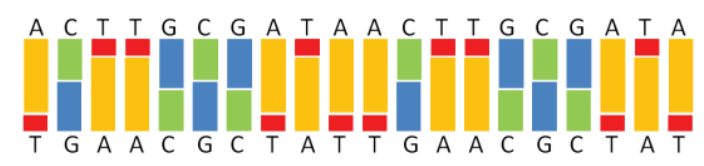

Op welke andere plek dan ook zal er nooit een goede match van de twee strengen zijn.

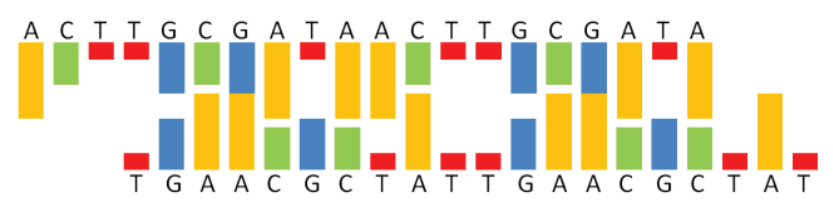

DNA kan enkelstrengs gemaakt worden door de temperatuur te verhogen, dit noemen we smelten. Als de temperatuur vervolgens weer daalt dan zoeken ze elkaar weer op.

Bij een FISH test maken we hier gebruik van. We pakken een stukje DNA en koppelen hier een fluorescent label aan: a-c-t-g-t en zijn complementaire sequentie: t-g-a-c-a.

Vervolgens voegen we dit toe aan de cel en smelten we voorzichtig het DNA. Als het nu weer aan elkaar wil gaan zitten (hybridiseren) gaat het stuk gelabelde DNA op de plek zitten van het originele:

a-c-t-g-t-g-a-c-a-t-a-g-a

a-c-t-g-t

t-g-a-c-a

t-g-a-c-a-c-t-g-t-a-t-c-t

In de cel kleurt dit dus heel specifiek een klein stukje van het DNA aan. 


\section{Wat kunnen we hiermee?}

We kunnen hiermee vier verschillende DNA afwijkingen zien in de cel:

Deleties: Een cel heeft twee kopieën van ieder gen. Het kan zijn dat het voor de tumorcel gunstig is als één van de twee genen weg is. Een cel die toevallig zo'n afwijking heeft, heeft een groeivoordeel en zal dus boven de andere uit groeien. Met FISH wordt dan maar één kopie van dit gen gevonden in de meeste kankercellen.

Amplificaties: Soms heeft een cel een groeivoordeel als er van een bepaald gen een heleboel kopieën zijn. FISH detecteert dan meerdere kopieën van dit gen.

Translocaties: Soms is er tijdens de celdeling iets misgegaan in de cel. Tijdens een celdeling wordt er veel geknipt en geplakt in een cel. Een gen dat de celgroei bevordert kan soms geplakt worden op een plek van een gen dat heel veel geproduceerd wordt in een cel. Vervolgens wordt er van dit andere gen veel geproduceerd en zal de cel harder gaan groeien dan de rest. Twee fluorescente DNAprobes met verschillende kleuren die normaal vlak naast elkaar liggen worden dan verder uit elkaar gevonden in de cellen.

Afwijkingen in het aantal chromosomen: In tumorcellen is het normale controlemechanisme van de celdeling en DNA verdeling verstoord. Vaak zal er in tumorcellen een afwijkend aantal chromosomen voorkomen. Chromosomen zijn pakketten van grote stukken DNA die voor iedereen hetzelfde zijn. Ze zijn onderverdeeld van groot naar klein: 1 is de grootste en 22 is de kleinste. Daarnaast zijn er de sex chromosomen $\mathrm{X}$ en $\mathrm{Y}$. Vrouwen hebben een $\mathrm{X}$ gekregen van hun vader en mannen krijgen van hun vader het $Y$ chromosoom.

Als er in meerdere cellen een afwijkend aantal chromosomen wordt gevonden dan is het vrijwel zeker dat deze cellen tumorcellen zijn.

\section{Inhoud van hoofdstuk 7}

In dit hoofdstuk laten we de techniek zien die we ontwikkeld hebben om de FISH uit te voeren op de CTC's. Het ingewikkelde was dat de cellen in een soort cassette zitten waarin de techniek uitgevoerd moest worden. Normaal is dat de cellen op een glaasje zitten waar je gewoon bij kan.

We laten zien dat het gelukt is om dit te doen door op een serie van samples van prostaatkanker patiënten een FISH te doen op vier verschillende chromosomen. Vrijwel zonder uitzondering laten de CTC's een afwijking zien in één of meerdere van 
de chromosomen. Dit bewijst dat deze cellen inderdaad, zoals verwacht, tumorcellen zijn.

\section{Hoofdstuk 8: Repeat free FISH probes}

\section{Achtergrond}

Hoofdstuk 8 gaat een stukje dieper in op de FISH techniek zelf. Het is een hoofdstuk dat ontstaan is tijdens het ontwikkelen van de FISH test op de CTC's wat samen met collega Brad Foulk uit Philadelphia is bedacht. Voor ik kan uitleggen wat het precies inhoudt eerst nog een beetje biologie.

\section{Chromosomen}

Ons DNA is in totaal ongeveer 3,5 miljard baseparen lang. Het is opgedeeld in grote stukken genaamd chromosomen. Elk met een eigen lengte: chromosoom 1 is de langste en heeft 245 miljoen baseparen (act of g), chromosoom 22 is de kortste en heeft 49 miljoen baseparen. Tijdens een celdeling zijn de chromosomen compact bij elkaar en kunnen we ze zien door de microscoop.

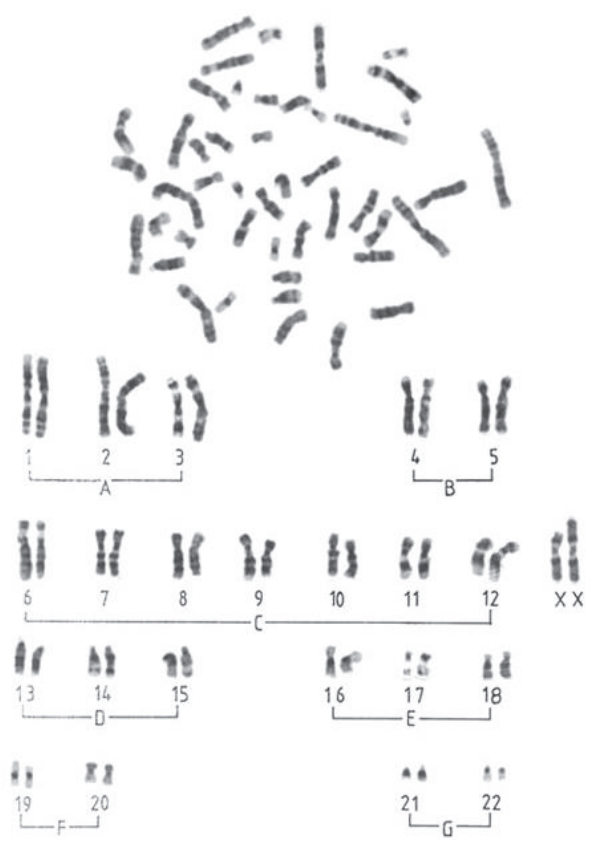

Voorbeeld van chromosomen zoals ze te zien zijn tijdens de celdeling. 


\section{Genen}

Op de chromosomen liggen de genen. De genen coderen voor eiwitten die het werk doen in de cel en in ons lichaam. Op een chromosoom liggen duizenden genen. Een gen bestaat uit korte stukjes echte informatie, dit noemen we unieke sequenties, met daartussen grote stukken ander DNA. Over dit andere DNA gaat dit hoofdstuk.

\section{Repetitief DNA}

Dit andere DNA bestaat uit basevolgordes die op erg veel plekken in het DNA herhalend voorkomen. Dit noemen we repetitief DNA. Als we een FISH test op een bepaald gen willen doen dan hebben we veel last van deze stukken repetitief DNA. Het stuk DNA waar het gen van interesse op ligt kan alleen in zijn geheel gelabeld worden met een fluorescent label. Hierbij worden dus ook de stukken repetitief DNA gelabeld. Als dit gebruikt wordt als FISH probe dan zal het gehele DNA kleuren en het gen van interesse zal niet te zien zijn.

\section{Inhoud van het hoofdstuk}

In dit hoofdstuk laat ik zien dat we een manier hebben gevonden om de repetitieve sequenties uit het DNA te verwijderen. We laten zien hoe we dit doen, bewijzen dat de repetitieve sequenties weg zijn en we laten zien dat het product ook nog efficiënter werkt dan de traditionele FISH probes.

De methode is gepatenteerd en wordt sinds een aantal jaren gebruikt door Kreatech/Leica voor de productie van commerciële FISH producten.

\section{Hoofdstuk 9: Het opvangen en scheiden van CTC's met een microchip}

\section{Achtergrond}

Hoofdstuk 6 en 7 beschrijven beiden een methode om enkele cellen te analyseren. In hoofdstuk 6 worden de cellen echt van elkaar gescheiden met behulp van een FACS. Het is echter zo dat deze methode erg veel tijd en vaardigheid van de gebruiker eist. Als we willen dat er een methode in een routinelaboratorium gebruikt kan worden dan is het zaak om het zo snel en efficiënt mogelijk te maken.

Hiervoor hebben we de zelf sorterende microchip bedacht. Het is een chipje waarin 6000 welletjes zijn gemaakt, zo groot dat er een cel in past. Onderin het welletje zit een gaatje dat te klein is voor een cel. Als er een cel op zo'n gaatje komt zal er in dit 
welletje geen vloeistof meer stromen en een volgende cel zal een leeg welletje zoeken. Hierdoor krijgen alle cellen een eigen welletje.
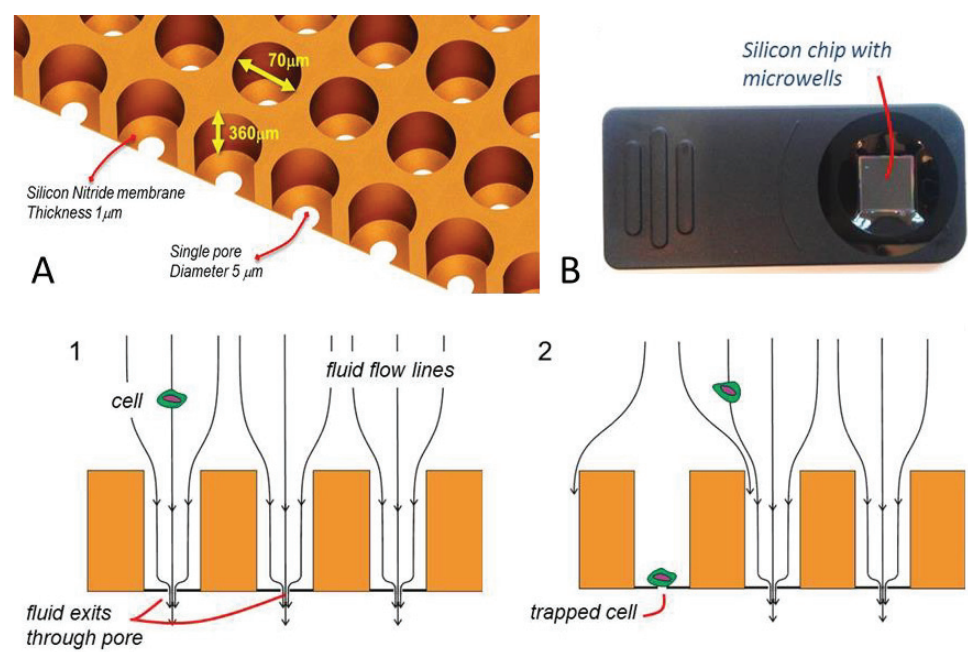

C

Nadat dit gebeurd is kunnen de cellen uitgekozen worden en met een naaldje (zo dik als een haar) uit de chip geprikt. Hierna kunnen we verder met het analyseren van het DNA van deze cellen.

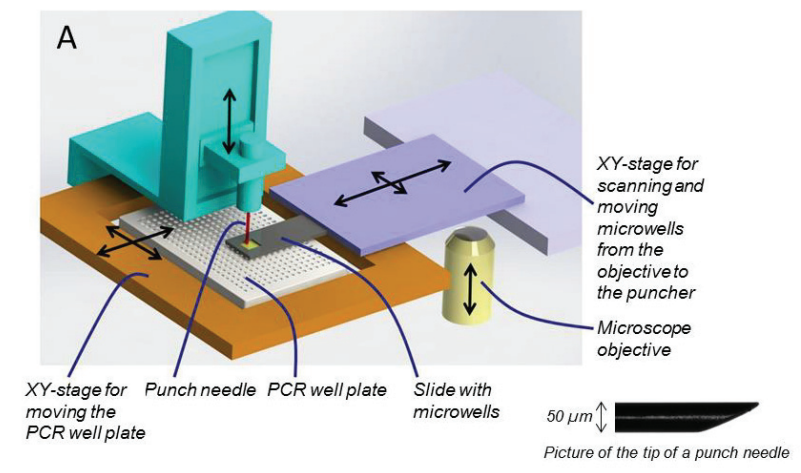

(1)

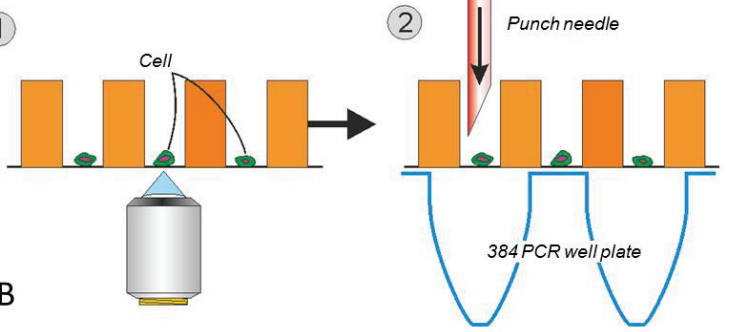




\section{Inhoud van het hoofdstuk:}

In dit hoofdstuk laten we zien hoe de chip gemaakt is, hoe efficiënt het werkt en dat we het DNA van de cellen kunnen analyseren en de juiste cellen terug kunnen vinden aan de hand van deze DNA analyse. De volgende stap zal zijn om deze methode te testen op patiënten samples. 


\section{Publication list}

1. van Garderen E, van der Poel HJ, Swennenhuis JF, Wissink EH, Rutteman GR, Hellmén E, Mol J a, Schalken JA: Expression and molecular characterization of the growth hormone receptor in canine mammary tissue and mammary tumors. Endocrinology 1999, 140:5907-14.

2. van Garderen E, Swennenhuis JF, Hellmén E, Schalken JA: Growth hormone induces tyrosyl phosphorylation of the transcription factors Stat5a and Stat5b in CMT-U335 canine mammary tumor cells. Domest Anim Endocrinol 2001, 20:123-35.

3. Malago JJ, Koninkx JFJG, Ovelgönne HH, van Asten FJ a M, Swennenhuis JF, van Dijk JE: Expression levels of heat shock proteins in enterocyte-like Caco-2 cells after exposure to Salmonella enteritidis. Cell Stress Chaperones 2003, 8:194-203.

4. Swennenhuis JF, Tibbe AGJ, Levink R, Sipkema RCJ, Terstappen LWMM: Characterization of circulating tumor cells by fluorescence in situ hybridization. Cytometry A 2009, 75:520-7.

5. Wind J, Tuynman JB, Tibbe AGJ, Swennenhuis JF, Richel DJ, van Berge Henegouwen MI, Bemelman W a: Circulating tumour cells during laparoscopic and open surgery for primary colonic cancer in portal and peripheral blood. Eur J Surg Oncol 2009, 35:94250 .

6. Attard G, Swennenhuis JF, Olmos D, Reid AHM, Vickers E, A'Hern R, Levink R, Coumans F, Moreira J, Riisnaes R, Oommen NB, Hawche G, Jameson C, Thompson EE, Sipkema R, Carden CP, Parker C, Dearnaley D, Kaye SB, Cooper CS, Molina A, Cox ME, Terstappen LWMM, de Bono JS: Characterization of ERG, AR and PTEN gene status in circulating tumor cells from patients with castration-resistant prostate cancer. Cancer Res 2009, 69:2912-8.

7. Scholtens TM, Schreuder F, Ligthart ST, Swennenhuis JF, Tibbe AGJ, Greve J, Terstappen LWMM: CellTracks TDI: an image cytometer for cell characterization. Cytometry A 2011, 79:203-13.

8. Swennenhuis JF, Foulk B, Coumans F a W, Terstappen LWMM: Construction of repeat-free fluorescence in situ hybridization probes. Nucleic Acids Res 2012, 40:e20. 
9. Scholtens TM, Schreuder F, Ligthart ST, Swennenhuis JF, Greve J, Terstappen LWMM: Automated identification of circulating tumor cells by image cytometry. Cytometry A 2012, 81:138-48.

10. Hoeppener AELM, Swennenhuis JF, Terstappen LWMM: Immunomagnetic separation technologies. Recent results cancer Res Fortschritte der Krebsforsch Progrès dans les Rech sur le cancer 2012, 195:43-58.

11. Swennenhuis JF, Reumers J, Thys K, Aerssens J, Terstappen LW: Efficiency of whole genome amplification of single circulating tumor cells enriched by CellSearch and sorted by FACS. Genome Med 2013, 5:106.

12. Yang Y, Swennenhuis JF, Rho HS, Le Gac SS, Terstappen LWMM, Suk Rho H, Le Gac SS, Terstappen LWMM: Parallel Single Cancer Cell Whole Genome Amplification Using Button-Valve Assisted Mixing In Nanoliter Chambers. PLoS One 2014, 9:e107958.

13. Sukas S, Schreuder E, de Wagenaar B, Swennenhuis J, van den Berg A, Terstappen L, Le Gac S: A novel side electrode configuration integrated in fused silica microsystems for synchronous optical and electrical spectroscopy. Lab Chip 2014, 14:1821-5.

14. Swennenhuis JF, Tibbe AGJ, Stevens M, Katika MR, van Dalum J, Tong HD, van Rijn CJM, Terstappen LWMM: Self-seeding microwell chip for the isolation and characterization of single cells. Lab Chip 2015, 15:3039-46.

15. Swennenhuis JF, Terstappen L: Sample Preparation Methods Following CellSearch Approach Compatible of Single-Cell Whole-Genome Amplification: An Overview. Methods Mol Biol 2015, 1347:57-67.

16. Swennenhuis JF, van Dalum G, Zeune LL, Terstappen LWMM: Improving the CellSearch® system. Expert Rev Mol Diagn 2016, 16:1291-1305. 


\section{Congress contributions,}

Posters:

Cytogenetic Analysis of Circulating Tumor Cells of Metastatic Prostate Cancer. J.F.Swennenhuis, A.G.J.Tibbe, R.Levink, H.Tissing, R.C.J.Sipkema, L.W.M.M.Terstappen. International Society for Cellular Oncology (ISCO), Amsterdam, 2008.

Single-Cell Whole Genome Amplification of Circulating Tumor Cells (CTC) Isolated with the CellSearch System. J.F.Swennenhuis, J.Reumers, J.Aerssens, K.Thys, L.W.M.M.Terstappen. Advances in Circulating Tumor Cells (ACTC), Athens, 2012.

Self-Sorting Nanowell Plate for the Isolation and Characterization of Single Circulating Tumor Cells. J.F.Swennenhuis, A.G.J.Tibbe, M.Stevens, H.D.Tong, C.van Rijn, L.W.M.M.Terstappen. Annual meeting of the American Association of Cancer Research (AACR), San Diego, 2014.

Single Cell Isolation and DNA Analysis from Circulating Tumor Cells using Self Sorting Microwell Filters. J.F.Swennenhuis, A.G.J.Tibbe, M.Stevens, N.H.Stoecklein, R.Neves, H.D.Tong, C.van Rijn, L.W.M.M.Terstappen. Annual meeting of the American Association of Cancer Research (AACR), Philadelphia, 2015.

Oral presentations:

Characterization of circulating tumor cells by Fluorescence in situ hybridization, J.F.Swennenhuis, A.G.J.Tibbe, R.Levink, R.C.J.Sipkema, L.W.M.M.Terstappen. International symposium on Minimal Residual Cancer, Athens, 2009.

Single cell isolation technology based on single cell self-seeding microwells. J.F.Swennenhuis, A.G.J.Tibbe, M.Stevens, H.D.Tong, C.van Rijn, L.W.M.M.Terstappen. CYTO 2015, 30th Congress of the International Society for Advancement of Cytometry, Glasgow, 2015 


\section{Curriculum Vitae}

Joost Franciscus Swennenhuis was born on July 231973 in Apeldoorn, The Netherlands. He graduated from high school at the Sonsbeek College in Arnhem in 1991 and studied Biology and Medical Laboratory-research at the IJselland University of professional education in Deventer. Internship for this study was done at the Pathology department of Veterinary Medicine at the Utrecht University where he studied the influence of Salmonella on heat shock protein levels in differentiated intestine epithelium (see also publication list: Malago JJ et al, 2003). After graduation in 1996, work in this group was continued under the supervision of Prof.Dr. Jaap van Dijk and Prof.Dr. Jack Schalken where, next to general laboratory management, work was done on the characterization of the growth hormone receptor and signal transduction pathways in mammary gland tissue and tumors. (See also publication list: van Garderen et al, 1999; van Garderen et al. 2001). In 2000 he started a job at a small company Kreatech Diagnostics in Amsterdam where he was responsible for the development of the Fluorescent in Situ Hybridization (FISH) application using the companies platinum based labelling technology and subsequently for the development and upscaling of the FISH probe production process. In 2004 he moved to Immunicon corporation in Enschede where he developed a FISH test on Circulating Tumor Cells (CTCs) (see also publications list: Swennenhuis et al, 2009). In 2009 he moved to the group of Prof. Dr. Leon Terstappen to the University of Twente to set up the laboratory of the new Medical Cell BioPhysics (MCBP) group. In 2012 he started a $\mathrm{PhD}$ program in this group, which led to this thesis. 


\section{Acknowledgements}

My PhD track was not a usual one. 8 years ago, after some great years working at "Immunicon Europe" Leon Terstappen asked me if I would be interested in setting up a new laboratory for a new research group in a new building at the University of Twente. The building would be finished in a few months and then we could start our work. We carefully started some experiments in the Zuidhorst in between other goups with shared workspaces. Due to some issues with the builders the few months turned out to be a few years. After drawing the actual labs, buying and installing the equipment, we had a beautiful large new workspace and the official part of my $\mathrm{PhD}$ track could start..

I really appreciate the MCBP Group and mainly the fact that there is such a great atmosphere. Research is central in the group and there is a big drive from everybody to keep their own topic going but also to help each other out. I really would like to thank everybody in this group for this. Christian: I think you deserve a special place here. Always being prepared giving support or fixing problems immediately in between your own projects. Me, but also the whole group owes you big credit!

I think the atmosphere in the MCBP group is possible due to the way Leon is managing the group. The enthusiasm and dedication he puts in his work are really amazing and this has its effect on the whole group. Leon thank you for giving me the opportunity to write this thesis and for you to do the guidance with ever-lasting energy, optimism and patience.

Already a lot of other PhD students have been at the group before me. They all, all in their own way, have helped to build this group to what it is today and therefore have made this work possible. Erik, Sjoerd, Frank, Tycho, Liesbeth, Yoon, Guus, Barbara and Iwan. Thanks for all your work. Especially I would like to thank Guus van Dalum for all technical and IT support he has given me.

A lot of students have done their internship at our group and I have been involved in a lot of their projects. I am very happy to see that many of you stay in touch or even come back to the group to a next internship or even a PhD! Sanne and Kiki special thanks to you and your contribution to the single cell and WGA work during your internships and good luck with your own work the coming years!

Roommates: Markus, Afrodite and Joost, (and former roommates Frank Coumans and Dodo) thanks for always being eager to look for solutions to the most diverse 
problems and to discuss the most diverse subjects. Thanks also for your patience with me walking in and out of the office all the time.

Paranymphs. Arjan, we have been working together for already 13 years. I highly value your critical "matter-of-fact" view on the CTC subjects. I really enjoyed working with you and hope to this continues for a while. Frank: Backpack adventures, squash/sports fights, camp-fires, school trips. I don't know where to start. Camp fire discussions about new forms of cancer and the after-squash conversations about the research (and lots of other stuff) were fun and valuable to me. Both of you: Thanks for supporting me in the last and heaviest steps of this adventure.

Dear sister, Maaike. It is always a pleasure having you around. Thanks for the critical and honest corrections to parts of this thesis. Also special thanks to my parents, Jos and Corrie, who have always been ready for helping us out and taking care of the kids every week. Hans and Greet, thank you for the almost daily backup in pre and post school hours. Hans thank you for bringing and getting Marius to and from school on a daily basis!

Beike: I hereby admit, and congratulate you, with winning our tailcoat contest. I am proud of you!

This work would not have been possible without my warm home. Beike, I cannot thank you enough for your unconditional support. Even in times where too many high priority projects came together (and there were enough of those moments), you could stay calm, supported me and always gave me enough room to continue and move forward. Sebastiaan, Jonathan, Jasmijn en Marius: ook door jullie is het vaak gelukt dat ondanks dat we met z'n allen in de woonkamer zitten, er ook gewoon lekker gewerkt kan worden. Er is een mooie balans thuis tussen (huis)werk, lol en sport. Sebas: Dank voor de supermooie omslag van dit boekje! 


\section{Supplementary protocols:}

\section{Protocol: Sigma GenomePlex on Ampligrid slide}

Kit components

scLFB: 10x Single Cell Lysis \& Fragmentation Buffer L1043, ProtK: Proteinase K Solution P4850, SCLPB: 1x Single Cell Library Preparation Buffer L0918, LSS: Library Stabilization Solution L7292, LPE: Library Preparation Enzyme E0531, AMM: 10x Amplification Master Mix A5604, Pol: WGA DNA polymerase W3891.

Other components needed:

Ampligrid slide: Beckmann coulter cat 11228, Sealing solution: Beckmann coulter, Ampligrid PCR, normal thermocycler.

Method:

1. Isolate a single cell onto a well of an ampligrid slide in $0,5 \mu$ l water.

2. Prepare lysis solution: $\quad(1 \mu \mathrm{l}$ ProtK $+16 \mu \mathrm{l} \mathrm{scLFB})$

3. Predilute the prepared lysis solution. $\quad(1 \mu \mathrm{l}$ from step $2+9 \mu \mathrm{l}$ MilliQ)

4. Add $0,5 \mu$ l step 3 buffer to the slide. Cover the well with $2 \mu$ sealing solution

5. Incubate $50{ }^{\circ} \mathrm{C}$ for 1 hour, then heat to $99{ }^{\circ} \mathrm{C}$ for EXACTLY four minutes. Note that the incubation is very time sensitive. Any deviation may alter results. Cool the slide on a (pre-cooled) ice-cold aluminum plate.

6. $\quad$ Prepare Library Preparation Buffer $\quad(2 \mu \mathrm{l} \mathrm{SCLPB}+1 \mu \mathrm{LSS}+3,5 \mu \mathrm{l}$ MilliQ)

7. $\quad$ Add $0,5 \mu$ l of the step 7 buffer under the oil.

8. Incubate for 2 minutes at $95^{\circ} \mathrm{C}$. 
9. Cool the slide on an ice-cold aluminum plate.

10. Prepare Library Preparation Enzyme $\quad(1 \mu \mathrm{l} \mathrm{LPE}+3,66 \mu \mathrm{l}$ MilliQ $)$

11. Add $0,5 \mu$ l of step 12 mix to each well.

12. Place sample on a PCR block which is at $16^{\circ} \mathrm{C}$ for 20 minutes

13. Place the sample on the AmpliSpeed and incubate as follows:

$24{ }^{\circ} \mathrm{C}$ for 20 minutes $37{ }^{\circ} \mathrm{C}$ for 20 minutes $\quad 75^{\circ} \mathrm{C}$ for 5 minutes

14. Remove samples from the amplispeed and cool on ice

Prepare amplification mix:

$(1 \mu \mathrm{l} \mathrm{AMM}+7 \mu \mathrm{l} \mathrm{MilliQ}+0,71 \mu \mathrm{l} \mathrm{Pol})$

15. Put the samples from the AmpliGrid slide into a PCR vial.

16. Rinse each spot $3 \mathrm{x}$ with $1 \mu \mathrm{l}$ of the prepared amplification mix and add to the PCR vial

17. Add the rest of the PCR buffer and cycle as follows in a thermocycler:

$95{ }^{\circ} \mathrm{C}$ for 3 minutes

Perform 25 cycles as follows:

Denature $\quad 94^{\circ} \mathrm{C}$ for 30 seconds

Anneal/Extend $\quad 65^{\circ} \mathrm{C}$ for 5 minutes

Hold $\quad 4{ }^{\circ} \mathrm{C}$

18. After cycling is complete, maintain the reactions at $4{ }^{\circ} \mathrm{C}$ or store at $-20{ }^{\circ} \mathrm{C}$ until ready for analysis or purification. The stability of WGA DNA is equivalent to genomic DNA stored under the same conditions. 


\section{Protocol: GE Genomiphi on slide}

Developed by: Kiki Andree.

Protocol for the WGA method on single cells, using the GE Healthcare illustra GenomiPhi V2 DNA Amplification Kit. Protocol is developed with two lysis methods. The $\mathrm{KOH}$ lysis method is supplied with the GenomiPhi kit and works on fresh cells. The Protease K method is added to be able to amplify DNA from formalin or CellSave fixed cells but also works for fresh cells.

Materials:

KOH 4M, EDTA 0.25M, DTT 1M, HCl 1M, Tris-HCl Buffer 1M, pH 7,5, 1X PBS, Water for molecular use (Sigma cat. 95284-100mL), Proteinase K (Sigma cat. P6556), Illustra GenomiPhi V2 DNA Amplification Kit (GE cat. 25-6600-31), Waterbath, Micromanipulator/ microscoop. Diagnostic glass slides, epoxy coated, 30 Well $2 \mathrm{~mm}$, (Thermo Scientific cat. X1XER312B\#MNZ), Small floatable plastic box, Glass slide holder

$\mathrm{KOH}$ lysis method:

1. Prepare lysis and neutralization solutions using pipetting schema shown in table XXa. Lysis solution contains 400mM KOH, 25mM EDTA, 100mM DTT (fresh). Neutralization solution contains $600 \mathrm{mM}$ Tris- $\mathrm{HCl} \mathrm{pH} \mathrm{7,5} \mathrm{and} \mathrm{400mM} \mathrm{HCl.}$ 
Pipetting scheme Lysis and neutralization buffer

Lysis solution

Compound Volume $(\mu \mathrm{l}) \quad$ Final conc

Water $\quad 375$

KOH (4M) $\quad 50 \quad 400 \mathrm{mM}$

EDTA $(0,25 M) \quad 25 \quad 12,5 \mathrm{mM}$

DTT (1M) $\quad 50 \quad 100 \mathrm{mM}$

Total $\quad 500$

Neutralization solution

Compound Volume $(\mu \mathrm{l}) \quad$ Final conc

Tris HCl 1M pH 7.5 $\quad 300 \quad 600 \mathrm{mM}$

$\mathrm{HCl}(1 \mathrm{M}) \quad 200 \quad 300 \mathrm{mM}$

Total 500

2. Apply the desired amount of cells on the 30 -well diagnostic glass slide in a small volume $(\max 0.5 \mu \mathrm{l})$.

3. Add $1 \mu \mathrm{L}$ lysis solution to the sample and incubate $10 \mathrm{~min}$. on ice

4. Prepare reaction mix: mix $7 \mu \mathrm{L}$ sample buffer, $9 \mu \mathrm{L}$ reaction buffer and $1 \mu \mathrm{L}$ enzyme mix.

5. $\quad$ Add $1 \mu \mathrm{L}$ neutralization solution to each sample.

6. Continue with the amplification reaction

ProtK lysis method 
1. Make the Lysis buffer: mix $16 \mu \mathrm{L} 10 \mathrm{X}$ Lysis and Fragmentation Buffer, $1 \mu \mathrm{L}$ Proteinase $\mathrm{K}$ and $143 \mu \mathrm{L}$ nuclease free water.

2. Select the cells and place them on a 30 well epoxy coated diagnostic slide.

3. Add $1 \mu \mathrm{L}$ of the Lysis buffer to the samples.

4. Put the sample slide upside down into a slideholder with on the bottom a wet tissue.

5. Place the slideholder into a floating box.

6. Incubate for 60 minutes at $50^{\circ} \mathrm{C}$ in a water bath.

7. Deactivate the proteinase $\mathrm{K}$ by heating from $50^{\circ} \mathrm{C}$ to $75^{\circ} \mathrm{C}$ and incubate for 20 minutes.

8. Continue with the amplification reaction

\section{Amplification reaction}

1. Add $4 \mu \mathrm{L}$ reaction mix to the sample.

2. Place the diagnostic glass slide containing sample(s) upside down in a glass slide holder, with on the bottom of the glass slide holder a wet tissue, and close it.

3. Place glass slide holder in a small plastic box with a wet tissues on the bottom.

4. Place the plastic box in a waterbath at $30^{\circ} \mathrm{C}$ (make sure it floates) and incubate for $2-4$ hours.

5. Pipet $10 \mu \mathrm{L}$ water in PCR epps, pipet the sample(s) from the slides and add them to the $10 \mu \mathrm{L}$ water.

6. Place the epps in the plastic box and incubate for $10 \mathrm{~min}$. at $65^{\circ} \mathrm{C}$ in the waterbath.

7. Samples can be stored at $-20^{\circ} \mathrm{C}$ 


\section{Protocol: 10 gene multiplex PCR MCBP}

For amplification: Qiagen multiplex pcr plus kit (Cat 206151)

1. Primermix: Prepare a primermix as given in table 1

\begin{tabular}{|c|c|c|}
\hline Target & Primer no. & Final concentration in mix $(10 x)$ \\
\hline 1q21 SCAMP3 & $35 / 45$ & \multirow{3}{*}{$1 \mu \mathrm{M}$} \\
\hline 2p24 ROCK2 & $37 / 47$ & \\
\hline 3p21 SCAP & $36 / 46$ & \\
\hline 4q21 SCARB2 & $34 / 44$ & \multirow{3}{*}{$2 \mu \mathrm{M}$} \\
\hline 11q13 SCYL1 & $41 / 51$ & \\
\hline 17q25 JMJD6 & $39 / 49$ & \\
\hline 7q22 CUX1 & $42 / 52$ & \multirow{4}{*}{$4 \mu \mathrm{M}$} \\
\hline 12q14 XPOT & $33 / 43$ & \\
\hline 14q23 ACTR10 & $38 / 48$ & \\
\hline 19q13 PPP5C & $40 / 50$ & \\
\hline
\end{tabular}

Table 1: Concentration of the primers in the mix used for the multiplex PCR. Concentrations are adjusted such that all amplicons are equally strong on the gel. All concentrations are for each primer separately.

2. Target: purify the target Ampli-1 product using a Qiagen column, Ampure beads or comparable method and measure the concentration. Dilute the DNA to be tested to $100 \mathrm{pg} / \mu \mathrm{l}$.

3. Prepare for each reaction:

$10 \mu$ l Mastermix $+2 \mu$ l Primermix $+3 \mu$ l water

Add $5 \mu$ l of the prepared target to each reaction

4. Run the program:

\begin{tabular}{lll}
\hline Time & Temp & Repeat \\
\hline $\mathbf{5}$ min & $95^{\circ} \mathrm{C}$ & 1 \\
\hline $\mathbf{3 0 ~ s e c}$ & $95^{\circ} \mathrm{C}$ & 35 \\
$\mathbf{3} \mathbf{~ m i n}$ & $72^{\circ} \mathrm{C}$ & \\
\hline $\mathbf{1 0 ~} \mathbf{m i n}$ & $72^{\circ} \mathrm{C}$ & 1 \\
\hline
\end{tabular}




\section{SUPPLEMENTARY PROTOCOLS}

Table 2: PCR reaction condition

Primer information:

\begin{tabular}{|c|c|c|c|c|c|c|c|c|}
\hline Chr. & $\begin{array}{l}\text { Gene } \\
\text { name }\end{array}$ & $\begin{array}{l}\text { Ampl. } \\
\text { size (bp) }\end{array}$ & $\begin{array}{l}\text { Msel frag } \\
\text { size (bp) }\end{array}$ & \# & Forward primer sequence $\left(3^{\prime} \rightarrow 5^{\prime}\right)$ & \# & Reverse primer sequence $\left(3^{\prime} \rightarrow 5^{\prime}\right)$ & Primer conc \\
\hline $7 q 22$ & CuX1 & 1009 & 3434 & 42 & AGG-TGC-TGC-TTC-CCA-TTG-TCC-CT & 52 & GGG-CAT-GGT-GGT-GGG-TGC-CTA-TAA & $400 \mathrm{nM}$ \\
\hline $11 q 13$ & SCYL1 & 900 & 2050 & 41 & AGC-AAC-AGG-TCA-GGT-AGC-CGC-AAT & 51 & CCA-AGG-TGA-GGA-GGG-CAG-GGA-ATG & $200 \mathrm{nM}$ \\
\hline 19q13 & PPP5C & 800 & 1292 & 40 & ACC-AGC-CTG-TCC-AAT-GTG-GTG-AAA & 50 & ACT-GCT-GCG-TGA-ACC-CTG-TGA-G & $400 \mathrm{nM}$ \\
\hline $17 q 25$ & JMJD6 & 720 & $1592^{* *}$ & 39 & GGG-AGG-GCT-GCT-GCT-CTT-CAG-TT & 49 & AGG-CTC-CAG-GAG-TCA-GCC-AGA-GA & $200 \mathrm{nM}$ \\
\hline $14 q 23$ & ACTR10 & 606 & $1840^{*}$ & 38 & CCA-CTG-CGC-CCG-AAC-GAG-TTT & 48 & CCA-GCC-TGG-GTG-ACA-GAG-TGA-GAA & $400 \mathrm{nM}$ \\
\hline $2 \mathrm{p} 24$ & ROCK2 & 498 & 934 & 36 & TGG-CCT-AGA-AGT-CTG-GAG-GCC-TGA & 46 & CCA-CAG-CGC-CTT-TGT-TGT-TGC-CAT & $100 \mathrm{nM}$ \\
\hline $3 p 21$ & SCAP & 397 & 706 & 37 & CCC-AGT-GCC-GAG-GGT-TCC-ATC-T & 47 & GGA-GCT-GGG-CAC-CAA-GAA-GGT-CAA & $100 \mathrm{nM}$ \\
\hline $1 q 21$ & SCAMP3 & 301 & 500 & 35 & ACC-GAC-CCA-GCC-GGC-AGT-ATG & 45 & AGG-CCT-TGC-CAG-CCT-CCA-GAT & $100 \mathrm{nM}$ \\
\hline $4 q 21$ & SCARB2 & 197 & 300 & 34 & GCT-TTC-ATG-CTT-GCT-GCC-CAC-CTT & 44 & GCC-TTC-AGA-GGC-CAC-CTC-CTT-CAC & $200 \mathrm{nM}$ \\
\hline $12 q 14$ & ХРОТ & 94 & 172 & 33 & TGT-CCA-GAC-TCA-AGT-GCA-GTG-GCA & 43 & GCT-ACT-TGG-GAG-GCA-GAG-GCA-GAA & $400 \mathrm{nM}$ \\
\hline
\end{tabular}

Table 3. Details of the primers for the 10 gene multiplex PCR. \# = number of the primer. ${ }^{*}=$ The original MseI fragment contains one MseI restriction site ${ }^{* *}=$ The original MseI fragment contains two MseI restriction sites. 


\section{Protocol: 5 gene multiplex PCR}

Developed by: Sanne de Wit

Reagents:

- $\quad$ 10x PCR Buffer (Sigma P2317)

- $\quad$ 25mM MgCl (Sigma M8787)

- $\quad$ Primermix : take $5 \mu \mathrm{l}$ of each of the $100 \mu \mathrm{M}$ primer stocks and add $50 \mu \mathrm{l}$ water.

- $\quad$ dNTP mix (GE Healthcare GE28-4065-64)

- $\quad$ JumpStartTaq without $\mathrm{MgCl}$ (Sigma D4184)

\begin{tabular}{llllll}
\hline $\mathbf{C h}$. & STS & $\begin{array}{l}\text { Ampl. } \\
\text { size } \mathbf{( b p})\end{array}$ & Forward primer sequence $\left(\mathbf{3}^{\prime} \rightarrow \mathbf{5}^{\prime}\right)$ & Reverse primer sequence $\left(\mathbf{3}^{\prime} \rightarrow \mathbf{5}^{\prime}\right)$ & Primer conc \\
\hline $\mathbf{4}$ & STB39J12.SP6 & 132 & GCAAAATCCATACCCTTTCTGC & TCTTTCCCTCTACAACCCTCTAACC & $500 \mathrm{nM}$ \\
\hline $\mathbf{2 2}$ & G50529 & 150 & GCTGTTAGAGCTTTTATTGCAGC & CTAGAAATTTCTGCATAAACCAACC & $500 \mathrm{nM}$ \\
\hline $\mathbf{2}$ & CSNPHARP & 196 & CATGGCTCACTGGCTTACAA & TTGCCTCTTACAGAGGAGCAG & $500 \mathrm{nM}$ \\
\hline $\mathbf{1 2}$ & SHGC147491 & 235 & TTTGATGTTAGGACACGCTGAAA & AAAAACGGAAGAAGTCTCTTGGC & $500 \mathrm{nM}$ \\
\hline $\mathbf{1 3}$ & SHGC105883 & 295 & GTCAGAAGACTGAAAACGAAGCC & GCTTGCCACACTCTTCTTCAAGT & $500 \mathrm{nM}$
\end{tabular}

Table 1. Chromosome, STS name, amplicon length, primer sequence and the primer concentration in the amplification mix.

Protocol:

1. Make the following master mix:

$2 \mu \mathrm{l}$ 10x PCR Buffer (Sigma P2317)

$1,2 \mu \mathrm{l} 25 \mathrm{mM} \mathrm{MgCl}$ (Sigma M8787)

$2 \mu \mathrm{l}$ Primermix

0,4 $\mu \mathrm{l}$ dNTP mix (GE Healthcare GE28-4065-64)

0,4 $\mu$ l JumpStartTaq without MgCl (Sigma D4184)

$13 \mu$ Water

Protocol: $3 \min 96^{\circ} \mathrm{C}$, (30 sec $\left.94^{\circ} \mathrm{C}, 1 \min 60^{\circ} \mathrm{C}, 1 \min 72^{\circ} \mathrm{C}\right) 30$ cycles $), 10 \min 72^{\circ} \mathrm{C}$, $4^{\circ} \mathrm{C}$ 


\section{Protocol: 10 gene qPCR MCBP}

Developed by : J.F.Swennenhuis

\begin{tabular}{|c|c|c|c|}
\hline & Gene & Forward primer $5^{\prime} \rightarrow 3^{\prime}$ & Reverse primer $\mathbf{5}^{\prime} \rightarrow 3^{\prime}$ \\
\hline 1 & ERBB2 & GGG-TGG-CAG-TGT-TCC-TAT-TT & ACT-TGG-TTG-TGA-GCG-ATG-AG \\
\hline \multicolumn{4}{|c|}{ gggtggcagtgttcctatttcagccccactctgcttcccctcccagGATATCCAGGAGGTGCAGGGCTACGTGCTCATCGCTCACAACCAAGT } \\
\hline 2 & CCND1 & ACA-GCT-GTC-ACT-TCC-CTT-TAC & GAT-TAG-GAG-CCA-CCC-AGA-ATT-AG \\
\hline \multicolumn{4}{|c|}{ acagctgtcacttccctttacaaccaggcagcggatagggtcaaatcctggagctttggtgtctaattctgggtggctcctaatc } \\
\hline 3 & MYC & CAT-AAC-GCG-CTC-TCC-AAG-TA & GGG-AGG-AAT-GAT-AGA-GGC-ATA-AG \\
\hline \multicolumn{4}{|c|}{ cataacgcgctctccaagtatacgtggcaatgcgttgctgggttattttaatcattctaggcatcgtttcctccttatgcctctatcattcctccc } \\
\hline 4 & PRMT2 & GTG-ACT-GTC-CCA-GAA-GTG-AAT-C & CTG-ACG-CTT-AGC-TCT-CTG-TAA-TG \\
\hline \multicolumn{4}{|c|}{ GTGACTGTCCCAGAAGTGAATCGCAGgtaatttccgttccacttcctaaaaatctgtgtttaatgaatgtgagcattacagagagctaagcgtcag } \\
\hline 5 & URB2 & CTG-GGA-TTG-TGA-GCT-TTC-TT & GGA-GGA-CTG-TGC-CTA-TCT-AT \\
\hline \multicolumn{4}{|c|}{ ctgggattgtgagctttcttcaatgtttgtgaagaggaaacatgacacgtaatggaacctgtatagataggcacagtcctcc } \\
\hline 6 & FGFR1 & GGT-GTG-AAG-CCT-GTT-TCT-T & AAA-GGC-ACC-GTG-GTA-ATG \\
\hline \multicolumn{4}{|c|}{ ggtgtgaagcctgtttcttgttctgagcccagaagctatcaacccttttgaaaaacattaccacggtgccttt } \\
\hline 7 & P53 & GCA-TCC-CGG-ATC-AGA-TTT-C & GGA-ACG-GGA-AAC-CTT-CTA-AC \\
\hline \multicolumn{4}{|c|}{ gcatcccggatcagatttcgcgggcgacccacggaacccgcggagccgggacgtgaaaggttagaaggtttcccgttcct } \\
\hline 8 & MUC1 & CCT-GCC-ATA-ACC-TCC-TAT-CT & AGC-TGC-CCG-TAG-TTC-TT \\
\hline \multicolumn{4}{|c|}{ CctgccataacctcctatctccccagGCTGTCTGTCAGTGCCGCCGAAAGAACTACGGGCAGCT } \\
\hline 9 & TRAM1 & CAG-GAG-AGC-AAT-TCT-TCA-GG & AGA-CAC-GTC-CTC-CTC-TTA-TC \\
\hline \multicolumn{4}{|c|}{ caggagagcaattcttcaggaaaaagaatacaaaggactccaggtttgggcaaaacgataagaggaggacgtgtct } \\
\hline 10 & PAK1 & TGG-ATC-CCA-GCA-CCT-AAT-A & GAG-AAG-GAC-TAC-AGG-CAT-TG \\
\hline
\end{tabular}

Table 1: Primers and complete amplicons of the qc qPCR. The complete amplicons are also given below each primer pair. Intronic regions are lower case and exonic regions are upper case.

Protocol:

1. Purify the WGA products and measure the DNA concentration.

2. Dilute the target DNA to $2 \mathrm{ng} / \mu \mathrm{l}$.

3. Predilute and premix the primer-pairs to $5 \mu \mathrm{M}$ each.

4. Make the mastermix:

- 6,25 $\mu$ l Mastermix Bio-Rad IQ SYBR green supermix cat. 170-8880

$-1.25 \mu \mathrm{l}$ primermix

5. Add $5 \mu$ l target to each reaction

6. Run the program: 


\begin{tabular}{lll}
\hline Time & Temp & Repeat \\
\hline 3 min & $95^{\circ} \mathrm{C}$ & 1 \\
\hline $\mathbf{1 5 ~ s e c}$ & $95^{\circ} \mathrm{C}$ & \\
$\mathbf{1 5 ~ s e c}$ & $62^{\circ} \mathrm{C}$ & 50 \\
$\mathbf{1 5 ~ s e c}$ & $72^{\circ} \mathrm{C}$ & \\
\hline
\end{tabular}




\section{Protocol: Six gene mpPCR}

Developed by: J. Knijnenburg et al. [3]

Reagents:

DNA template is the product of the Ampli-1 kit without any purification.

Dream Taq Green PCR Master Mix (2x) - Fermentas \#K1082, Nuclease free water

Primer Master mix:

\begin{tabular}{llllll}
\hline Primer & Sequence & Stock conc. & $\begin{array}{l}\text { Volume } \\
\text { to use }\end{array}$ & Conc in Mix & Conc in reaction \\
\hline LAMC1 For & tctgctttgggcattcttct & $100 \mu \mathrm{M}$ & $10 \mu \mathrm{l}$ & $2 \mu \mathrm{M}$ & $0,2 \mu \mathrm{M}$ \\
\hline LAMC1 Rev & ttctaacaggttgggggatg & $100 \mu \mathrm{M}$ & $10 \mu \mathrm{l}$ & $2 \mu \mathrm{M}$ & $0,2 \mu \mathrm{M}$ \\
\hline GRIK5 For & ctagctcccaccaacctcag & $100 \mu \mathrm{M}$ & $5 \mu \mathrm{l}$ & $1 \mu \mathrm{M}$ & $0,1 \mu \mathrm{M}$ \\
\hline GRIK5 Rev & ctcgatgatcccgttgatct & $100 \mu \mathrm{M}$ & $5 \mu \mathrm{l}$ & $1 \mu \mathrm{M}$ & $0,1 \mu \mathrm{M}$ \\
\hline NEK9 For & gcaggagggaacctgtatga & $100 \mu \mathrm{M}$ & $4 \mu \mathrm{l}$ & $0,8 \mu \mathrm{M}$ & $0,08 \mu \mathrm{M}$ \\
\hline NEK9 Rev & caggaaagaaagcccacaga & $100 \mu \mathrm{M}$ & $4 \mu \mathrm{l}$ & $0,8 \mu \mathrm{M}$ & $0,08 \mu \mathrm{M}$ \\
\hline CADPS For & ccccacccttcttcactaca & $100 \mu \mathrm{M}$ & $4 \mu \mathrm{l}$ & $0,8 \mu \mathrm{M}$ & $0,08 \mu \mathrm{M}$ \\
\hline CADPS Rev & gtgtgcacataccaccgaag & $100 \mu \mathrm{M}$ & $4 \mu \mathrm{l}$ & $0,8 \mu \mathrm{M}$ & $0,08 \mu \mathrm{M}$ \\
\hline PICK1 For & tcgtatgctggagtcctgtg & $100 \mu \mathrm{M}$ & $4 \mu \mathrm{l}$ & $0,8 \mu \mathrm{M}$ & $0,08 \mu \mathrm{M}$ \\
\hline PICK1 Rev & gggatggctttgttgaggta & $100 \mu \mathrm{M}$ & $4 \mu \mathrm{l}$ & $0,8 \mu \mathrm{M}$ & $0,08 \mu \mathrm{M}$ \\
\hline DNAH9 For & gggtctcatcaccagcattt & $100 \mu \mathrm{M}$ & $4 \mu \mathrm{l}$ & $0,8 \mu \mathrm{M}$ & $0,08 \mu \mathrm{M}$ \\
\hline DNAH9 Rev & gccatcttccacatggtctt & $100 \mu \mathrm{M}$ & $4 \mu \mathrm{l}$ & $0,8 \mu \mathrm{M}$ & $0,08 \mu \mathrm{M}$ \\
\hline dH ${ }_{2} \mathbf{O}$ & & & $436 \mu \mathrm{l}$ & & \\
\hline & & total & $500 \mu \mathrm{l}$ & $\left(\right.$ Aliquot, store at $-20^{\circ} \mathrm{C}$ )
\end{tabular}

Prepare the following mix on ice

\begin{tabular}{ll}
\hline & $\mathbf{1}$ Sample \\
\hline Dream Taq Green PCR Master mix (2x) & $5 \mu \mathrm{l}$ \\
\hline Primers master mix & $1 \mu \mathrm{l}$ \\
\hline $\mathbf{H}_{2} \mathbf{O}$ & $3,7 \mu \mathrm{l}$ \\
\hline total & $9,7 \mu \mathrm{l}$ \\
\hline & \\
\hline DNA (not purified whole genome amplified) & $0,3 \mu \mathrm{l}$ \\
\hline total & $10 \mu \mathrm{l}$ \\
\hline
\end{tabular}


In the thermalcycler of Bio-rad run:

$95^{\circ} \mathrm{C}$ for $2^{\prime}$

$33 \mathrm{x} \quad 95^{\circ} \mathrm{C}$ for $30^{\prime \prime}$

$60^{\circ} \mathrm{C}$ for $40^{\prime \prime}$

$72^{\circ} \mathrm{C}$ for $1^{\prime}$

$72^{\circ} \mathrm{C}$ for $5^{\prime}$

$4^{\circ} \mathrm{C}$

Run the complete reaction volume $(10 \mu \mathrm{l})$ in a $1 \%$ Agarose gel with ladder 


\section{Protocol: Evagreen monitoring of RubiconNGS, Genomeplex, NEB, Qiagen, GE and Ampli-1.}

For each kit it is possible to replace $1 / 40$ volume of water in the end reaction by Evagreen(20x) (Biotium, cat 31000T). At MCBP we use a 384 well plate qPCR machine. For kits that have end volumes higher than $30 \mu \mathrm{l}$ all volumes should be reduced to fit the 384 well plates. Isothermal kits should be measured every 5 or 10 minutes, PCR amplification kits can be measured every cycle during the final amplification. The ampli-1 kit needs to be split up in three individual PCR steps since it is not possible at the Bio-Rad machine to measure more than 1 repetitive cycle. 
ISBN: 978-90-365-4268-5 